\title{
Functions of extracellular vesicle mediated signalling from blood to brain in neurodegenerative diseases
}

\author{
Dissertation \\ zur Erlangung des Doktorgrades \\ der Naturwissenschaften
}

vorgelegt beim Fachbereich Biowissenschaften

der Johann Wolfgang Goethe-Universität

in Frankfurt am Main

\author{
von \\ Ivan Maximiliano Kur \\ aus Córdoba
}

Frankfurt (2021)

(D30) 

Vom Fachbereich 15 der

Johann Wolfgang Goethe-Universität als Dissertation angenommen.

Dekan: $\quad$ Prof. Dr. Sven Klimpel

Gutachter: Prof. Dr. Anna Starzinski-Powitz

Prof. Dr. Karl-Heinz Plate

Datum der Disputation: 01.10.2021 


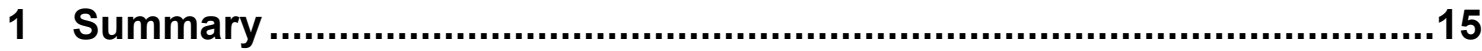

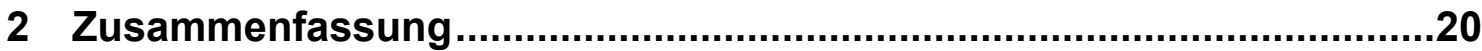

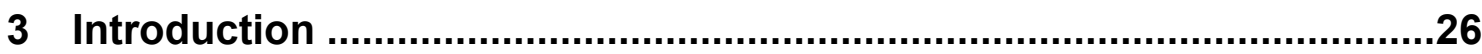

3.1 Origins of cellular signalling ............................................................ 26

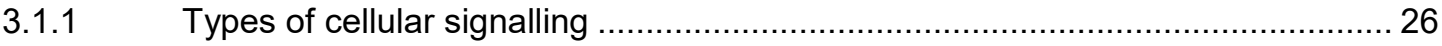

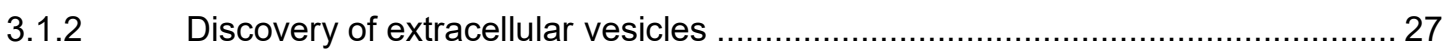

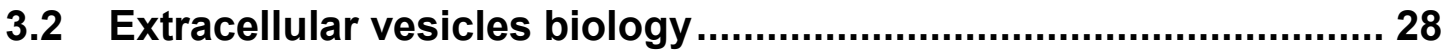

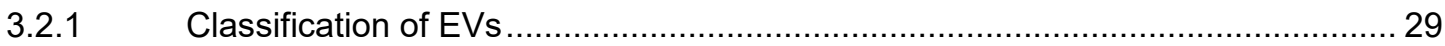

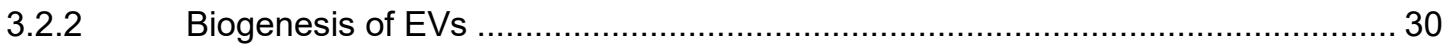

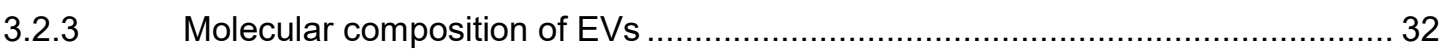

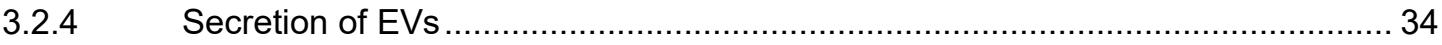

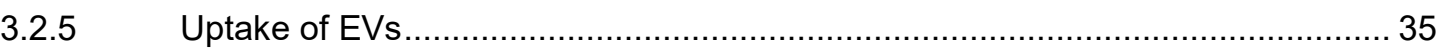

3.3 Extracellular vesicle functions ...................................................... 36

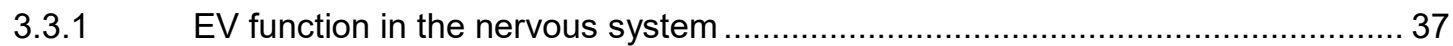

3.3.2 Relevance of EVs in neurodegenerative diseases........................................ 38

3.4 Cross-talk between the immune system and the brain .................. 39

3.5 Contribution of the haematopoietic system to the brain ................ 41

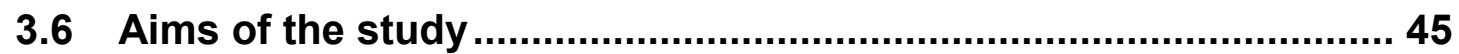

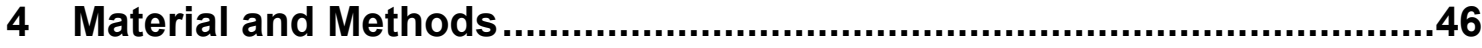

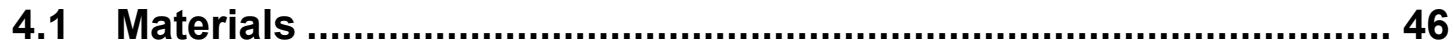

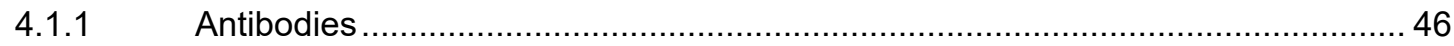

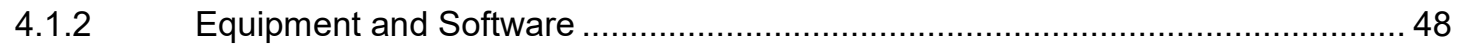

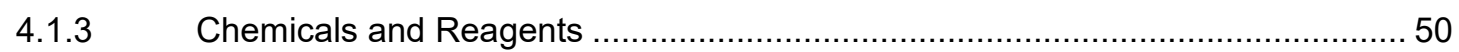

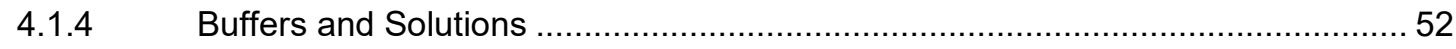

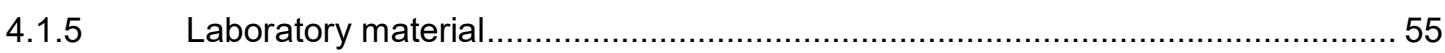

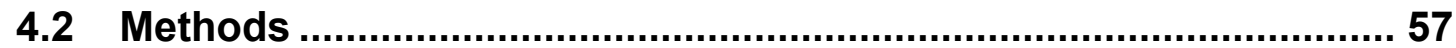

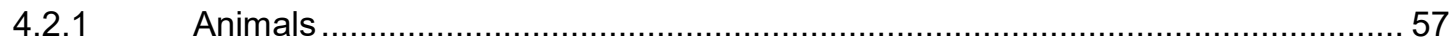

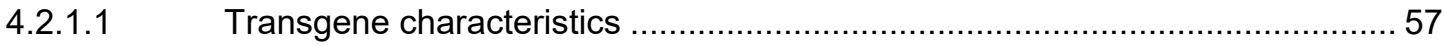

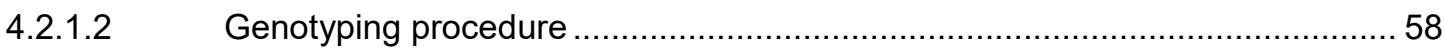

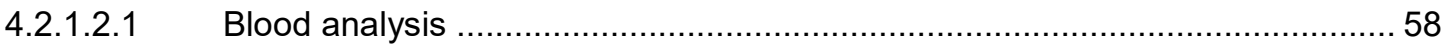

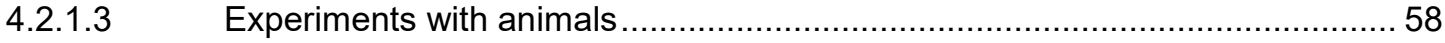

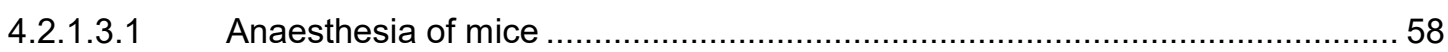

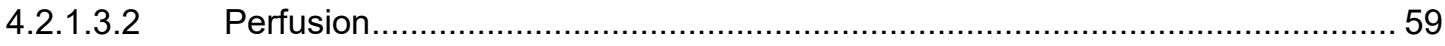

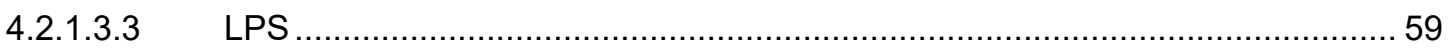

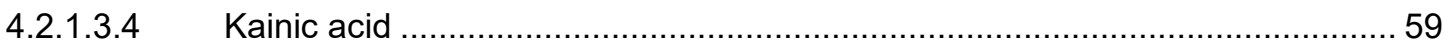

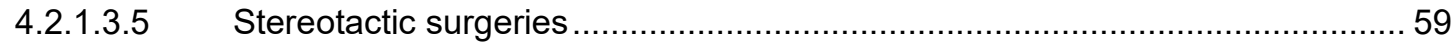




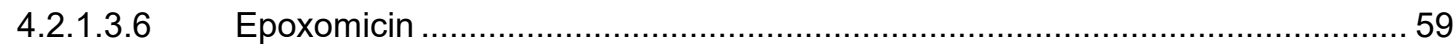

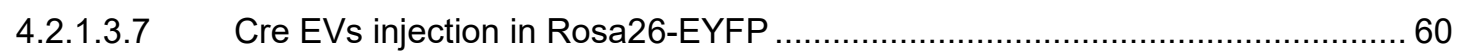

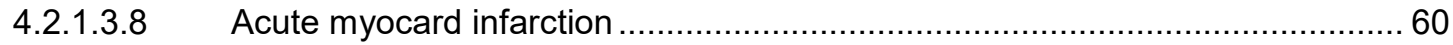

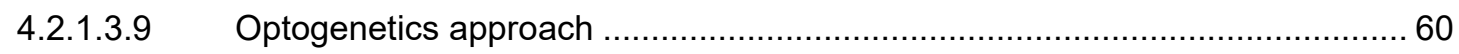

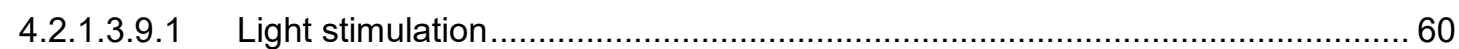

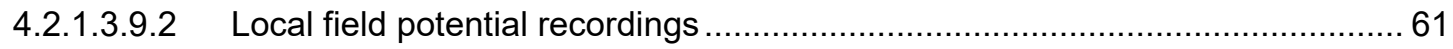

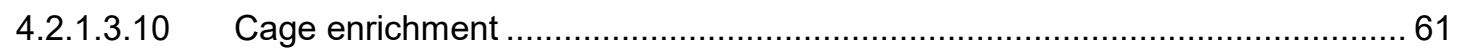

4.2.1.3.11 Brain digestion and analysis using FACS ............................................. 61

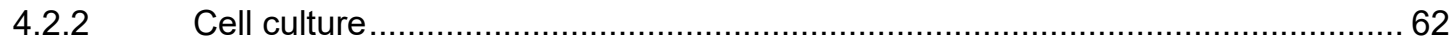

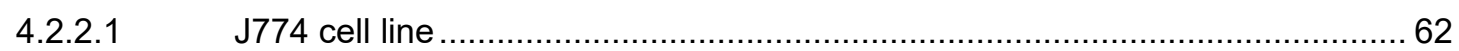

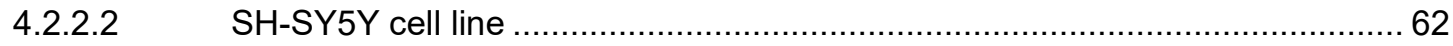

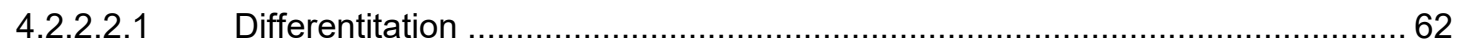

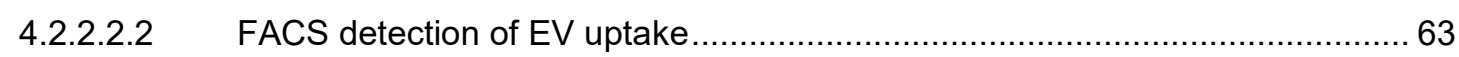

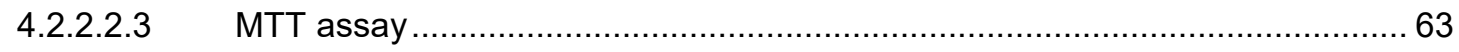

4.2.2.3 Isolation and culture of prenatal neurons from Rosa26-EYFP .....................63 63

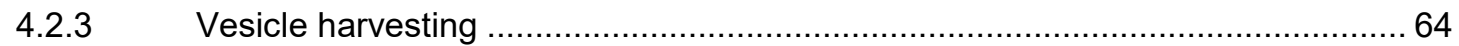

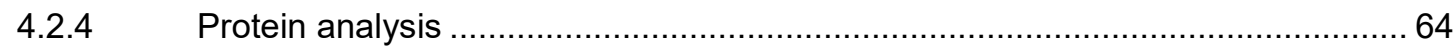

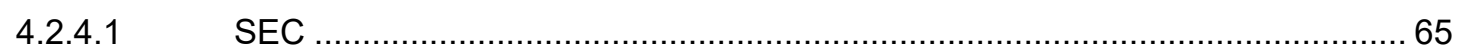

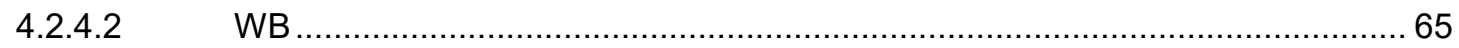

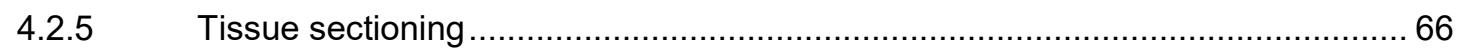

4.2.6 Immune-Histo, Cyto-chemistry (IHC-ICC) / Tyramide Signal Amplification (TSA)66

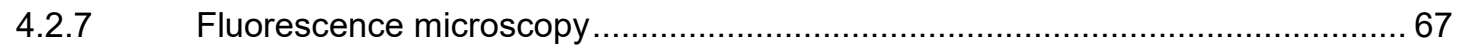

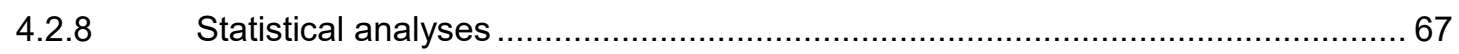

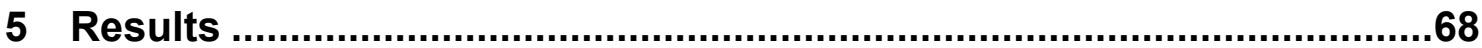

5.1 Characterization of EVs from mouse blood.................................. 68

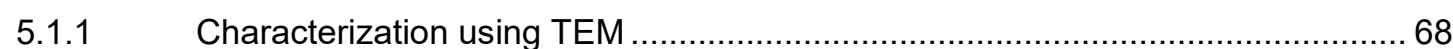

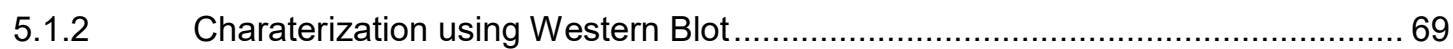

5.2 Peripheral inflammation, induced by LPS, leads to EV uptake in the

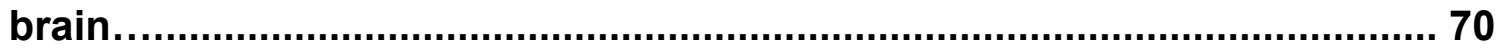

5.2.1 Peripheral injection of LPS leads to EV uptake in the hippocampus (HC)..........73

5.2.2 Peripheral injection of LPS leads to EV uptake in the Substantia Nigra (SN) ...... 75

5.2.3 Cellular EV targeting in EpoR-Cre mice differs from that of vav-iCre mice......... 76

\subsection{Specific stimulation of neuronal activity induced by KA leads to}

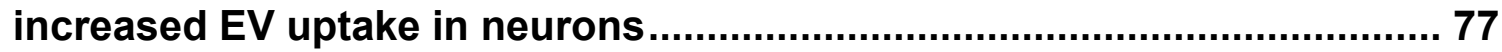

5.3.1 KA leads to EV uptake in the hippocampus ....................................... 77

5.3.2 KA leads to EV uptake in the Substantia Nigra ........................................... 79

5.4 No detectable peripheral immune cell infiltration after LPS or KA injection 
5.5 Recombination events are not caused by unspecific expression of Cre recombinase.

5.6 Intranigral epoxomicin infusion leads to specific EV uptake in DA neurons

5.7 Specific induction of neuronal activity by an optogenetic approach 86

5.8 Induction of neuronal activity in the hippocampus by novel object placement

5.9 EV uptake by prenatal neurons from Rosa26-EYFP mouse in vitro.. 95

5.10 EV uptake by SH-SY5Y cells in vitro 98

5.11 FACS sorting of NeuN+ recombined and non-recombined cell populations

6 Discussion

6.1 Peripheral injections of LPS and KA caused EV uptake in the brain

6.2 Neuronal activity triggers EV uptake in diseased and healthy animals

6.2.1 Neuronal activity triggers EV uptake in the brain

6.2.2 Neuronal activity triggers uptake of EVs in a model of Parkinson disease

6.3 EV uptake after physiological stimulation of neurons.

6.4 Use of EVs in therapeutics and as biomarkers 119

6.5 Possible beneficial role in EV uptake 122

6.6 Summary and conclusions

7 References 


\section{List of figures}

Figure 1. Biogenesis of extracellular vesicles

Figure 2. Genetic murine tracing model used visualize the contribution of haematopoietic cells from blood to other organs

Figure 3. Scheme for transgenic mouse model to trace EV transfer from blood to brain in vivo

Figure 4. Transmission electron microscopy reveals exosome-like particles after ultracentrifugation.

Figure 5. Western Blot of blood EV fractions from control and LPS injected mice

Figure 6. Peripheral inflammation induced by LPS leads to EV uptake in the brain

Figure 7. Marker gene expression mapping after LPS-induced inflammation in different brain areas

Figure 8. Absence of marker gene expression in different brain cell populations

Figure 9. Peripheral inflammation induced by LPS leads to EV uptake in the hippocampus

Figure 10. Peripheral inflammation induced by LPS leads to EV uptake in the Substantia Nigra. 75

Figure 11. Recombination in the EpoR-Cre model 76

Figure 12. Intraperitoneal KA injection leads to EV uptake in the hippocampus ..

Figure 13. Intraperitoneal KA injection leads to EV uptake in the Substantia Nigra

Figure 14. LPS or KA injection does not lead to infiltration of peripheral blood macrophages in the brain parenchyma.

Figure 15. Experimental procedure to control for unspecific expression of Cre recombinase.

Figure 16. Peripheral injection of Cre EVs leads to marker gene expression after local neuronal stimulation.

Figure 17. Neuronal activation using epoxomicin is sufficient to trigger EV uptake in the Substantia Nigra. 85

Figure 18. Scheme of neuronal activation by optogenetic stimulation. 86 
Figure 19. Expression of ChR2-mCherry for optogenetic stimulation 87

Figure 20. Local Field Potential for optogenetic stimulation

Figure 21. Injection of AAV alone or fiber optic stimulation without AAV injection does not lead to EV uptake.

Figure 22. Injection of AAV together with fiber optic stimulation leads to EV uptake

Figure 23. EV uptake extends to the contralateral hemisphere after optogenetic stimulation 90

Figure 24. Optogenetic ChR2 stimulation does not lead to marker gene expression in distant areas

Figure 25. Novel object placement for neuronal stimulation.......................... 92

Figure 26. Neuronal stimulation by novel object placement ............................ 93

Figure 27. Neuronal stimulation does not extend to distant brain regions........ 94

Figure 28. Distribution pattern of Arc and c-Fos after novel object placement 95 Figure 29. Growth over time of neurons isolated from prenatal Rosa26-EYFP mouse

Figure 30. Expression markers of neurons isolated from prenatal Rosa26-EYFP mouse 96

Figure 31. Evaluation of cell viability after $\mathrm{H}_{2} \mathrm{O}_{2}$ and $\mathrm{EV}$ treatment in prenatal neurons 97

Figure 32. Growth and differentiation over time of SH-SY5Y cells. 98

Figure 33. Expression markers of SH-SY5Y cells after differentiation 99

Figure 34. SH-SY5Y gating strategy for FACS analysis and EV titration ....... 100 Figure 35. Schematic representation of the method to study the effects in EV uptake 101

Figure 36. Decrease of EV uptake in SH-SY5Y cells treated with $\mathrm{KCl}$ for 6 and 24 hours 102

Figure 37. Increasing LPS concentrations promote EV uptake in SH-SY5Y cells 103

Figure 38. Increasing $\mathrm{H}_{2} \mathrm{O}_{2}$ concentrations decrease $\mathrm{EV}$ uptake in $\mathrm{SH}-\mathrm{SY} 5 \mathrm{Y}$ cells 103

Figure 39. KA increases EV uptake in SH-SY5Y cells 104

Figure 40. Increasing Epoxomicin concentrations decrease EV uptake in $\mathrm{SH}$ SY5Y cells 105 
Figure 41. EVs reverse effects of LPS on SH-SY5Y cells ........................... 106

Figure 42. EVs reverse effects of $\mathrm{H}_{2} \mathrm{O}_{2}$ on SH-SY5Y cells ......................... 108

Figure 43. EVs reverse effects of low concentration KA on SH-SY5Y cells ... 109 Figure 44. Gating strategy to sort NeuN+ recombined and non-recombined cell populations. 112

Figure 45. Schematic representation to follow EV mRNA transfer from blood to the brain (actual case). 124

Figure 46. Extracellular vesicles are involved in intercellular and inter-tissue communication 125 


\section{List of tables}

Table 1. Table summarizing the classification and biogenesis of different EVs ...

Table 2. Primary antibodies.................................................................. 46

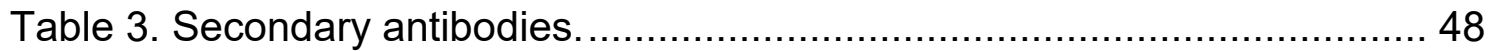

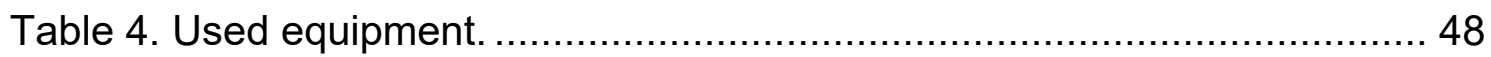

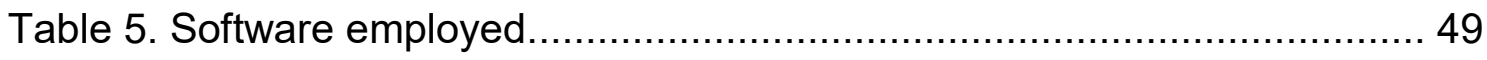

Table 6. Chemicals and Reagents. .................................................. 50

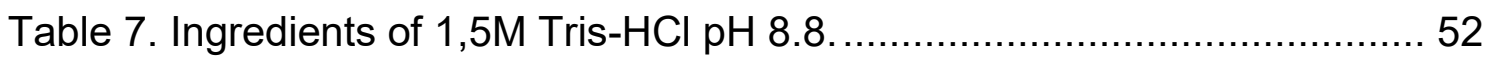

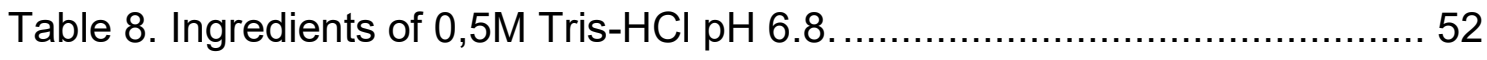

Table 9. Ingredients of EV Lysis Buffer. ................................................ 53

Table 10. Ingredients of 2X Laemmli Buffer........................................... 53

Table 11. Ingredients of Transfer Buffer 10X..................................... 53

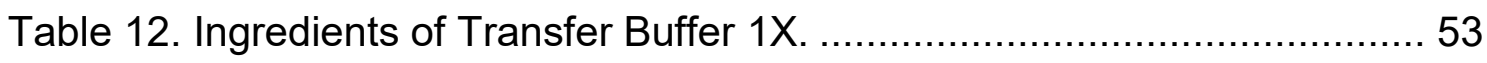

Table 13. Ingredients of Running Buffer 10X ....................................... 54

Table 14. Ingredients of Blocking Buffer WB.................................... 54

Table 15. Ingredients of Washing Buffer WB. ..................................... 54

Table 16. Ingredients of Blocking Buffer Stainings................................. 54

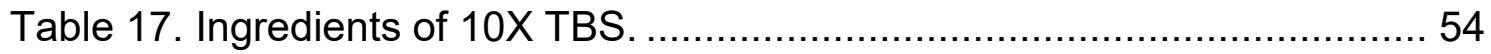

Table 18. Ingredients of TNT Buffer.............................................. 55

Table 19. Ingredients of TNB Buffer............................................... 55

Table 20. Consumables used for this thesis....................................... 55

Table 21. Transgenic mouse lines used in this project............................. 57

Table 22. EV uptake increases or decreases after challenging SH-SY5Y cell line

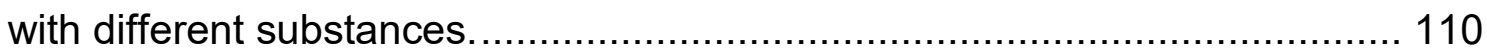

Table 23. Effect of EV uptake in cell viability after challenging SH-SY5Y cell line with different substances. 


\section{List of abbreviations}

- $\mathrm{A} / \mathrm{P}$

- APP

- a-Syn

- AVV

- BBB

- BDNF

- BSA

- C6-NBD

- $\mathrm{Cb}$

- ChR2

- D/V

- DA

- DAPI

- DG

- DMEM

- DMSO

- DNAsel

- EDTA

- ESCRT

- EVs

- EYFP

- FACS

- $\mathrm{FB}$

- FBS

- FCS

- GFAP

- GFP

- $\mathrm{H}_{2} \mathrm{O}_{2}$

- $\mathrm{HB}$

- HBSS

- $\mathrm{HC}$

- HE anterior / posterior

Amyloid Precursor Protein

Alpha-Synuclein

adeno-associated virus

Blood-brain barrier

brain derived neurotrophic factor

bovine serum albumin

6-(7-Nitrobenzofurazan-4-ylamino) hexanoic acid

Cerebellum

Channelrhodopsin-2

dorsal / ventral

dopaminergic neurons

4',6-diamidino-2-phenylindole

Dentate Gyrus

Dulbecco's Modified Eagle Medium

Dimethyl sulfoxide

deoxyribonuclease I

Ethylenediaminetetraacetic acid

Endosomal Sorting Complex Required for Transport

extracellular vesicles

enhanced yellow fluorescent protein

fluorescence-activated cell sorting

forebrain

fetal bovine serum

fetal calf serum

Glial fibrillary acidic protein

green fluorescent protein

Hydrogen peroxide

hindbrain

Hank's balanced salt solution

Hippocampus

Hematoxylin - Eosin 
- HEPES

- HRP

- i.p.

- i.v.

- ICC

- IHC

- ILVs

- KA

- $\mathrm{KCl}$

- $\mathrm{kDa}$

- L1CAM

- LFP

- LPS

- $\mathrm{M} / \mathrm{L}$

- MB

- MHC-II

- MTT 4-(2-hydroxyethyl)-1-piperazineethanesulfonic acid horseradish peroxidase

intraperitoneal

intravenous

immunocytochemistry

immunohistochemistry

Intraluminal vesicles

kainic acid

Potassium chloride

kilo Daltons

L1 cell adhesion molecule

local field potential

lipopolysaccharide

medial / lateral

midbrain

Major histocompatibility complex class II

3-(4,5-Dimethylthiazol-2-yl)-2,5-

diphenyltetrazoliumbromid

- MVBs

Multivesicular bodies

- $\mathrm{mW}$

milli-wats

- PBS

phosphate buffered saline

- PEG

Polyethylene glycol

- PFA

Paraformaldehyde

- PrPsc

Prion Protein scrapie form

- PVDF

polyvinylidene difluoride

- ROS reactive oxygen species

- Rpm

revolutions per minute

- RT room temperature

- SDS

Sodium dodecyl sulphate

- SEC

Size exclusion chromatography

- SN

Substantia Nigra

- TEMED

Tetramethylethylenediamine

- $\mathrm{TH}$

Tyrosine hydroxylase

- TNF- $\alpha$

Tumor Necrosis Factor alpha 
- TSA

- UPS

- WB

- YFP
Tyramide signal amplification

ubiquitin proteasome system

Western Blot

yellow fluorescent protein 


\section{Abkürzungsverzeichnis}

- $\alpha-S y n$

- Cre

- EV

- EYFP

- $\mathrm{H}_{2} \mathrm{O}_{2}$

- $\mathrm{HC}$

- KA

- LPS

- $\quad$ D

- RNA

- SEC

- SN

- WB
a-Synuklein

Cre-Rekombinase

Extrazelluläres Vesikel

verstärkt gelb fluoreszierendes Protein

Wasserstoffperoxid

Hippocampus

Kainsäure

Lipopolysaccharide

Morbus Parkinson

RNS, Ribonukleinsäure

GPC, Gel-Permeations-Chromatographie

Substantia Nigra

Western Blot 


\section{Summary}

Cellular communication is a concept that can be explained as the transfer of signals or material (such as cytokines, ions, small molecules) between cells from the same or different type, across either short or long distances. Once this signal or material is received, it will, as a rule, promote a functional effect. Several routes, involved in this transfer, are well described and are of global importance for organ/tissue communication in an organism.

The brain interacts dynamically with the immune system, and the main route known to mediate this communication, is via the release of cytokines (by peripheral blood cells), which can then activate certain brain cell types, such as microglia, directly, or activate the vagus nerve transferring signals to neuronal populations in the brain. The communication between these two systems plays a key role in the pathophysiology of neurodegenerative diseases, and the mechanisms involved in this interaction are of central importance for understanding disease initiation and progression and search for therapeutic models.

The Momma lab previously addressed the mechanisms of interaction between the peripheral immune system and the brain by investigating cellular fusion of haematopoietic cells with neurons after inflammation. They addressed the question of whether this phenomenon also occurs under non-invasive conditions. To approach this problem, a genetic tracing model that relies on the Cre-Lox recombination system was used. Transgenic mice expressing Cre recombinase specifically in the haematopoietic lineage were crossed into a Cre-reporter background, thus all haematopoietic cells irreversibly express the reporter markergene EYFP. Using this model, EYFP was detected in non-haematopoietic tissues, suggesting the existence of a communication mechanism never described before. As cells containing two nuclei were never detected, fusion as a mechanism was excluded, suggesting that Cre reaches non-haematopoietic cells via a different signalling pathway. The Momma lab investigated whether the transfer of material through extracellular vesicles (EVs) could be behind this periphery-to-brain communication. Using the genetic mouse model, they were able to trace the transfer of Cre RNA via EVs between cells in vivo, generating the first in vivo evidence of functional RNA transfer by EVs between blood and brain. 
The last decade has witnessed a rapid expansion of the field of EVs. Initially considered as waste disposal material, recent evidence has challenged this view. EVs are currently considered as a widespread intercellular communication system that can transport and transfer all types of biomolecules, from nucleic acids to lipids and proteins. However, several important questions are still under investigation. One of them is whether EVs are involved in brain pathophysiology, as inflammation plays an important role in onset and progression of neurodegenerative diseases and is well described in Parkinson Disease (PD). Based on preliminary data in a mouse, peripherally injected with a low dose of Lipopolysaccharide (LPS, an endotoxin found in the outer-membrane of Gram-negative bacteria, which causes an immune response), neurons and other cell population in the brain take up EVs from the periphery. Particularly, dopaminergic neurons from Substantia Nigra and Ventral Tegmental Area have been shown to receive functional RNA, transported through EVs, which can lead up to $20 \%$ of recombination. Furthermore, different neuronal populations from Hippocampus, Cortex and Cerebellum exhibit recombination, indicating a widespread signalling from blood to the brain. Therefore, the goal of my $\mathrm{PhD}$ thesis was to investigate the mechanisms of this transfer and the triggers that lead to EV uptake by neural cells in vivo both in pathological and physiological conditions.

In this project, the extent and function of EV-mediated signalling from blood to brain is explored in the context of peripheral inflammation and neurodegenerative diseases. Firstly, EVs isolated from WT mice were further characterized using sizeexclusion chromatography (SEC), Western Blot (WB) and electron microscopy in order to extend the knowledge from previous work done in the Momma lab. Secondly, to expand on the biological relevance of the fact that inflammation is correlated with an increase in EV uptake, different approaches using the genetic murine tracing model were used. Recombination events from haematopoietic cells to the brain have been followed after peripheral injection of LPS. Peripheral inflammation caused by LPS injection led to widespread recombination events in the brain, specifically in microglia and neurons, including dopaminergic (DA) neurons. In contrast, astrocytes, oligodendrocytes and endothelial cells were never or very rarely recombined. Additionally, peripheral LPS injection in a murine model, where Cre is expressed only in erythrocytes, led to recombination events only in 
microglia, suggesting that the type of EV-secreting cell plays a role in the targeting of EVs to a specific cell population.

Peripheral injection of low dose of kainic acid (KA), an analog of glutamate recognized by kainate receptors that leads to neuronal firing, was used as another paradigm of injury and led to recombination in neurons, microglia and dopaminergic neurons. However, an increase in the percentage of recombined neurons was observed compared to injection of LPS. These results led to the hypothesis that neuronal activity leads to EV uptake. Furthermore, if the electrical activity of the neurons determines EV uptake, it will ultimately influence neuronal function, and therefore, act as an important regulator in disease as well as in healthy behaviour.

To check for specific uptake after neuronal stimulation, an optogenetics approach was used. Here, a virus is targeted to a specific region in the brain and infected cells will express a light-sensitive ion channel. Cells expressing this channel, will start firing upon stimulation with optic fiber light. Expression of reporter gene EYFP was observed in the virus-infected area but was also detected in adjacent cortical areas and in the hippocampus, suggesting that neuronal activity triggers EV uptake not only in directly stimulated neurons but also in other cells in the network, reaching as far as the contralateral hemisphere. This observation points to the importance of the electrical activity of a neuron to regulate EV uptake.

In the context of neurodegenerative diseases, evidence points to EVs as vehicles for the removal of toxic products as well as for the spread of disease to healthy cells and tissues. Particularly in the case of PD, a plethora of murine models is described in the literature. The model used in this thesis consists in the infusion of epoxomicin, a selective proteasome inhibitor that leads a progressive loss of dopaminergic neurons by the accumulation of aggregates that cannot be degraded. An approach to mimic the pathophysiology of PD is the unilateral infusion of epoxomicin in the ventral midbrain, which leads to a selective increase of in vivo firing frequencies of surviving neurons in the Substantia Nigra (SN). The injection of epoxomicin into RosaYFPxvav-iCre mice revealed marker gene-positive events specifically in DA neurons of the $\mathrm{SN}$. No recombination events have been observed in the contralateral hemisphere or in other cell types, further supporting the hypothesis that neuronal electrical activity regulates EV uptake. 
In all experimental models, used in this thesis, no evidence of the entrance of immune cells into the brain has been detected, indicating no persistent peripheral immune infiltration or injury that could make the BBB (blood-brain barrier) leaky to an extent as to allow the entry of leukocytes into the brain.

Using a non-pathologic paradigm, in which novel objects are placed in mouse cages, it was possible to determine if neuronal firing in healthy animals is enough to cause EV uptake. The presence of novel objects causes neural responses and the activation of immediate-early-genes such as c-Fos and Arc. The analysis of mouse brains revealed recombination in the midbrain, mostly in the hippocampus. Other brain regions, in which neuronal activation did not occur, showed less recombined cells. This fact suggest a possible role of EV signalling in cognitive tasks and behaviour (recognition, learning, etc.) in the healthy brain, not only after impairment and disease, and opens up the question of whether normal physiology and behaviour could be influenced by peripheral EVs in the medium and long term.

In order to address the question of whether EV uptake is beneficial or detrimental for cells, in vitro experiments were conducted in which cells were challenged using $\mathrm{H}_{2} \mathrm{O}_{2}$, LPS, KA or epoxomicin and fluorescence-labelled EVs were added to the culture. EV uptake was assessed using flow cytometry and cell viability was studied using metabolic activity as a readout. A decrease in cell viability was observed when SH-SY5Y cells were challenged with $\mathrm{H}_{2} \mathrm{O}_{2}$, LPS and KA. In combination with EVs, there was no decrease in cell viability, suggesting a protective mechanism, thus a beneficial role for EV uptake when cells are impaired.

To conclude, this project shows that functional EV transfer from blood to brain is widespread and consistent with the hypothesis that EV uptake is triggered by neuronal activity under pathological and physiological conditions. In the experimental approaches used in this thesis, EV signalling is driven by the status of the target cell, independent of EV availability. As mentioned above, no peripheral blood cell infiltration has been observed. A possible mechanism that could explain the entrance of EV into the brain is transcytosis, since the BBB might not be damaged.

EV-related research, in the field of neurodegenerative diseases like PD, is focused on the clearance or transfer of $\alpha$-Syn from or between cells as well as the use of EVs as diagnostic markers or therapeutic particles delivering drugs or even RNA to 
modulate and fight against brain diseases. The results shown in the project contribute to the understanding of the mechanism by which EVs transfer their content between cells and will help to develop strategies that may impact disease onset and progression.

In terms of EV-inter-tissue communication (EVs coming from different tissues), the transgenic model used in this thesis reports the transfer of EVs from blood to brain only, while EVs from any different cell types and organs were not studied. Taking this into account, the influence exerted by EVs from different organs to the brain may be substantial.

Efforts are being made to target EVs to a specific cellular population. Notably, in this project, it has been shown that EVs seem to naturally target stimulated neurons with high specificity both in pathological and physiological conditions. 


\section{Zusammenfassung}

Zelluläre Kommunikation ist ein biologischer Vorgang, der durch die Übertragung von Signalen oder Substanzen (wie Zytokinen, Ionen, kleinen Molekülen) zwischen Zellen von identischem oder unterschiedlichem Typ über lange oder kurze Distanzen definiert wird. Sobald das Signal oder die Substanz empfangen wurde, leitet es eine funktionelle Reaktion in der Zielzelle ein. Eine Vielzahl an unterschiedlichen Signalwegen, die bei dieser Art der Kommunikation relevant sind, sind bereits gut erforscht und von enormer Bedeutung für den Informationsaustausch und Weiterleitung in lebenden Organismen.

Das Gehirn interagiert aktiv mit dem Immunsystem und ein Großteil dieser Kommunikation findet über den Austausch von Zytokinen, mittels peripherer Blutzellen, statt. Diese Reize sind in der Lage entweder direkt bestimmte Hirnzellen wie Mikroglia zu aktivieren oder den Vagusnerv, der dann Signale an neuronale Hirnzellen weiterleitet. Die Interaktion dieser beiden Systeme spielt eine entscheidende Rolle in neurodegenerativen Erkrankungen und ist von großer Bedeutung, um die Ursachen dieser Krankheiten und deren Fortschreiten zu verstehen und neue Therapieansätze zu entwickeln.

In der AG Momma wurde die Interaktion zwischen dem peripheren Immunsystem und dem Gehirn anhand von zellulärer Fusion von hämatopoetischen Zellen und Neuronen unter Entzündungsbedingungen untersucht.

Des Weiteren wurde die Fragestellung, ob dieses Fusionsphänomen auch unter normalen, nicht entzündlichen Bedingungen stattfindet, mit einem murinen Cre-Lox$P$ Rekombinationsmodell untersucht. Hierzu wurden transgene Mäuse, die CreRekombinase nur in hämatopoetischen Zellen exprimieren, mit Mäusen gekreuzt, die eine EYFP-Reporter Sequenz in allen Körperzellen exprimieren. Folglich exprimieren in der Nachkommengeneration alle Zellen von hämatopoetischen Ursprung das EYFP- Reporter Gen. Mit diesem Modell wurde EYFP Expression auch in nicht hämatopoetischen Zellen detektiert, was eine neue Art der zellulären Kommunikation vermuten lässt, die bislang nicht bekannt war. Zellfusion als Ursprung dieser Beobachtung wurde ausgeschlossen, da betreffende Zellen nur jeweils einen Nucleus aufwiesen, sodass ein anderer Übertragungsweg von CreRekombinase aus den hämatopoetischen Zellen zu den jeweiligen rekombinierten, nicht hämatopoetischen Zellen, existieren muss. Als eine Möglichkeit wurde der 
Transfer von Molekülen via extrazellulärer Vesikel (EVs) untersucht. Mit Hilfe des oben beschriebenen Mausmodells hat die AG Momma den Transfer funktioneller Cre RNA durch EVs zwischen Zellen in vivo nachgewiesen, was zugleich der erste Nachweis eines Transfers funktioneller RNA zwischen dem Blutsystem und dem Hirn via EVs in vivo überhaupt war.

EVs wurden lange Zeit lediglich als Müllentsorgungssystem der Zellen betrachtet, aber durch eine Reihe von wichtigen Erkenntnissen hat sich die Forschung in diesem Feld innerhalb der letzten Jahrzehnte enorm weiterentwickelt. Mittlerweile werden EVs als eines der Hauptkommunikationsmittel von Zellen betrachtet, da sie von allen Zelltypen produziert werden können und in der Lage sind, eine Vielzahl von Molekülen, wie Nucleinsäuren, Lipiden und Proteinen zwischen Zellen zu transferieren.

Trotz der zahlreichen neuen Erkenntnisse in diesem Forschungsbereich gibt es immer noch viele ungeklärte Fragen. Unter anderem, ob EVs in der Pathophysiologie des Gehirns involviert sind, da Entzündungsprozesse eine entscheidende Rolle bei der Entstehung und dem Fortschreiten von neurodegenerativen Erkrankungen spielen, wie zum Beispiel bei Morbus Parkinson.

Vorläufige Ergebnisse aus Tierversuchen zeigen, dass in Mäusen, die eine periphere Injektion einer niedrigen Dosis von Lipopolysacchariden (LPS, ein Endotoxin aus der äußeren Membran von gram-negativen Bakterien, das eine Immunreaktion hervorruft) erhalten haben, Neurone und andere Zellpopulation im Gehirn EVs aus der Peripherie aufnehmen. Insbesondere wurde die Übertragung funktioneller RNA durch EVs in dopaminerge Neuronen in der Substantia Nigra (SN) und im ventralen tegmentalem Areal nachgewiesen, was zu Rekombinationsraten von bis zu 20\% führte. Der Nachweis von Rekombination in anderen neuralen Populationen in Hippocampus, Cortex und Cerebellum lässt eine weitreichende Signalweiterleitung von Blut zum Gehirn vermuten.

Basierend auf diesen Erkenntnissen ist das Ziel dieser Studie, die Mechanismen von EV mediiertem Transfer und dessen Auslöser, die zur Aufnahme von EVs aus der Peripherie durch neurale Zellen im Gehirn führen, sowohl unter pathologischen als auch physiologischen Bedingungen zu untersuchen. Innerhalb dieses Projektes wurde das Ausmaß und die Auswirkungen von EV basierter Signalübertragung von 
Blut zum Gehirn im Zusammenhang mit Entzündungsprozessen und neurodegenerativen Erkrankungen untersucht.

Zuerst wurden EVs aus dem Blut von wildtyp Mäusen isoliert und mit Hilfe von Size Exclusion Chromatographie (SEC), Western Blot und Elektronenmikroskopie charakterisiert, um deren Eigenschaften detaillierter beschreiben zu können. Darauffolgend wurde in verschiedenen Ansätzen mit dem oben beschriebenen Mausmodell untersucht, welche biologische Relevanz die Tatsache hat, dass Entzündungsprozesse mit einer erhöhten EV Aufnahme einhergehen. Dazu wurde die Rekombination in Hirnzellen, ausgelöst durch den Transfer von CreRekombinase aus hämatopoetischen Zellen, nach peripherer LPS Injektion analysiert.

Periphere Entzündungen, ausgelöst durch LPS Gabe, verursachten vermehrte Rekombinationsraten in Hirnzellen, insbesondere in Mikroglia und Neuronen, einschließlich dopaminergen Neuronen. Im Gegensatz dazu wurde in Astrozyten, Oligodendrozyten und Endothelzellen keine oder kaum Rekombination festgestellt. Interessanterweise wurde bei einem Versuch mit einem weiteren Mausmodell, in dem Cre-Rekombinase ausschließlich in Erythrozyten exprimiert wird, Rekombination nur in der Mikrogliapopulation festgestellt. Diese Beobachtung lässt vermuten, dass die EV produzierende Zelle eine Rolle hinsichtlich der EV aufnehmenden Zelle spielt.

In einem weiterführenden Projekt wurde eine geringe Dosis von Kainsäure (ein Analog von Glutamat, das von Kainat Rezeptoren erkannt wird und zu neuronaler Stimulation führt) als weiterer Entzündungsreiz genutzt, um die bisher gefundenen Daten zu untermauern. Tatsächlich wurde Rekombination in Neuronen, Mikroglia und dopaminergen Neuronen beobachtet, jedoch in einer höheren Prozentzahl als bei LPS Injektionen. Das lässt vermuten, dass neuronale Aktivität zu vermehrten EV Aufnahme führt. Gegeben, dass die elektrische Aktivität von Neuronen die EV Aufnahme bestimmt und so schlussendlich die neuronale Funktion beeinflussen kann, wäre das ein wichtiger Regulator der EV Aufnahme, sowohl unter krankhaften als auch physiologischen Bedingungen.

Zur Analyse von EV Aufnahme nach neuronaler Stimulation wurde ein optogenetischer Ansatz verfolgt. Dabei wurde ein Virus eingesetzt, das spezifische Regionen im Gehirn infiziert und dazu führt, dass betroffene Zellen ein 
lichtsensitiven Ionen Kanal exprimieren. Diese Zellen können mit Glasfaserlicht stimuliert werden. Die Exprimierung des EYFP-Reporter Gens wurde in virusinfizierten Bereichen des Gehirns nachgewiesen, aber auch in angrenzenden Cortexbereichen und im Hippocampus. Das lässt vermuten, dass neuronale Aktivität nicht nur die EV Aufnahme in direkt stimulierten Zellen erhöht, sondern auch in anderen Zellen in der Umgebung, bis hin zur kontralateralen Hemisphäre. Dieses Ergebnis verdeutlicht die Relevanz der Aktivität von Neuronen bei der Aufnahme von EVs.

Im Zusammenhang mit neurodegenerativen Krankheiten gibt es Hinweise, das EVs sowohl als Transportmoleküle zur Beseitigung von toxischen Substanzen dienen, als auch zur Übertragung der Krankheit an gesunde Zellen und Gewebe. Besonders bei Morbus Parkinson ist eine Fülle von entsprechenden Mausmodellen charakterisiert. In dieser Studie wurde ein Mausmodell benutzt, in dem die Infusion mit Epoxomicin, einem selektiven Proteasom-Hemmer, der durch die Ansammlung von Aggregaten die nicht abgebaut werden können zu fortschreitendem Abbau von dopaminergen Neuronen führt, eingesetzt.

Ein Weg um die Pathophysiologie von Morbus Parkinson nachzuahmen ist die unilaterale Infusion von Epoxomicin ins ventrale Mittelhirn, was zu einer selektiven Erhöhung von in vivo Aktivität überlebender Neuronen in der SN führt. Die Injektion von Epoxomicin in RosaEYFP x vav-iCre Mäuse zeigt Markergen positive Zellen vor allem in dopaminergen Neuronen in der SN. Im Gegensatz dazu wurde keine Rekombination in der kontralateralen Hemisphäre oder in anderen Zellpopulationen nachgewiesen, was die Hypothese unterstützt, dass neuronale Aktivität die EV Aufnahme reguliert.

In keinem der in dieser Studie benutzen Mausmodelle konnten Immunzellen im Hirn nachgewiesen werden. Das zeigt, dass die Blut-Hirn-Schranke nicht verletzt wurde und keine Immuninfiltration sattfindet, die es erlauben würde, dass Leukozyten ins Gehirn eindringen.

In einem nicht pathologischem Ansatz, in dem für die Maus neuartige Objekte in deren Käfigen platziert wurden, wurde nachgewiesen, dass neurale Aktivität ausreicht um EV Aufnahme in gesunden Tieren zu induzieren. Die Aussetzung an neuen Reizen führte zu neuralen Signalen und zur Stimulation von unmittelbaren frühen Genen wie c-Fos und Arc. Die Analyse der entsprechenden Hirne zeigte 
Rekombination im Mittelhirn, hauptsächlich im Hippocampus. Andere Regionen, in denen keine neuronale Stimulation stattfand, wiesen weniger Rekombination auf. Das zeigt eine mögliche Rolle von EV Signalübertragung in kognitiven Zusammenhängen und Verhalten (Erkennung, Lernen, etc.) im gesunden Gehirn und nicht nur unter veränderten oder krankhaften Bedingungen. Das wirft die Frage auf, ob physiologische Prozesse und Verhalten auf lange Sicht durch die Aufnahme von peripheren EVs beeinflusst werden können.

Um festzustellen, ob die EV Aufnahme insgesamt vorteilhaft oder schädlich für die aufnehmende Zelle ist, wurden in vitro Experimente ausgeführt, in denen Zellen $\mathrm{H}_{2} \mathrm{O}_{2}$, LPS, KA oder Epoxomicin ausgesetzt wurden. Diesen Zellkulturen wurden fluoreszent markierte EVs zugeführt und die Aufnahme von EVs mit Hilfe von Durchflusszytometrie gemessen. Des Weiteren wurde die Zellviabilität anhand der metabolischen Aktivität bestimmt. Hierbei wurde eine Abnahme der Viabilität festgestellt, wenn SH-SY5Y Zellen nur mit $\mathrm{H}_{2} \mathrm{O}_{2}$, LPS und KA kultiviert wurden. Nach dem Zufügen von EVs konnte keine Abnahme der Zellviabilität festgestellt werden, was eine Art Schutzmechanismus, ausgelöst durch EV Aufnahme, vermuten lässt und demnach einen insgesamt positive Effekt der EV Aufnahme auf geschädigte Zellen.

Insgesamt zeigt dieses Projekt, dass der funktionale Transport von EVs vom Blut zum Gehirn häufig vorkommt und das die Aufnahme von EVs unter physiologischen und pathologischen Bedingungen durch neuronale Aktivität stimuliert wird.

In den experimentellen Ansätzen in dieser Studie wird die EV induzierte Signalübertragung durch die Zielzelle limitiert, unabhängig von der Anzahl an verfügbaren EVs. Wie bereits erwähnt wurde keine Infiltration von peripheren Blutzellen ins Hirn beobachtet. Da die Blut-Hirn-Schranke nicht beschädigt ist, wäre zum Beispiel Transzytose als Eintrittsmechanismus ins Hirn vorstellbar.

Im Bereich von neurodegenerativen Erkrankungen wie Morbus Parkinson konzentriert sich die EV Forschung zum einen auf den Abtransport von a-Syn aus den Zellen durch EVs, aber auch auf den Aspekt EVs als diagnostisches Mittel oder als Shuttle für den Transport von Medikamenten oder RNA als Therapiemöglichkeit.

Die Erkenntnisse, die aus dieser Studie erlangt wurden, tragen dazu bei zu verstehen, wie EVs ihren Inhalt zwischen Zellen austauschen und werden hilfreich 
sein, um neue Behandlungsmöglichkeiten im Bereich (neuro-) degenerativer Erkrankungen zu entwickeln.

Hinsichtlich des Einflusses von EVs, die von unterschiedlichen Organen produziert werden, auf das Gehirn liefert diese Studie keine Erkenntnisse. In den genutzten Mausmodellen wird ausschließlich der EV Transfer vom Blut zum Hirn untersucht. Es sollte jedoch nicht außer Acht gelassen werden, dass die Herkunft der aufgenommenen EVs Einfluss auf deren Wirkung haben kann.

Ein wichtiger Aspekt um EVs als Therapiemöglichkeit zu nutzen ist, dass sie nur von spezifischen, vorher definierten, Zellen aufgenommen werden können, um so Moleküle zielgerecht zu steuern. In dieser Studie wurde gezeigt, dass EVs in hohem Maße von stimulierten Neuronen aufgenommen werden, sowohl unter pathologischen als auch physiologischen Bedingungen. 


\section{Introduction}

\subsection{Origins of cellular signalling}

Cellular communication is an ancient concept that appeared with the first evidence of multicellular organisms 3.5 billion years ago. Multicellular organisms require a complex network of connections to enable communication between cells and hence enabling different functions and behaviour. An intricate machinery, able to receive and to respond to intercellular signals is the basis for tissue homeostasis, allowing cells to respond to their microenvironment and to each cell to play its particular role. Impairment or failure in this communication may be the cause of the origin or spread of a disease.

The mechanisms a cell uses to influence the behaviour of another cell are present in unicellular organisms; in animal cells / tissues, signalling is mostly performed by exocytosis of molecules from the initiator cell, although molecules can be secreted by diffusion or remain in the plasma membrane. Then, the receptor cell will interact and generate a downstream cascade of intracellular signalling affecting behaviour and function. Over the past decades, new techniques have been developed, allowing researchers to study in greater detail both cell signalling networks and the mechanisms which cells use to communicate between each other.

\subsubsection{Types of cellular signalling}

Cell signalling can be classified into four categories, based on the type of signal molecules, such as proteins, lipids, ions, etc. The multitude of signalling molecules can be transported via various mechanisms, increasing the complexity of the system. Depending on the distance between effector and receptor cell, these signals molecules can be categorized into autocrine, juxtacrine, paracrine and endocrine.

Autocrine: The signalling cell and the target cell can be the same cell or other cells from the same cell-type within the tissue, whereby cells secrete signalling molecules that can interact with their own receptors. Hence, they target themselves and cells in the vicinity if they belong to the same type. Pain and inflammatory responses, among others, are regulated by autocrine signalling. An infected cell can therefore, undergo dell-death signalling by itself. Moreover, during development, once a cell is directed down a specific differentiation program, autocrine signalling starts to boost this decision (Herrmann \& Broihier, 2018). 
Juxtacrine: The effector cell is adjacent to the receptor cell, it is a contact-dependent signalling. Although there are different types of juxtacrine signalling, the most known are gap junctions, linking intracellular compartments of two cells and allowing the transfer of small molecules. Juxtacrine signalling is involved in the transfer of cytokines, chemokines and growth factors, playing a critical role in immune response. This type of signalling has been indicated in development, cardiac and neural function (“Juxtacrine Signaling - Developmental Biology - NCBI Bookshelf," n.d.).

Paracrine: Paracrine signals are emitted by the effector cell and act as local mediators, affecting cells within a small environment. Paracrine molecules are usually degraded by enzymes, taken up by cells in the vicinity or immobilized in the extracellular matrix. Therefore, paracrine signalling last very short time and diffuses quickly. An example of this type of signalling is the transfer of signals between nerve cells. When these cells (neurons) get activated by a synaptic signal (e.g. chemical signals), fast electrical impulses will be generated and propagated to reach the end of the axon, where the signal will be transferred to the dendrite of the next neural cell by release of neurotransmitters (chemical signal). This transfer occurs at specialized cell junctions, the synapses (Roy \& Kornberg, 2015).

Endocrine: In humans, endocrine signalling is based on hormones, secreted by endocrine glands such as pituitary, pineal, thyroid, adrenal, etc., directly into the blood circulation, regulating target cells and organs throughout large distances. This type of signalling is relatively slow and acts at very low concentrations. In addition to the main endocrine glands, other organs, such as bone, kidney, liver, heart, have endocrine functions. Hormones are secreted into the circulatory system and are used for communication between organs and tissues, regulating digestion, physiological tissue function, stress reaction, growth, development and others. ("Signaling Molecules and Their Receptors - The Cell - NCBI Bookshelf," n.d.)

\subsubsection{Discovery of extracellular vesicles}

In addition to neighbouring (such as autocrine) and distant communication (through soluble factors), intercellular communication can be mediated through extracellular vesicles (EVs). The concept of extracellular vesicles appeared for the first time in 1983, when P. Stahl and R. M. Johnstone were studying the maturation of reticulocytes to erythrocytes. 
It is known that this process involves the loss of the transferrin receptor; however, the fate of this receptor was unknown. In particular, researchers were looking into the endocytosis and recycling mechanism of this receptor. Interestingly, the study showed that transferrin receptor was endocytosed and released intact from cells without being intracellularly degraded. Intracellular transferrin receptor was confined and transported in vesicles inside multivesicular compartments that could be exocytosed from the cell into the extracellular environment after fusion of the multivesicular compartment with the plasma membrane. This mechanism of signalling was catalogued as lateral mobility, nowadays known as horizontal transfer of biological signals (Harding, Heuser, \& Stahl, 1983; Pan \& Johnstone, 1983).

Following the discovery of EVs in vitro, the interest in these particles has grown enormously. The initial role assigned to EVs was as a vehicle for the removal of unwanted products from the cell. However, the lack of techniques to study them due to small size and unknown function kept EVs under research interest and were suddenly ignored. The recent development of new techniques of isolation, analysis and imaging changed the field, showing that EVs are involved in multiple pathways, performing some critical functions in the biology of an organism (György et al., 2011; Margolis \& Sadovsky, 2019; Raposo \& Stoorvogel, 2013; Valadi et al., 2007).

\subsection{Extracellular vesicles biology}

Extracellular vesicles are spheroid lipid-bilayer enclosed particles, containing cytosol of the secreting cell. EVs are naturally secreted by virtually all cell types and have been isolated from body fluids such as cerebrospinal fluid, nasal secretion, saliva, breast milk, synovial fluid, bile, blood, amniotic fluid, seminal fluid, uterine fluid, urine, faeces, etc. The population of extracellular vesicles is diverse and depends on the origin and the state of the secreting cell (such as stimulation, stress, etc.).

The first indication, that EVs are involved in intercellular signalling causing cellular responses, arose from a study, showing that major histocompatibility complex class II (MHC-II) is transported to compartments-containing vesicles, which are secreted to the extracellular environment by B-cells and able to cause a specific response in antigen-presenting T-cell (Raposo et al., 1996). In view of these observations, further research followed, aiming to explain EV biogenesis and the mechanism for $\mathrm{EV}$ release. 


\subsubsection{Classification of EVs}

A broad variety of names has been used to refer to these vesicles. However, in the field researchers refer to them now as extracellular vesicles to generally designate all secreted vesicles. EVs have been broadly classified according to their properties and cellular origin (Table 1).

Table 1. Table summarizing the classification and biogenesis of different EVs

\begin{tabular}{|l|l|l|}
\hline \multicolumn{1}{|c|}{ EVs } & \multicolumn{1}{|c|}{ Classification } & \multicolumn{1}{c|}{ Biogenesis } \\
\hline Exosomes & Homogeneous population & Released after fusion of \\
with $50-150 \mathrm{~nm}$ of & multivesicular bodies to \\
diameter size & the plasma membrane \\
\hline Microvesicles & Heterogeneous & Released directly from the \\
population with $100-$ & plasma membrane by \\
Apoptotic bodies & Variable particle size & Released by separation of \\
\hline ranging from $100-$ & cytosolic fragments from a \\
& $5000 \mathrm{~nm}$ of diameter & cell \\
\hline
\end{tabular}

Exosomes are a subtype of small vesicles, released after the fusion of multivesicular bodies (MVBs) with the plasma membrane. MVBs originate from the late endocytic trafficking compartments and contain small particles, intraluminal vesicles (ILVs), which will later be secreted and called exosomes. Microvesicles (also called microparticles or ectosomes) are produced after the outward budding and fission of membrane vesicles from the plasma membrane. It has been shown, that microvesicles could bud from extensions of membrane such as microvilli, filopodia, cilia, flagella, etc. Apoptotic bodies are formed when cells undergo apoptosis, whereby cells fragment and dissociate into bodies of different sizes, surrounded by membrane (plasma membrane blebbing), which are hard to distinguish from other types of EVs.

All these EVs have a particular common feature, compared to other intracellular trafficking system, namely, the orientation of the membrane is the same as the plasma membrane of the cell, allowing these particles to contain cytosolic and transmembrane material from the cellular source. (Lee, El Andaloussi, \& Wood, 
2012; Maas, Breakefield, \& Weaver, 2017; Mathieu, Martin-Jaular, Lavieu, \& Théry, 2019).

In order to study a specific EV subgroup, different approaches have been used to isolate them, for example by size. The lack of standardization in these procedures, added to the difficulty in isolating the EVs, made it problematic to study a specific EV population. Differential centrifugation, affinity chromatography, specific antibodies, ligands, precipitation, gradient fractionation, sucrose density ultracentrifugation and size exclusion chromatography are on the list of methods used for EV isolation and purification. All of them depend on the source of EVs. Other factors also play an important role in the isolation and purification, such as types of centrifuges, the used speed, the sizes of columns, media in which EVs are contained, etc.

\subsubsection{Biogenesis of EVs}

Exosomes and microvesicles are generated at different sites in a cell, but they share common mechanisms and pathways during biogenesis (Fig. 1). The very first step, involved in the formation of EVs, is the transport of a specific cargo either to the plasma membrane (microvesicles) or to the endosomes, forming multivesicular bodies (exosomes). Once the cargo is at the site of secretion, it needs to be diposited inside the vesicle. These steps are performed by different clustering and budding machineries prior to the exocytosis of the EV. The mechanisms involved in the biogenesis will modulate the shape, size, and content of the EVs, therefore influencing their role. 


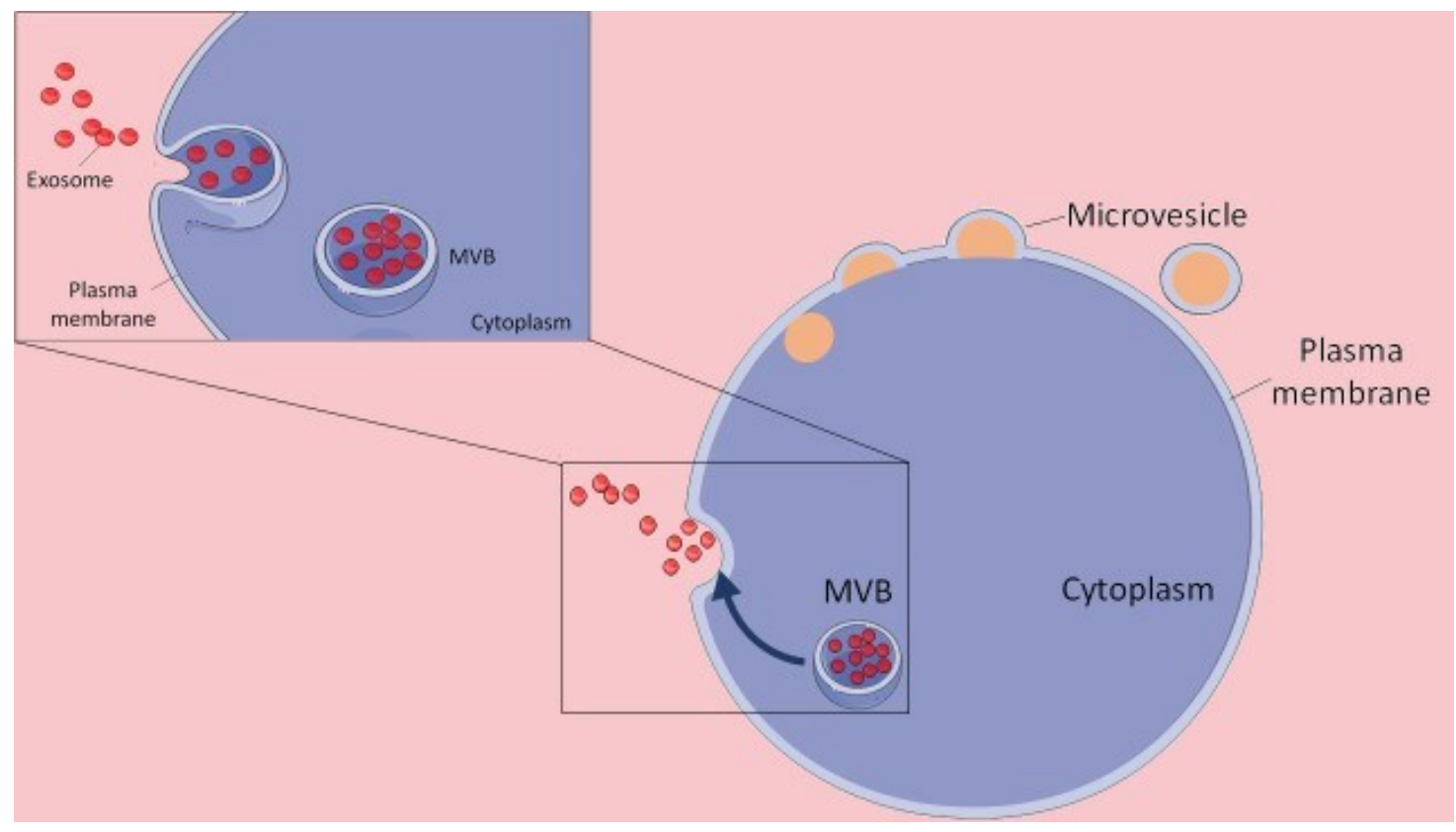

Figure 1. Biogenesis of extracellular vesicles. Microvesicles are generated through the direct budding of the plasma membrane. Intraluminal vesicles (ILVs) are formed by inward budding of the endosome forming the multivesicular body (MVB); therefore, the fusion of MVB with the plasma membrane release the vesicles, which are then called exosomes.

One of the best-characterized machineries, involved in the biogenesis of multivesicular bodies are the Endosomal Sorting Complexes Required for Transport (ESCRT), which consist in four cytosolic protein complexes along with accessory proteins (such as Alix and TSG101), capable of recruiting cargo and remodelling membrane structure to form ILVs. This machinery, first discovered in yeast and conserved through to eukaryotes, is also used by viruses to perform exocytosis and in membrane abscission during cytokinesis. Moreover, some studies demonstrate that the inhibition or impairment of these complexes affects the secretion and the content of EVs (Colombo et al., 2013). The ESCRT machinery, together with accessory proteins is not the only one involved in the formation of exosomes. Indeed, some evidence show that Syndecan, Syntenin and Alix proteins also play a role in the biogenesis of exosomes. Indeed, the ESCRT complexes have been shown to be regulated by tetraspanins such as CD63, CD9 and others, involved in cargo sorting into exosomes (Baietti et al., 2012). However, the biogenesis of exosomes can also be achieved in an ESCRT-independent manner, as it has been shown previously, that the inhibition of key proteins of ESCRT does not prevent formation of the MVBs (Stuffers, Sem Wegner, Stenmark, \& Brech, 2009). Other 
mechanisms involve the synthesis of ceramide, to promote membrane curvature and budding (Hurley, 2008; van Niel et al., 2011).

The biogenesis of microvesicles is less characterized, since microvesicles are not just vesicles with some cellular content. Indeed, studies demonstrate that ESCRT machinery is also involved in the clustering of cargo and budding, together with other proteins such as ARF6 and Rab22a, involved in cargo recruitment. The biogenesis involves considerable morphologic-membrane changes localized at the site of exocytosis. This is accompanied with lipid and protein translocation, such as the exposure of phosphatidylserine to the cell surface causing a structural change in membrane curvature and subsequent budding. Moreover, the process is dependent on the presence of membrane-enriched cholesterol, as it has been shown that its depletion causes impairment of microvesicle biogenesis. Several enzymes are involved here, such as flippases, scramblases and calpain, as well as proteins implicated in cytoskeleton regulation which are able to generate or modulate asymmetry of the plasma membrane. Although these mechanisms are still under investigation, ultrastructural observations suggest that the populations of ILVs (and later exosomes) and microvesicles are heterogeneous, probably destined to exert different functions, thus highlighting the mechanistic complexity of EV biogenesis (McMahon \& Boucrot, 2015; Tricarico, Clancy, \& D'Souza-Schorey, 2017; Wang et al., 2014).

\subsubsection{Molecular composition of EVs}

Accumulating data in the last few years showed that the content and membrane composition of EVs is heterogeneous and dynamic, depending on the state (physiologic or pathologic) of the cell of origin, on stimuli, affecting the production and release of EVs, and on the biogenesis and depending on the environment.

EVs contain proteins, lipids and nucleic acids, which define some of the differences between exosomes and microvesicles, i.e. their composition. As mentioned above, microvesicles resemble the plasma membrane composition while exosomes contain cytosolic proteins from endocytic pathways. Different features have been proposed for each subgroup of EVs, but up to date, there is yet no consensus about specific markers to distinguish and classify them (Colombo, Raposo, \& Théry, 2014; Maas et al., 2017; Yáñez-Mó et al., 2015). 
Several studies, performed using proteomics and mass spectrometry showed a comparable cargo in diverse source of EVs, suggesting a controlled sorting mechanism rather than random protein content from the cell of origin. EV proteins such as tetraspanins, integrins, heat shock proteins, proteins from and related to the ESCRT, cytoskeleton proteins as well as proteins related to vesicle structure, biogenesis and trafficking, are the most common and present in most EV subtypes. A wide variety of proteins is known to be sorted in EVs and there are open access databases such as Vesiclepedia (http://microvesicles.org/), EVpedia (https://exosome-rna.com/tag/evpedia/) or ExoCarta (http://www.exocarta.org/), based on community entries from proteomic studies, which shows over 350000 protein entries coming from more than 1200 studies (Kalra et al., 2012; van Niel et al., 2011).

A large amount of work has been dedicated to understanding not only the protein composition but also lipid and nucleic acid composition of the EVs. As mentioned above, lipids are involved in the biogenesis and formation of EVs, playing a role in membrane stability, structure and budding process. Sphingomyelin, phosphatidylcholine, phosphatidylserine, phosphatidylinositol, prostaglandins, ceramide and cholesterol are some of the known membrane lipid components of EVs, as well as being involved in different signalling pathways. Compared to the plasma membrane, the levels of these components resemble lipid-microdomains similar to lipid rafts, strengthening their role as signalling and functional molecules in EVs. Some of the databases, mentioned before, provide more than 1000 lipid entries identified in multiple organisms (Laulagnier et al., 2004; Yoon, Kim, \& Gho, 2014).

In addition to proteins and lipids, extracellular vesicles can carry nucleic acids such as mRNA, DNA, miRNA and others. The first indication, that EVs can carry mRNA, came from two studies, investigating microvesicles and exosomes. In Ratajczak J., et al., 2006, the presence of mRNA has been identified in EVs. When EVs were transferred to the target cells, mRNA remained stable and altered cellular function. The authors have been studying in vitro intercellular communication between embryonic stem cells and hematopoietic progenitor cells. The study showed that the transfer of EVs enhanced survival and proliferation of the latter, upregulated specific markers and induced epigenetic changes. The population of EVs was enriched in mRNA for diverse transcription factors that could be translated by the target cell, 
exerting their effects. The second study one year later, showed in vitro that murine RNA from exosomes was transferred to the human mast cells where was translated and functional. Additionally, the authors identified some transcripts, only present in EVs and not in the source cell, suggesting a complex sorting mechanism for nucleic acids (Ratajczak et al., 2006; Valadi et al., 2007).

A more recent study, employing next-generation sequencing in endothelial cells, revealed the presence of small RNAs, such as miRNA, small nucleolar RNA, yRNA, vault RNA, mitochondrial RNA and small RNA fragments. Some of them were expressed only in EVs while others were enriched in the particles, suggesting a complex mechanism involved in the sorting and regulation of genetic material (Van Balkom, Eisele, Michiel Pegtel, Bervoets, \& Verhaar, 2015).

Several approaches, using next-generation sequencing and microarrays, revealed significant mRNA and miRNA levels within the EVs. Although the nucleic acid sorting mechanism is poorly understood, some studies showed that EV composition differs from the source cell, and in particular, miRNAs are enriched in EVs. The fact, that EVs can carry genetic material, makes them potential vehicles, able to horizontally transfer genetic information and cause genetic reprogramming in the recipient cell. Moreover, as their cargo varies depending on the state of the cell, it could be used as a biomarker or as a diagnostic tool (Valadi et al., 2007; Van Niel, D’Angelo, \& Raposo, 2018).

\subsubsection{Secretion of EVs}

Extracellular vesicle release may represent a universal and conserved process in evolution, since they are produced both by bacteria and by virtually all cell types in multicellular organisms, cataloguing them as ubiquitous intercellular transport system (Théry, Zitvogel, \& Amigorena, 2002). The release of EVs is a highly regulated process and there are different factors that can influence EV release, such as pathophysiologic stimuli or cell type.

With regard to exosomes, MVBs, can be either degraded by fusion with lysosomes or the content can be secreted by fusion with the plasma membrane. Recent evidence shows that the impairment of lysosomal degradation leads to an increase in EV exocytosis, indicating the presence of a mechanism, regulating the balance between secretion and degradation. Although this mechanism is still not clearly 
defined, it involves some accessory proteins, related to ESCRT-independent machinery or tetraspanins. The family of Rab proteins are involved in the regulation of intracellular vesicular trafficking. Some of them are involved in exosome secretion as well as lysosomal degradation, suggesting that dynamic changes in cargo and membrane play a role in the balance between secretory and degradatory pathways of MVBs (Eitan, Suire, Zhang, \& Mattson, 2016; Song, Trajkovic, Tsunemi, \& Krainc, 2016).

In contrast, microvesicles do not require a transport step before being secreted as seen in exosomes, which could indicate a faster release to the extracellular space. Here, proteins from the ARF family are involved in the exocytosis mechanism, interacting with actin and myosin and allowing vesicles to bud off the plasma membrane. Some machinery related to ESCRT, as well as lipid composition changes, are controlling the release of microvesicles. There is evidence, showing that the translocation of acid sphingomyelinase promotes the curvature of the plasma membrane to allow microvesicles secretion by the generation of ceramide. Moreover, levels of ions, such as intracellular levels of calcium, can modulate MV release, and can be used to stimulate microvesicles release (Bianco et al., 2009; Krämer-Albers et al., 2007).

Several of the proteins, listed above, are involved in the biogenesis and secretion of EVs. Moreover, they play similar roles for both exosomes and microvesicles. This makes it difficult to distinguish between EV subtypes, emphasizing the need of new techniques in order to understand the mechanisms controlling vesicle release (Van Niel et al., 2018).

\subsubsection{Uptake of EVs}

Once EVs are released to the extracellular space, they can be taken up by other cells. As described above, EVs are rich in specific lipids and proteins, which could function as signalling molecules to target a specific cell or be recognized by specific receptors. Several routes are reported for EV uptake, but the mechanism, by which EVs are addressed to a specific recipient cell, is still under investigation.

One mechanism, potentially involved in EV uptake, has been proposed, based on the interaction between specific proteins and receptors from EVs and the surface of the target cell. Several players are described in mediating these interactions, such 
as integrins, immunoglobulins, tetraspanins, proteoglycans, lectins, lipids and components of the extracellular matrix (Hoshino et al., 2015).

EVs can be endocytosed by clathrin- or caveolin- dependent or -independent internalization mechanisms. Mutations or knockdown of different clathrin/caveolin components correlated with the reduction in EV uptake. Other processes, by which a cell can engulf content from the extracellular space, are macropinocytosis and phagocytosis. Although the latter is a receptor-mediated event, evidence suggests EV internalization by this mechanism. It has been shown that lipid rafts, microdomains present in the outer leaflet of the plasma membrane, enriched in cholesterol and several proteins and glycoproteins, could interact with EVs, promoting their endocytosis. A disruption in lipid raft composition causes reduced EV uptake. Other possible mechanism would likely be the direct fusion of EV and the plasma membrane, although it is probably not the main entry route for EVs (Barrès et al., 2010; Mulcahy, Pink, \& Carter, 2014).

Another important factor to consider is the origin (source) of EVs and the status of the recipient cell. As it has been shown few years ago, the specificity of EV binding changed depending on which was the source of EVs (cell type producing EVs) or depending on the status of the recipient cell (such as upon stimulation) (Chivet et al., 2014).

\subsection{Extracellular vesicle functions}

The first reports, describing the existence of extracellular vesicles and their functions, came from the field of immunology, attributing some of their functions solely to this or related area (explained in section 1.2. Discovery of EVs). These studies generated some initial findings, showing that EVs released from $B$ cells induced specific T cell responses (Raposo et al., 1996). Several years later, it has been shown that EVs from dendritic cells were able to induce varied functional $T$ cell responses and naïve $T$ cell priming, and that these functions depended on the maturation status of the dendritic cells (Segura, Amigorena, \& Théry, 2005; Segura, Nicco, et al., 2005). Moreover, the uptake of EVs from dendritic cells by epithelial cells induced the release of cytokines and chemokines, initiating a pro-inflammatory innate immune response driven by TNF- $\alpha$ (tumor necrosis factor-alpha) (Obregon, Rothen-Rutishauser, Gerber, Gehr, \& Nicod, 2009). Indeed, EVs participate in innate and adaptive immune response, modulating different aspects of these 
processes. It has been shown that EVs play a role in inflammation, contributing to its induction and propagation across the whole body (Cossetti et al., 2014). In the last few years, a considerable amount of evidence has been accumulated allowing to list the roles and functions of EVs. However, the majority of the studies have been performed in vitro, and a scarce number of in vivo studies exists. Due to the complexity of EVs, there is a need to further develop the techniques, necessary to study EVs in order to understand mechanisms of biogenesis, their composition and functions. (Mulcahy et al., 2014).

\subsubsection{EV function in the nervous system}

In the last decades, extracellular vesicles gained importance not only in the context of immune response and inflammation, but also in other systems such as the nervous system. Cells forming this system communicate to each other via synaptic connections (transfer of electrical / chemical signal from one cell to the other), local communication (cell - cell contact) and through release of soluble factors, although now there is substantial evidence that place EVs as key mediators of intercellular communication in the nervous system (Smalheiser, 2007).

For example, EVs are found in the cerebrospinal fluid and can be secreted from different cell types in the brain, including neurons, microglia, astrocytes, and oligodendrocytes among others. The secretion is regulated by calcium influx and glutamatergic activity (Lachenal et al., 2011). Some proteins transferred by EVs contribute to local synaptic plasticity and, together with mRNAs and miRNAs, regulate neuronal function. Moreover, EVs provide the transfer of diverse components in the brain, propagated over short as well as long distances, connecting this static network of different cell types (Lee et al., 2012).

Some studies provide evidence that extracellular vesicles are able to cross the blood-brain barrier. In particular, tumor-derived EVs have been shown to cross the $\mathrm{BBB}$ in vivo via transcytosis, while the integrity of the barrier remained unaffected (Morad et al., 2019). Therefore, EV signalling adds an extra level of complexity to the intercellular signalling between different organs and the brain.

In the last few years, extracellular vesicles have been related to neural development, as they were detected in the luminal fluid of the neural tube and in neurons from embryo cultures. Some of the proteins released by EVs, such as $\mathrm{L} 1$ cell adhesion 
molecule (L1CAM), suggest their role in synaptic activity. Studies in vitro report EV release and modulation through glutamate, calcium influx and AMPA and NMDA receptors (Bakhti, Winter, \& Simons, 2011; Marzesco et al., 2005). EVs and their cargo have also been involved in signalling between oligodendrocytes and neurons, controlling the assembly of myelin. The internalization of EVs by neurons has been associated with an increase in the resistance to stress and enhanced cell viability (Fröhlich \& Kuo, 2014). Other in vitro studies suggest, that EV release can alter the physiological state of the recipient cell, as evidenced by the transfer of miRNA from neurons to astrocytes, upregulating the excitatory amino acid transporter 2 , involved in glutamate uptake (Morel et al., 2013).

\subsubsection{Relevance of EVs in neurodegenerative diseases}

Emerging evidence connects extracellular vesicles to neurological disorders after the observation, that EVs can contain associated pathogenic proteins, such as prion-protein scrapie-form (PrPsc), alpha-synuclein (a-Syn), amyloid precursor protein (APP), amyloid beta, etc.

Some of these studies relate EVs to a disease spread mechanism. However, other publications indicate that EVs could serve as a vehicle to remove all toxic products, obsolete proteins, RNA, unwanted waste from the cell. As has been shown in vitro by Yuyama et al., the uptake of amyloid-beta-containing EVs by microglial cells ended up in the clearance of amyloid protein, exhibiting a protective mechanism (Yuyama, Sun, Mitsutake, \& Igarashi, 2012). Extracellular vesicle involvement in AD has been suggested following the observation of hyperphosphorylated Tau protein in EVs in neural cultures and in CSF in humans. Microglia cells might be the responsible for the spread of Tau protein to the different cell types and brain regions via EV release (Pluta, Ułamek-Kozioł, Januszewski, \& Czuczwar, 2018; Rajendran et al., 2006).

Similar to $A D$, Parkinson Disease is a proteinopathy, and is characterised by the accumulation of a-Syn, a presynaptic protein, found in healthy conditions in monomeric and oligomeric state. Neuropathological hallmark of PD is accumulation of intracellular misfolded a-Syn and aggregation of fibril structures in inclusions called Lewy bodies. It has been shown that a-Syn could be sorted in EVs and supporting studies correlate the uptake of a-Syn-containing EVs to a decline in survival of dopaminergic neurons through activation of caspase- 3 and subsequent 
apoptosis, with a general toxic effect for recipient cells (Emmanouilidou et al., 2010). Moreover, EV-associated a-Syn from CSF of PD patients was able to induce aggregation of naïve a-Syn (Stuendl et al., 2016). Furthermore, inflammation is described to play a role in PD. Indeed, reactive microglia has been found in the SN of PD patients accompanied by increased levels of cytokines in CSF and blood, suggesting a link with the periphery and its role in neurodegenerative diseases (Lecours et al., 2018; Y.S. \& T.H., 2006). In addition, lysosome impairment (another neuropathological hallmark of PD), induced either pharmacologically or by genetic manipulation, caused an increase in EV release. However, it is not yet clear whether EVs are involved in spreading of the disease or in removal of toxic products (Alvarez-Erviti et al., 2011; Tancini et al., 2019).

Another neurodegenerative disease with a potential EV involvement is prion disease. Prion proteins, in their misfolded state, are able to induce misfolding in naïve proteins. PrPsc is another protein, which can be incorporated in- and transferred through EVs, then infect other cells and induce the misfolded state of the protein. PrP was found associated with EVs in the CSF of sheep, suggesting a mode of transport through the brain via EVs (Fevrier et al., 2004).

Although some of the studies, mentioned above, suggest a role of EVs as pathologic spread vehicles, a considerable amount of research is focused on the use of extracellular vesicles as means of toxic products removal. For instance, EVs are associated with the transport of miRNAs that could activate microglia phagocytosis in order to clear toxic products (Bahrini, Song, Diez, \& Hanayama, 2015). Moreover, certain enzymes, related to amyloid-beta degradation were found associated to EVs (Bavisotto et al., 2019).

\subsection{Cross-talk between the immune system and the brain}

Intercellular communication goes beyond the interaction between cells in the brain; it can take place between organs. In particular, the brain is in dynamic contact with the immune system. Activation of the immune system in the periphery alters the function of the brain and inflammation and microglia activation are common events occurring and associated with many neurodegenerative diseases and their pathogenesis (Paolicelli, Bergamini, \& Rajendran, 2019). A considerable amount of literature describes the major routes involved in the communication between the immune system and the brain, particularly in an inflammation event and the role 
inflammation plays in the onset and progression of brain diseases. The communication between the brain and the immune system is conducted and modulated by different cell types of the brain, such as myeloid cells, microglia, as well as macrophages, mast cells and monocytes. Common molecules, mediating this communication are cytokines, such as tumor necrosis factor alpha (TNF-a), TGF-beta, IL-1, IL-6, etc., chemokines, toll-like receptors, MHC. These molecules, once in circulation, can activate microglia or other brain cell types directly or via endothelial cells (Czirr, Wyss-coray, Czirr, \& Wyss-coray, 2012). Another way of communication is through the vagus nerve, which extends from the cranial vault, and branches out in several directions, straight down the neck, chest and abdomen and ends in the colon. The vagus nerve carries sensory information from the internal organs back to the CNS, enabling the brain to control and to be informed about different organ status and activity. Recent evidence shows a connection between the immune system and the vagus nerve; whereby the vagus nerve is involved in the control of innate immune responses and inflammation during injury, transferring signals from pro-inflammatory cytokines, secreted by the immune cells to the brain (Pavlov \& Tracey, 2012). The majority of these molecules have been traced to EVs, involved either in cargo sorting or in transport and delivery to recipient cells. In the context of neurodegenerative diseases, EVs are also involved in the transport of inflammatory modulators and cytokines; once they reach the target cell, they can exert inflammatory responses causing substantial changes (Paolicelli et al., 2019).

The central nervous system is immunologically privileged and under homeostatic conditions (healthy, absence of inflammation) cells from the immune system do not enter the brain. For this reason, a common model, used to study the effect of the immune system activation on the brain, is the injection of lipopolysaccharide (LPS). LPS is an endotoxin and the major component of the outer membrane of Gramnegative bacteria. It has been shown to promote activation of microglia, secretion of pro-inflammatory cytokines, induction of reactive oxygen species (ROS), B cell activation and, moreover, an increase in EV release. This peripheral immune response has an effect on the brain and has been particularly studied in microglial cells, the resident immune cells in the brain. The studies showed a pro-inflammatory phenotype together with alterations in morphology, gene expression and recruitment (Hoogland, Houbolt, van Westerloo, van Gool, \& van de Beek, 2015; Kloss, Bohatschek, Kreutzberg, \& Raivich, 2001). Of note, depending on LPS 
concentrations and how often it is injected, effects can vary. Intracranial infusion of LPS has been used as an alternative inflammatory mechanism to cause some of the aspects observed in PD, such as the progressive loss of tyrosine hydroxylase (TH)-positive dopaminergic neurons in the SN, thereby highlighting the importance of inflammation in the context of neurodegenerative diseases (Qin et al., 2007).

The cross talk occurring between the peripheral immune system and the brain has enormous consequences for brain function and it is suggested, that periphery-tobrain communication has an implication in the pathophysiology on neurodegenerative disorders. As mentioned above, growing evidence places extracellular vesicles as important players, involved in this periphery-to-brain communication axis, probably occurring both in physiology as well as in pathology. Moreover, as EVs are able to cross the BBB, peripheral inflammation could modulate brain physiology via EV uptake. Still, the signalling routes used by EVs to enable communication between haematopoietic system and the brain irrespective of an inflammation or homeostasis, need to be elucidated. (Balusu et al., 2016; Glass, Saijo, Winner, Marchetto, \& Gage, 2010).

\subsection{Contribution of the haematopoietic system to the brain}

Earlier research from the Momma Lab addressed distinct mechanisms of interaction between the immune system and the brain. Cellular fusion of haematopoietic cells with neurons in the brain has been observed following inflammation and / or invasive manipulation (Johansson et al., 2008; Nygren et al., 2008). Whether the cell fusion phenomenon occurred only under invasive experimental conditions or it could be a physiological process has been extensively discussed in a previous publication (Nern et al., 2009). To address this question and to overcome the drawbacks of highly invasive techniques, such as irradiation and bone marrow transplantation, a genetic murine tracing model based on the Cre-LoxP system has been developed. In this system, peripheral haematopoietic cells express Cre recombinase under the vav1-promoter and when this mouse is crossed with a Cre reporter line, the stop codon is excised and the haematopoietic lineage will express EYFP (Fig. 2). Consequently, haematopoietic cells are endogenously and irreversibly labelled and could be traced through the whole body. Thus, their contribution to different tissues can be tested without confounding artefacts. Labelled non-haematopoietic cells have been observed in the heart, liver as well as Purkinje cells in the brain. However, 
Purkinje neurons never contained two nuclei, indicating that cell fusion does not occur in physiological conditions (Nern et al., 2009).

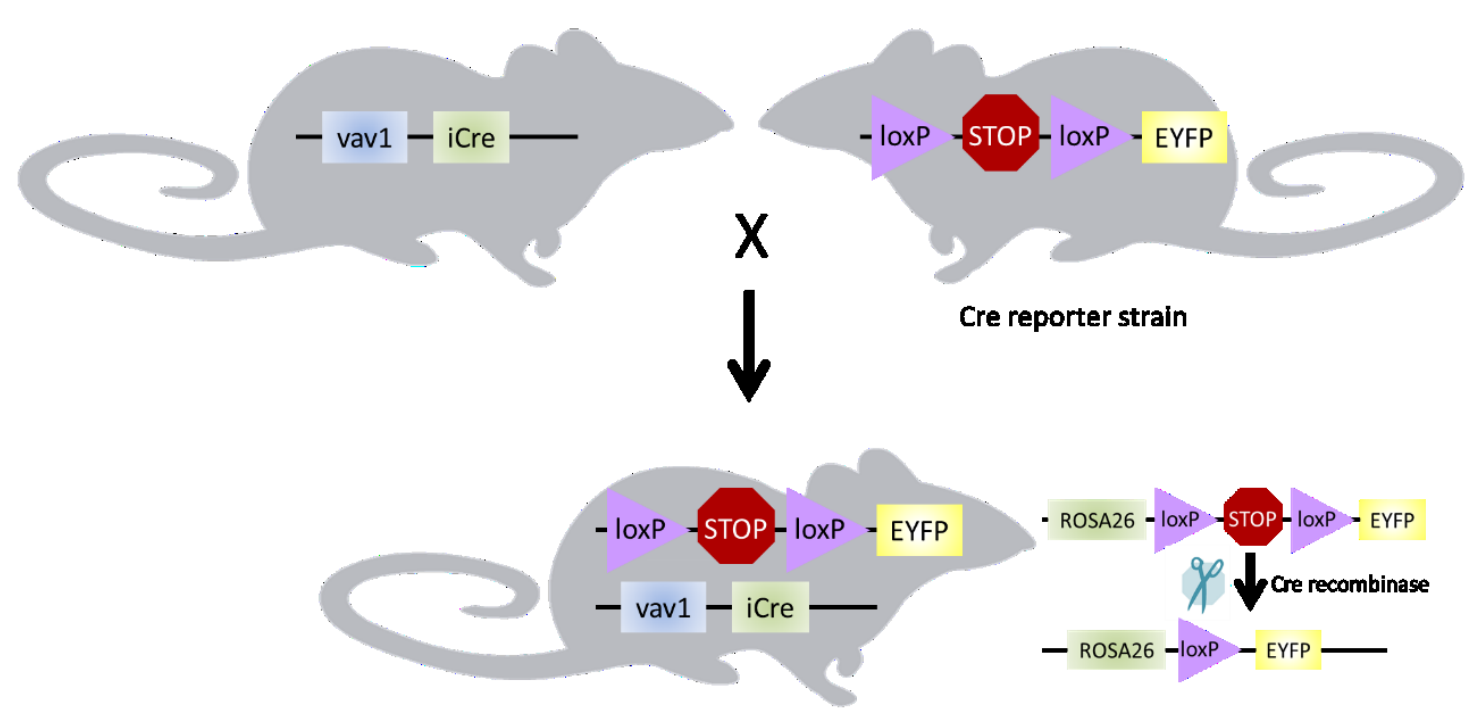

EYFP fluorescence confirms Cre activity in haematopoietic lineage

Figure 2. Genetic murine tracing model used to visualise the contribution of haematopoietic cells from blood to other organs. Left mouse constitutively expresses Cre under the vav1 promoter while the right mouse expresses EYFP as a reporter marker-gene but its expression is only possible after the activity of Cre recombinase. The double-transgenic progeny expresses Cre recombinase in haematopoietic cells and the subsequent expression of marker-gene in these cells.

Furthermore, this contribution was always boosted following the peripheral inflammation. The mechanism by which Cre mRNA is transferred from haematopoietic cells to the brain has been addressed in another publication from the Momma lab in greater detail (Ridder et al., 2014). Looking for a possible mechanism able to explain this inter-tissue transfer of material, trans-differentiation was discarded, as no changes in morphology were observed; fusion of both cell types was excluded, as only one nucleus was detected and no extra chromosome was found. To this end, the emergence of extracellular vesicles as carriers of intercellular communication have been implied in the transfer of different kinds of molecules between cells in vitro. Indeed, EV mRNA transfer could be the mechanism involved in this inter-tissue communication. The analysis of peripheral blood, obtained from the mice, revealed low levels of Cre mRNA, but not the protein, in pellets of membrane vesicle fraction, isolated by ultracentrifugation but not in the supernatant. Data suggests that Cre mRNA was contained in membrane structures, such as EVs. After the treatment of these pellets with detergent and RNase, no Cre mRNA could be detected, supporting the hypothesis that Cre mRNA is enclosed in 
EVs, which can be secreted and travel through other tissues. Furthermore, following the peripheral inflammatory response, the transfer of mRNA by EVs increased and extended through other brain regions such as HC, SN and CTX (Ridder et al., 2014).

Therefore, the genetic tracing model for intercellular communication would be explained as the transfer of Cre mRNA from blood to brain. Here, Cre construct is present in all tissues but Cre is expressed only in haematopoietic cells under the haematopoietic-specific vav1 promoter and its mRNA can be released into the circulation via EVs. Thus, in a mouse with a Cre reporter background, after the excision of the stop-codon flanked by LoxP sequences, EV uptake in other cell types can be visualised by the expression of a marker-gene, in this case EYFP, detected as green fluorescence (Fig. 3). Cre recombinase activity is irreversible and the Rosa26 promoter controlling the expression of EYFP is expressed ubiquitously.

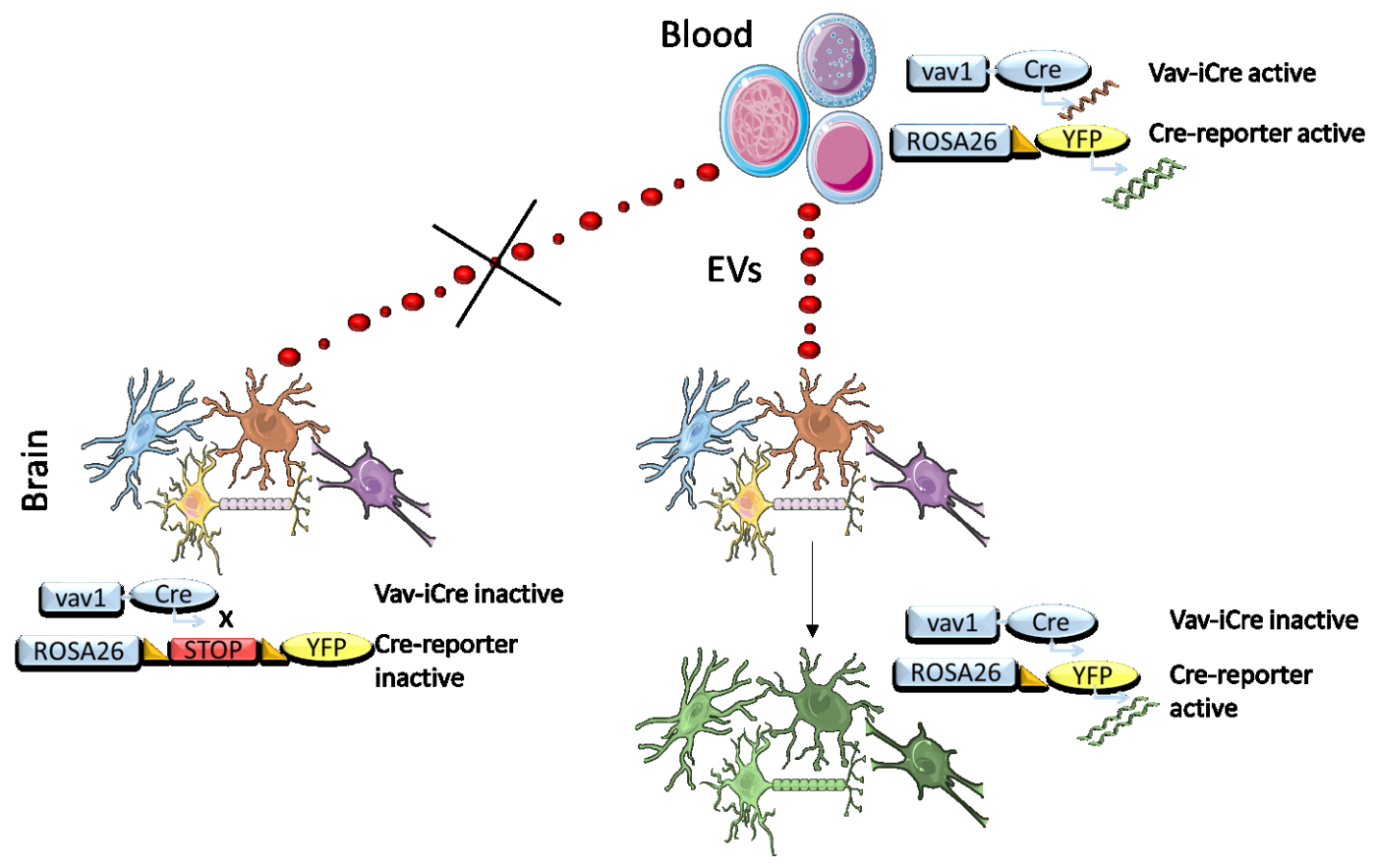

Figure 3. Scheme for transgenic mouse model to trace EV transfer from blood to brain in vivo. Blood cells from the haematopoietic system constitutively express Cre under the Vav1 promoter. Cre mRNA is transferred via EVs to the brain and other tissues. Crossed to a Cre-reporter background, Cre mRNA is translated and excises the stop codon, initiating expression of the marker gene, here YFP, even in cells that do not actively express Cre.

The Cre-LoxP system allowed to genetically trace the transfer of RNA via EVs between cells in vivo. This system enabled the Momma lab to generate the first in vivo evidence of functional RNA transfer by EVs between blood and brain. This evidence therefore suggests a novel way of communication between the immune 
system and the brain, a communication that may be wider and more profound than previously known (Robinson, 2014).

However, several questions remain unknown and need further investigation. For example, the machinery involved in EV uptake and whether this mechanism is specific remain unclear. The driving mechanism behind the uptake of EVs by some cells but and not others, and if there is any influence of the source of EVs. Other important topics under investigation are the spread of EVs in different brain regions and the cell types that are prone to EV uptake. Of note, very few studies addressed the permeability of the BBB as an entrance route for EVs, as major studies were done in vitro. A big effort is being made in order to study EV uptake in physiology and pathology, such as PD, and their downstream effects, as well as the consequences of EV uptake at a molecular and functional level. Some of these key questions will be addressed in this thesis. 


\subsection{Aims of the study}

In the past few years, considerable efforts have been made in order to understand the mechanisms underlying blood to brain communication in the context of peripheral inflammation and neurodegenerative diseases, and how extracellular vesicles are taken up and modulate neural cell fate. Most of the studies related to EV functions have been performed either in vitro or ex-vivo, highlighting the challenge of studying these particles and their role in an in vivo model.

In 2014, the Momma lab was a pioneer in showing that information from haematopoietic cells could be transferred through EVs to the brain and that this effect was amplified by peripheral inflammation. In particular, Ridder et al. proved that mRNA from haematopoietic cells is enclosed in EVs and is transferred into neurons where it is translated to protein. These observations report a novel in vivo communication mechanism between the haematopoietic system and different organs, such as the brain. Moreover, recent results from the Momma lab, studying the effect of inflammation caused by LPS injection in the context of PD, showed EV signalling towards neurons displaying signs of cellular stress.

Based on these findings, this project was conceived with the goal to investigate the driving and triggering mechanism of extracellular vesicle uptake by neural cells in vivo and whether this signalling pathway, periphery-to-brain, occurs under physiological conditions.

This general aim includes the following experimental parts:

- Explore the extent and function of EV-mediated signalling from blood to brain in the context of peripheral inflammation and in the context of neurodegenerative diseases with a focus in Parkinson Disease

- Explore the possible mechanism involved in EV uptake by neuronal cells and analyse whether extracellular vesicle signalling occurs not only under pathological conditions but also in physiology

- Give insights about the possible downstream effects of EV uptake, either beneficial or detrimental for the cells, influencing survival or vulnerability 


\section{Material and Methods}

\subsection{Materials}

\subsubsection{Antibodies}

Table 2: Primary antibodies

\begin{tabular}{|c|c|c|c|c|c|}
\hline ANTIBODY & CLONE & HOST & SPECIFICITY & DILUTION & COMPANY \\
\hline Arc & & rabbit & Rat, mouse & 1:1000 & $\begin{array}{l}\text { Synaptic } \\
\text { systems, } \\
156003\end{array}$ \\
\hline $\begin{array}{l}\text { Calbindin D- } \\
28 \mathrm{k}\end{array}$ & & rabbit & Many species & $1: 5000$ & Swant, CB-38 \\
\hline CD31 & PECAM-1 & $\begin{array}{l}\text { rat, } \\
\text { IgG2a }\end{array}$ & mouse & $1: 100$ & $\begin{array}{l}\text { BD } \\
\text { Pharmingen, } \\
557355\end{array}$ \\
\hline CD45 & $30-\mathrm{F} 11$ & $\begin{array}{l}\text { rat, } \\
\text { lgG2b }\end{array}$ & mouse & $1: 50$ & $\begin{array}{l}\text { BD } \\
\text { Pharmingen, } \\
553076\end{array}$ \\
\hline CD49d & $\begin{array}{l}\mathrm{R} 1-2 \\
(\mathrm{R} \cup O)\end{array}$ & rat & mouse & $1: 400$ & $\begin{array}{l}\text { BD Horizon, } \\
564395\end{array}$ \\
\hline CD-9 & D3H4P & $\begin{array}{l}\text { Rabbit } \\
\mathrm{Ab}\end{array}$ & human & $\begin{array}{l}1: 250 \\
(\mathrm{WB})\end{array}$ & $\begin{array}{l}\text { Cell Signalling } \\
13403\end{array}$ \\
\hline Ceramide & MID15B4 & $\begin{array}{l}\text { mouse } \\
\text { IgM }\end{array}$ & & $\begin{array}{l}1: 100 \\
\text { (FACS) }\end{array}$ & $\begin{array}{l}\text { Alexis Bioch., } \\
\text { ALX-804-196 } \\
\text { (Enzo) }\end{array}$ \\
\hline C-Fos & & rabbit & $\begin{array}{l}\text { Mouse, rat, } \\
\text { human }\end{array}$ & $1: 2000$ & $\begin{array}{l}\text { Santa Cruz } \\
\text { Biotech sc-52 }\end{array}$ \\
\hline DAT & & $\begin{array}{l}\text { Rat, } \\
\text { IgG2ak }\end{array}$ & & $1: 1000$ & $\begin{array}{l}\text { Millipore, } \\
\text { MAB369 }\end{array}$ \\
\hline Flotillin1 & & $\begin{array}{l}\text { Mouse } \\
\text { IgG1 }\end{array}$ & $\begin{array}{l}\text { Chicken, } \\
\text { human, } \\
\text { mouse }\end{array}$ & $\begin{array}{l}1: 500 \\
(W B)\end{array}$ & $\begin{array}{l}\text { BD } \\
\text { Biosciences } \\
610821\end{array}$ \\
\hline GFAP & & rabbit & many species & $1: 1000$ & Dako, ZO334 \\
\hline
\end{tabular}




\begin{tabular}{|c|c|c|c|c|c|}
\hline GFP & polyclonal & $\begin{array}{l}\text { Chicken } \\
\lg Y\end{array}$ & & $1: 500$ & $\begin{array}{l}\text { Abcam, } \\
\text { ab13970 }\end{array}$ \\
\hline $\begin{array}{l}\text { GFP - } 488 \\
\text { conj. }\end{array}$ & & $\begin{array}{l}\text { rabbit, } \\
\lg G\end{array}$ & & $1: 500$ & $\begin{array}{l}\text { ThermoFisher, } \\
\text { A21311 }\end{array}$ \\
\hline HSP70 & & $\begin{array}{l}\text { Rabbit } \\
\text { IgG }\end{array}$ & $\begin{array}{l}\text { Human, } \\
\text { mouse, rat, } \\
\text { horse }\end{array}$ & $\begin{array}{l}1: 1000 \\
(\mathrm{WB})\end{array}$ & $\begin{array}{l}\text { SBI ExoAb } \\
\text { HSP70A-1 } \\
\text { (System } \\
\text { Biosciences) }\end{array}$ \\
\hline Iba-1 & & rabbit & $\begin{array}{l}\text { human, } \\
\text { mouse, rat }\end{array}$ & $1: 1000$ & $\begin{array}{l}\text { WAKO, } \\
19741\end{array}$ \\
\hline $\begin{array}{l}\text { IgG2a } \\
\text { Isotype }\end{array}$ & R35-95 & $\begin{array}{l}\text { rat, } \\
\text { lgG2a }\end{array}$ & & $1: 1000$ & $\begin{array}{l}\text { BD } \\
\text { Biosciences, } \\
559073\end{array}$ \\
\hline IgM Isotype & & mouse & & $1: 1000$ & $\begin{array}{l}\text { eBioscience, } \\
\text { 14-4752-82 }\end{array}$ \\
\hline MAP2 & HM-2 & $\begin{array}{l}\text { mouse, } \\
\text { lgG1 }\end{array}$ & many species & $1: 1000$ & Sigma, M4403 \\
\hline Nestin & $\begin{array}{l}401 \\
\text { (RUO) }\end{array}$ & rat & & $1: 500$ & $\begin{array}{l}\text { BD } \\
\text { Biosciences, } \\
556309\end{array}$ \\
\hline NeuN & & $\begin{array}{l}\text { mouse, } \\
\text { lgG1 }\end{array}$ & many species & $1: 300$ & $\begin{array}{l}\text { Millipore, } \\
\text { MAB377 }\end{array}$ \\
\hline NeuN-Cy3 & & mouse & & $1: 300$ & MAB377C3 \\
\hline $\begin{array}{l}\text { NeuN- } \\
\text { RBFOX3- } \\
\text { APC }\end{array}$ & $1 \mathrm{~B} 7$ & mouse & & $1: 300$ & $\begin{array}{l}\text { Novus } \\
\text { Biologicals, } \\
\text { NBP1- } \\
\text { 92693APC }\end{array}$ \\
\hline $\mathrm{NF}-\mathrm{H}$ & EP673Y & $\begin{array}{l}\text { rabbit, } \\
\lg G\end{array}$ & human & $1: 100$ & $\begin{array}{l}\text { Novus } \\
\text { Biologicals, } \\
\text { NB110-57241 }\end{array}$ \\
\hline Olig2 & 211F1.1 & mouse & & $1: 100$ & $\begin{array}{l}\text { Millipore, } \\
\text { MABN50 }\end{array}$ \\
\hline ß-actin & BA3R & Mouse & & & $\begin{array}{l}\text { Thermo Fisher, } \\
\text { MA5-15739 }\end{array}$ \\
\hline
\end{tabular}




\begin{tabular}{|c|c|c|c|c|c|}
\hline ß-III Tubulin & Tuj1 & $\begin{array}{l}\text { Mouse, } \\
\text { lgG2a }\end{array}$ & mammalian & $1: 2000$ & $\begin{array}{l}\text { Biolegend, } \\
801201\end{array}$ \\
\hline $\begin{array}{l}\text { Tyrosine } \\
\text { Hydroxylase }\end{array}$ & & $\begin{array}{l}\text { Mouse, } \\
\text { lgG1k }\end{array}$ & & $\begin{array}{l}1: 500 \\
1: 1000\end{array}$ & $\begin{array}{l}\text { Millipore, } \\
\text { MAB318 }\end{array}$ \\
\hline
\end{tabular}

Table 3. Secondary antibodies

\begin{tabular}{|c|c|c|c|}
\hline $\begin{array}{l}\text { SECONDARY } \\
\text { ANTIBODY }\end{array}$ & HOST & SPECIFICITY & COMPANY \\
\hline Alexa Fluor R 488 & goat & anti-mouse $\lg G(\mathrm{H}+\mathrm{L})$ & Invitrogen, A11001 \\
\hline Alexa Fluor ${ }^{R} 488$ & goat & anti-rat IgG $(\mathrm{H}+\mathrm{L})$ & Invitrogen, A11006 \\
\hline Alexa Fluor R 488 & goat & anti-rabbit IgG $(\mathrm{H}+\mathrm{L})$ & Invitrogen, A11008 \\
\hline Alexa Fluor ${ }^{R} 488$ & goat & anti-chicken $\lg \mathrm{Y}(\mathrm{H}+\mathrm{L})$ & Abcam, ab150169 \\
\hline Alexa Fluor ${ }^{R} 568$ & goat & anti-mouse $\lg G(\mathrm{H}+\mathrm{L})$ & Invitrogen, A11004 \\
\hline Alexa Fluor ${ }^{R} 568$ & goat & anti-rat IgG $(\mathrm{H}+\mathrm{L})$ & Invitrogen, A11077 \\
\hline Alexa Fluor ${ }^{R} 568$ & goat & anti-rabbit $\lg G(\mathrm{H}+\mathrm{L})$ & Invitrogen, A11011 \\
\hline Alexa Fluor R 647 & goat & anti-mouse $\lg G(\mathrm{H}+\mathrm{L})$ & Invitrogen, A21235 \\
\hline Alexa Fluor R 647 & goat & anti-rabbit IgG $(\mathrm{H}+\mathrm{L})$ & Invitrogen, A21244 \\
\hline Alexa Fluor R 647 & goat & anti-rat IgG $(\mathrm{H}+\mathrm{L})$ & Invitrogen, A21247 \\
\hline HRP & goat & anti-chicken & Novex, A16054 \\
\hline HRP & goat & anti-mouse IgG & $\begin{array}{l}\text { Perkin Elmer, } \\
\text { NEF822001EA }\end{array}$ \\
\hline HRP & goat & anti-rabbit IgG & $\begin{array}{l}\text { Perkin Elmer, } \\
\text { NEF812001EA }\end{array}$ \\
\hline
\end{tabular}

\subsubsection{Equipment and Software}

The microscopes and laboratory instruments (Table 3), together with the software (Table 4) employed for this thesis are listed below.

Table 4. Used equipment

\begin{tabular}{|l|l|l|}
\multicolumn{1}{c|}{ INSTRUMENT } & \multicolumn{1}{c|}{ MODEL } & \multicolumn{1}{c|}{ COMPANY } \\
\hline Autoclave & V-150 & Systec \\
\hline Binocular Microscope & Nikon SMZ 1500 & Nikon Instruments \\
\hline Centrifuge & 5415 & Eppendorf \\
\hline
\end{tabular}




\begin{tabular}{|c|c|c|}
\hline Centrifuge & Labofuge 400R & Heraeus \\
\hline $\begin{array}{l}\text { Confocal laser scanning } \\
\text { microscope }\end{array}$ & Eclipse TE 2000-E & Nikon Instruments \\
\hline Cryotom & CM3050S & Leica \\
\hline FACS Flow Cytometer & Canto II & BD Biosciences \\
\hline FACS Flow Cytometer & Aria & BD Biosciences \\
\hline Fluorescence Microscope & Eclipse 80i & Nikon Instruments \\
\hline Incubator & HERA cell 150 & $\begin{array}{l}\text { Thermo Electron } \\
\text { Corporation }\end{array}$ \\
\hline Microwave & $\mathrm{R}-208$ & Sharp \\
\hline pH-meter & WTW series & Inolab® \\
\hline Stereotactic apparatus & Model 900 / 940 & KOPF Instruments \\
\hline Tecan Plate reader & Infinite 200Pro & Life Sciences \\
\hline UC-Rotor small volume & FiberLite T45 L & Piramoon \\
\hline Ultracentrifuge & WX Ultra Series 80 & Sorvall \\
\hline Vibratome & VT 1000S & Leica \\
\hline WB imaging system & Odyssey Fc & LI-COR Biosciences \\
\hline
\end{tabular}

Table 5. Software employed

\begin{tabular}{|c|c|}
\hline SOFTWARE & COMPANY \\
\hline FACS Diva v6.1.3 & BD Bioscience \\
\hline GraphPad Prism 5.03 & GraphPad Software \\
\hline i-control software & Tecan \\
\hline Image Studio Software & LI-COR Biosciences \\
\hline ImageJ $1.48 \mathrm{v}$ & $\mathrm{NIH}$ \\
\hline Mendeley Desktop & Mendeley, Ltd. \\
\hline Microsoft Office 2013 & Microsoft Deutschland $\mathrm{GmbH}$ \\
\hline $\begin{array}{l}\text { NIS-Elements Microscope Imaging } \\
\text { Software AR }\end{array}$ & Nikon Instruments \\
\hline Affinity Designer 1.7.2.471 & Serif Europe \\
\hline Affinity Photo 1.7.0.367 & Serif Europe \\
\hline
\end{tabular}




\subsubsection{Chemicals and Reagents}

All chemicals and reagents are listed below (Table 5).

Table 6. Chemicals and Reagents

\section{CHEMICAL / REAGENT}

$(-)-(\alpha)-K a i n i c$ Acid (hydrate)

2-Mercaptoethanol

2-Propanol

Accutase Solution

Animal-Free Recombinant Human EGF

Aqua-Poly/Mount

AR6 buffer

B-27 Supplement

Bepanthen eye cream

Blocking Reagent

Brain-derived neurotrophic factor human, BDNF

Bromophenol blue sodium salt

C-6 NBD Ceramide

Cell Proliferation Kit I (MTT)

CitroPlus

DAPI

Deoxyribonuclease I from bovine pancreas

Dimethyl sulphoxide (DMSO)

DMEM, high glucose, GlutaMAX ${ }^{\mathrm{TM}}$

DMEM, high glucose, GlutaMAX ${ }^{\mathrm{TM}}$

DMEM/F12 GlutaMAX Supplement EDTA

Ethanol

Foetal bovine serum

Formaldehyde solution $37 \%$

\section{COMPANY}

Cayman Chemical 58002-62-3

Sigma M7154

Sigma 33539-5L-R-D

Sigma A6964

Peprotech AF-100-15

Polysciences 18606-20

Perkin Elmer AR6001KT

Thermo Fischer 17504-044

Bayer, 5\% dexpanthenol

Perkin Elmer FP1020

Sigma B3795

Sigma B5525

Biomol-Cayman Cay62527-1

Roche 11465007001

Biogenesx HK080-9K

Sigma D9542

Sigma D4527-20KU

Roth 4720.4

Thermo Fisher 31966-047

Gibco 31966-021

Thermo Fisher 31331-093

AppliChem A1103,0500

Roth K928.4

Pan Biotech P30-3702

Sigma F1635-4L 
GlutaMAX ${ }^{\mathrm{TM}}$ Supplement

Glycerin ROTIPURAN® $>86 \%$, p.a. Roth 4043.1

Glycine, ReagentPlus $®$, $\geq 99 \%$ (HPLC) Sigma G7126

Halt $^{\mathrm{TM}}$ Protease and Phosphatase Thermo Fisher 78440

Inhibitor Cocktail (100X)

HBSS, calcium, magnesium

HEPES Buffer

Hibernate $®-A$ Medium

Histoacryl Tissue Glue

Horse Serum (Heat inactivated)

Hydrochloric Acid $5 \mathrm{~mol} / \mathrm{l}$

Hydrogen peroxide

ROTIPURANR

Isoflurane

Kainic Acid

Ketaset

Laminin, $1 \mathrm{mg}(2 \mathrm{ml})$

Lipopolysaccharides from Escherichia coli 055:B5

Low melt agarose

Luminol Reagent

Methanol

Milk powder

Neurobasal $\circledast$ Medium

Normal Goat Serum

O.C.T. Kryoeinbettmedium

Opal ${ }^{\mathrm{TM}}$ 6-color flHC Kit

PageRuler ${ }^{\mathrm{TM}}$ Plus Prestained Protein Thermo Scientific 26619

Ladder

Panexin NTA

PBS, $\mathrm{pH} 7.4$

PBS, $\mathrm{pH} 7.4$

Penicillin-Streptomycin
Thermo Fisher 24020-091

AppliChem Panreac A6916,0125

Thermo Fisher A1247501

Braun Surgical S.A. 1050052

Sigma, H1138

AppliChem 182109.1211

$30 \%$, Roth 8070.2

Floren, Abbott

Abcam chemicals ab120100

Zoetis

Roche 11243217001

Sigma L2637-5MG

Roth 6351.5

Santa Cruz Biotechnology sc-2048

Sigma 33213-5L-D

Roth T145.2

Thermo Fisher 21103049

Sigma G9023

Weckert Labortechnik 4583

Perkin Elmer NEL796001KT

PAN Biotech P04-95700

Thermo Fisher 10010-056

Gibco 10010-015

Sigma P4333 


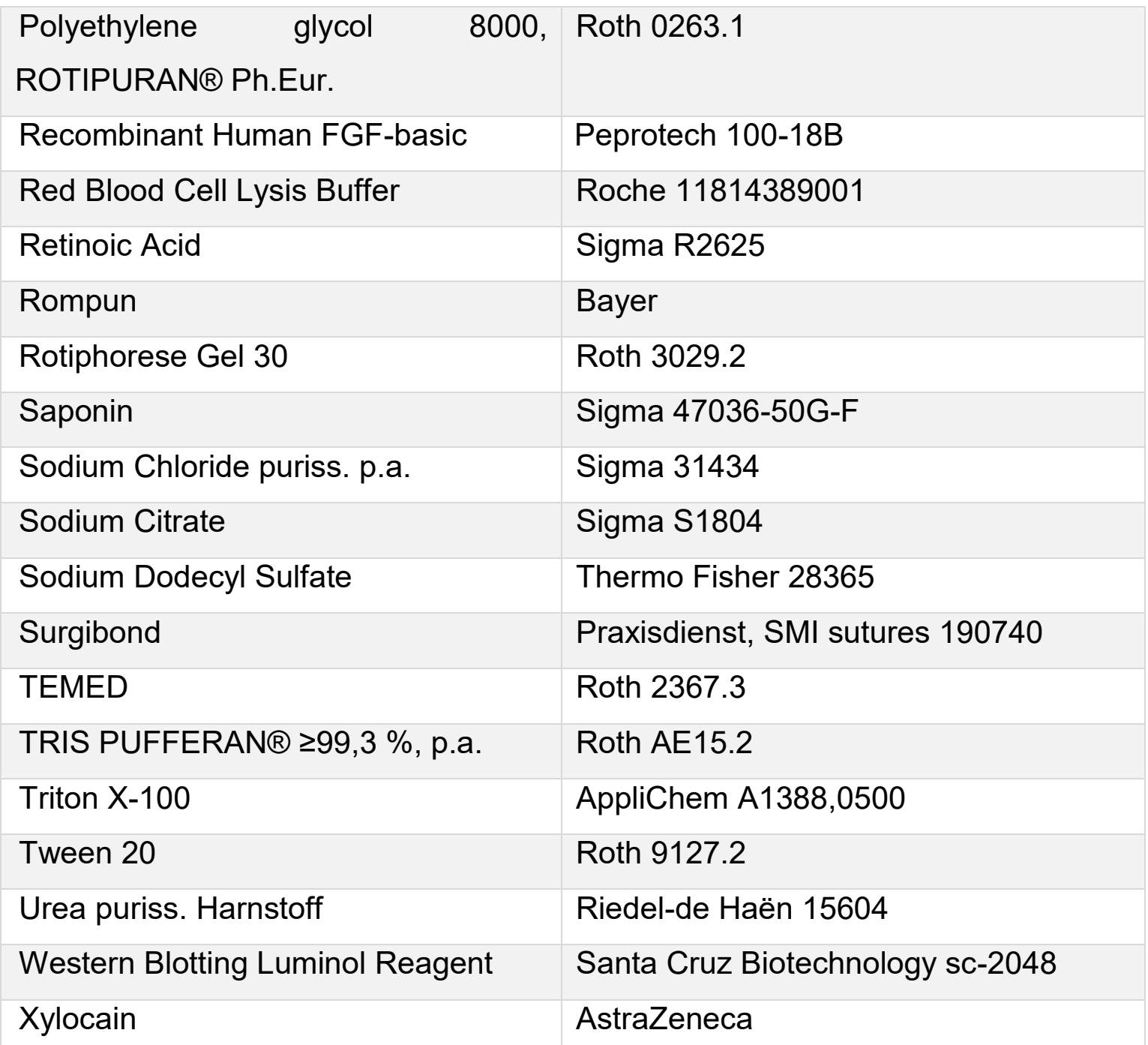

\subsubsection{Buffers and Solutions}

Table 7. Ingredients of 1,5M Tris- $\mathrm{HCl}$ pH 8.8

\begin{tabular}{|l|l|}
\hline CHEMICAL / REAGENT & AMOUNT / FINAL CONCENTRATION \\
\hline Tris base & $181,71 \mathrm{~g}$ \\
\hline $\mathrm{HCl}(37 \%)$ & $21,42 \mathrm{ml}$ \\
\hline Millipore water & Add to $1 \mathrm{~L}$ \\
\hline
\end{tabular}

Table 8. Ingredients of $0,5 \mathrm{M}$ Tris $-\mathrm{HCl} \mathrm{pH} 6.8$

\section{CHEMICAL / REAGENT}

Tris base

$\mathrm{HCl}(37 \%)$

Millipore water

\section{AMOUNT / FINAL CONCENTRATION}

$60,57 \mathrm{~g}$

$39,43 \mathrm{ml}$

Add to $1 \mathrm{~L}$ 
Table 9. Ingredients of EV Lysis Buffer

\begin{tabular}{|l|l|}
\hline CHEMICAL / REAGENT & AMOUNT / FINAL CONCENTRATION \\
\hline 2-mercaptoethanol & $2,5 \%$ \\
\hline EDTA & $10 \mathrm{mM}$ \\
\hline Sodium Dodecyl Sulphate (SDS) & $5 \%$ \\
\hline Tris-HCl pH 6.8 & $120 \mathrm{mM}$ \\
\hline Urea & $8 \mathrm{M}$ \\
\hline
\end{tabular}

Table 10. Ingredients of $2 X$ Laemmli Buffer

\begin{tabular}{|l|l|}
\hline CHEMICAL / REAGENT & AMOUNT / FINAL CONCENTRATION \\
\hline Bromophenol blue & $0.02 \%$ \\
\hline Glycerol & $20 \%(\mathrm{v} / \mathrm{v})$ \\
\hline Pyronin Y & $0.01 \%$ \\
\hline SDS & $4 \%(\mathrm{w} / \mathrm{v})$ \\
\hline ß-mercaptoethanol & $10 \%(\mathrm{v} / \mathrm{v})$ \\
\hline Tris-HCl pH 6.8 & $125 \mathrm{mM}(200 \mathrm{ml}=3,03 \mathrm{~g}$ Tris $+1,8 \mathrm{mlHCl})$ \\
\hline
\end{tabular}

Table 11. Ingredients of Transfer Buffer 10X

\begin{tabular}{|l|l|}
\hline CHEMICAL / REAGENT & AMOUNT / FINAL CONCENTRATION \\
\hline Tris base & $250 \mathrm{mM}$ \\
\hline Glycine & $1.92 \mathrm{M}$ \\
\hline Millipore water & Add to $1 \mathrm{~L}$ \\
\hline
\end{tabular}

Table 12. Ingredients of Transfer Buffer $1 X$

\begin{tabular}{|l|l|}
\hline CHEMICAL / REAGENT & AMOUNT / FINAL CONCENTRATION \\
\hline Transfer Buffer 10X & $100 \mathrm{ml}$ \\
\hline Methanol & $200 \mathrm{ml}$ \\
\hline Millipore water & Add to 1L \\
\hline
\end{tabular}


Table 13. Ingredients of Running Buffer 10X

\begin{tabular}{|l|l|}
\hline CHEMICAL / REAGENT & AMOUNT / FINAL CONCENTRATION \\
\hline Tris base & $250 \mathrm{mM}$ \\
\hline Glycine & $1.92 \mathrm{M}$ \\
\hline SDS & $35 \mathrm{mM}$ \\
\hline Millipore water & Add to $1 \mathrm{~L}$ \\
\hline
\end{tabular}

Table 14. Ingredients of Blocking Buffer WB

\begin{tabular}{|l|l|}
\hline CHEMICAL / REAGENT & AMOUNT / FINAL CONCENTRATION \\
\hline Milk powder & $5 \%(\mathrm{w} / \mathrm{v})$ \\
\hline PBS & Desired volume \\
\hline
\end{tabular}

Table 15. Ingredients of Washing Buffer WB

\begin{tabular}{|l|l|}
\hline CHEMICAL / REAGENT & AMOUNT / FINAL CONCENTRATION \\
\hline Tween 20 & $0,05 \%$ \\
\hline PBS & Desired volume \\
\hline
\end{tabular}

Table 16. Ingredients of Blocking Buffer Stainings

\begin{tabular}{l|l} 
CHEMICAL / REAGENT & AMOUNT / FINAL CONCENTRATION \\
\hline Triton X-100 & $0,1 \%$ \\
\hline Normal Goat Serum & $10 \%$ \\
PBS & Desired volume
\end{tabular}

Table 17. Ingredients of 10X TBS

While Millipore water was added, $\mathrm{pH}$ was set to 7.5 using $\mathrm{HCl}$.

\begin{tabular}{|l|l|}
\hline CHEMICAL / REAGENT & AMOUNT / FINAL CONCENTRATION \\
\hline Tris-Base & $121,14 \mathrm{~g}$ \\
\hline $\mathrm{NaCl}$ & $88 \mathrm{~g}$ \\
\hline Millipore water & Add to $1 \mathrm{~L}$ \\
\hline
\end{tabular}


Table 18. Ingredients of TNT Buffer

\begin{tabular}{|l|l|}
\hline CHEMICAL / REAGENT & AMOUNT / FINAL CONCENTRATION \\
\hline Tris- $\mathrm{HCl} \mathrm{pH} \mathrm{7.5}$ & $0,1 \mathrm{M}$ \\
\hline $\mathrm{NaCl}$ & $0,15 \mathrm{M}$ \\
\hline Tween 20 & $0,05 \%$ \\
\hline TBS 1X & Add to 1L \\
\hline
\end{tabular}

Table 19. Ingredients of TNB Buffer

\begin{tabular}{|l|l|}
\hline CHEMICAL / REAGENT & AMOUNT / FINAL CONCENTRATION \\
\hline Tris-HCl pH 7.5 & $0,1 \mathrm{M}$ \\
\hline $\mathrm{NaCl}$ & $0,15 \mathrm{M}$ \\
\hline Blocking reagent & $0,5 \%$ \\
\hline TBS $1 \mathrm{X}$ & Add to $1 \mathrm{~L}$ \\
\hline
\end{tabular}

\subsubsection{Laboratory material}

Table 20. Consumables used for this thesis

\begin{tabular}{ll|}
\hline CONSUMABLES & COMPANY \\
\hline $10 \mathrm{~cm}$ dishes & Corning 430167 \\
\hline 24 well culture plate & Sigma M8812-100EA \\
\hline 4 well culture plate & Sigma D6789-1CS \\
\hline 6 well culture plate & Sigma CLS3516-50EA \\
\hline 96 well culture plate & Corning CLS3595-50EA \\
\hline Cell counting chamber & Kova 87144E \\
\hline Cell culture flask 250ml & Greiner Bio-One 658175 \\
\hline Centrifuge Tubes 15ml & Sigma T1943-1000EA \\
\hline Centrifuge Tubes 50ml & Sigma T2318-500EA \\
\hline Chirurgische Bohrer 1RF HP 330 104 001 001 & Meisinger 0859056 \\
007 & \\
\hline CRYO.S 2ml & Greiner Bio-One 122279 \\
\hline EDTA coated tubes & SARSTEDT 20.1341 \\
\hline FACS tubes & BD Biosciences 352054 \\
\hline
\end{tabular}


Glass capillaries

Microscope cover glasses

Microscope slides

Microscope Slides, SUPERFROST® PLUS

Mini-PROTEAN® Short Plates

Needles

One cell culture insert

Scalpel

Serologic pipettes

Syringe filter unit 0,22um

Syringe filter unit 0,45um

Syringes

\section{Syringes}

Ultracentrifugation tubes

Western Blotting Filter Paper
Hirschmann, VWR 612-2401

Marienfeld superior 0111530

Engelbrecht

Thermo

SCIENTIFIC

J1800AMNZ

Bio-Rad 1653308

BD Microlance

Millicell Millipore PICM0RG50

Feather 0200130023

Eppendorf

Millipore SLGV033RS

Millipore SLHA033SS

B. Braun 4606108V / Terumo SS+01T25161

Beckmann 357448

Thermo Fischer 88600 


\subsection{Methods}

\subsubsection{Animals}

All animal experiments were approved by the regional Ethical Commission for Animal Experimentation of the state of Hessen, Germany (ethical permissions Gen. Nr. F90/10, F94/12, FK/1090, F94/19), the state of Rhineland-Palatina (ethical permission G 14-1-040) and the Institutional Animal Care and Use Committee for Massachusetts General Hospital.

All animals were group housed under standard conditions, day:night cycle of $12 \mathrm{~h}: 12 \mathrm{~h}$ and food and water ad libitum. All experiments were performed with mice aged between 6- to 30-week-old, and cage enrichment was conducted between 10:00h and 13:00h during the day cycle.

\subsubsection{Transgene characteristics}

All different mouse lines used in the experiments are based in the C57BL/6 background (except of EpoR-iCre whose stain is BALB/cJ) and are listed in the table below (Table 20).

Table 21. Transgenic mouse lines used in this project

\begin{tabular}{|c|c|c|}
\hline Name & Characteristics & Reference \\
\hline Rosa26-EYFP & $\begin{array}{l}\text { Cre reporter; Ubiquitous ability of } \\
\text { enhanced YFP expression in } \\
\text { case of recombination }\end{array}$ & $\begin{array}{l}\text { JAX-mice stock } \\
\text { number } 005130\end{array}$ \\
\hline Rosa26-mTom/mGFP & $\begin{array}{l}\text { Cre reporter; Ubiquitous ability of } \\
\text { GFP expression in case of } \\
\text { recombination }\end{array}$ & $\begin{array}{l}\text { Muzumdar et al., } \\
2007\end{array}$ \\
\hline Vav-iCre & $\begin{array}{l}\text { Expression of codon improved } \\
\text { Cre recombinase in } \\
\text { hematopoietic cells }\end{array}$ & $\begin{array}{l}\text { JAX-mice stock } \\
\text { number } 008610\end{array}$ \\
\hline EpoR-iCre & $\begin{array}{l}\text { Expression of codon improved } \\
\text { Cre recombinase in erythroid } \\
\text { lineage }\end{array}$ & $\begin{array}{l}\text { Heinrich et al., } \\
2004\end{array}$ \\
\hline $\begin{array}{l}\text { vav-iCre } x \text { Rosa26- } \\
\text { EYFP }\end{array}$ & $\begin{array}{l}\text { "double transgenic"; Expression } \\
\text { of codon improved Cre }\end{array}$ & $\begin{array}{l}\text { Refer to mouse } \\
\text { lines above }\end{array}$ \\
\hline
\end{tabular}


recombinase in hematopoietic

cells: subsequent expression of

reporter gene in recombined cells

EpoR-iCre x Rosa26- "double transgenic"; Expression Refer to mouse mTmG of codon improved Cre lines above recombinase in erythroid lineage:

subsequent expression of

reporter gene in recombined cells

\subsubsection{Genotyping procedure}

Rosa26EYFP and vav-iCre mouse lines were crossed and for the detection of double-transgenic offspring, was necessary to check for the expression of Cre recombinase in a reporter background. If Cre recombinase is present, will be expressed in haematopoietic cells, therefore positive for the EYFP reporter.

\subsubsection{Blood analysis}

A small piece from the tip of the tail was cut and two drops of blood were collected in an EDTA tube. Subsequently, 300ul of red blood cell lysis buffer (Roche, 11814389001) were added, mixed with the blood and the content transferred to an Eppendorf tube and incubated for $12 \mathrm{~min}$ at room temperature with periodic shaking. Afterwards, 700 ul of PBS $+2 \%$ FCS was added to each tube and centrifuged for 4 $\min$ at $6000 \mathrm{rpm} 4^{\circ} \mathrm{C}$. The pellet was resuspended with PBS.

Each tube contained blood cells from each mouse and were analysed using Fluorescence-Activated Cell Sorting (BD FACS Canto ${ }^{\mathrm{TM}}$ II Flow Cytometer) for EYFP expression.

\subsubsection{Experiments with animals}

\subsection{Anaesthesia of mice}

Prior to all invasive procedures, mice were anesthetized with isoflurane (Floren, Abbott), $2 \% \mathrm{v} / \mathrm{v}$ in $\mathrm{O}_{2}$. Anaesthesia was maintained by inhalation throughout the procedure.

At the end of the experiments, mice were sacrificed by an i.p. overdose of freshly made solution of Ketaset (Zoetis, 100mg Ketamine, 100mg/kg) / Rompun (Bayer, 
$2 \%$ Xylazine, $5 \mathrm{mg} / \mathrm{kg}$ ). The lethal dose was confirmed by the absence of reflexes in the hind paws.

\subsection{Perfusion}

Deeply anesthetised mice were transcardially perfused with $20 \mathrm{ml}$ room temperature PBS (Phosphate Buffered Saline, Gibco, 10010-015) followed by $20 \mathrm{ml}$ cold $4 \%$ PFA (Formaldehyde solution 37\% in H2O, Sigma, F1635-4L) in PBS. Organs of interest were harvested, post-fixed in 4\% PFA in PBS for 24 hours and conserved for subsequent analysis.

\subsection{LPS}

To induce peripheral inflammation, $200 \mu$ l of lipopolysaccharide (LPS from E. coli O55:B5, 1mg/ml/kg, L2637 Sigma) was injected intraperitoneal (i.p.) every $24 \mathrm{~h}$ for 2 days. After 48 hours post injection, animals were perfused. Brain was collected for further analysis.

\subsection{Kainic acid}

To test another injury paradigm, 100ul of kainic acid (KA) (2,5mg/ml, ab120100, Abcam chemicals) was injected i.p. once. After $48 \mathrm{~h}$ mice were killed and transcardially perfused. Brain was collected for further analysis.

\subsection{Stereotactic surgeries}

For experiments using stereotactic surgeries (sections 1.3.6, 1.3.7 and 1.3.9), mice were placed in a stereotactic apparatus (Model 900 / 940 KOPF Instruments) with components adapted to allow inhalation anaesthesia. Mice were kept warm using a warming blanket and eyes were protected with Bepanthen eye cream (Bayer, 5\% dexpanthenol). Prior to surgery, Xylocain (AstraZeneca) was administered as a local analgesic at the incision site on the skin. Few drops of tissue adhesive Surgibond (190740, SMI sutures, Praxisdienst) were used for wound closure.

\subsection{Epoxomicin}

For epoxomicin infusion, craniotomy was performed at the following coordinates in millimetres from Bregma $M / L=0,9 ; A / P=-2,85 ; D / V=4$ and $10 u M$ epoxomicin in $1 \%$ DMSO, or $1 \%$ DMSO alone as a control, were infused unilaterally using a micropump (UMP3-1, WPI, Berlin, Germany; 10-IL nanofil syringe, 33-gauge steel needle; 
flow rate of $100 \mathrm{~nL} / \mathrm{min}$ ). After 14 days post-infusion, the animals were anesthetized and transcardially perfused. Brain was collected for further analysis.

\subsection{Cre EVs injection in Rosa26YFP}

To determine the effect of exogenous Cre recombinase, a combination of EV injection i.v. and local neuronal stimulation was performed. ROSA26-EYFP mice received an intracranial injection of $0.5 \mu \mathrm{g}$ of $\mathrm{KA}$ in $1 \mu \mathrm{l}$ of saline solution (ipsilateral) and $1 \mu \mathrm{l}$ of saline solution only (contralateral); at the coordinates in millimetres from Bregma $M / L= \pm 1.5 ; A / P=-2 ; D / V=2)$. Immediately afterwards, $100 \mu \mathrm{l}$ of an $E V$ preparation from blood plasma of an LPS injected vav-iCre mouse was injected i.v. via the tail vein. Mice were left for $48 \mathrm{~h}$ to allow for reporter gene expression and were transcardially perfused. Brain was collected for further analysis.

\subsection{Acute myocard infarction}

Animals with the genotype Rosa26-EYFP and vav-iCre $x$ Rosa26YFP were treated at the Institute of Cardiovascular Regeneration under the supervision of Stephanie Dimmeler as a collaborative project. Mice were subsequently perfused and brains and hearts were further analysed.

\subsection{Optogenetics approach}

Adeno-associated virus (AAV, titer of $3 \times 10^{12}$ virus particles per $\mathrm{ml}$ ) with CamKII promoter driven hChR2-(H134R)-mCherry (VB4411, Vector Biolabs) was used for optogenetic assay. Intracranial injection was performed unilaterally with elongated glass capillaries (612-2401, Hirschmann, VWR) in a $35^{\circ}$ angle and $1 \mathrm{ul}$ of viral particles was injected at the coordinates in millimetres from Bregma $M / L=2,5 ; A / P=-$ 3,$1 ; \mathrm{D} / \mathrm{V}=0,5$. At the end of the injection, capillaries were kept at the site for $4 \mathrm{~min}$ and then slowly withdrawn. Viral expression was assessed 4 weeks after surgery.

\subsection{Light stimulation}

In order to light-stimulate AAV-infected cells, a $200 \mu \mathrm{m}$ multimode fiber with a numerical aperture of 0.39 (Thorlabs, Munich, Germany) was positioned unilaterally (touching the cortex), over the site of the AAV injection. The fiber was coupled with a solid state $488 \mathrm{~nm} 50 \mathrm{~mW}$ laser (Lighthub, Rodgau- Dudenhofen Germany), controlled by the Omicron proprietary software. The laser output power was adjusted to read 5,8 $\mathrm{mW}$ measured at the fiber $\left(\sim 185 \mathrm{~mW} / \mathrm{mm}^{2}\right)$. The laser was 
pulsed at $10 \mathrm{~Hz}$ with $10 \mathrm{~ms}$ pulse width at $0.1 \mathrm{~Hz}$ for $1 \mathrm{~h}$, using an external pulse stimulator (CED 1401 Cambridge Electronic Design, Cambridge, UK). After the stereotaxic surgery, the animals were left for two days to allow for expression of EYFP and then perfused. Brains were collected for further analysis.

\subsection{Local field potential recordings}

In vivo local field potential (LFP) recordings were performed by inserting glass pipettes (impedance $\approx 1 \mathrm{M} \Omega$ ) in layer $\mathrm{V}$ of primary visual cortex 4 weeks after rAAV2CaMKIla-hChR2-(H134R)-mCherry-WPRE-pA virus injection (section 1.3.9). A silver wire was inserted into the cerebellum as a ground electrode. To induce neuronal activity, single blue light pulses $(10 \mathrm{~ms})$ were administered at $0.1 \mathrm{~Hz}$ via a $200 \mu \mathrm{m}$-diameter multimode fiber. The laser output power at the fiber tip was adjusted to $0.5,1,2,3,4,6$ and $8 \mathrm{~mW}$ (corresponding to 16, 32, 64, 95, 127, 191 and $255 \mathrm{~mW} / \mathrm{mm}^{2}$ at fiber tip). At each intensity, 10 sweeps were recorded and averaged. LFP amplitudes were normalized to the amplitudes evoked at 16 $\mathrm{mW} / \mathrm{mm}^{2}$ intensity.

\subsection{Cage enrichment}

Cages used for the experiment were standard cages for mice (365 x $207 \times 140 \mathrm{~mm}$, 1284L Eurostandard Type II L). Mice continuously inhabited this cage before an assortment of objects of different sizes and colours were placed in the cage for one hour before they were removed again. Mice were kept for an additional two days before they were killed and brains were removed for further analysis.

\subsection{Brain digestion and analysis using FACS}

In order to analyse differences between neurons that received or not EVs, Rosa26EYFP and Vav-iCre-ROSA26EYFP mice were injected with LPS. After 48 hours cervical dislocation was performed with no perfusion, brains were collected, meninges were removed and midbrain isolated. From midbrain, hippocampus was isolated. Tissue was minced in small pieces using a scalpel and incubated with enzyme mixture (Adult Brain dissociation Kit, 130-107-677, MACS Miltenyi Biotec) for 1 hour at $37^{\circ} \mathrm{C}$. Using the same kit, debris was removed following manufacturers instructions, resulting cell suspension was flushed through a size-strainer and red blood cells were removed using manufacturers red blood cell lysis reagent. Remaining cells were transferred into FACS buffer and further FACS analysis was 
performed using one-color staining to set gating. Cell populations were analysed using FACS Aria Sorter. Cells were gated using DAPI counterstaining to separate cells from debris, and a specific neuronal population was identified using NeuNAPC, which was further separated using GFP-488 for recombined cells (YFP+ cells) vs non-recombined (YFP- cells).

\subsubsection{Cell culture}

\subsubsection{J774 cell line}

J774 cells (murine monocyte- and macrophage- like cells from reticulum cell sarcoma, ATCC) were used for EVs harvest. Cells were cultured in DMEM (Dulbecco's Modified Eagle Medium) + Glutamax (Gibco, 31966-021) + 1\% Penicillin / Streptomycin (P/S, Sigma, P4333) + 10\% Foetal bovine serum (FBS, Pan Biotech, P30-3702), under standard conditions in humidified atmosphere at $37^{\circ} \mathrm{C} 5 \% \mathrm{CO} 2$.

In order to visualise and follow EVs, J774 cells were labelled with C6-NBD (6-(7Nitrobenzofurazan-4-ylamino) hexanoic acid, Cayman, 62527) Ceramide, a greenfluorescent lipid dye. J774 cells were washed with PBS and incubated for 20 min with 2 UM C6-NBD in serum-free medium. Cells were then washed three times with PBS and green-fluorescent labelled EVs were harvested as described below (Section 3).

\subsubsection{SH-SY5Y cell line}

SH-SY5Y (human neuroblastoma cell line, ATCC) cells are able to differentiate along the neuronal lineage and express dopaminergic markers. Cells were cultured under standard conditions in DMEM + Glutamax $+1 \% \mathrm{P} / \mathrm{S}+15 \% \mathrm{FBS}$. These cells were used for subsequent experiments to test the effect of EVs after different cell stimuli or impairment.

\subsubsection{Differentiation}

For differentiation, retinoic acid 10uM (Sigma, R2625) was added one day after plating $5 \times 10^{4}-10 \times 10^{4}$ cells/well in a $96 \mathrm{w}$ plate and cells were incubated for further five days. Afterwards cells were washed with PBS, incubated in serum-free medium $+50 \mathrm{ng} / \mathrm{ml}$ of brain derived neurotrophic factor (BDNF; 5 ug dissolved in DMEM + 1\%BSA + 10mM HEPES; Sigma, B3795) and left for five more days. As a result, 
homogenous population of cells with neuronal morphology was obtained. Based on the literature, expression of neuronal differentiation markers such as NF-H, MAP-2 and $\mathrm{TH}$, was tested.

\subsubsection{FACS detection of EV uptake}

SH-SY5Y cells were incubated with increasing EV concentrations from a stock batch obtained from $J 774$ cells (as described in Section 3) stained with C6NBD at increasing time-points to find the required time for EV uptake and maximal signal intensity. After incubation, cells were washed with PBS and detached using Accutase solution (Sigma, A6964). Cells were then centrifuged at $2500 \mathrm{~g}$ for $10 \mathrm{~min}$ and resuspended in PBS for FACS analysis.

\subsection{MTT assay}

Cell Proliferation Kit I (MTT, Roche 11465007001) was used to assess the viability of cells under different conditions. The MTT assay is based on the cleavage of MTT (3-[4,5-dimethylthiazol-2-yl]-2,5-diphenyl tetrazolium bromide) salt by metabolic active cells forming a purple precipitate called formazan.

SH-SY5Y cells were cultured in a 96w plate with a final volume of 100 ul cell culture media/well. After subjecting the cells to different conditions (stimuli or impairment using different substances such as kainic acid, epoxomicin, $\mathrm{H}_{2} \mathrm{O}_{2}$ and others) for shorter or longer incubation time, 10ul of MTT labelling reagent was added per well to determine the strongest effect. After 2 hours of incubation, 100ul of solubilisation solution was added per well and the plate was left for overnight incubation.

The resulting coloured solution was quantified using a Tecan Plate reader (Infinite 200Pro, Life Sciences, i-control software) configured for multiple reads per well at a wavelength of 590nm. The data obtained was analysed using GraphPad Prism 5.0 Software.

\subsubsection{Isolation and culture of prenatal neurons from Rosa26-EYFP}

Pregnant female at approximately day 19 was euthanized by cervical dislocation. Rapidly mid-ventral side was opened and pups were removed from uterus and placenta and maintained in cold HBSS (Thermo Fisher 24020-091) medium. With the help of small scissors, the skull of each pup was opened from caudal to rostral end and the brain was maintained in new cold HBSS medium. Using a microscope, 
meninges were removed and tissue was minced using a scalpel. Then, HBSS was removed and 1ml Accutase (Sigma A6964) + DNAsel (Sigma D4527-20KU) was added and incubated for $15 \mathrm{~min}$ at $37^{\circ} \mathrm{C}$ in a shaker. Tissue was washed three times with HBSS and was minced further with fire-polished pipettes. Supernatant was collected and the trituration was repeated two more times. Afterwards, cells were counted and plated in 6- or 24- well plates coated with laminin with Neurobasal complete medium (1X B27, 0.5mM Glutamine, 25uM Glutamate, 1\% P/S, 1mM HEPES buffer, 10\% HI-Donor Horse Serum). Every four days, half of the medium was removed and new serum-free medium was added.

\subsubsection{Vesicle harvesting}

Peripheral blood from deeply anesthetized reporter or double-transgenic mouse, previously injected with LPS, was collected during perfusion. Platelet-free plasma was isolated through centrifugation steps (Heraeus Labofuge 400R) 2500 rpm 15min RT twice and diluted 1:1 with 10mM HEPES buffer (A6916,0125 AppliChem Panreac) in Millipore water. The solution was 0,45um filtered to remove larger particles and mixed with Polyethylene glycol (PEG) 8000 (Rotipuran, 0263.1, Roth) solution at $1: 5$ for vesicle precipitation during an overnight incubation at $4^{\circ} \mathrm{C}$. Samples were centrifuged at $1500 \mathrm{~g} 30 \mathrm{~min} 4^{\circ} \mathrm{C}$ and pellets were resuspended in 10mM HEPES buffer followed by an ultracentrifugation step (Sorvall WX Ultra Series 80 , Thermo Fischer) at $100.000 \mathrm{~g}$ for $90 \mathrm{~min}$. The pellets were resuspended in $10 \mathrm{mM}$ HEPES buffer and kept at $4^{\circ} \mathrm{C}$ for immediate use or at $-80^{\circ} \mathrm{C}$ for longer storage.

The $\mathrm{J} 774$ cells were cultured under standard conditions to $75 \%$ confluence in $10 \times 10 \mathrm{~cm}$ dishes (Corning, 430167). Afterwards, cells were washed 3 times with PBS and serum-free medium + 4\% Panexin (Pan Biotech, P04-95700) was added for $48 \mathrm{~h}$. Conditioned medium was harvested for $\mathrm{EV}$ isolation and centrifuged for 10 $\min \mathrm{RT}$ at $200 \mathrm{~g}$ to remove dead cells. The solution was $0,45 \mathrm{um}$ filtered to remove larger debris and mixed with PEG 8000 solution 1:5 and incubated overnight. Samples were then centrifuged, ultra-centrifuged and conserved as above.

\subsubsection{Protein analysis}

Platelet-free plasma, isolated from healthy and LPS-treated mice, was used to study protein content and EV-related proteins. 


\subsubsection{SEC}

Size exclusion chromatography (SEC) is a chromatographic method that separates molecules in suspension by their size or molecular weight. SEC was used to separate heterogeneous populations of EVs and to filter out unwanted protein in the sample. Columns for each sample were prepared as follows.

The following solutions were needed to prepare SEC columns:

- Sepharose CL-2B (GE Healthcare), porous beads, made of agarose

- PBS with $0.32 \%$ trisodiumcitrate $\mathrm{pH} 7.4,0.22 \mu \mathrm{m}$ filtered

- $10 \mathrm{ml}$ plastic syringe with concentric tip and lid

- $20 \mu \mathrm{m}$ filter nylon filter, cut to fit to the bottom of the syringes

Sepharose was poured into a beaker and let to compact. Supernatant was aspirated and PBS-Citrate buffer was added, mixed well and let to compact again. These steps were repeated 3 times. A nylon filter was placed at the bottom of the syringe and the sepharose was poured in carefully. The bottom tip was closed when the compacted sepharose reached $10 \mathrm{ml}$. The column was ready to use. The bottom tip of the column was removed and after the excess buffer flowed through, $1 \mathrm{ml}$ of the sample was carefully added. Afterwards $16 \mathrm{ml}$ of buffer was added by steps of $1 \mathrm{ml}$ and fractions of $1 \mathrm{ml}$ were collected (total of 16 fractions collected) for further analysis using Western Blot (WB).

\subsubsection{WB}

Western Blot gels were prepared using 1,5M Tris- $\mathrm{HCl}$ pH 8.8, 0,5M Tris- $\mathrm{HCl}$ pH 6.8, 30\% Acrylamide (3029.2, Roth), 10\% Ammonium persulfate (A3678, Sigma) and TEMED (2367.3, Roth). The 16 SEC collected fractions were used to analyse the protein content. 25ul from each sample were mixed with 25ul EV Lysis Buffer and $15 \mathrm{ul}$ of $2 \mathrm{x}$ Laemmli Buffer. The mixture was incubated at $80^{\circ} \mathrm{C}$ for $10 \mathrm{~min}$ and cooled on ice for additional $10 \mathrm{~min}$. 55ul of sample were loaded per lane and the gel was run for $1 \mathrm{~h}$ at $100 \mathrm{~V}$. The separated proteins were transferred to a PVDF (polyvinylidene difluoride, Thermo Fisher) membrane at $200 \mathrm{~mA}$ for $90 \mathrm{~min}$ at $4^{\circ} \mathrm{C}$. Afterwards the membrane was blocked using blocking buffer and incubated at $4^{\circ} \mathrm{C}$ with the primary antibodies overnight. On the next day, the membrane was washed using washing buffer and incubated with the secondary antibodies in blocking buffer 
for $1 \mathrm{~h}$ at room temperature. Then, membranes were washed and incubated in developing solution (Luminol Reagent, sc-2048, Santa Cruz Biotechnology). Membranes were revealed using imaging system (LI-COR Odyssey Fc).

\subsubsection{Tissue sectioning}

For fresh fixed tissue, serial coronal sections (30um) were cut on a vibratome (Leica VT1000S) and kept in PBS at $4^{\circ} \mathrm{C}$ until further use.

For cryosectioning (Cryostat CM3050 S, Leica), organs were cryoprotected in 15\% sucrose for an additional $24 \mathrm{~h}$ before they were embedded in OCT medium to form a frozen block or snap frozen in methyl butane previously cooled in liquid nitrogen, and serial sections were cut at 10um. Sections were collected onto super-frost glass slides and stored at $-20^{\circ} \mathrm{C}$ until further use.

\subsubsection{Immune- Histo, Cyto-chemistry (IHC - ICC) I Tyramide Signal Amplification (TSA)}

Staining was performed on vibratome sections and on cryosections. First, sections were washed with PBS and cell membranes permeabilized by incubating sections for $30 \mathrm{~min}$ in blocking buffer. Then, sections were incubated with the primary antibodies in blocking buffer at the desired concentration, overnight at $4^{\circ} \mathrm{C}$. Next, sections were washed in PBS and incubated with the secondary antibodies in blocking buffer without serum for $2 \mathrm{~h}$ at $4^{\circ} \mathrm{C}$. Afterwards sections were again washed in PBS and nuclei counterstained with DAPI (Sigma, D9542, 1:1000) for 20 min at room temperature. Finally, sections were washed and mounted with AquaPoly/Mount (18606-20, Polysciences).

Cells, attached to coverslips, were stained using the same protocol. Coverslips were mounted on a microscope slide cell side down.

Some antibodies did not work using normal IHC therefore, TSA method was used. This approach is used in order to ensure primary antibody access to the epitopes of interest and usually requires treatment with harsh buffers at extreme $\mathrm{pH}$ values to loosen the protein binding. In this case, sections were incubated for 40 minutes in AR6 buffer (AR6001KT, Perkin Elmer). Then, sections are washed in TNT buffer for $5 \mathrm{~min}$ and blocked using TNB buffer for $30 \mathrm{~min}$. Sections were then incubated overnight with only one primary antibody at $4^{\circ} \mathrm{C}$. On the next day, sections were washed and incubated with horseradish (HRP)-specific secondary antibody for 30 
min at room temperature. Afterwards, sections were washed and incubated in TSA Plus working solution of the desired fluorophore, diluted in Plus Amplification Diluent for $10 \mathrm{~min}$ at room temperature. Lastly, sections were washed and incubated again in AR6 buffer to proceed to the next primary antibody as before. Finally, nuclei were counterstained with DAPI, and after the last wash, sections were mounted as before.

\subsubsection{Fluorescence microscopy}

Images were captured with either an Epi-fluorescence microscope (Nikon eclipse $80 \mathrm{i}$ ) or a Confocal inverted microscope (Nikon eclipse TE2000-E). For confocal imaging, a z-stack of images of area(s) of interest was captured. Images were analysed with NIS-elements imaging software (version 4.13.05) and ImageJ (https://imagej.nih.gov/ij/). To assess YFP and mCherry expression in the contralateral hemisphere we used a confocal microscope (SP8, Leica, Mannheim, Germany) using multiple objectives, namely 20x, 40x and 63x magnification (HCX PL APO 20x/0,7 dry, HC PL APO 40X/1,40 Oil CS2, HC PL APO 63X/1,40 Oil CS2, Leica).

\subsubsection{Statistical analyses}

No statistical methods were used to predetermine sample sizes. Sample sizes were based on those reported previous publications. Animals were randomly allocated into different experimental groups. No specific randomization method was used. Mice showing incorrect injection sites or optic fiber placement were excluded from experimenters. In control mice, marker gene expression is zero. This fact causes a high difference in variability between mouse groups. For this reason, a two-sided nonparametric Wilcoxon-Mann-Whitney $U$ test was used to compare experimental and control groups. Additionally, mean, standard deviation, minimum, maximum and $p$-values were calculated. If samples were $n \geq 5$, confidence intervals were calculated. 


\section{Results}

\subsection{Characterization of EVs from mouse blood}

Previous work in the lab established that the transfer of Cre mRNA from cell to cell is driven mostly by extracellular vesicles, which are secreted in this case in blood circulation and transported to different organs like the brain (Ridder et al., 2014). However, the methodologies used to isolate EVs are diverse. Therefore, it was necessary to characterize the population of EVs. To this end, blood from LPS injected and non-injected mice was collected as described in the Methods (Section 4.2.3), and EVs were isolated using a combination of precipitation and ultracentrifugation techniques.

\subsubsection{Characterization using TEM}

The pellets, containing EVs, were obtained as described in the Methods part and as expected, a heterogeneous population of different size particles was observed using transmission electron microscope. However, these particles were ranging between 20 to $120 \mathrm{~nm}$ in diameter; the majority had a diameter around $50 \mathrm{~nm}$ with the typical cup-shaped morphology, associated with exosomal population in published data (Théry, 2011) (Fig. 4).

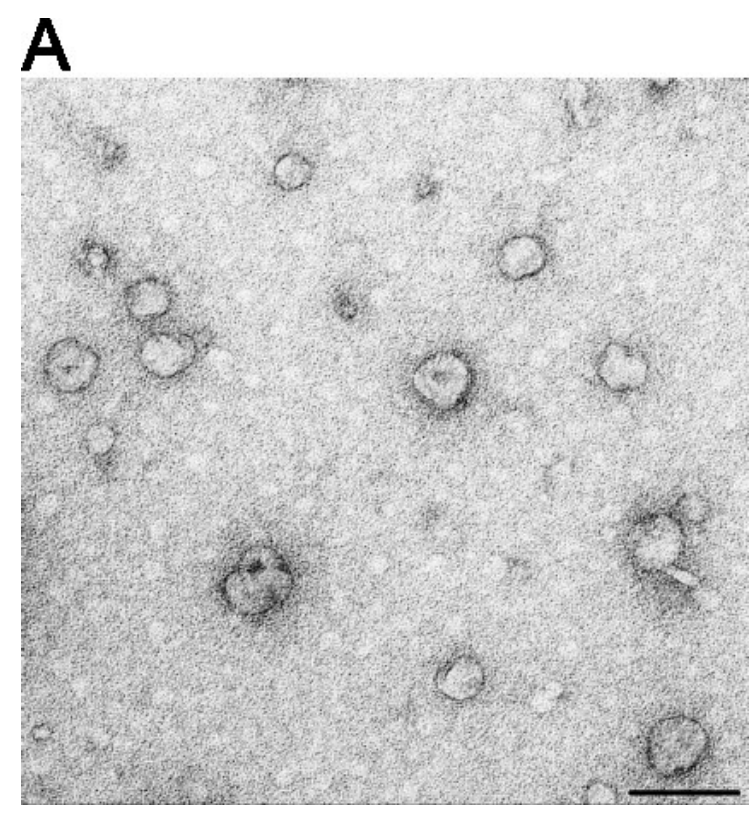

Figure 4. Transmission electron microscopy reveals exosome-like particles after ultracentrifugation. (A) The analysis of the pellet after ultracentrifugation shows vesicles with different morphologies and sizes. However these particles were mostly around 50nm diameter and cup-shaped. Scale bar $100 \mathrm{~nm}$ in A. 


\subsubsection{Characterization using Western Blot}

Although previous analysis indicated an enrichment of EVs in the pellet, as mentioned above the population obtained was quite heterogeneous. To separate the EV sample by size, size exclusion chromatography (SEC) was performed, obtaining a total of 18 fractions according to their size, followed by Western Blot (WB) from all SEC fractions to analyse vesicular identity.

WB was used to demonstrate the presence of exosomes, each fraction was analysed using three specific exosomal markers: CD9 (25kDa), Flotillin (48kDa) and HSP70 (50 and 70kDa). In the fractions 5 to 12, CD9 and Flotillin could be clearly detected, while HSP70 was only visible in some of them (lane 3 to 11). The fractions 1 to 4 and 15 to 18 did not show expression of marker for exosomes, meaning that the content of these samples is a different EV type of membrane blebs. A Rosa26EYFP control mouse was used for comparison with the other 3 samples (vav-iCre $x$ Rosa26YFP mouse injected with LPS). Here, less intensive bands can be appreciated, suggesting lesser overall EV content, compared to a LPS injected mouse (Fig. 5). 


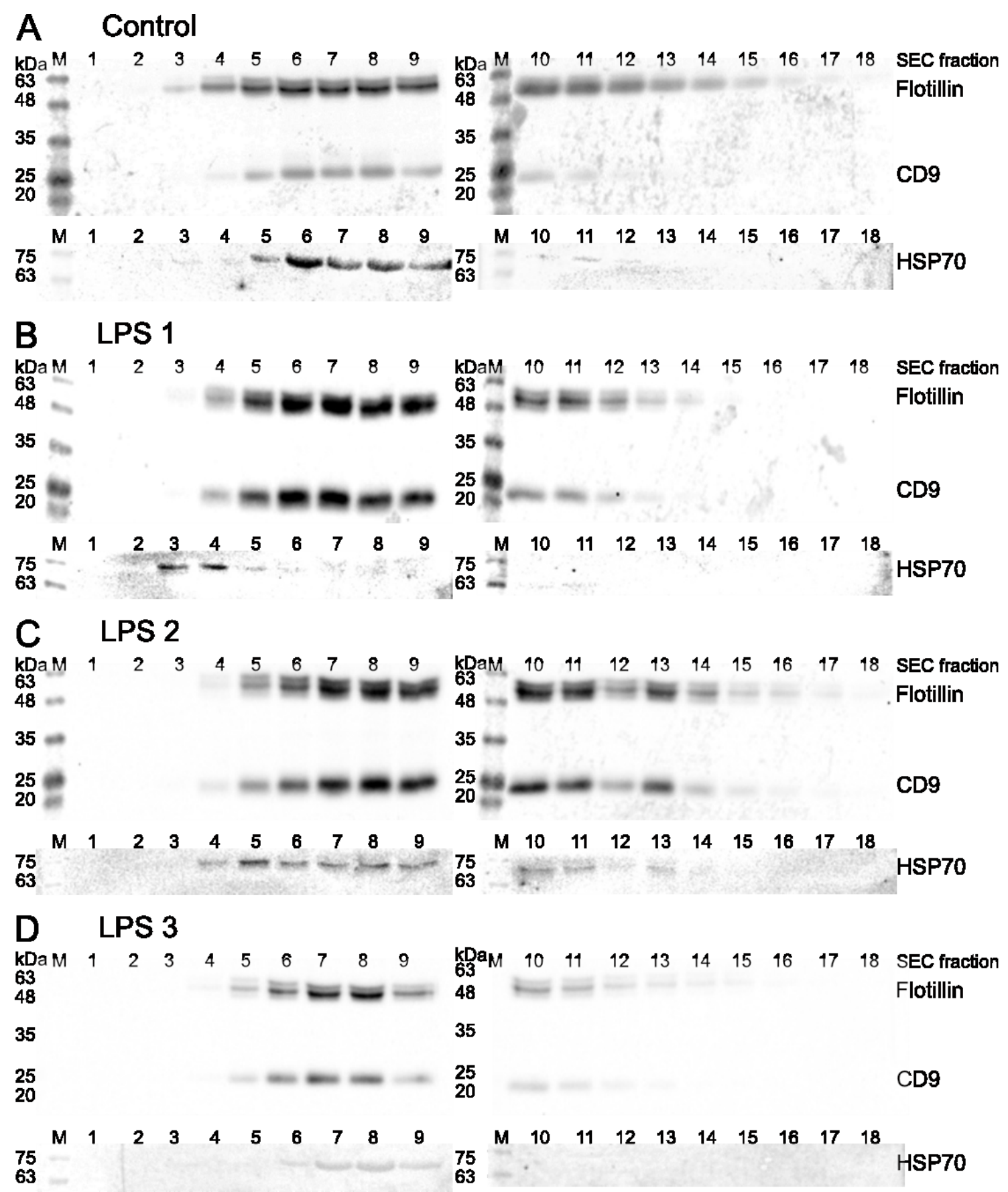

Figure 5. Western Blot of blood EV fractions from control and LPS injected mice. M (Marker); SEC fractions (size-exclusion chromatography fractions, 18 in total). $\mathrm{kDa}$ (kilodaltons, molecular weight of proteins). The fractionated EV samples are positive for exosomal marker proteins CD9, Flotillin and HSP70. Spleen lysate from vav-iCre $x$ Rosa26YFP was used as a control in all WB experiments. A) Detection of EV markers in $E V$ isolated fractions from blood of control mouse. ( $B, C$ and D) Detection of EV markers in EV isolated fractions from blood from mice injected with LPS $(n=3)$. Note the higher intensity of bands in the LPS injected mice.

\subsection{Peripheral inflammation, induced by LPS, leads to EV uptake in the brain}

Preliminary work, done in the laboratory (Ridder et al., 2014), showed that peripheral inflammation by injecting LPS $(1 \mathrm{mg} / \mathrm{kg})$ in mice, causes recombination and marker 
gene expression in different brain zones, indicative of EV signalling (Fig. 6B). In the healthy animal, no or very few neural cells show recombination marker expression (Fig. 6A).

To characterize the recombination events in general, a wide analysis of different brain regions, together with markers for different cell populations, was performed. Vibratome and cryostat sections, obtained from vav-iCre $x$ Rosa26YFP, were stained against the reporter marker protein EYFP together with other markers of interest (NeuN for neurons and Iba1 for microglia). Reporter gene expression was qualitatively assessed using fluorescence microscope and quantified from immunefluorescent images.
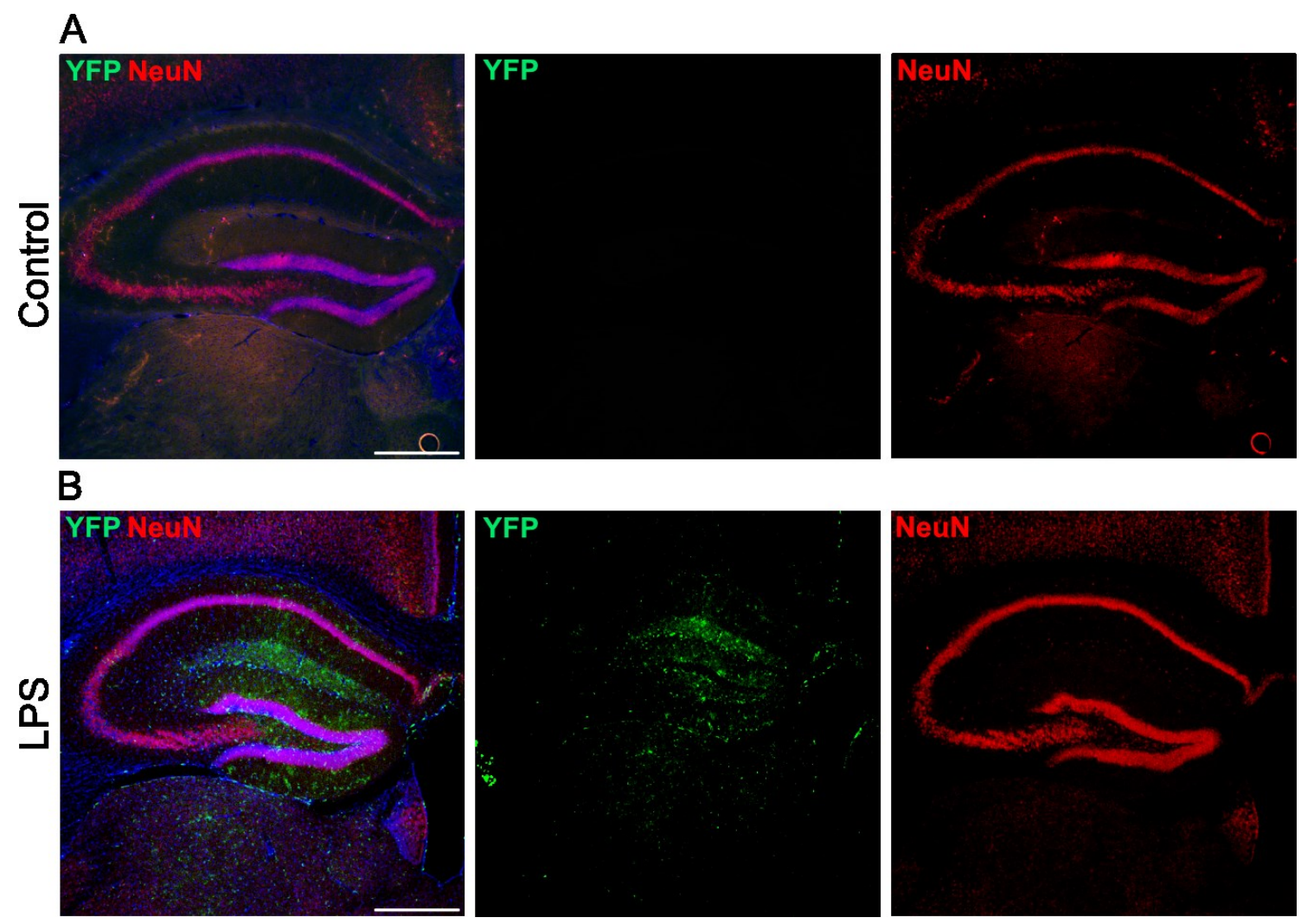

Figure 6. Peripheral inflammation induced by LPS leads to EV uptake in the brain. (A) Hippocampal section of a double transgenic control mouse. (B) Hippocampal section of a double transgenic mouse injected i.p. with LPS. After 48 hours, frequent events of recombination were observed in green (YFP+) in the hippocampal area. Scale bars 500um.

Recombination events were observed in different brain regions (Fig. 7), particularly in $\mathrm{NeuN}+$ and lba1+ cells (neurons and microglia respectively). Marker gene expression in cells of endothelial (CD31+), astrocytic (GFAP+) or oligodendroglial (Olig2+) lineages were very rarely or never observed (Fig. 8). 


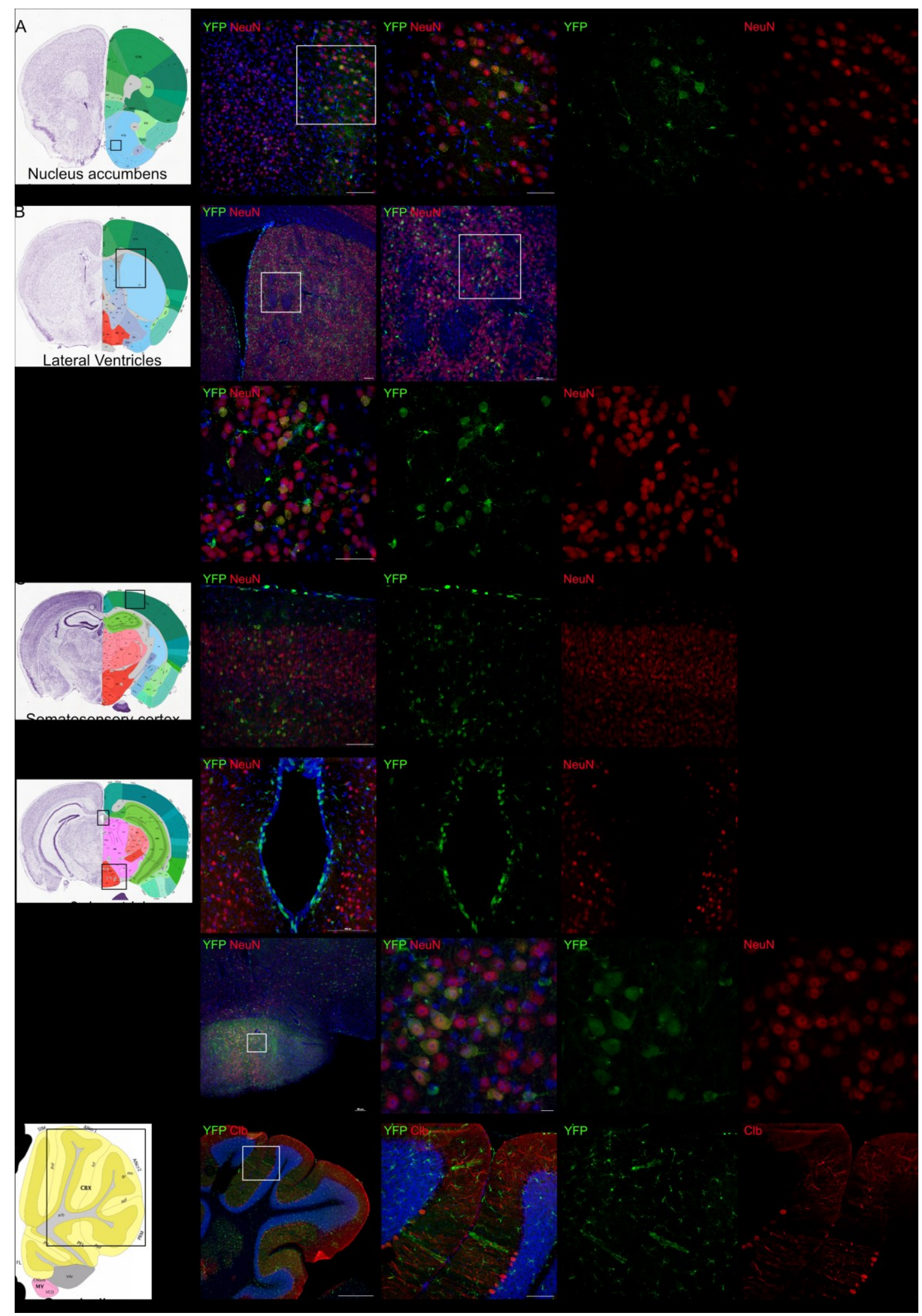

Figure 7. Marker gene expression mapping after LPS-induced inflammation in different brain areas. Mouse brain coronal schemes were from Allen Mouse Brain Atlas (Image credit: Allen Institute). (A) Recombination events in Nucleus accumbens and Lateral septal nucleus. (B) Recombination events in lateral ventricles and striatum, predominantly neurons. (C) Recombination events in the somatosensory cortex. Some recombined cells are present at the surface of the brain 
that might be peripheral macrophages. (D) Recombination events observed in the walls of the third ventricle (upper panel) predominantly ependymal cells and in the hypothalamus (lower panel). (E) Recombination events in the cerebellum, predominantly Purkinje neurons. Images on the right show higher magnification of the area marked with white squares. DAPI was used for nuclear counterstain. Scale bars from left to right and from top to bottom: $100 \mathrm{um}$ and $50 \mathrm{um}$ in $\mathrm{A} ; 100 \mathrm{um}, 100 \mathrm{um}$ and $50 \mathrm{um}$ in B; 100um in C; 100um, 100um, and 10um in D; 500um and 100um in E.

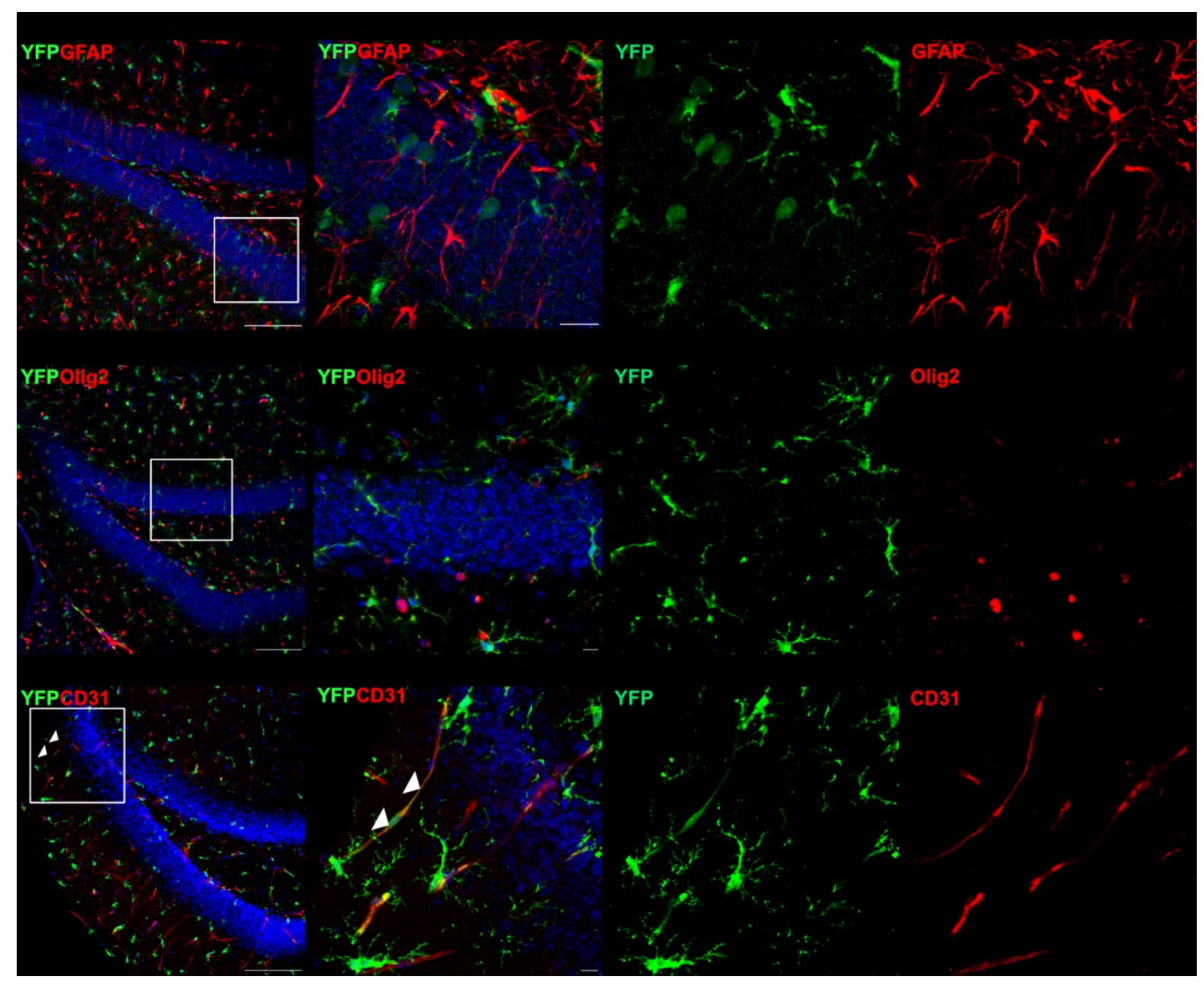

Figure 8. Absence of marker gene expression in different brain cell populations. ( $A$ and $B$ ) Costaining of marker gene expression with markers of $A$ - Astrocytes (GFAP) and B - Oligodendrocytes (Olig2) showed no recombination. (C) A single endothelial cell (CD31) showed co-expression of EYFP (indicated with white arrowheads). Latter three images in each panel show magnification of white squares. DAPI was used for nuclear counterstain. Scale bars from left to right and from top to bottom: 100um and 20um in A; 100um and 10um in B; 100um and 10um in C.

\subsubsection{Peripheral injection of LPS leads to EV uptake in the hippocampus $(\mathrm{HC})$}

Frequent recombination events in $\mathrm{HC}$ were observed after peripheral inflammation. Indeed, in the dentate gyrus (DG) of the $\mathrm{HC}$, percentage of marker gene NeuNpositive neurons reached an average of $12.3 \%$ ( $\pm 4.7 \%$ SD), and that of Iba1-positive microglia $52.3 \%$ ( $\pm 3 \% \mathrm{SD}$ ) (Fig. 9). 
A
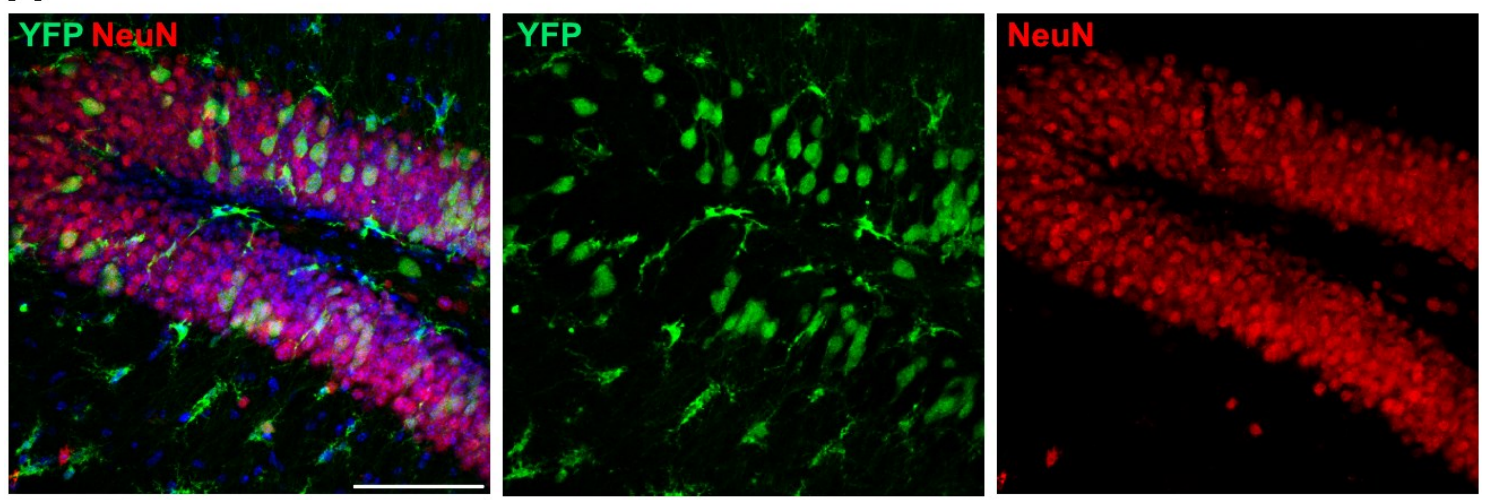

B
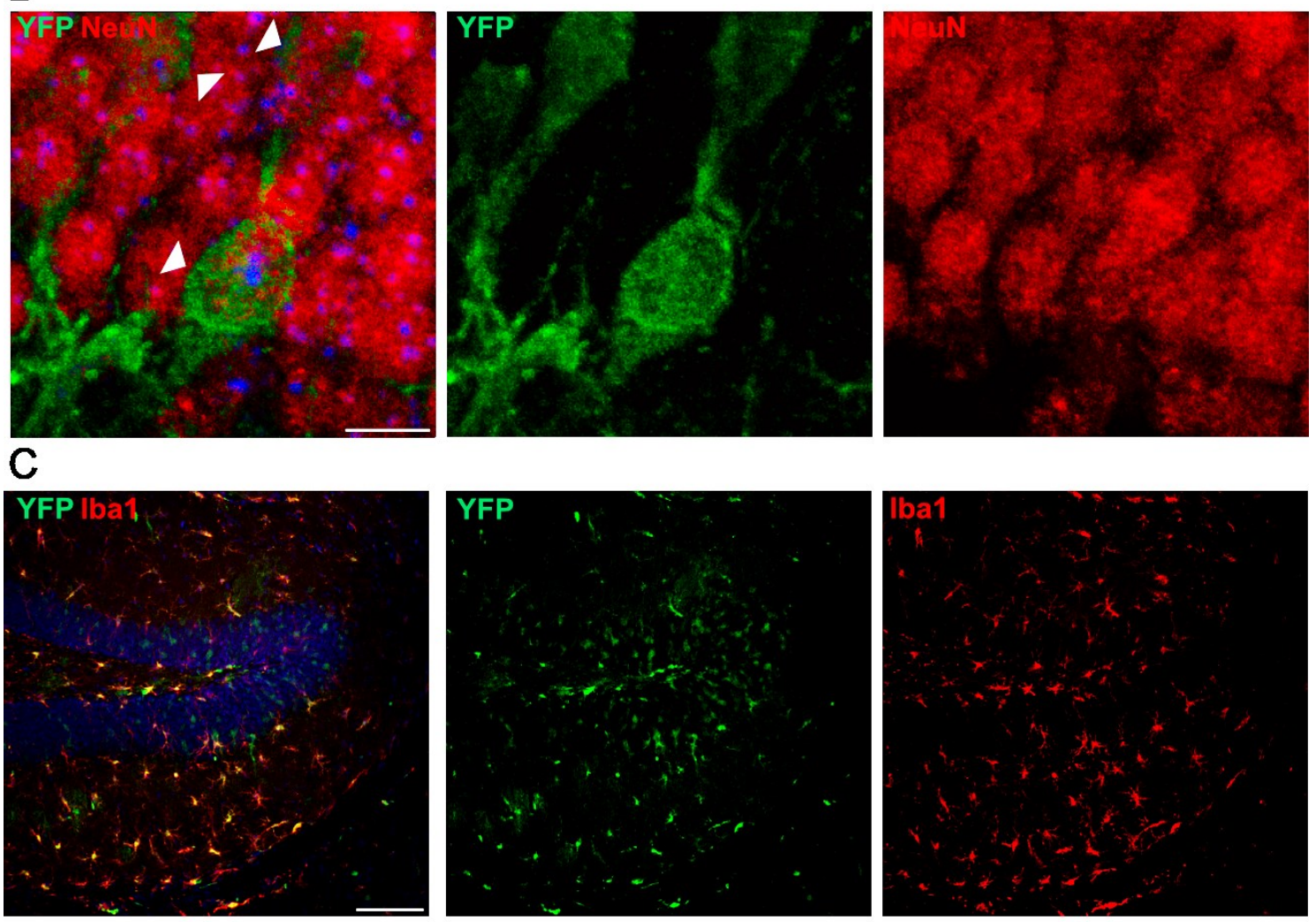

D
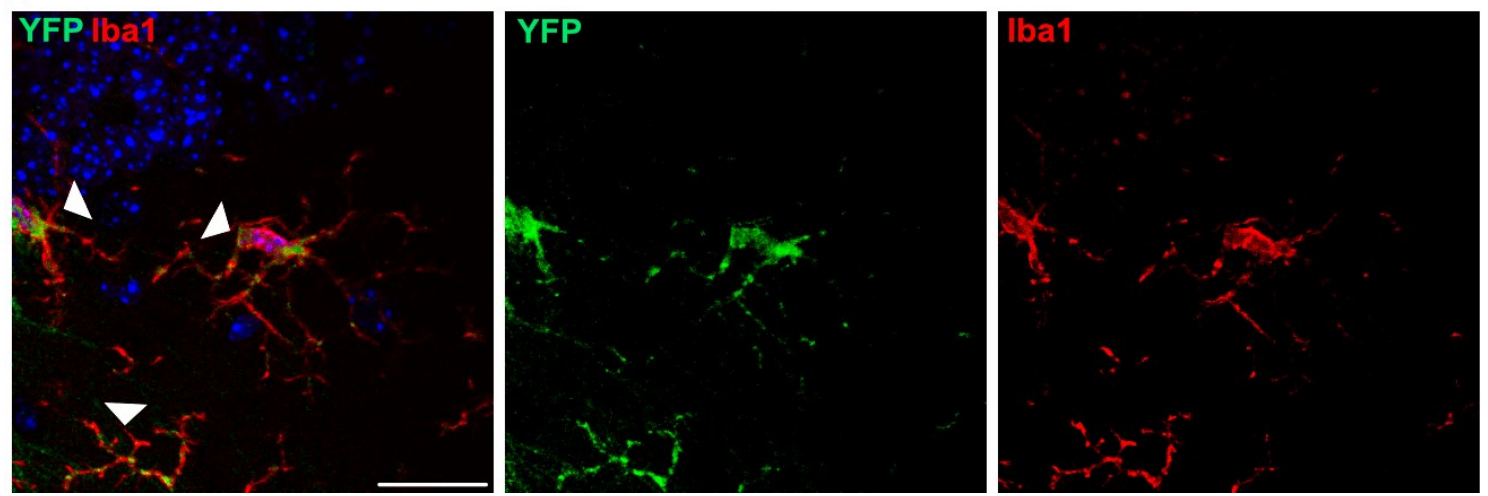

Figure 9. Peripheral inflammation induced by LPS leads to EV uptake in the hippocampus.

Images show immune-fluorescent staining of hippocampal sections from a double transgenic mouse, injected with LPS. (A) Dentate gyrus, showing predominantly recombined neurons (YFP+ NeuN+). (B) High magnification of DG, showing three recombined neurons (YFP+NeuN+, arrowheads). (C) 
Dentate gyrus, showing predominantly recombined microglia (YFP+lba1+). (D) High magnification, showing three Iba1+ cells recombined (YFP+lba1+, arrowheads). DAPI was used for nuclear counterstain. Scale bars 100um in A, C; 10um in B, D.

\subsubsection{Peripheral injection of LPS leads to EV uptake in the Substantia Nigra} (SN)

Frequent recombination events were observed in the SN. Here, the percentage of TH-positive dopaminergic neurons (DA), expressing the marker gene EYFP, reached an average of $11.2 \%( \pm 3.2 \% \mathrm{SD})$ and that of Iba1-positive microglia $47.4 \%$ ( $\pm 15.8 \%$ SD) (Fig. 10).

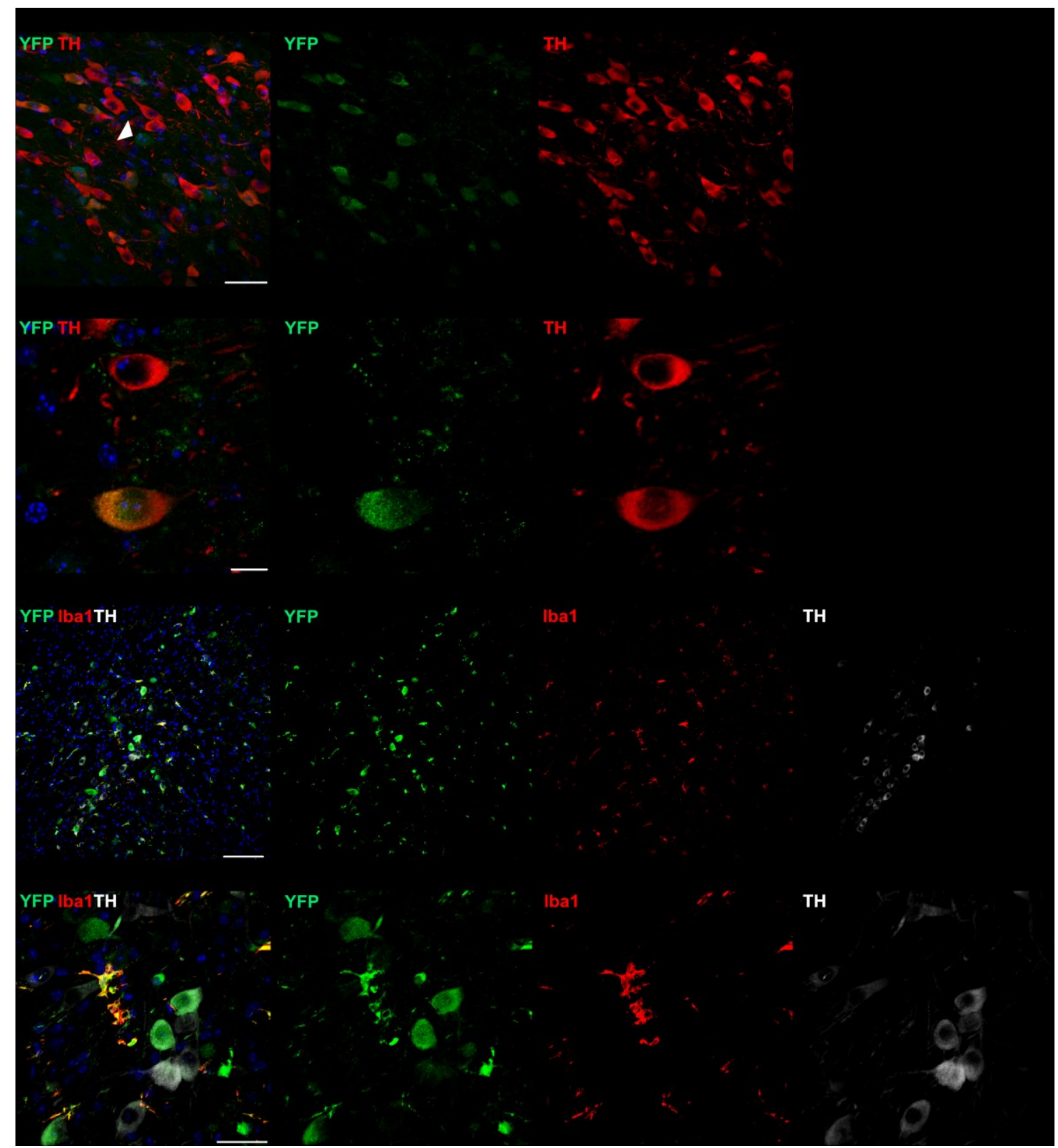

Figure 10. Peripheral inflammation induced by LPS leads to EV uptake in the Substantia Nigra. Images show immune-fluorescent staining of Substantia Nigra sections from a double transgenic 
mouse injected with LPS. (A) SN showing predominantly recombined dopaminergic neurons (YFP+ $\mathrm{TH}+$ ). Arrowhead indicates a recombined cell with the morphology of a DA neuron. (B) High magnification of $S N$ showing one recombined DA neuron. (C) $S N$, showing predominantly recombined DA neurons (TH+YFP+) and some microglia (Iba1+YFP+). (D) High magnification showing two Iba1+ cells recombined. DAPI was used for nuclear counterstain. Scale bars 100um in C; 50um in $A$; 10um in $B, D$.

Interestingly, in the SN, some recombined cells with the morphology of DA, but negative for TH marker, could be observed (Fig. 10A). Given the prominent role of inflammation in Parkinsons disease, this may point to a previously unidentified factor, linking these events.

\subsubsection{Cellular EV targeting in EpoR-Cre mice differs from that of vav-iCre mice}

There is an increasing evidence of the role played by the EV donor cell type and its effect on the selectivity of target cells (Matsumoto et al., 2017). Therefore, to investigate if the EV donor cell influences the target cell, a collaboration with $\mathrm{Dr}$. Saumya Das from the Cardiovascular Research Center, Massachussets General Hospital, was started. An LPS injection was performed in EpoR-iCre x Rosa26mTmG mice. In this mouse model, iCre is expressed under the control of the erythropoietin receptor, restricting its expression to the erythroid lineage (Heinrich, Pelanda, \& Klingmüller, 2004).

Analysis of recombination events revealed that in this case no neurons expressing the reporter gene EYFP were detected, while only Iba1 + microglia were positive for the reporter gene (Fig. 11). This is a clear indication that EVs are targeted to a specific cell type, and this specificity is determined by the cell of origin.

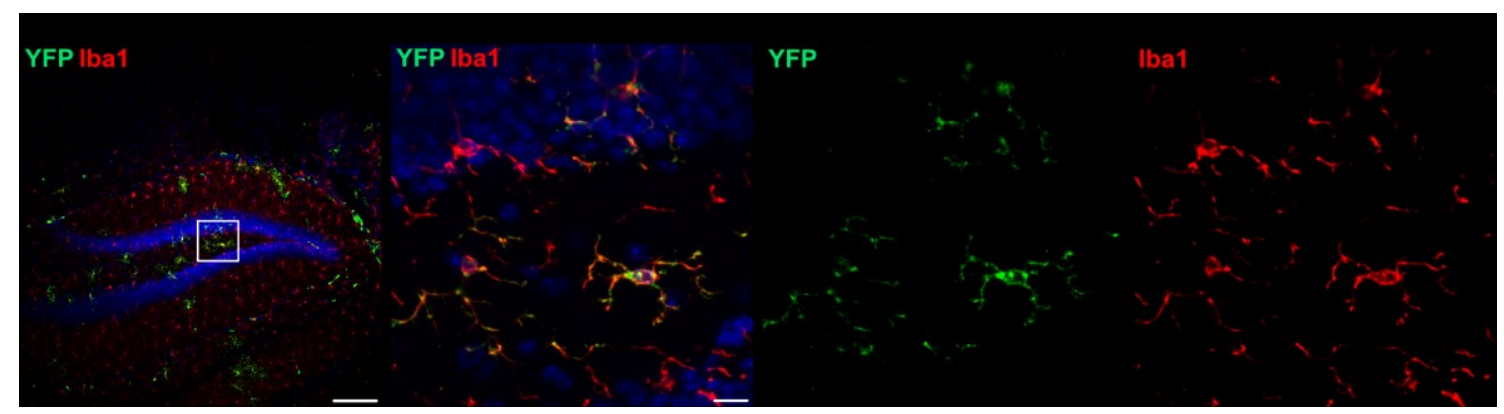

Figure 11. Recombination in the EpoR-Cre model. (A) Recombination after LPS treatment in EpoR-Cre mouse is restricted to microglia (Iba1+). Images on the right are a magnification from the white square. DAPI was used for nuclear counterstain. Scale bars from left to right: 100um and 10um in $\mathrm{A}$. 
Next, to further probe our hypothesis and in collaboration with Dr. Stephanie Dimmeler, from the Institute of Cardiovascular Regeneration in Frankfurt, an acute myocardial infarction was induced in vav-iCre $x$ Rosa26YFP mice and hearts from this model and from EpoR-Cre mice were analysed. The results obtained show that cardiomyocytes in the EpoR-Cre model, but not in the vav-iCre model, where recombined, strengthening the hypothesis that the targeting of EVs is controlled by the cell of origin.

\subsection{Specific stimulation of neuronal activity induced by KA leads to increased EV uptake in neurons}

Kainic acid (KA) is an analogue of excitotoxic glutamate, a neuroexcitatory molecule, acting on kainate receptors (Zhu, Zheng, Zhang, \& Luo, 2011). KA activates kainate receptors that control sodium channels and leads to excitatory postsynaptic potentials.

$\mathrm{KA}$ is frequently used as an epilepsy-like model, causing selective cell death and mimicking neurodegeneration in the brain of rodents. The fact that KA in small concentrations (a single injection of $10 \mathrm{mg} / \mathrm{kg}$ ) can be used as a stimulator of neurons (Tasker et al., 2002) was an advantage.

In this paradigm, a single injection of KA leads to the transfer of Cre mRNA to the brain, indicated by expression of the marker gene EYFP in different cell populations such as neurons and microglia. As in the LPS model, recombination was present in several brain regions.

\subsubsection{KA leads to EV uptake in the hippocampus}

After $\mathrm{KA}$ injection, frequent recombination events in the $\mathrm{HC}$ were observed. In the dentate gyrus $(D G)$ of the $\mathrm{HC}$, percentage of EYFP+ NeuN+ neurons reached an average of $18.5 \%( \pm 14.6 \% \mathrm{SD})$, and EYFP+ Iba1+ microglia $35.2 \%( \pm 16.3 \% \mathrm{SD})$ (Fig. 12). Taken together, the percentages of recombination where similar to those after LPS injection, but with a higher variability between mice, as well as a tendency to more neuronal and less microglial recombination. 
A
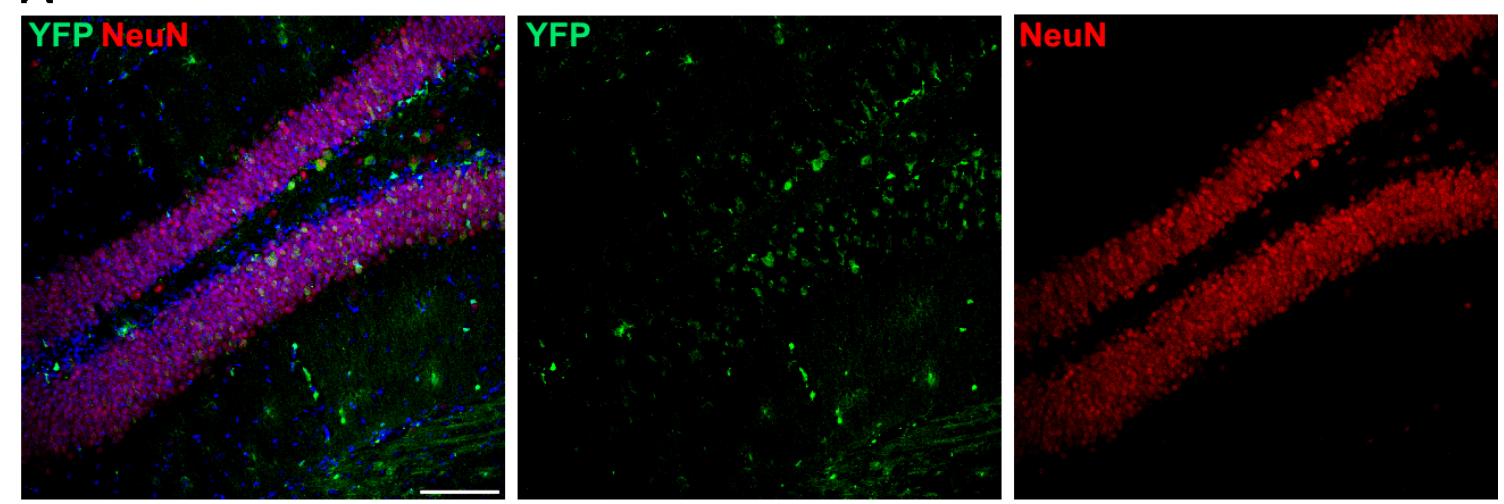

B
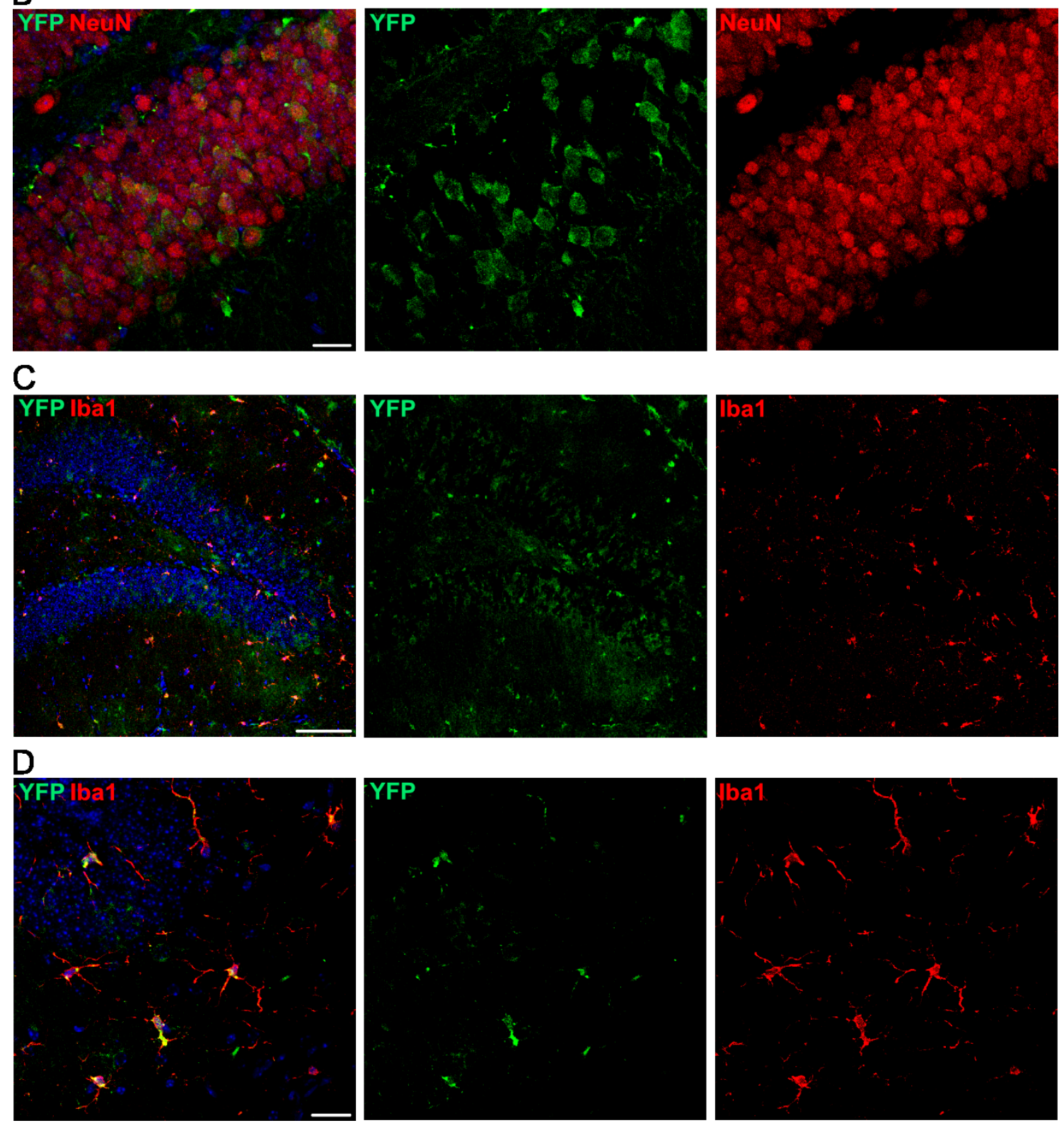

Figure 12. Intraperitoneal KA injection leads to EV uptake in the hippocampus. Images show immune-fluorescent staining of hippocampal sections from a double transgenic mouse, injected with KA. (A) Dentate gyrus showing predominantly recombined neurons (YFP+ NeuN+). (B) High magnification of DG, showing recombined neurons. (C) Dentate gyrus, showing recombined 
microglia (YFP+lba1+). (D) High magnification, showing few recombined Iba1+ cells. DAPI was used for nuclear counterstain. Scale bars 100um in A, C; 20um in B, D.

\subsubsection{KA leads to EV uptake in the Substantia Nigra}

Frequent recombination events were observed in the SN after KA injection. The percentage of TH-positive DA neurons, expressing the marker gene EYFP, reached an average of $23.2 \%( \pm 3.1 \%$ SD $)$ and that of Iba1-positive microglia $29.2 \%( \pm 7.0 \%$ SD) (Fig. 13). Levels of marker gene expression were similar to those in the LPS model.

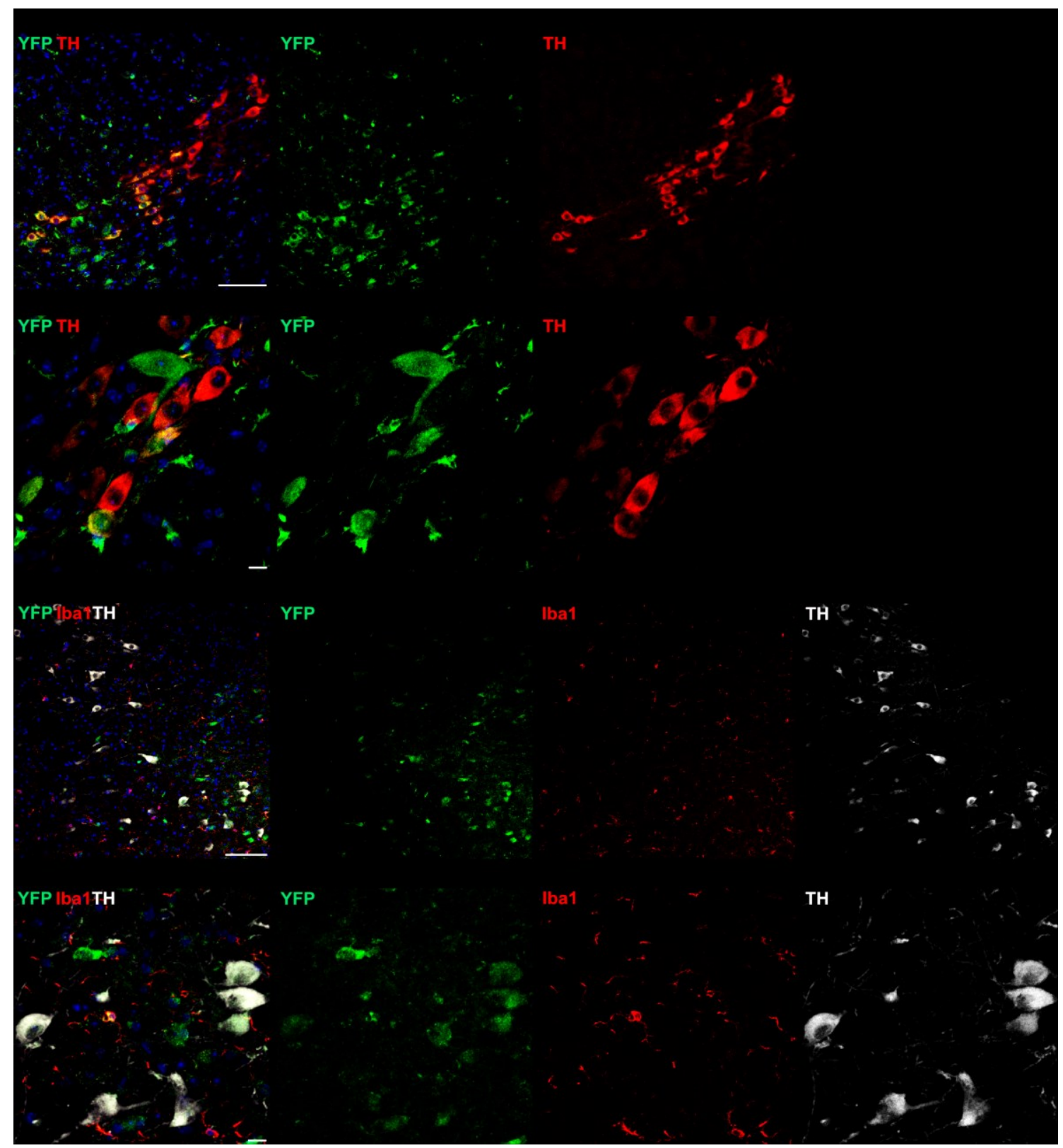

Figure 13. Intraperitoneal KA injection leads to EV uptake in the Substantia Nigra. Images show immune-fluorescent staining of Substantia Nigra sections from a double transgenic mouse, injected with KA. (A) SN, showing predominantly recombined dopaminergic neurons (YFP+ $\mathrm{TH}+$ ). (B) High 
magnification of $S N$ showing two recombined DA neurons. (C) $S N$ showing predominantly recombined DA neurons (YFP+ $\mathrm{TH}+$ ) and few microglia (YFP+lba1+). (D) High magnification showing a recombined Iba1+ cell. DAPI was used for nuclear counterstain. Scale bars 100um in A, C; 10 um in B, D.

\subsection{No detectable peripheral immune cell infiltration after LPS or KA injection}

In order to account for the possibility of immune cell infiltration after LPS or KA injection (Cazareth, Guyon, Heurteaux, Chabry, \& Petit-Paitel, 2014), specific markers were used to detect peripheral macrophages in the brain. Peripheral macrophages can be distinguished from brain resident microglia by expression of the integrin subunit alpha 4 (Itga4/CD49d) (Bowman et al., 2016).

Sections, obtained from LPS and KA injected mice, were stained against CD49d, but did not reveal CD49d-positive cells in the brain parenchyma thereby excluding peripheral immune cell infiltration.

Sections from stroke and glioblastoma models were used as positive controls, as it is known that in these conditions there is a high degree of infiltration of peripheral monocytes (Fig. 14).

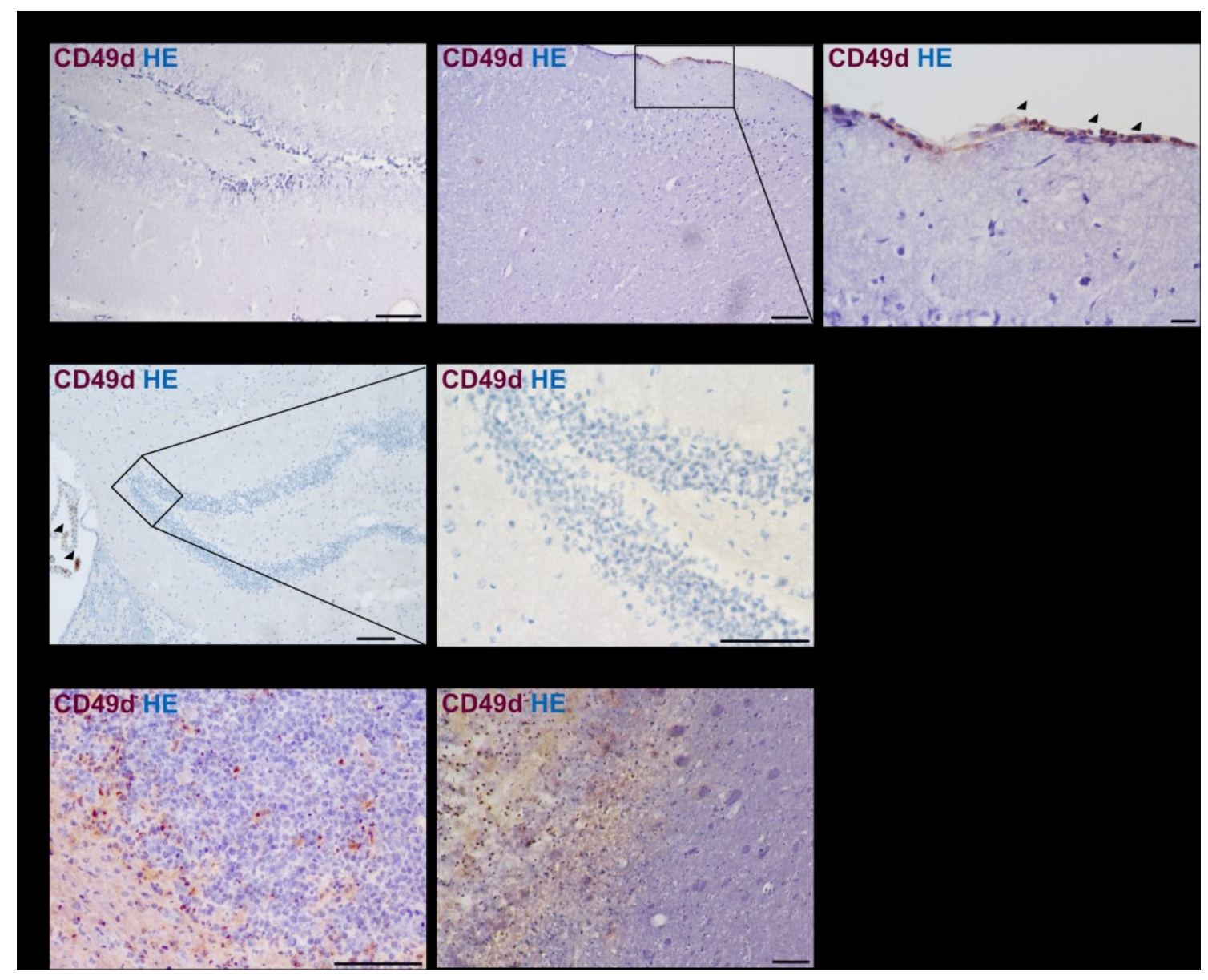


Figure 14. LPS or KA injection does not lead to infiltration of peripheral blood macrophages in the brain parenchyma. (A) Brain sections from LPS injected mouse do not show CD49d-positive staining in the hippocampus or other brain regions such as cortex (B). (C) High magnification showing CD49d-positive meningeal macrophages on the brain surface (arrowheads). ( $D$ and E) KA injection does not lead to infiltration of peripheral macrophages. Arrowheads indicate CD49d-positive cells in the choroid plexus. ( $F$ and $G$ ) Positive control brain sections in conditions causing a high influx of peripheral blood cells into the brain ( $F$, Glioblastoma; G, Middle Cerebral Artery Occlusion (MCAO)). All sections were stained with CD49d and counterstained with hematoxylin - eosin (HE). (C, E) Higher magnification from areas marked by black squares. Scale bars 100um in A, B, D, E, F, G; 20um in C.

\subsection{Recombination events are not caused by unspecific expression of Cre recombinase}

In the mouse model vav-iCre $x$ Rosa26YFP, haematopoietic cells contain the Crereporter construct together with the Cre-expressing construct. This leads to the theoretical possibility of unspecific Cre recombinase expression leading to marker gene expression.

To account for this possibility, the following experiment was performed (Fig. 15). Rosa26YFP Cre-reporter mice, lacking endogenous Cre expression, received an intracranial injection of KA in one hemisphere (Bielefeld et al., 2017) and a saline solution injection in the contralateral hemisphere. Then, EVs, isolated from blood of the vav-iCre mice, stimulated with LPS, were injected into the tail vein.

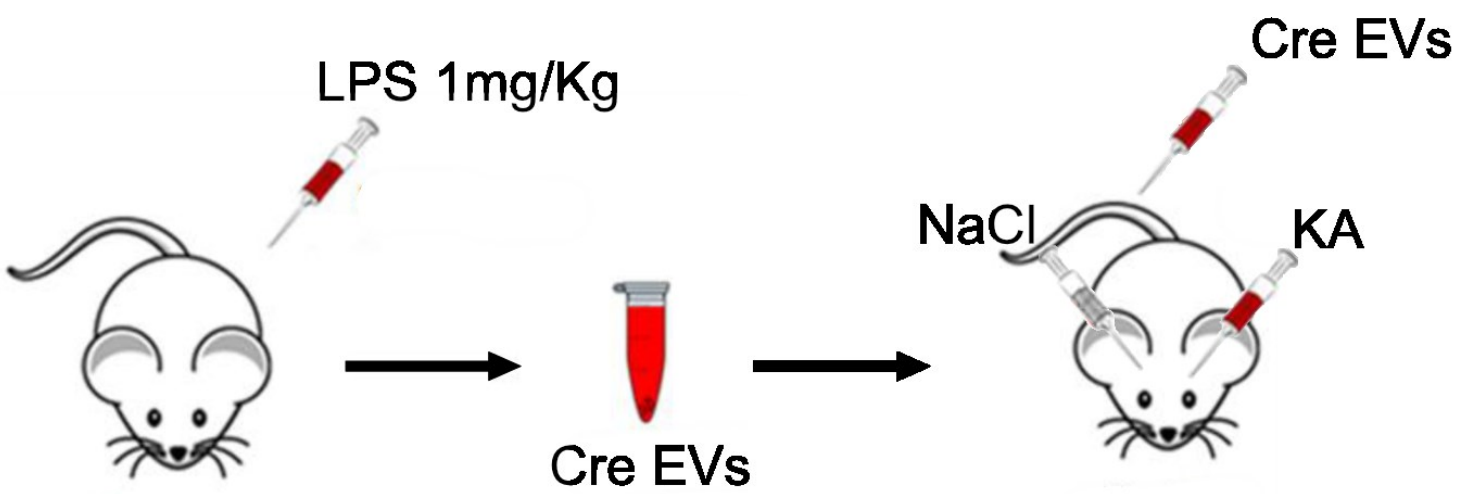

vav-iCre-R26EYFP

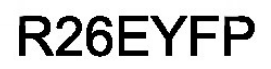

Figure 15. Experimental procedure to control for unspecific expression of Cre recombinase.

Experimental protocol for peripheral EV injection, followed by local neuronal activation by intracerebral injection of KA or with saline solution into the contralateral hemisphere as control. 
After 48h, brains were analysed histologically and recombination events were only observed in the ipsilateral hemisphere (KA injected), but not in the contralateral hemisphere, receiving a saline injection. Hence, recombination could only have been possible through EVs, entering the brain via the peripheral circulation. Additionally, local neuronal activation, caused by KA injection, was necessary and sufficient for EV uptake, whereas saline injection did not lead to EV uptake (Fig. 16 $A$ and $B$ ).

Furthermore, intracranial injection of EVs from vav-iCre, together with KA, led to a widespread recombination compared to Cre-EV peripheral injection (Fig. 16C). Intracranial injections of KA together with EVs from Rosa26YFP mouse (no Cre expression) were performed to check the possibility of auto-fluorescence, caused by cell death (Fig. 16D).

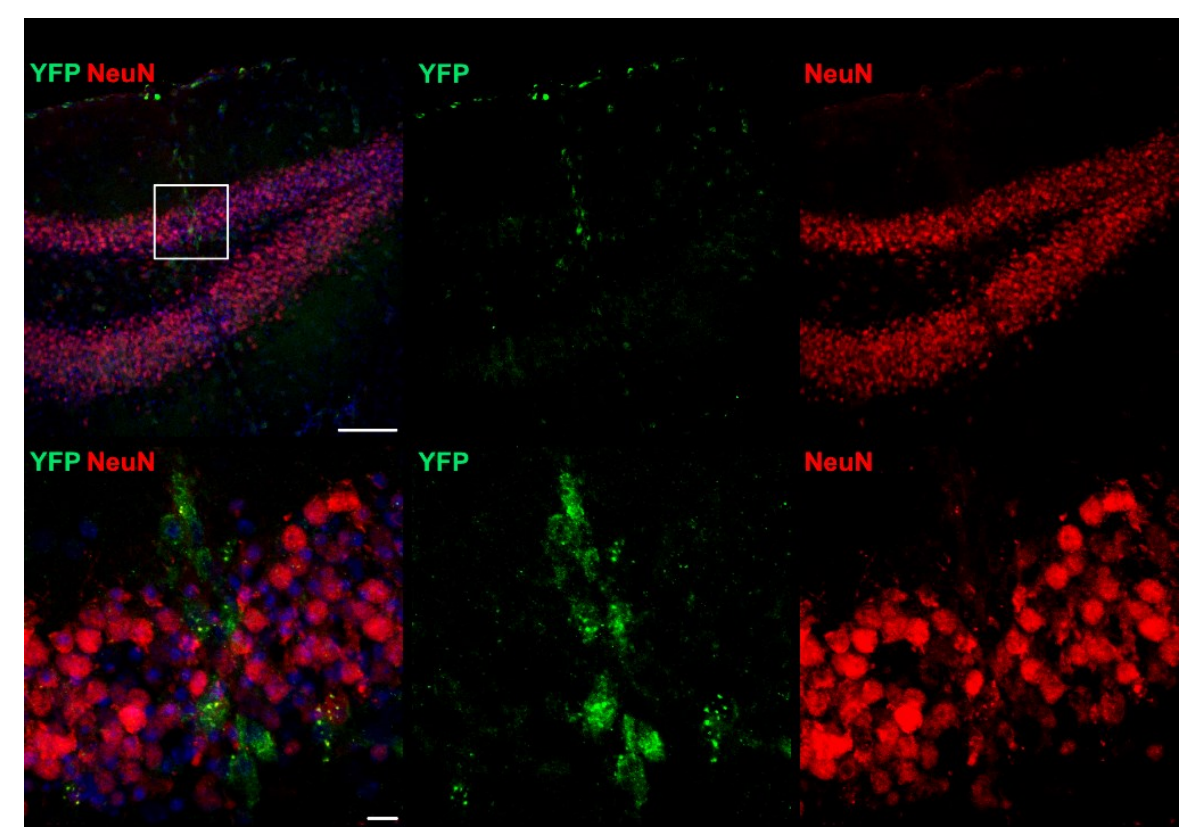



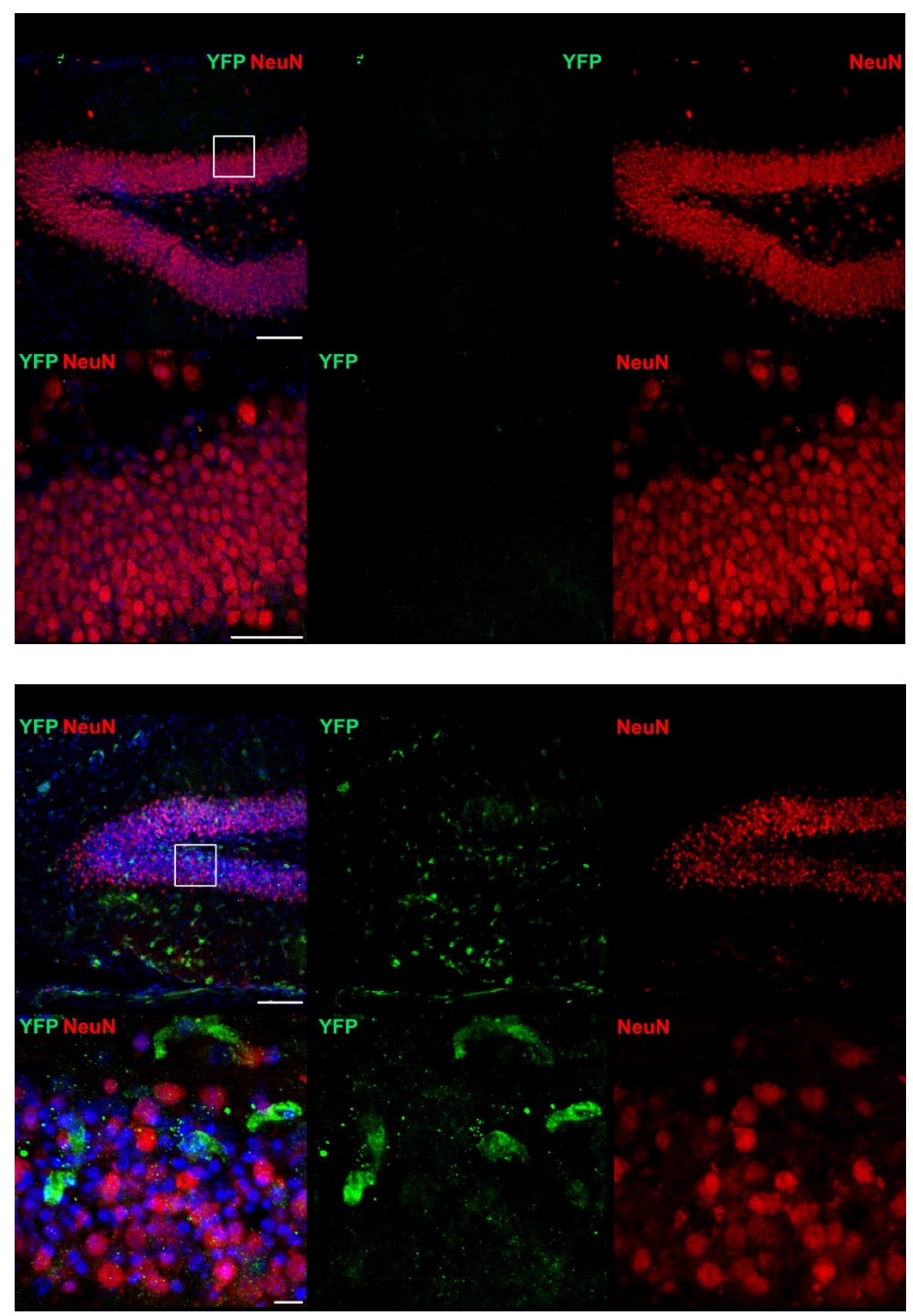


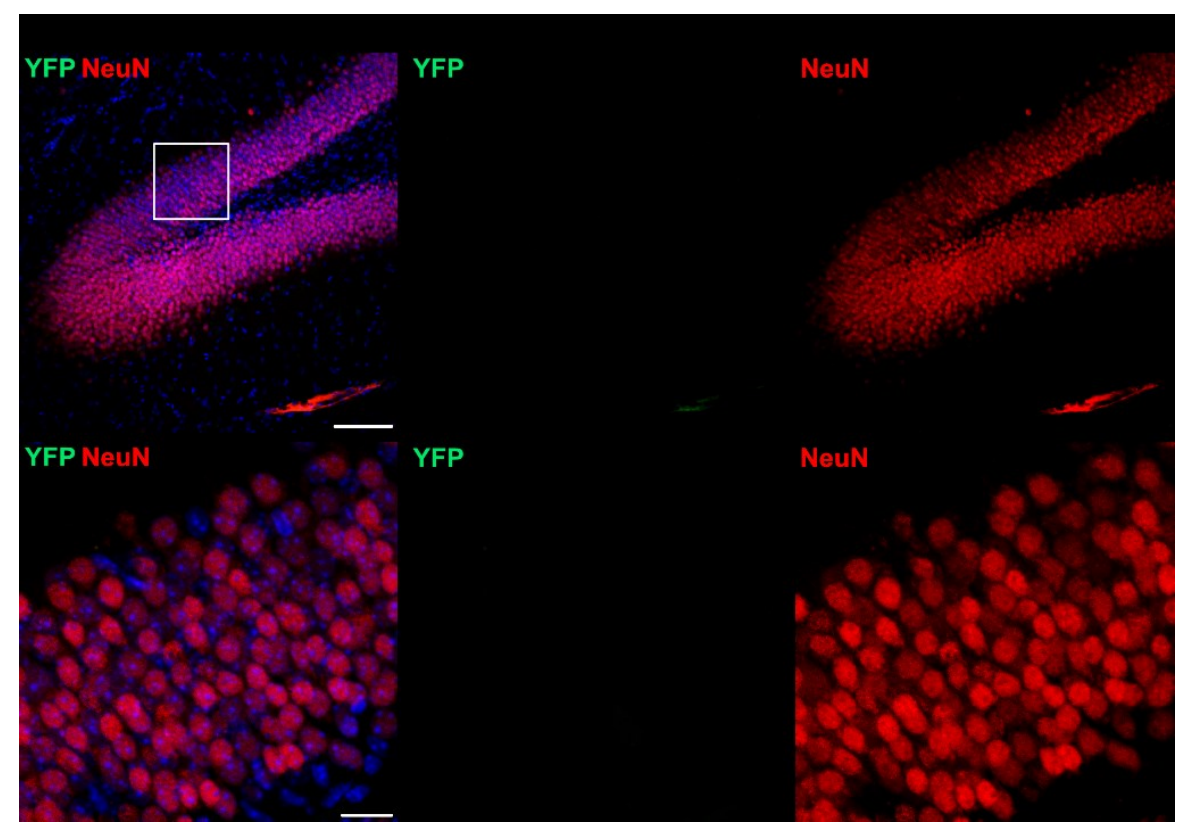

Figure 16. Peripheral injection of Cre EVs leads to marker gene expression after local neuronal stimulation. (A) Intracranial KA injection, together with intravenous injection of EVs from LPS injected vav-iCrexRosa26EYFP mouse (Cre EVs). YFP+NeuN+ cells can be observed in the hippocampus. (B) Cre EVs intravenous injection, together with intracranial injection of saline solution (control, contralateral hemisphere). No YFP-positive cells are detectable, except for meningeal macrophages on the brain surface. (C) Intracranial KA injection, together with Cre EVs, led to widespread marker gene expression. (D) Intracranial KA injection, together with EVs from Rosa26EYFP mouse plasma did not lead to induction of marker gene expression. White squares indicate magnification from this zone in the images in the lower panels. DAPI was used for nuclear counterstain. Scale bars from top to bottom: 100um and 10um in A; 100um and 50um in B; 100um and 10um in C; 100um and 50um in D.

Overall, these results indicate that $\mathrm{EV}$ uptake may be regulated by neuronal activity. Therefore, the following experimental paradigms were conceived to specifically address this hypothesis.

\subsection{Intranigral epoxomicin infusion leads to specific EV uptake in DA neurons}

Epoxomicin (Meng et al., 1999), a natural product from the Gram-positive bacteria Actinomycetes, is a selective and irreversible inhibitor of the ubiquitin proteasome system (UPS). The impairment of protein degradation via UPS, either genetically or pharmacologically, produces transient activation in neuronal firing, a common pathological feature in Parkinsons disease well-studied in animal models (Subramaniam et al., 2014). 
In collaboration with Dr. Jochen Roeper from the Institute of Neurophysiology, Frankfurt, epoxomicin was unilaterally infused into the $\mathrm{SN}$ of the ventral midbrain as described in Subramaniam et al., 2014.

Two weeks after infusion, the presence of marker gene expression EYFP in DA neurons in $\mathrm{SN}$ was assessed histologically. In the ipsilateral site, $\mathrm{TH}$-positive cells expressing EYFP were detectable and reached an average of $8.6 \%( \pm 3.1 \% \mathrm{SD})$. No recombination events were observed in $\mathrm{TH}$-positive cells in the contralateral hemisphere in animals that received an infusion of carrier solution only (Fig. 17).

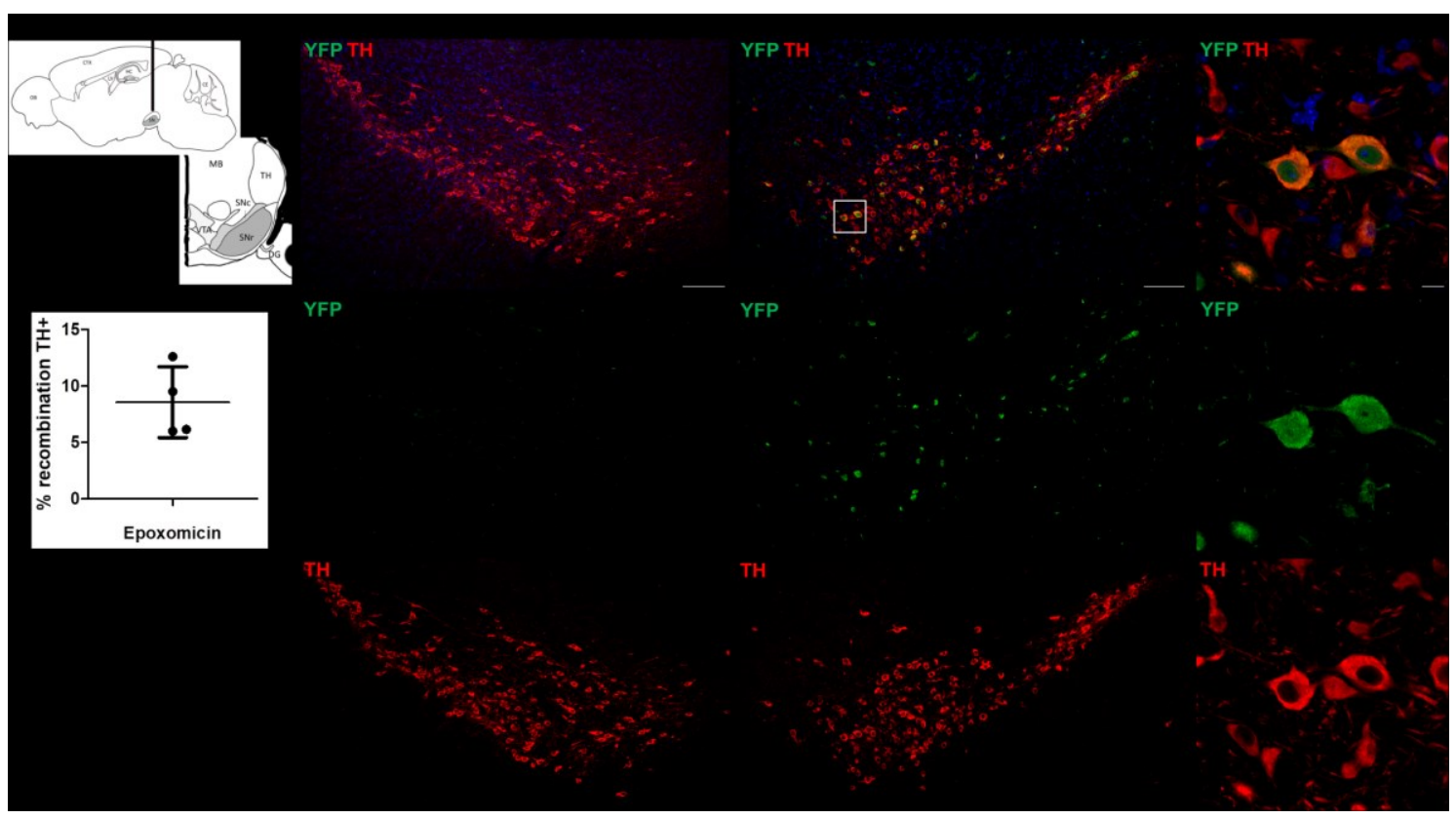

Figure 17. Neuronal activation using epoxomicin is sufficient to trigger EV uptake in the Substantia Nigra. (A) Scheme of the unilateral infusion of the selective proteasome inhibitor epoxomicin into the ventral midbrain that leads to increase in in vivo firing frequencies of DA SN neurons. (B) Two weeks after infusion, no marker gene-expressing DA neurons were observed in the contralateral hemisphere. (C) In the ipsilateral hemisphere, recombination events were observed, meaning that DA neurons took up EVs leading to marker gene-expression. (D) High magnification of the area marked with white square. (E) Histogram showing the percentage of recombined DA neurons in each mouse used in the experiment. DAPI was used for nuclear counterstain. Scale bars: 100um in B, C; 10um in D.

These results are in line with the hypothesis that neuronal activity may regulate the uptake of EVs, since increased firing frequencies in DA neurons in SN led to a highly specific uptake of EVs. Curiously, very few or no Iba1-positive microglia cell showed recombination, which may be due to the reported anti-inflammatory properties of epoxomicin (Meng et al., 1999). 


\subsection{Specific induction of neuronal activity by an optogenetic approach}

Optogenetic methods are used to directly stimulate neuronal activity with high specificity (Miller, 2006). In collaboration with Dr. Albrecht Stroh from the Institute of Pathophysiology, University Medical Center Mainz, the rAAV2-CaMKIla-hChR2(H134R)-mCherry-WPRE-pA virus was injected into the visual cortex of vav-iCre $x$ Rosa26EYFP mice (Fig. 18).

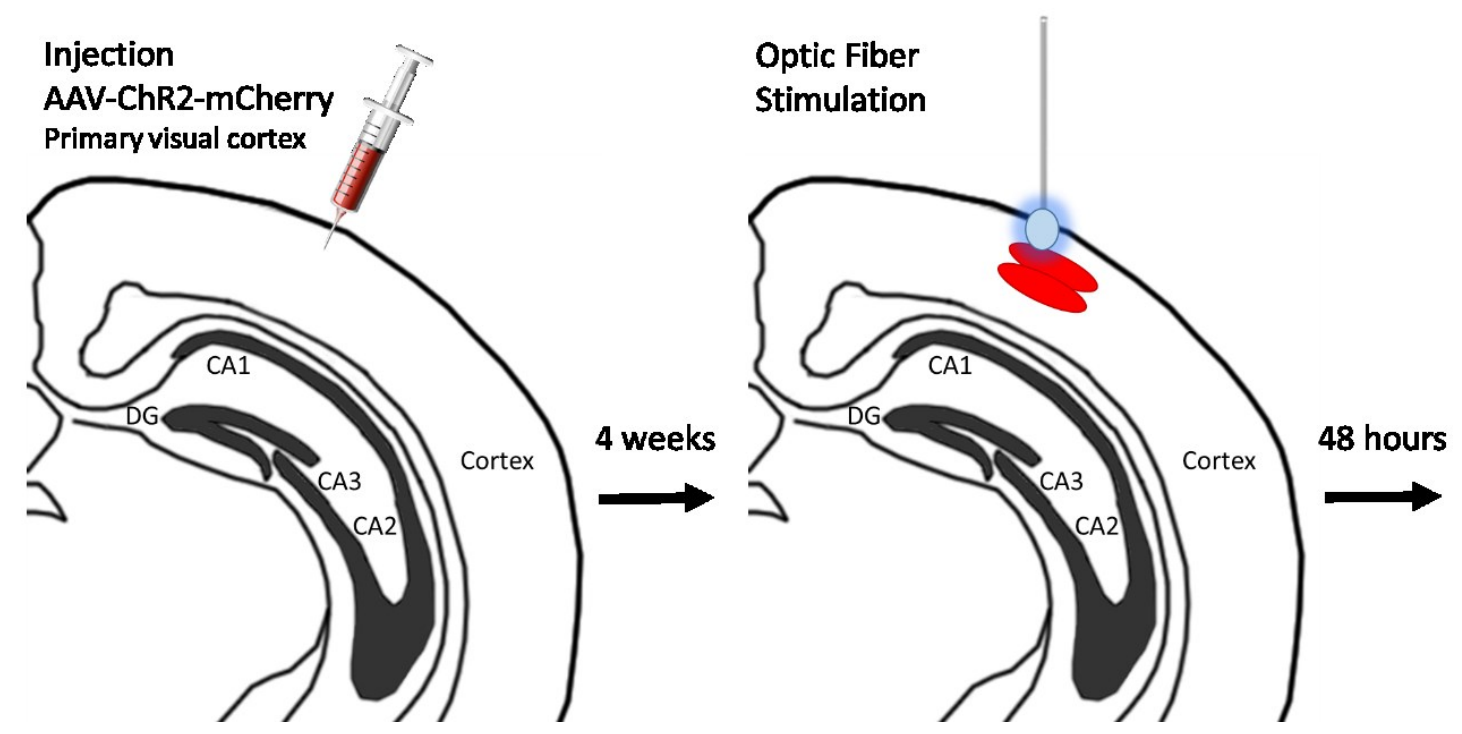

Figure 18. Scheme of neuronal activation by optogenetic stimulation. Scheme for the injection of ChR2-mCherry-AAV in layer $V$ of the primary visual cortex and optical fiber stimulation after 4 weeks.

CaMKIIA is a specific promoter of excitatory neurons, this means that the virus will be specifically expressed in these cells. Channelrhodopsin-2 (ChR2) is a lightsensitive voltage-gated cation channel that becomes activated in response to blue light inducing an influx of sodium that depolarizes cell membrane and can evoke action potential firing in neurons (Moeyaert et al., 2014).

Four weeks after virus injection, the expression profile of ChR2 was assessed by expression of the fluorophore mCherry. Strong membrane-bound expression of ChR2-mCherry was found in cortical layer V; in layers II and III the expression of ChR2-mCherry was less prominent (Fig. 19). 

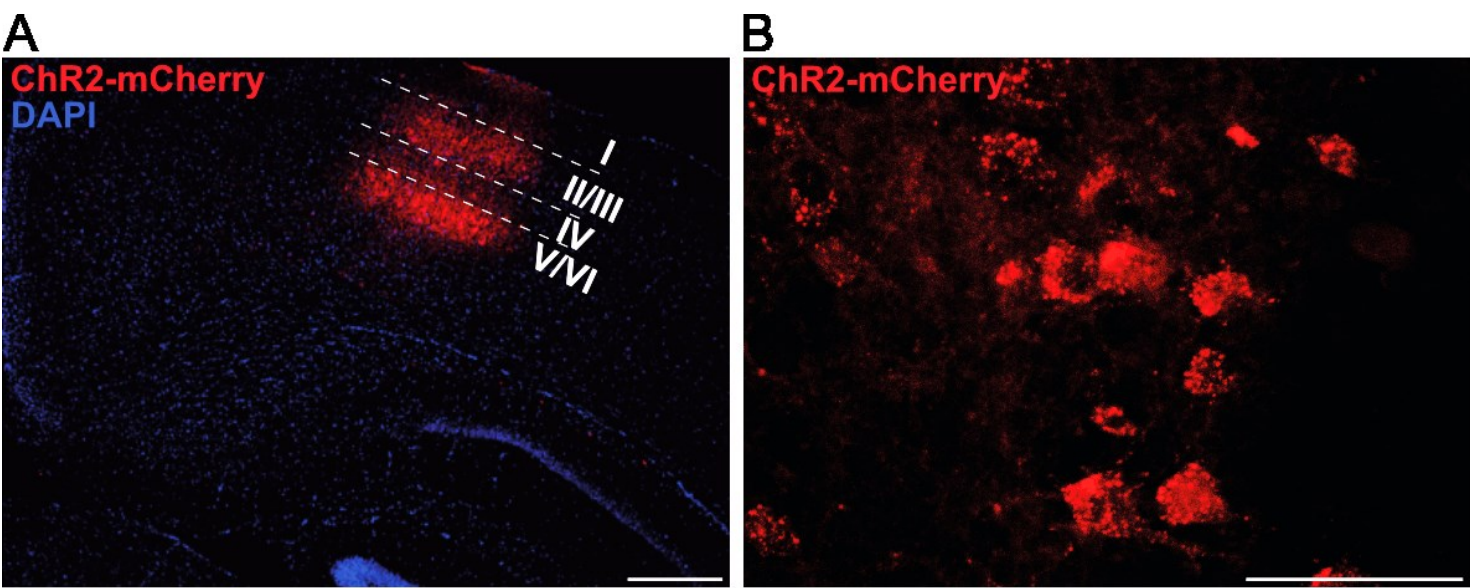

Figure 19. Expression of ChR2-mCherry for optogenetic stimulation. (A) Expression pattern of ChR2-mCherry in primary visual cortex (VI), 4 weeks after AAV injection. Layer-specific expression of ChR2-mCherry, mainly in layer V of VI. (B) Membrane-bound expression of ChR2-mCherry. Scale bars: 500 um in $A$; 50 um in $B$.

To test the functionality of the approach, in vivo electrophysiological field potential recordings were carried out. The ChR2-expressing region was stimulated with an optic fiber, emitting blue light of different intensities. A typical sigmoidal doseresponse curve was recorded (Fois, Prouvot, \& Stroh, 2014) and the light intensity that evoked strong neuronal responses was chosen (Fig. 20).

A
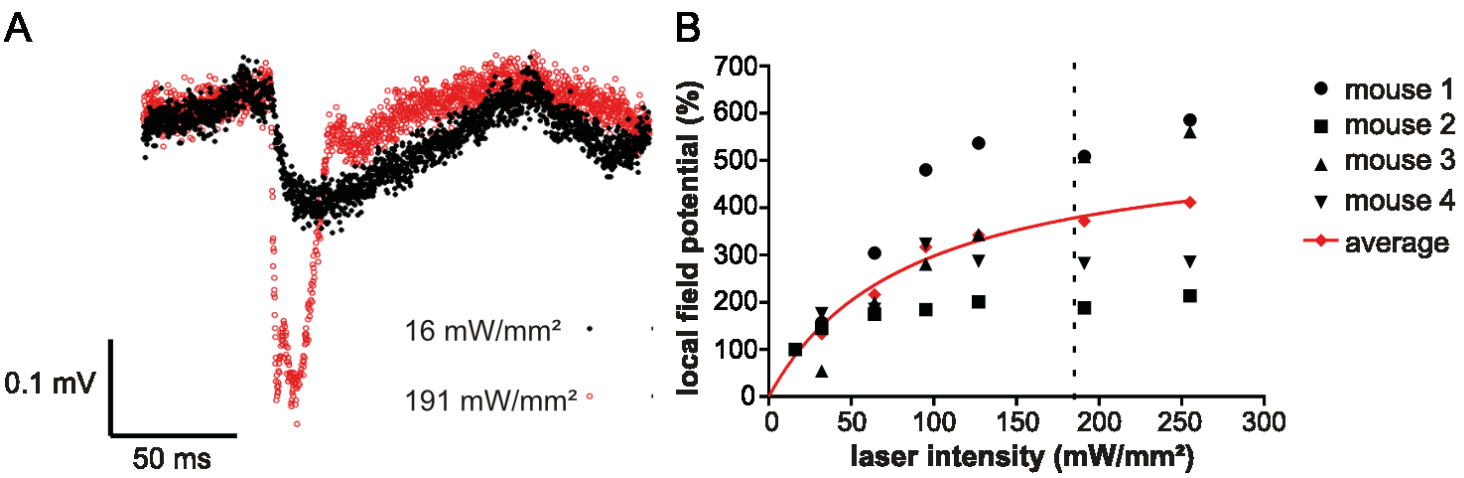

Figure 20. Local Field Potential for optogenetic stimulation. (A) Representative in vivo local field potential (LFP) traces from mouse 4 upon optic-fiber-based illumination with blue light with an intensity of 16 and $191 \mathrm{~mW} / \mathrm{mm}^{2}$ at the tip of the fiber. (B) Normalized LFP amplitudes, plotted against light intensity. Averaged amplitude was fitted into a nonlinear curve. The dotted line marks the light intensity, used in subsequent experiments $(\sim 185 \mathrm{~mW} / \mathrm{mm} 2)$.

To control for unspecific EV uptake, a group of mice received only the virus (no light stimulation) or only light stimulation (no virus). In both cases, there was no induction of EV uptake and thus no marker gene expression was observed (Fig. 21). 


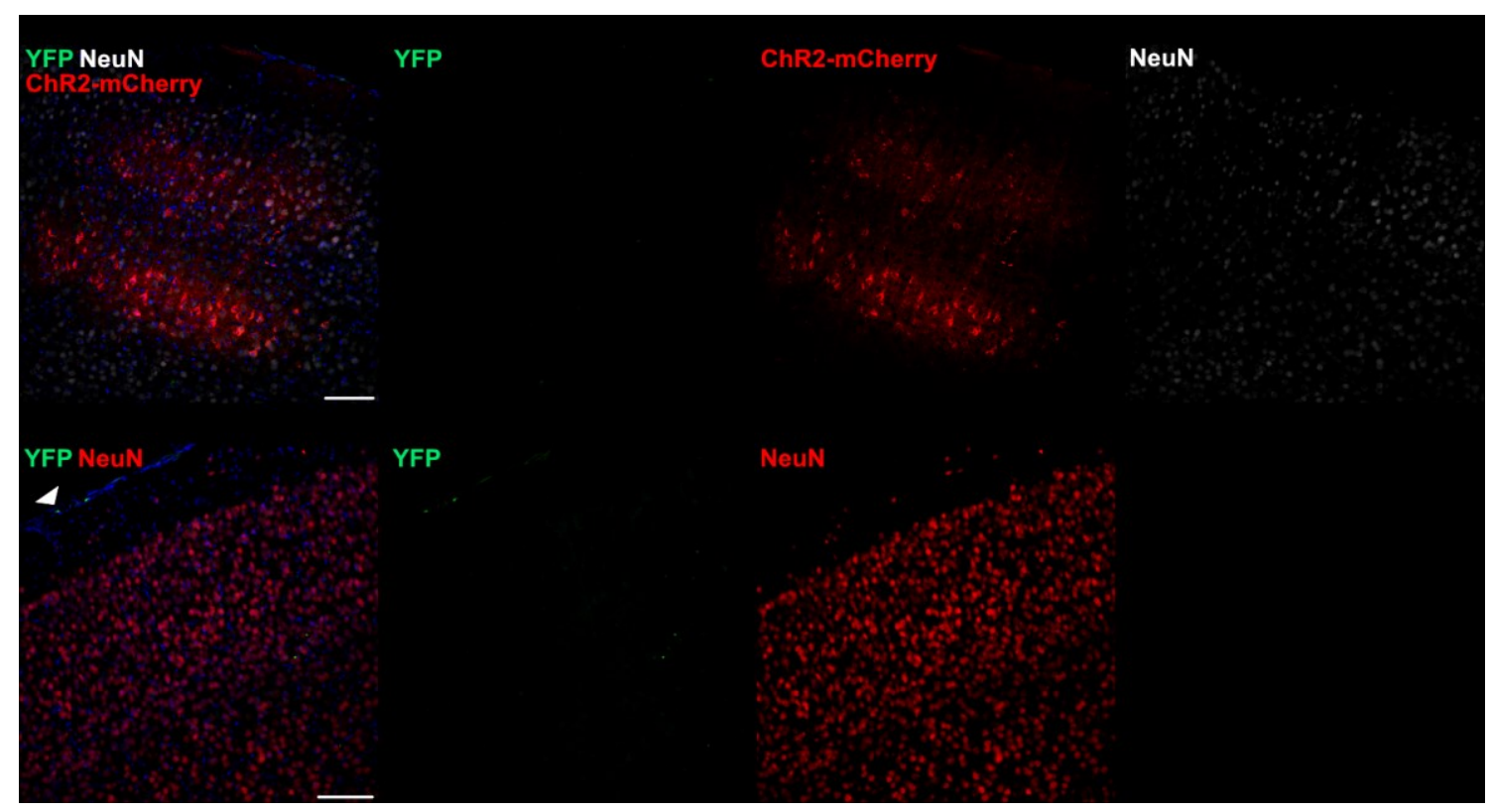

Figure 21. Injection of AAV alone or fiber optic stimulation without AAV injection does not lead to EV uptake. (A) Control section of AAV injected mouse without optical stimulation. (B) Control section from mouse that received only an optical stimulation without $A A V$ injection. White arrowheads indicate marker gene-positive meningeal macrophages. DAPI was used for nuclear counterstain. Scale bars: 100um in A, B.

In contrast, the combination of virus injection and light stimulation produced an uptake of EVs in NeuN-positive cells and a few Iba1-positive cells. EYFP-marker gene positive cells were quantified in ChR2-mCherry expression area, with an average of 43.6 cells per $0.01 \mathrm{~mm}^{3}\left( \pm 6.8\right.$ cells per $0.01 \mathrm{~mm}^{3} \mathrm{SD}$ ) from which $3.8 \%$ $( \pm 3.5 \%$ SD) were EYFP-positive microglia (Fig. 22). 


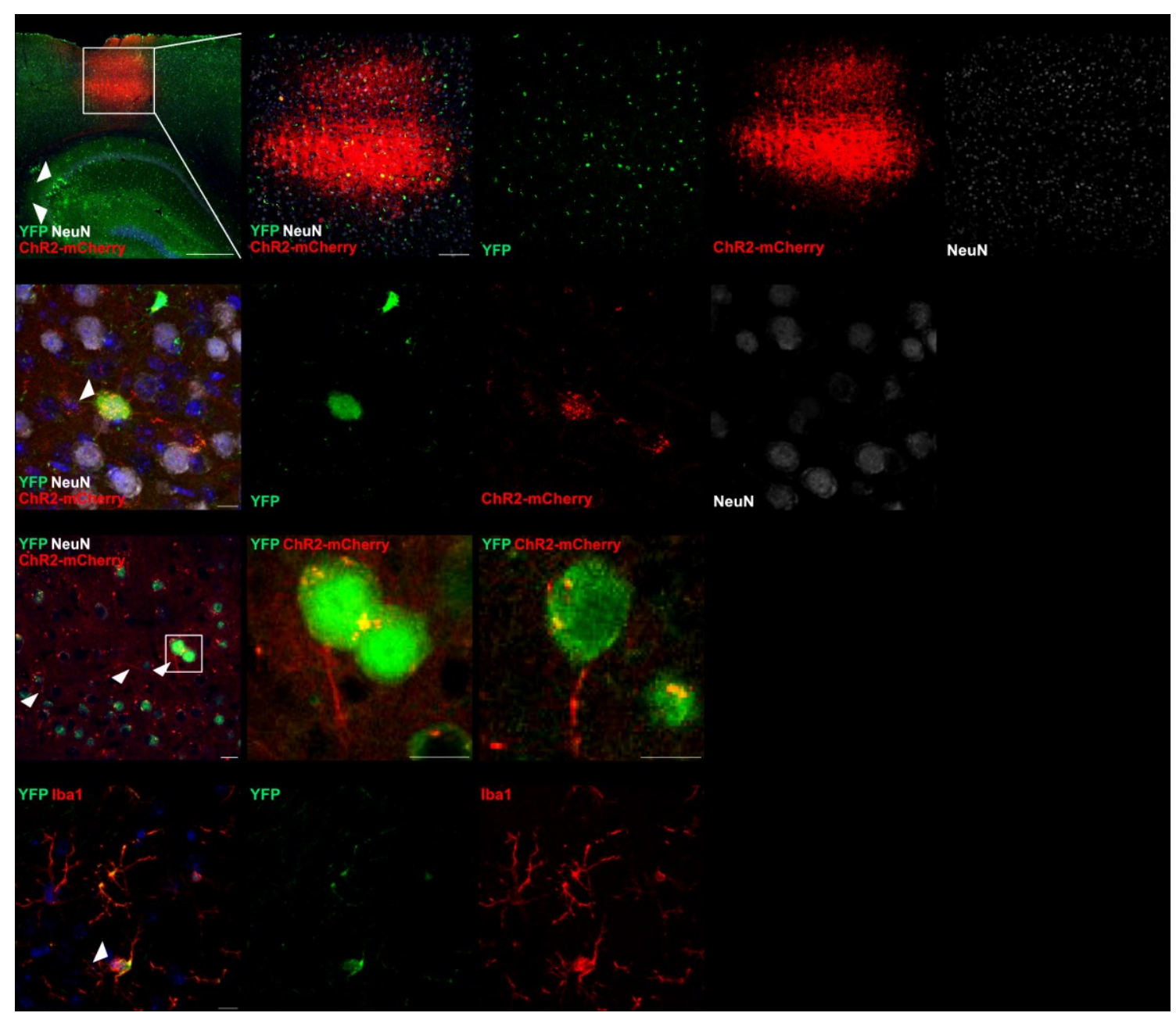

Figure 22. Injection of AAV together with fiber optic stimulation leads to EV uptake. (A) Recombination occurs in ChR2-mCherry-positive and -negative neurons; note positive cells in the hippocampus (arrowheads). (B) High magnification of the AAV injection zone (white square in A), showing recombined neurons inside and outside this region. (C) Higher magnification, showing a recombined neuron expressing ChR2-mCherry (arrowhead). (D) ChR2-mCherry positive fiber projection (arrowheads) far from the injection area, communicating with recombined neurons; images on the right showing higher magnification of area marked with white square. (E) Recombination is also observed in a few Iba1-positive microglia. DAPI was used for nuclear counterstain. Scale bars from left to right: 500um in A; 100um in B; 20um in D and 10um in C, E.

Only some of the recombined neurons co-expressed ChR2-mCherry, and there were more recombination events outside of the injection area in adjacent cortical areas and in hippocampus. Furthermore, it was possible to follow projections from virally transduced neurons to the contralateral hemisphere that were accompanied by recombination events in the surrounding brain parenchyma (Fig. 23). 

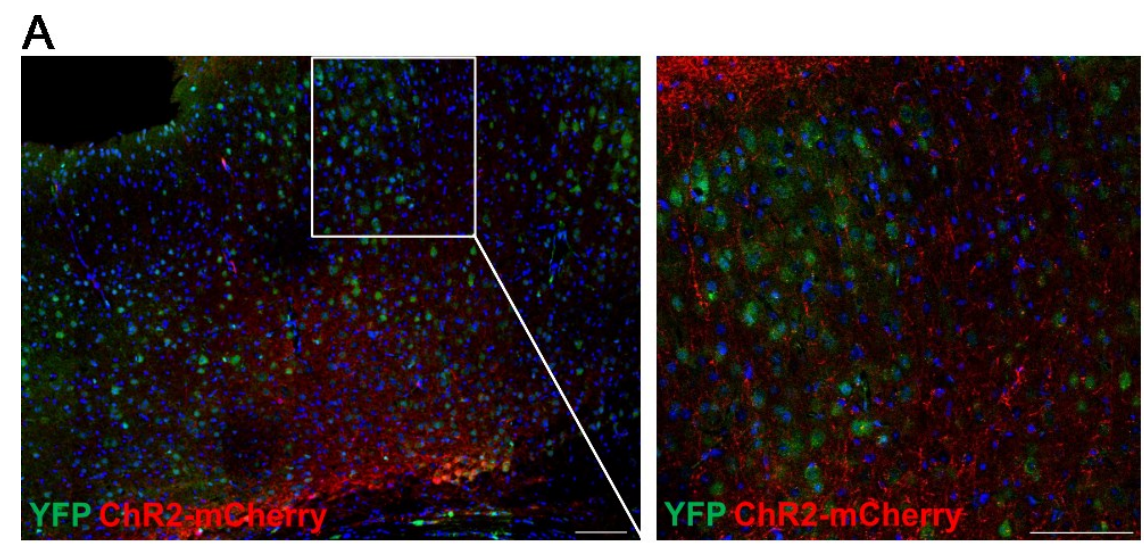

B
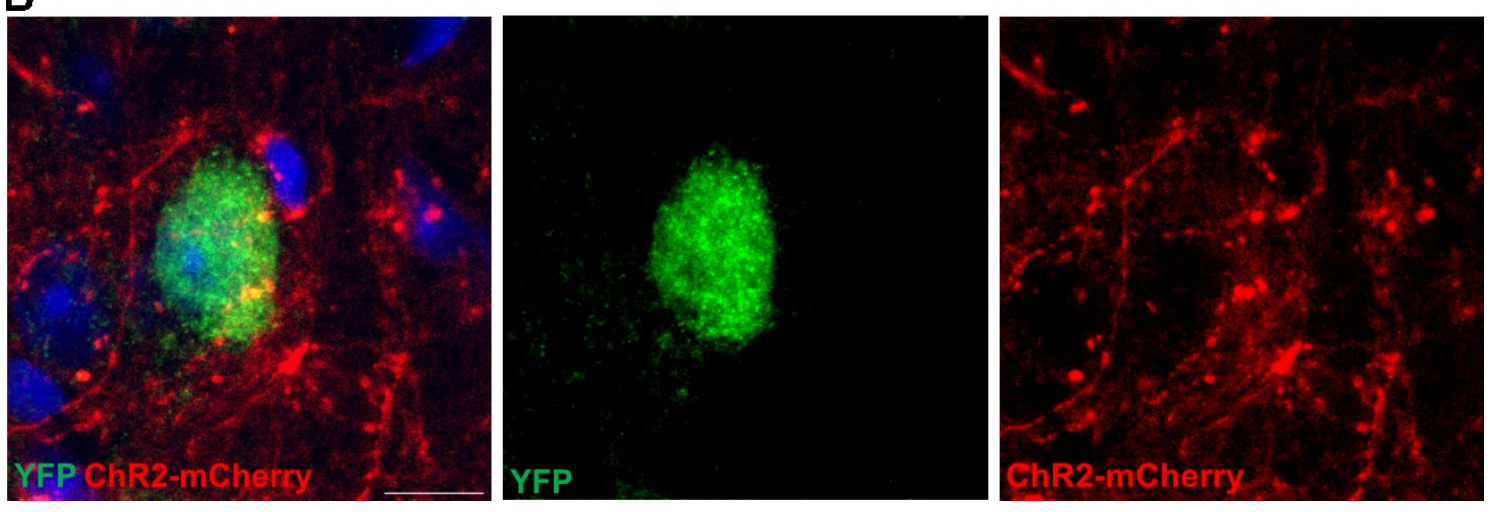

Figure 23. EV uptake extends to the contralateral hemisphere after optogenetic stimulation.

Fiber projections with ChR2-mCherry positive staining continued from the site of injection to the contralateral hemisphere. (A) Contralateral hemisphere with some recombined cells in target areas, image on the right is a higher magnification of the area marked with white square. (B) High magnification of a recombined cell in the contralateral hemisphere. DAPI was used for nuclear counterstain. Scale bars from left to right: 100um and 100um in A; 10um in B.

This result can be attributed to the connections between neurons, which can be stimulated at a specific point in the network, increasing their firing and leading to EV uptake in cells distant from the stimulated area. Notably, in distant areas, such as forebrain or cerebellum, recombination events were not observed, highlighting the highly localized stimulation (Fig. 24). 
A
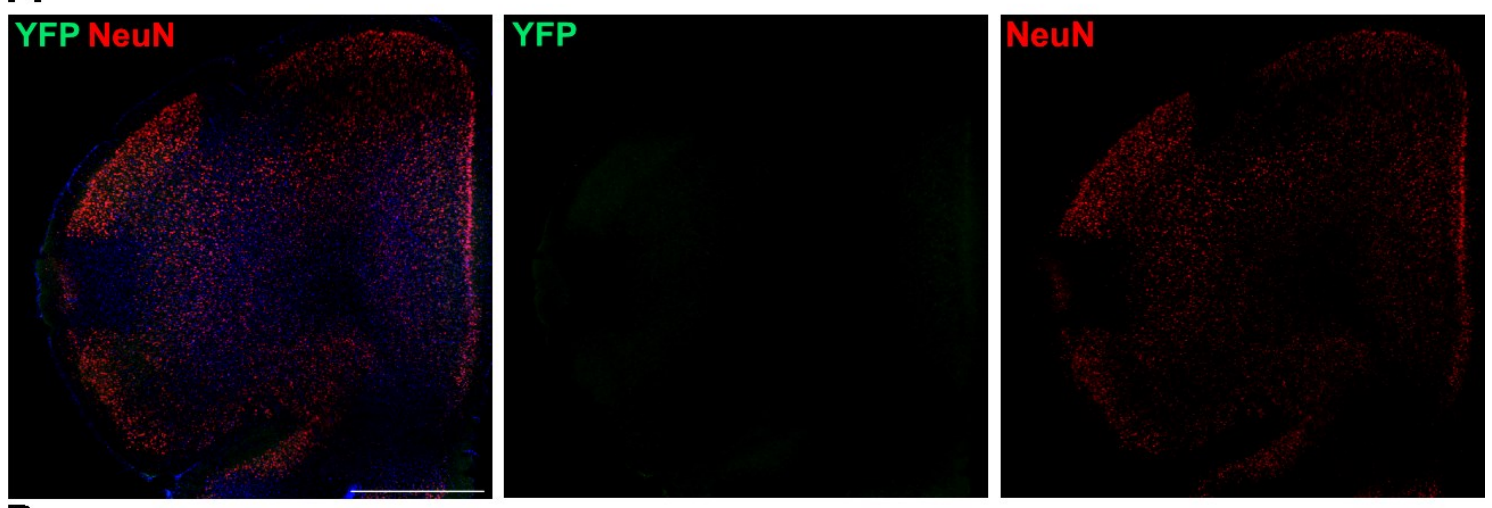

B
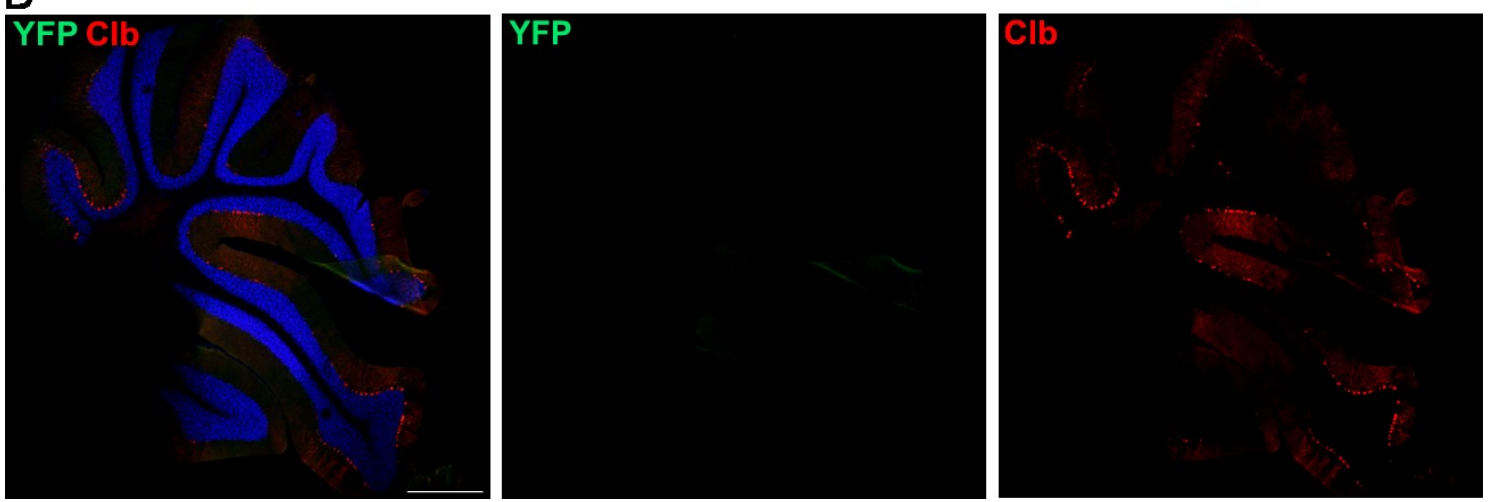

Figure 24. Optogenetic ChR2 stimulation does not lead to marker gene expression in distant areas. (A) No marker gene-positive cells can be observed in the forebrain. (B) No recombination events are observed in the cerebellum. DAPI was used for nuclear counterstain. Scale bars: $1 \mathrm{~mm}$ in A; 500 um in B.

\subsection{Induction of neuronal activity in the hippocampus by novel object placement}

Until now, the results can be regarded as the induction of EV uptake through pathological paradigms or via ectopic stimuli. Next, we wanted to probe whether physiological stimuli would be sufficient to increase neuronal activity thus causing EV uptake.

A non-invasive technique, known as environmental enrichment, refers to enhancing brain stimulation in motor, somatosensory or visual cortex and cognitive zones, in standard housing conditions (Nithianantharajah \& Hannan, 2006). In particular, hippocampus, the most studied region in this thesis, is known to be involved in the formation of contextual memory and it has been shown that addition of novel objects in normal housing cages leads to a selective increase in neuronal early-genes expression, such as c-Fos or Arc (VanElzakker, Fevurly, Breindel, \& Spencer, 2008)(Cleland, Willis, Bartlett, \& Vukovic, 2017). 
Some objects were placed in a housing cage with one to two vav-iCre $x$ Rosa26EYFP mice. After one hour, objects were removed and mice were killed after $48 \mathrm{~h}$, then brains were analysed at different rostro-caudal levels (Fig. 25).

A

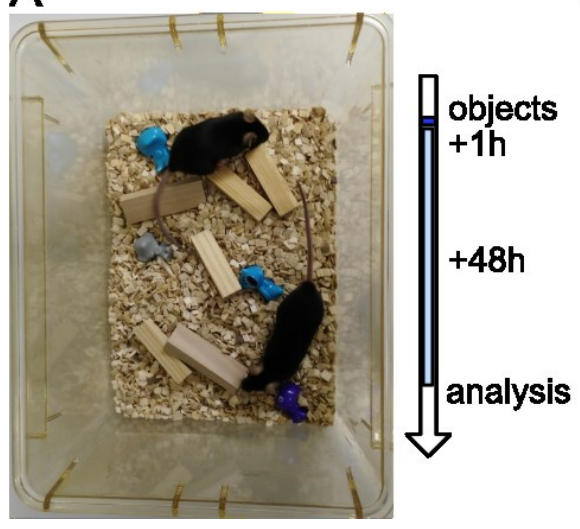

B

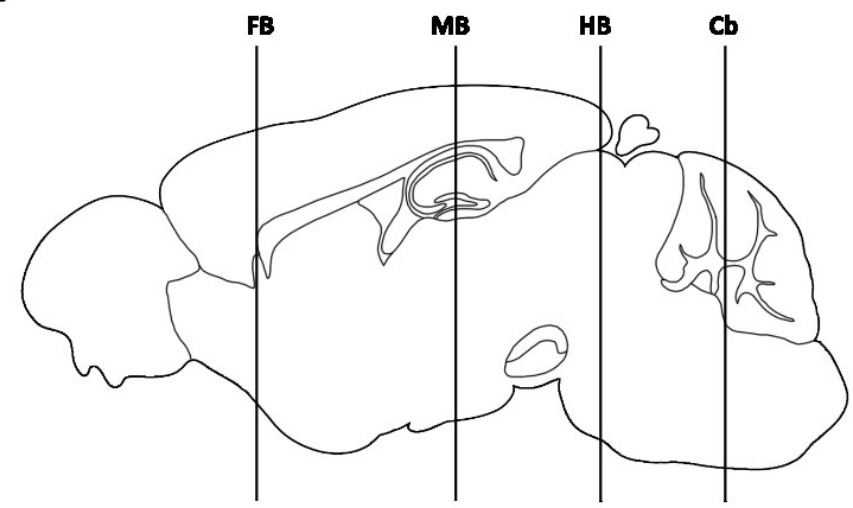

Figure 25. Novel object placement for neuronal stimulation. (A) Photo of a cage with two double transgenic mice with novel objects placed for one hour. (B) Brains were analysed after $48 \mathrm{~h}$ along the entire rostro-caudal length; FB (forebrain), MB (Mid-brain), HB (Hindbrain) and Cb (Cerebellum).

No recombination was found in mice housed without novel objects (Fig. 26A). YFPpositive neurons, counted in animals housed with novel objects, reached an average of 118 cells per $0.01 \mathrm{~mm}^{3}\left( \pm 14.1\right.$ cells per $\left.0.01 \mathrm{~mm}^{3} \mathrm{SD}\right)$ for the dentate gyrus (DG) and 45 cells per $0.01 \mathrm{~mm}^{3}\left( \pm 13.8\right.$ cells per $\left.0.01 \mathrm{~mm}^{3} \mathrm{SD}\right)$ for the CA1 and CA2 hippocampal subfields, with $13.5 \%( \pm 1.8 \% \mathrm{SD})$ of YFP-positive cells being microglia (Fig. 26B, C). 


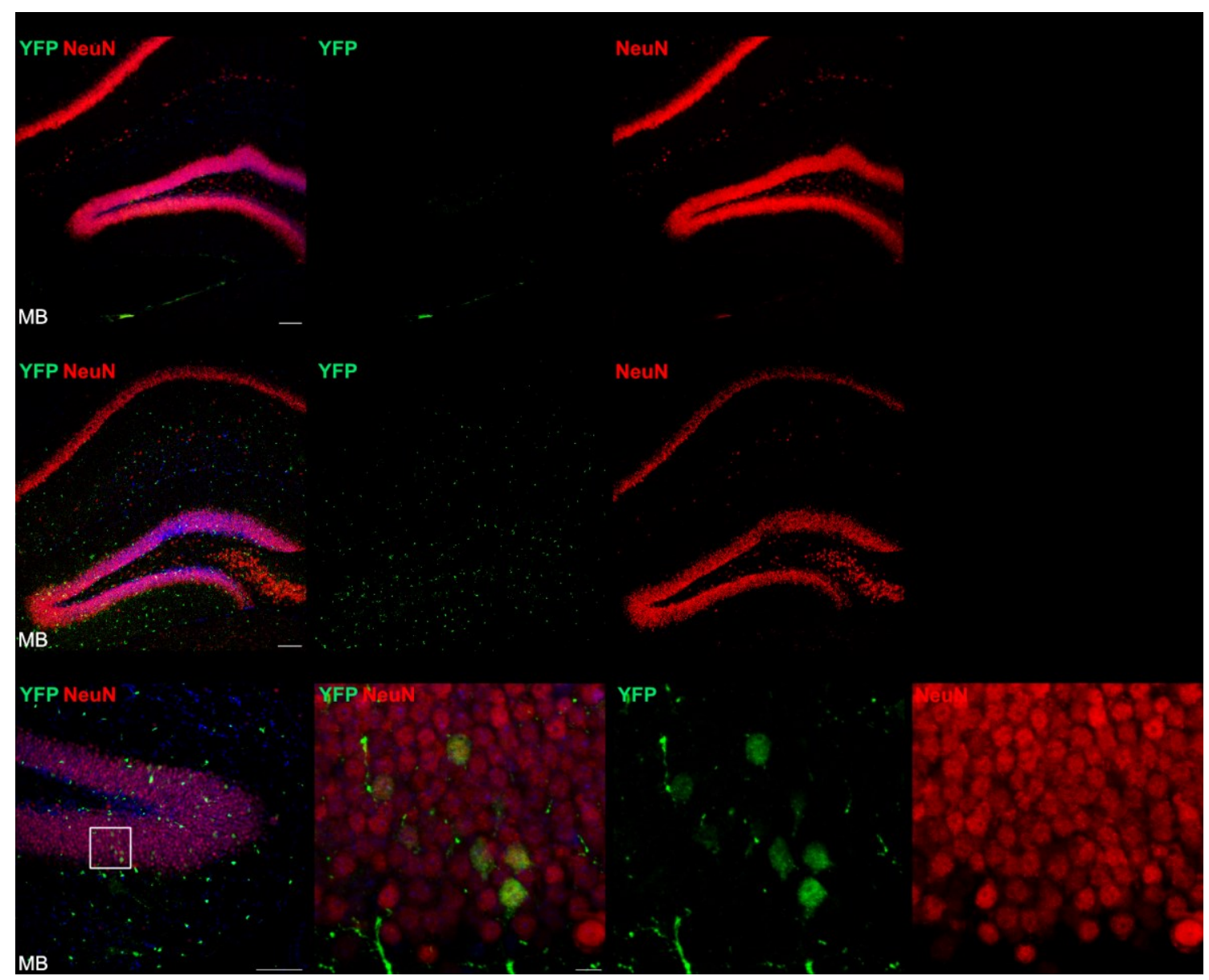

Figure 26. Neuronal stimulation by novel object placement. (A) Mid-brain section of a control mouse without novel object placement showing no marker gene expression. (B) Mid-brain section from a mouse with novel objects showing that recombination occurs predominantly in neurons from hippocampal areas such as DG, CA1 and CA2. (C) High magnification of DG showing marker genepositive neurons, images on the right show further magnification of the area marked with white square. DAPI was used for nuclear counterstain. Scale bars: 100um in A, B; 100um and 10um in C. Recombination events were very rarely or not observed in other brain regions, such as the forebrain, hindbrain or cerebellum, where no neuronal activation would be expected (Fig. 27). 


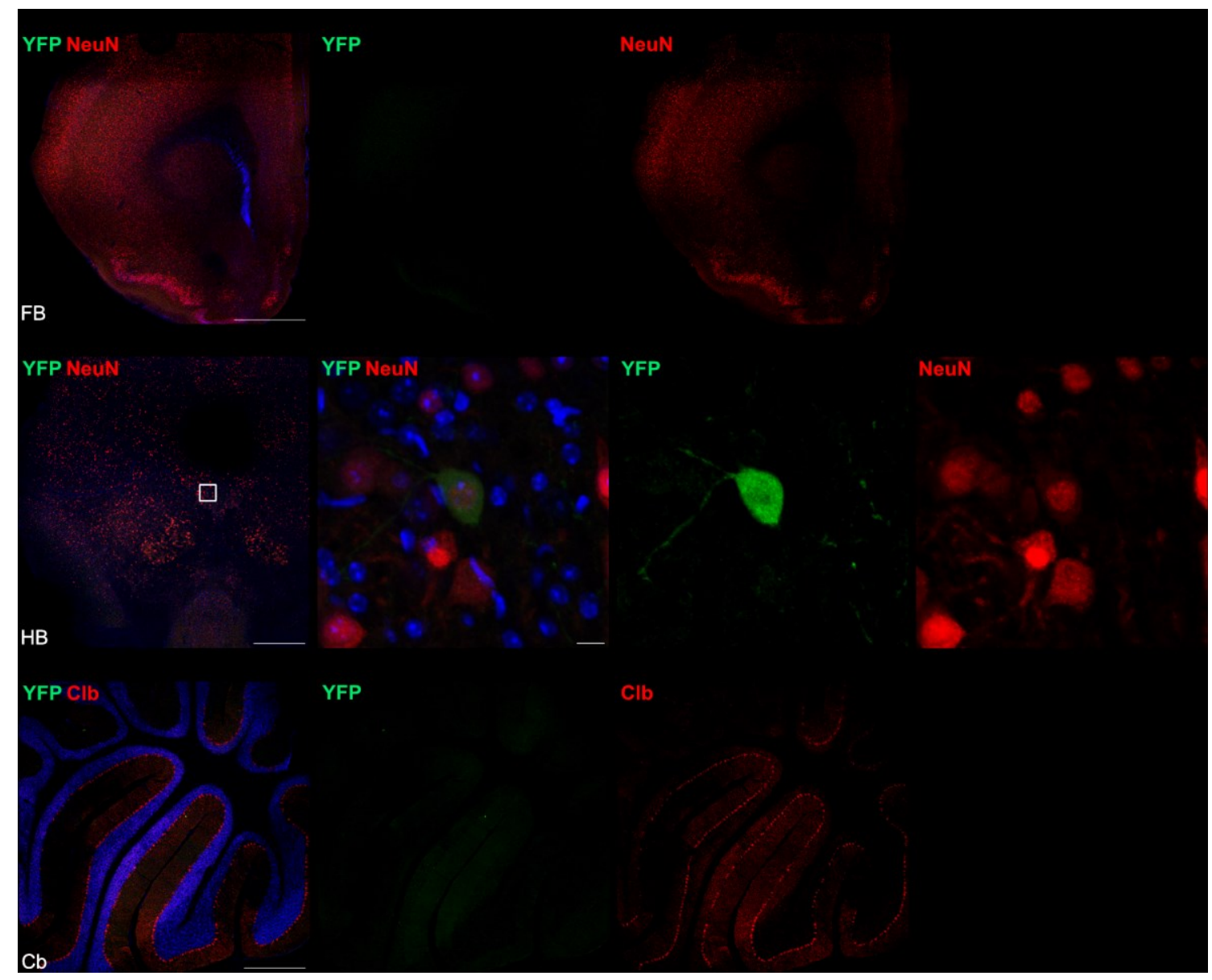

Figure 27. Neuronal stimulation does not extend to distant brain regions. (A) Marker geneexpression was absent in forebrain. (B) Recombination events were very rare in Hindbrain. Only one recombined cell was found from all sections analysed. Images on the right show higher magnification of the area marked with a white square. (C) YFP+ cells were absent in Cerebellum. DAPI was used for nuclear counterstain. Scale bars: $1 \mathrm{~mm}$ in $A ; 500$ um and 10 um in B; 500um in C.

The transient expression of immediate early genes such as c-Fos and Arc is associated with recognition, learning and memory processes. These markers have been commonly used to measure changes in neuronal activity (Gallo, Katche, Morici, Medina, \& Weisstaub, 2018). To study expression of immediate early genes, Rosa26EYFP mice were placed for 1 hour with novel objects and were euthanized immediately after object removal. Hippocampal sections were stained against c-Fos or Arc. The histological analysis showed different distribution of positive cells, with Arc+ cells having a similar pattern to the neuronal recombination (Fig. 28). 


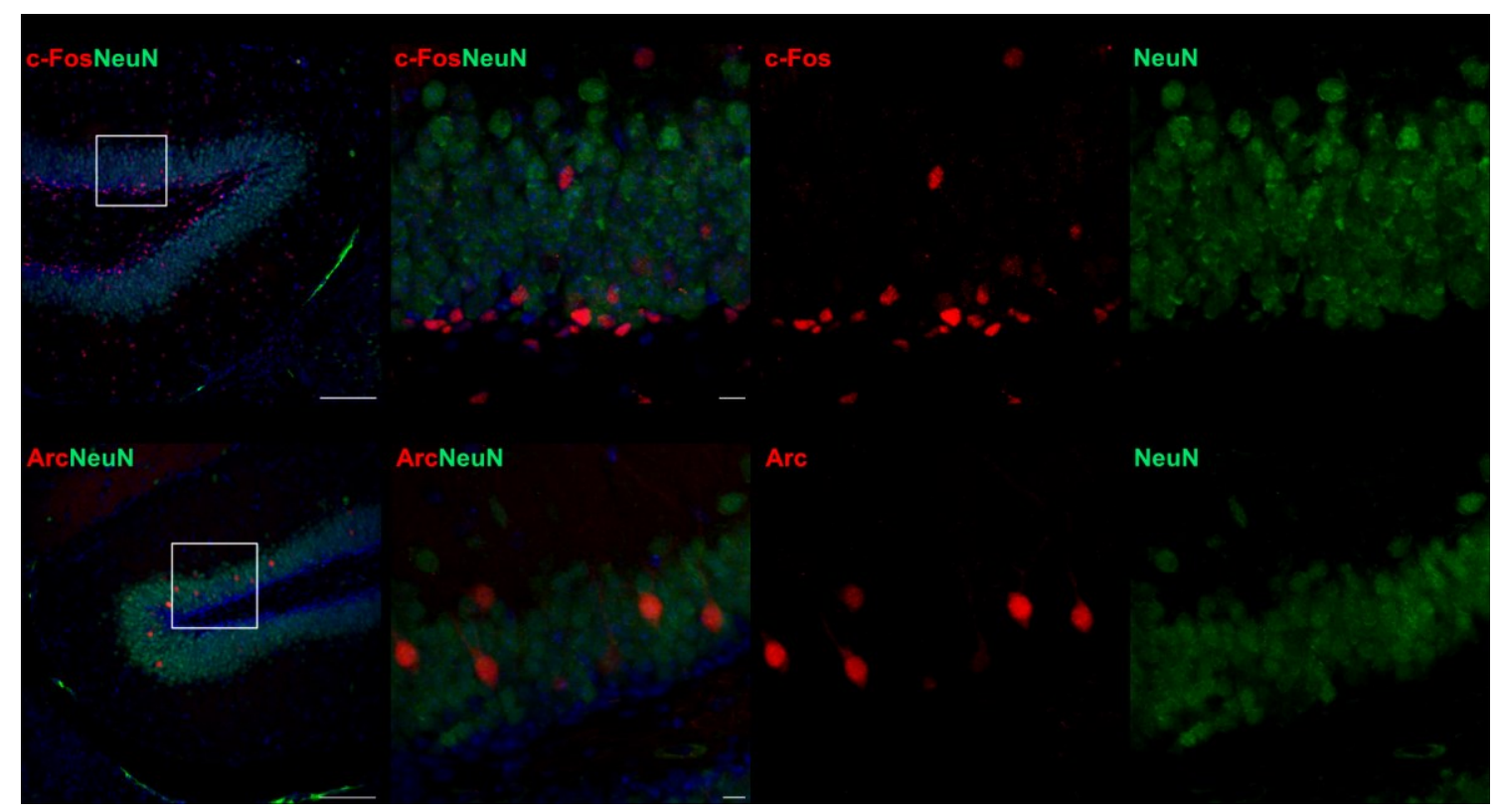

Figure 28. Distribution pattern of Arc and c-Fos after novel object placement. Dentate gyrus sections from Rosa26EYFP mice euthanized directly after novel object placement. (A) Expression and distribution of c-Fos in DG. (B) Expression and distribution of Arc in DG. Cell distribution is similar to the one observed in recombined cells. Images on the right show higher magnification of the areas marked with white squares. DAPI was used for nuclear counterstain. Scale bars: 100um and 10um in $A, B$.

In summary, these experiments show that EV uptake can be triggered by neuronal activity both in pathological as well as in physiological conditions. An important question, arising from these results, is whether EV uptake is beneficial or detrimental for cells. To address this question, multiple approaches were used in vitro.

\subsection{EV uptake by prenatal neurons from Rosa26-EYFP mouse in vitro}

In order to study possible effects that EVs have on cells, neural cells were isolated and cultured from prenatal mice (Seibenhener \& Wooten, 2012). After cells were plated, their growth was monitored (Fig. 29) and after 10 days, cells were used in experiments. 

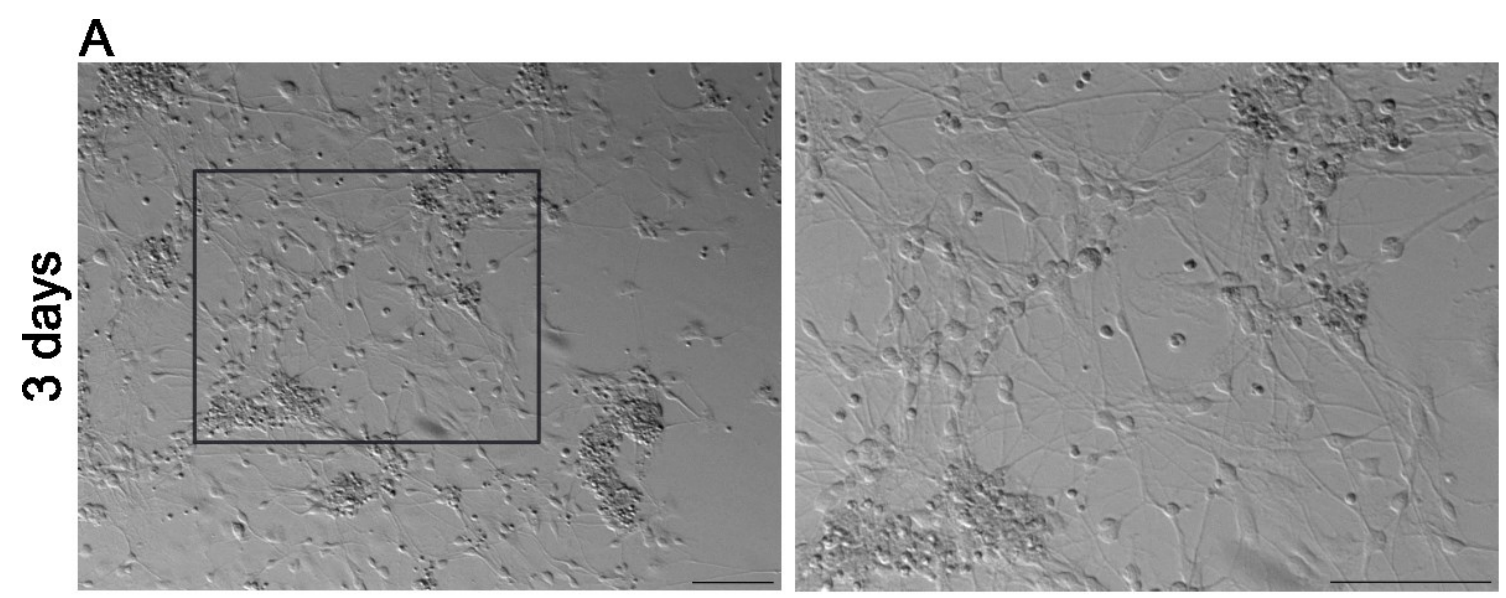

B
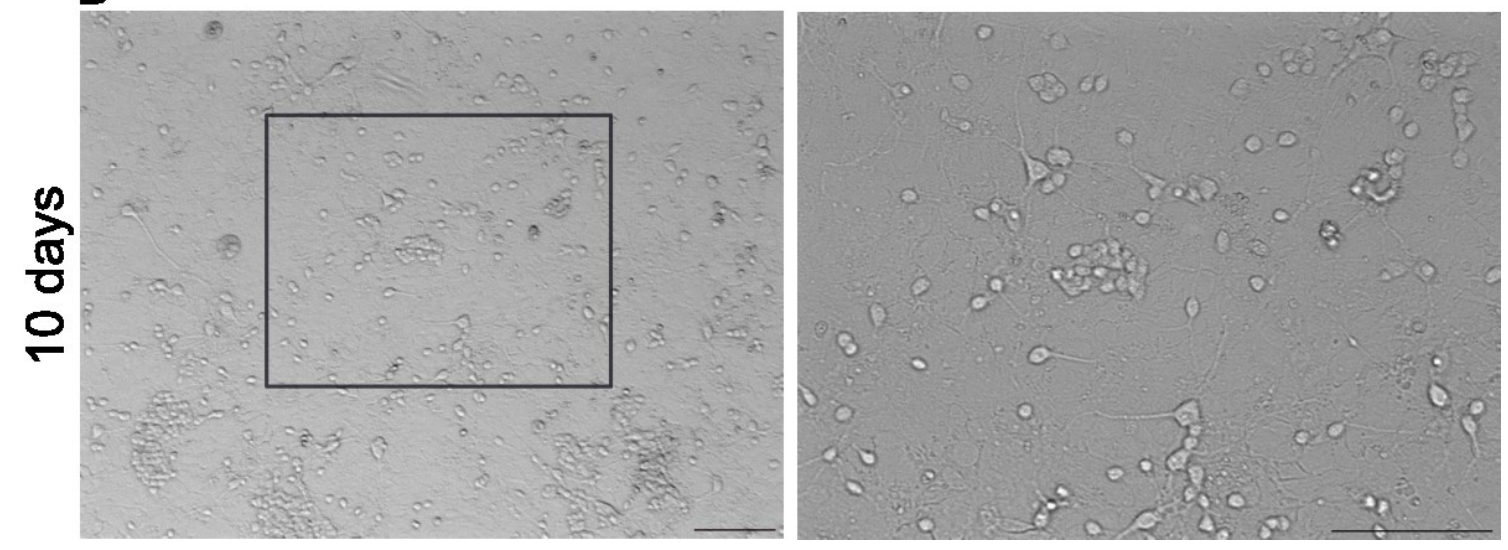

Figure 29. Growth over time of neurons isolated from prenatal Rosa26EYFP mouse. Hippocampal neurons isolated from prenatal mouse brain and cultured 3 days after plating $(A)$ and 10 days after plating (B). Neural processes are already observable after 3 days of plating. Images on the right show higher magnification of areas marked with black squares. Scale bars: 100um in A, B.

Expression of different markers was checked by immunofluorescence, such as NeuN for fully differentiated neurons, GFAP for astrocytes and Tuj 1 for immature neurons (Fig. 30).
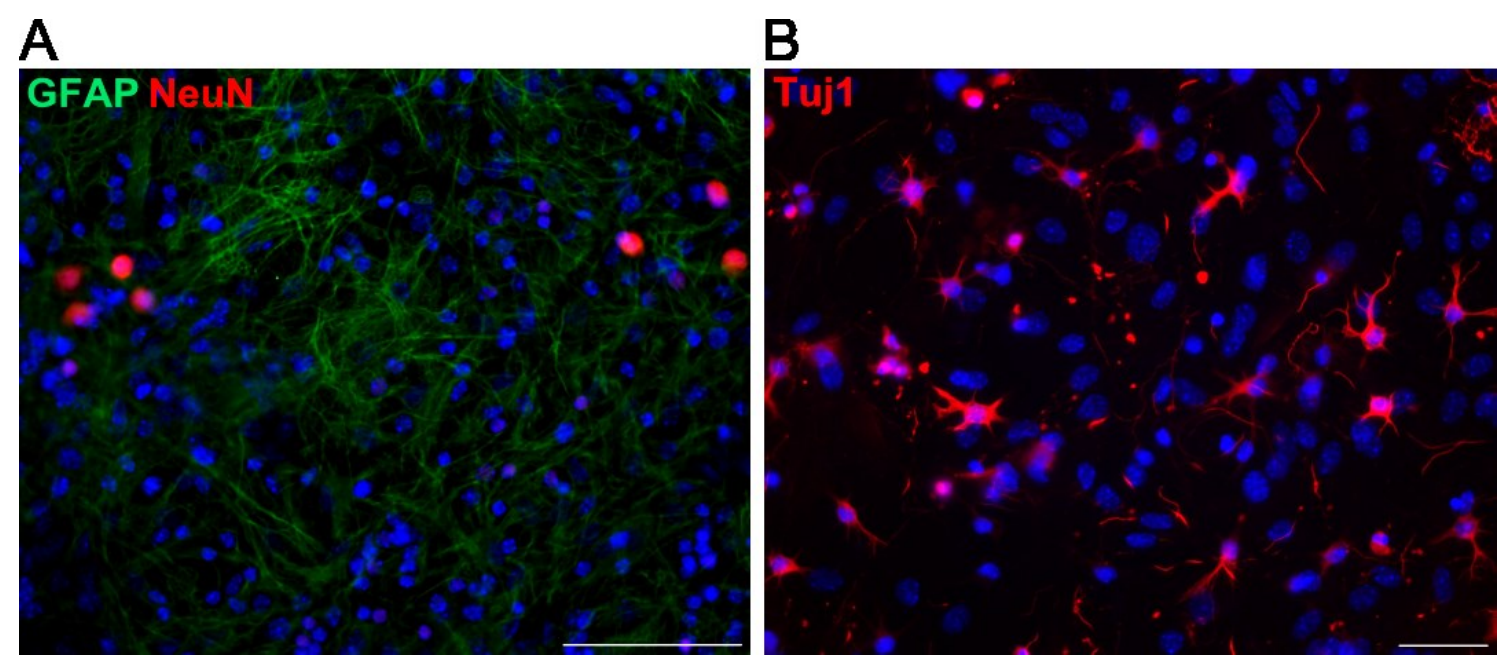
Figure 30. Expression markers of neurons isolated from prenatal Rosa26EYFP mouse. Hippocampal neurons were stained for GFAP and $\operatorname{NeuN}(A)$ and Tuj1 (B). Note that the population is heterogeneous (different cell types in different proportions). DAPI was used for nuclear counterstain. Scale bars: 100 um in $A ; 50$ um in B.

Having a heterogeneous population instead of only one cell type mimics the physiological in vivo context, where EVs are available to all cells and not only to a specific cell type. Different concentrations of Cre containing EVs were added to cells and incubated for different time. Cells were challenged using increasing concentrations of $\mathrm{H}_{2} \mathrm{O}_{2}$ (200uM and $\left.500 u M\right)$ and incubated with or without EVs. After FACS analysis, the percentage of viable cells in comparison with the control decreased to a lesser extent in cells, co-incubated with EVs. Prenatal neurons that were not treated with $\mathrm{H}_{2} \mathrm{O}_{2}$ showed a viability of $99.7 \%$. The treatment with $\mathrm{H}_{2} \mathrm{O}_{2}$ decreased the viability to $67.7 \%$ whereas the same treatment together with EVs maintained the higher viability $(70.8 \%)$. The same happened when cells were treated with $1 \mathrm{mM} \mathrm{H}_{2} \mathrm{O}_{2}$, the viability was $58.9 \%$ and together with $\mathrm{EVs}$ was $68.9 \%$, indicating a possible beneficial rescuing effect (Fig. 31).
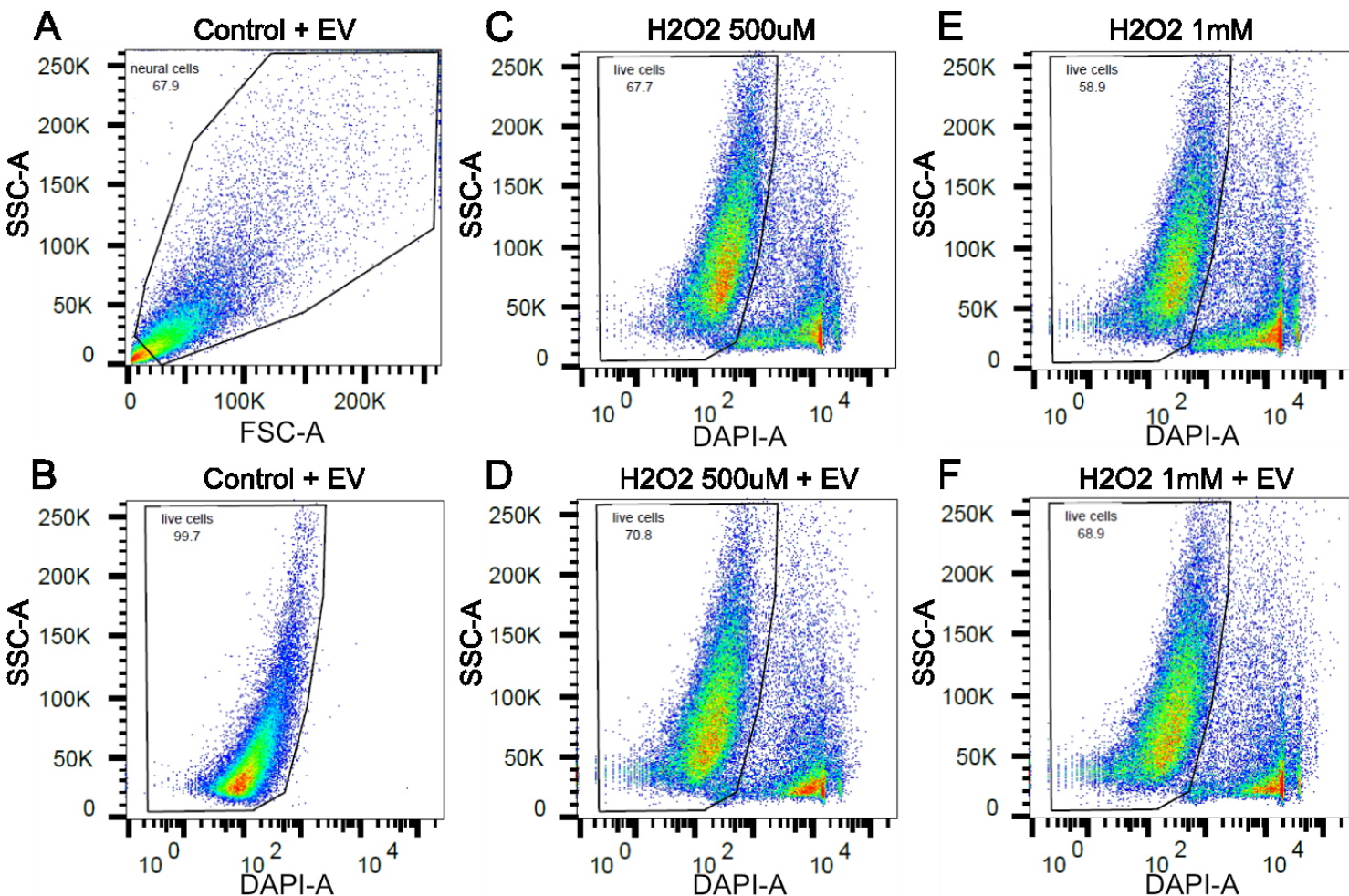

Figure 31. Evaluation of cell viability after $\mathrm{H}_{2} \mathrm{O}_{2}$ and $\mathrm{EV}$ treatment in prenatal neurons. (A) Distribution of prenatal neurons according to size and granularity. The irregular gate delineates the cell population. (B) Percentage of live cells counterstaining with DAPI. (C) Prenatal neurons incubated with $500 u m \mathrm{H}_{2} \mathrm{O}_{2}$ but not incubated with EVs. (D) Prenatal neurons incubated with 500um $\mathrm{H}_{2} \mathrm{O}_{2}$ and with EVs. (E) Prenatal neurons incubated with $1 \mathrm{mM} \mathrm{H}_{2} \mathrm{O}_{2}$ but not incubated with EVs. 
Prenatal neurons incubated with $1 \mathrm{mM} \mathrm{H}_{2} \mathrm{O}_{2}$ and with $\mathrm{EVs}$. Live cells percentages are shown in each FACS plot.

\subsection{EV uptake by SH-SY5Y cells in vitro}

SH-SY5Y is a human neuroblastoma cell line originally obtained from a bone marrow biopsy of a neuroblastoma patient (Biedler, Helson, \& Spengler, 1973). This cell line is characterized by its neuronal properties and its easy maintenance in culture. They express different neuronal markers, such as MAP-2, NF-H or NF-M.

SH-SY5Y cells are widely used because a mostly pure population of neuron-like cells can be obtained. Following different protocols, cells were maintained, expanded and differentiated using retinoic acid, which inhibited cell growth and promoted differentiation towards neuronal phenotype, and BDNF, which enhances the differentiating effects of RA and brings cells to form networks and neuritic arborisations (Encinas et al., 2002; Teppola, Sarkanen, Jalonen, \& Linne, 2016). The differentiation was followed day by day as shown in the figure 32. Afterwards, cells were maintained in these conditions and used for further experiments.
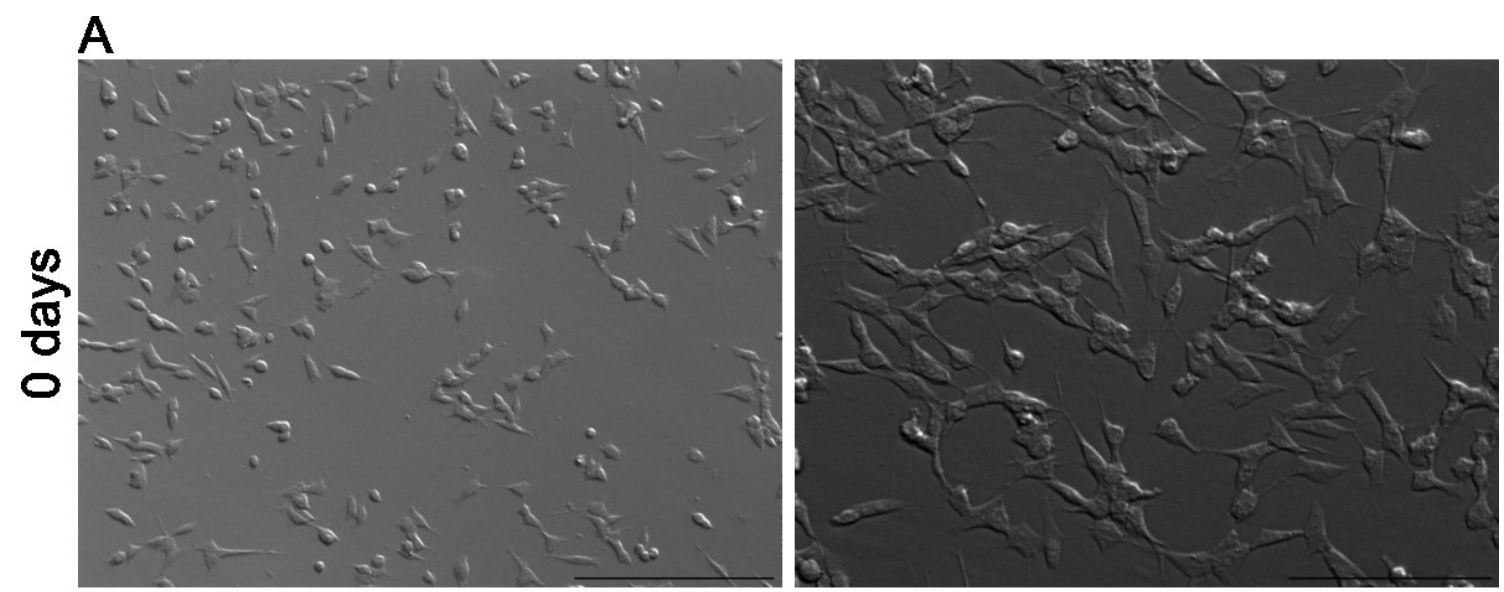

\section{B}
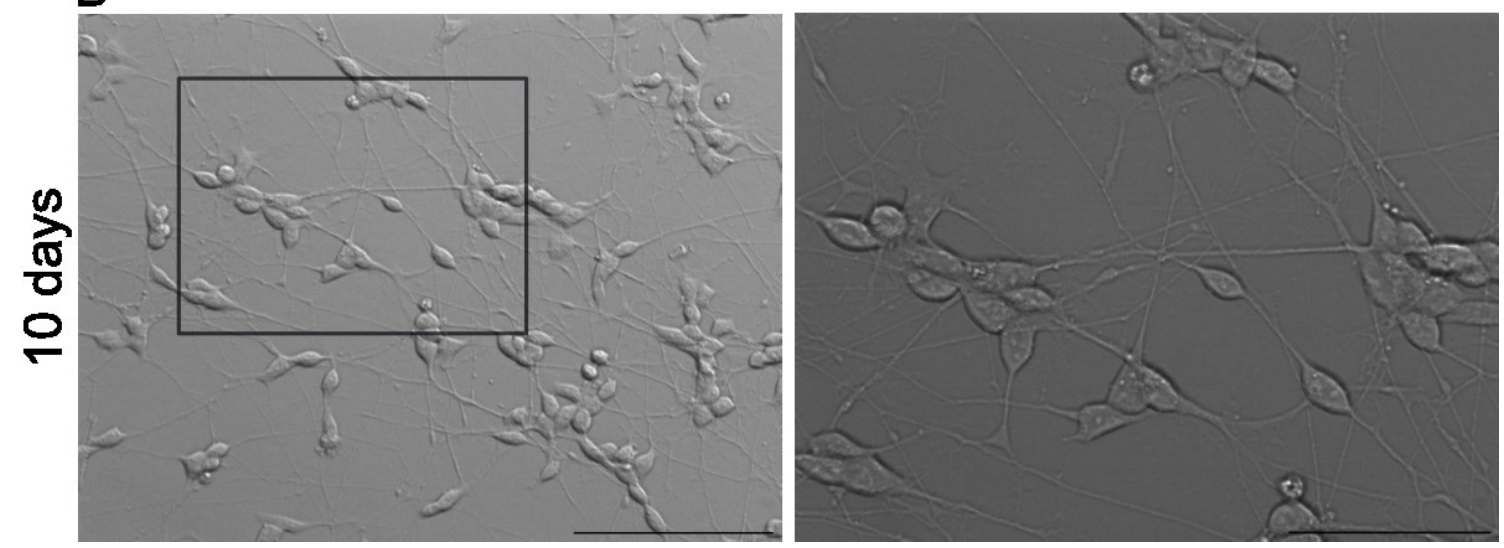

Figure 32. Growth and differentiation over time of SH-SY5Y cells. (A) SH-SY5Y cells one day after plating and before treatment with RA and BDNF. (B) Cells after five days treatment with RA and 
five more days with BNDF. Neural processes are already visible after 5 days of culture. Images on the right show higher magnification of areas marked with a black square. Scale bars: 100um and 50 um in $A, B$.

Different expression markers, listed above, were checked using fluorescence microscope (Fig. 33).
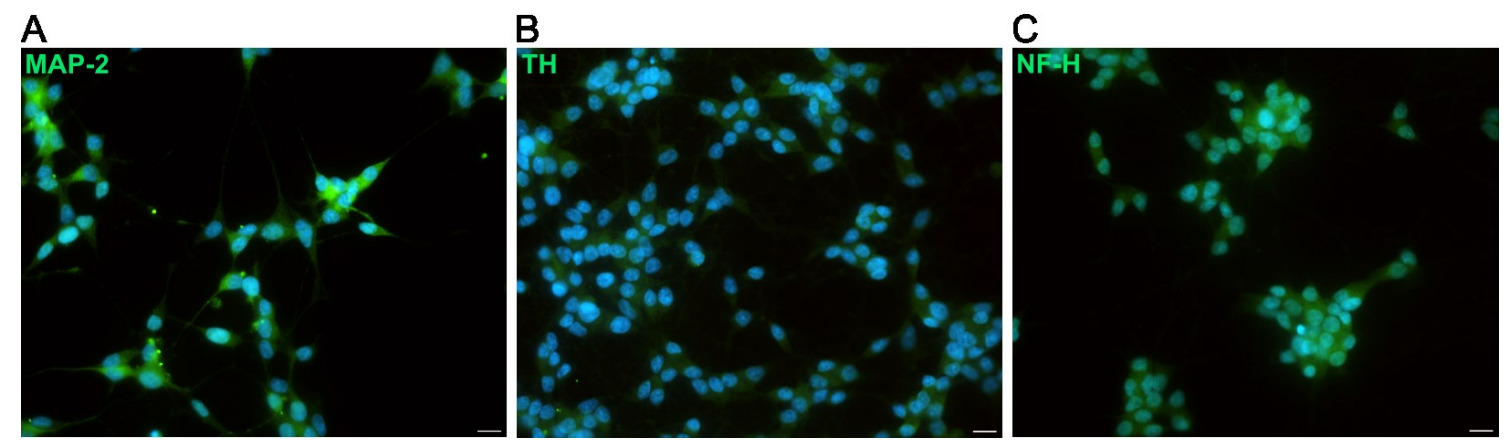

Figure 33. Expression markers of SH-SY5Y cells after differentiation. After cell plating, incubation with RA and BDNF was performed. Cells were evaluated for different expression markers such as MAP-2 (A), TH (B) and NF-H (C) for further studies. All cells expressed the same markers, therefore, this cell population can be described as homogeneous. DAPI was used for nuclear counterstain. Scale bar 10um for A, B and C.

SH-SY5Y cells were treated with different concentrations of J774 EVs, previously labelled with C6-NBD ceramide, a fluorescent analogue of ceramide, which stains membrane and Golgi apparatus (Rosenwald \& Pagano, 1993). C6-NBD incubation gives rise to a labelled EV population and the possibility to follow EV uptake in a receiving cell line. Cells were maintained with EVs for different time periods. The optimal EV dilution and incubation time were established using FACS analysis and plate reader. Live cells were quantified and gated after counterstaining with DAPI. Based on the results, the EV dilution subsequently used was 1:25 and cells were left in contact with EVs for 24 hours to achieve maximum uptake (Fig. 34). 
A

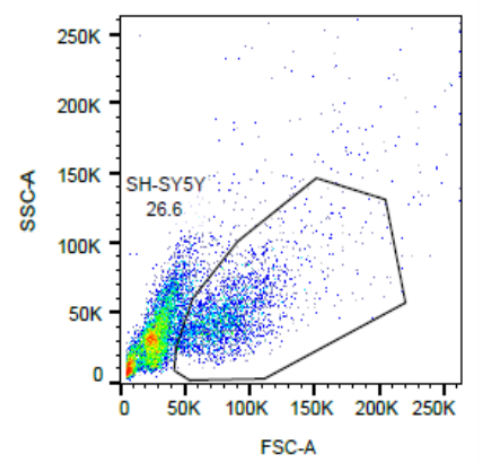

D

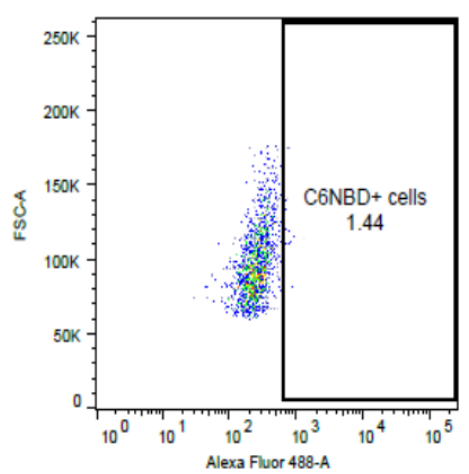

G

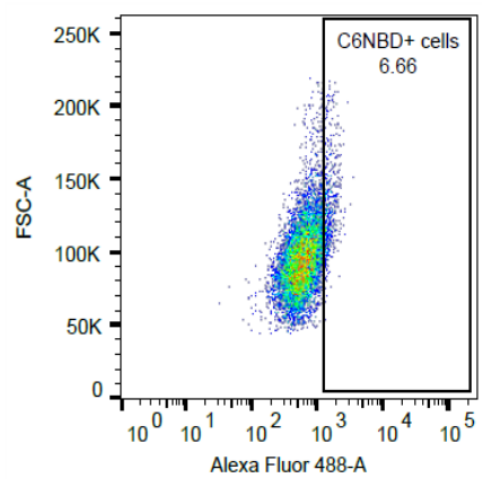

B

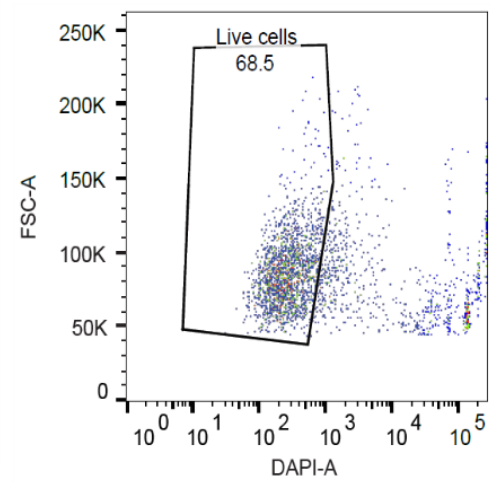

$\mathrm{E}$

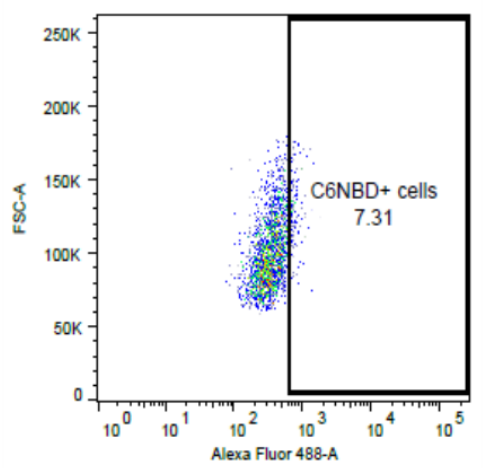

$\mathrm{H}$

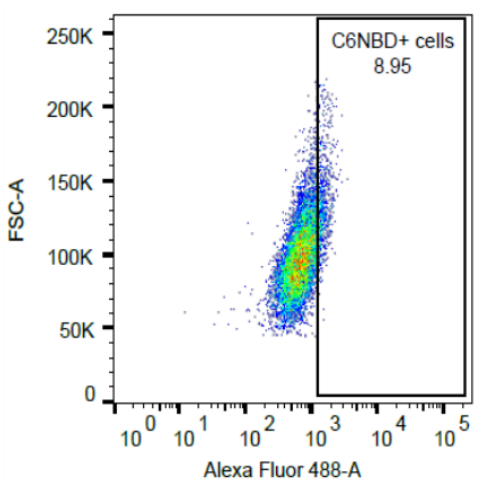

C

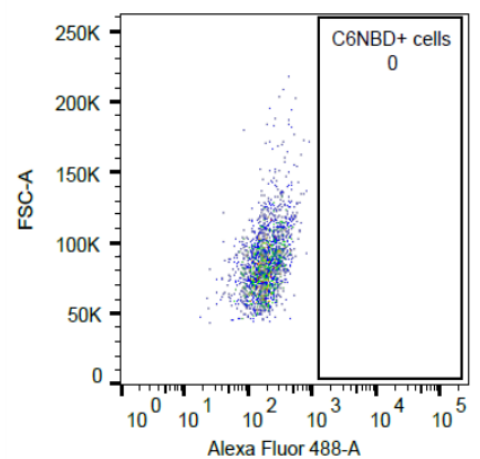

$\mathrm{F}$

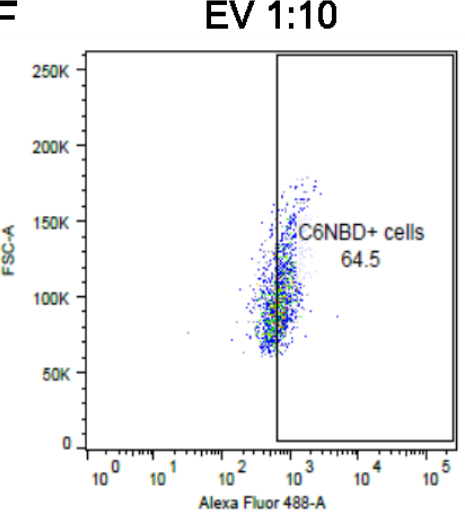

Figure 34. SH-SY5Y gating strategy for FACS analysis and EV titration. (A) Distribution of SHSY5Y cells according to size and granularity. The irregular gate delineates the cell population. (B) Percentage of live cells counterstaining with DAPI. (C) Presence of C6NBD (green, Alexa 488) from EVs in cells that were not incubated with EVs. (D, E and F) SH-SY5Y cells incubated with higher volumes of EVs; $1: 100,1: 50$ and 1:10 respectively. (G) SH-SY5Y cells incubated with 1:25 EV dilution for 6 hours. (H) SH-SY5Y cells incubated with 1:25 EV dilution for 24 hours. (I) Absorbance of EV dilutions at different timepoints with plate reader.

Once the technique was established and EV uptake was detectable, further experiments involving $\mathrm{SH}-\mathrm{SY} 5 \mathrm{Y}$ cells were performed. Here, cells were treated with different substances, such as $\mathrm{KCl}$ (Potassium chloride), LPS, $\mathrm{H}_{2} \mathrm{O}_{2}$ or $\mathrm{KA}$, affecting their firing and altering their physiological state. SH-SY5Y cells also present cathecholaminergic and dopaminergic activity, being widely used as a model in 
several studies of Parkinsons disease, as human dopaminergic primary neurons are difficult to obtain and to maintain (Xicoy, Wieringa, \& Martens, 2017). Because of this feature, and because of the fact that epoxomicin is used to impair the ubiquitin proteasome system, SH-SY5Y cells were additionally treated with Epoxomicin (Fig. 35).

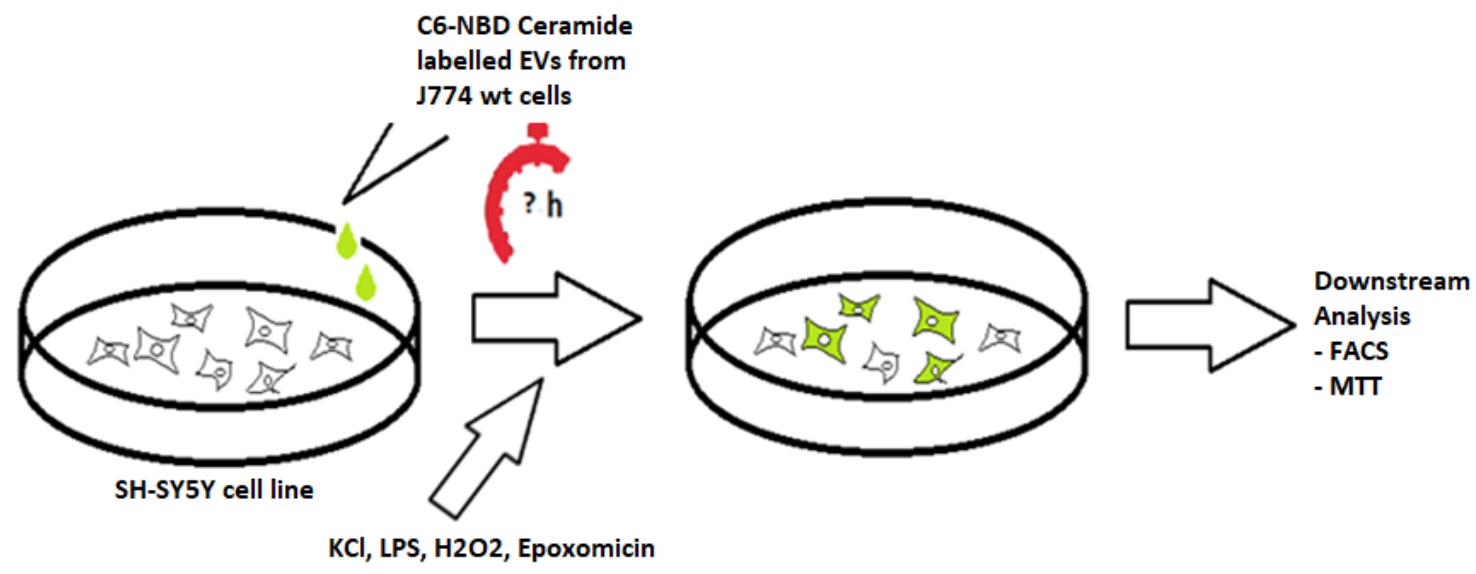

Figure 35. Schematic representation of the method to study the effects in EV uptake. SH-SY5Y cells were treated with different substances, affecting the electrical activity or physiological state, together with labelled-EVs from J774 cells for a determined time. Afterwards, the outcome is analysed via FACS or via a metabolic assay (MTT).

Next, all in vitro experiments with their respective analyses will be explained in detail. In order to alter neuronal electrical activity in vitro, SH-SY5Y cells were incubated with different concentrations of $\mathrm{KCl}, 20 \mathrm{mM}, 40 \mathrm{mM}$ and $100 \mathrm{mM}$ for 6 hours or 24 hours. $\mathrm{KCl}$ induces depolarization of cell membranes and is associated with $\mathrm{EV}$ secretion (Frühbeis et al., 2013). In this paradigm, both 6 and 24 hours incubation with increasing $\mathrm{KCl}$ concentrations reduced the uptake of $\mathrm{EV}$ in SH-SY5Y, with the exception of $100 \mathrm{mM}$ after $24 \mathrm{~h}$, were an increase in uptake was observed (Fig. 36). 
A

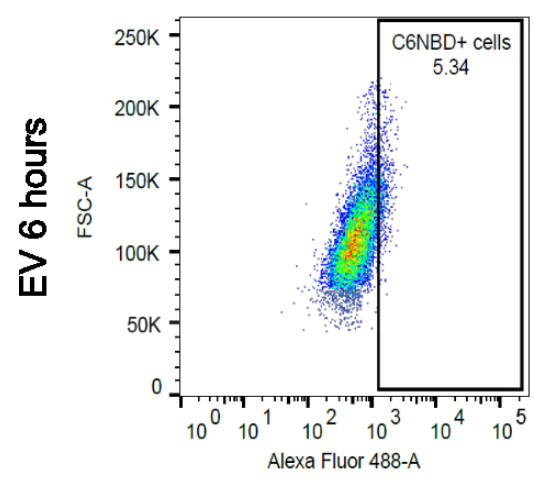

B

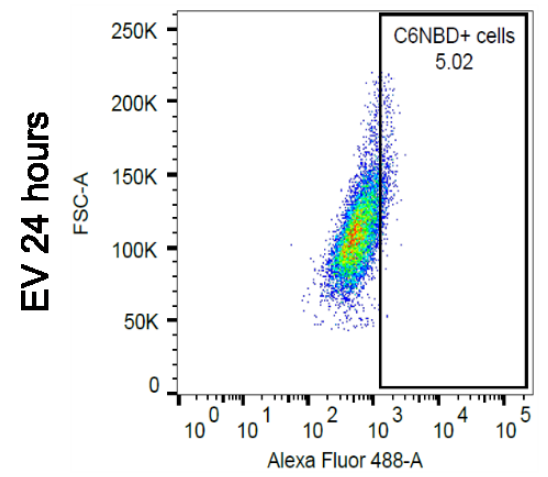

$\mathrm{KCl} 40 \mathrm{mM}$
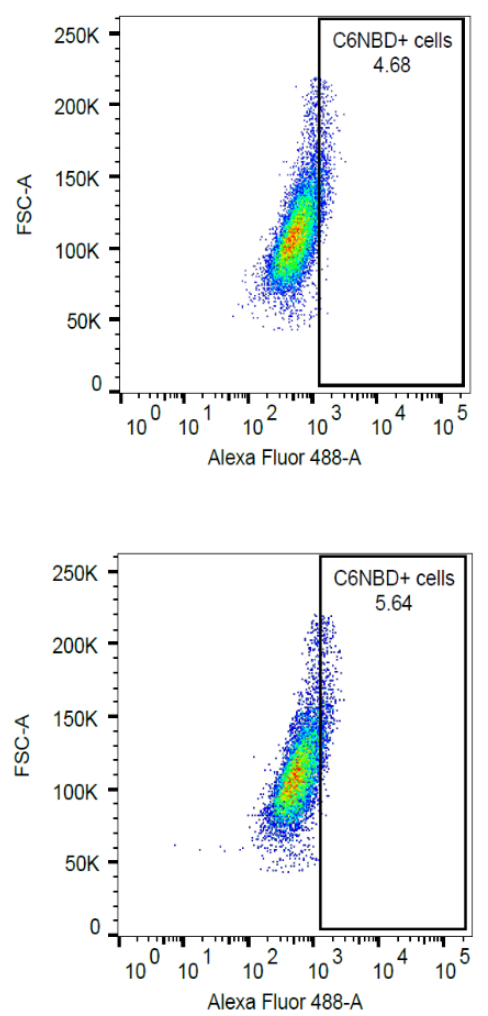

$\mathrm{KCl} 100 \mathrm{mM}$
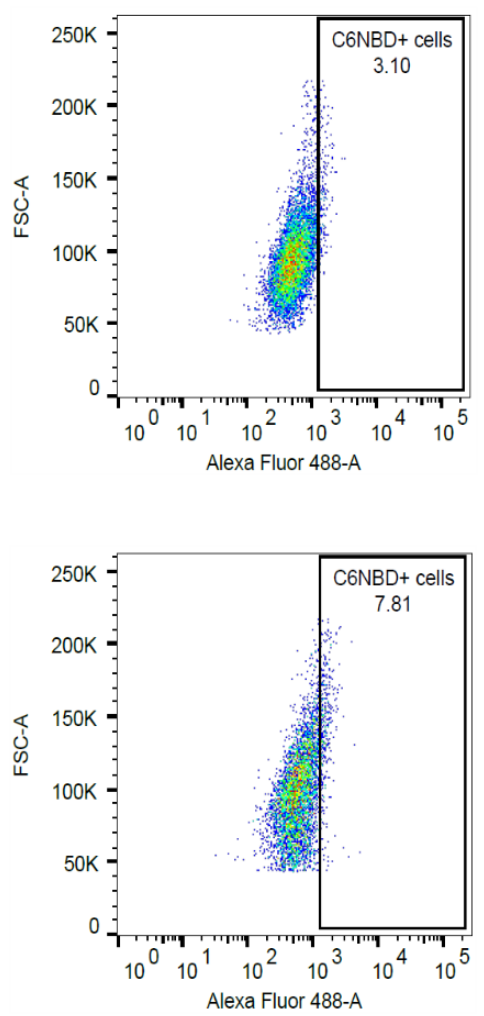

Figure 36. Decrease of EV uptake in SH-SY5Y cells treated with $\mathrm{KCl}$ for $\mathbf{6}$ and 24 hours. (A) EV uptake in SH-SY5Y cells is decreased, compared to control ( $G$, in the above figure) after increasing concentrations of $\mathrm{KCl}$. (B) EV uptake is decreased, compared to control $(\mathrm{H}$, in the above figure) after increasing concentrations of $\mathrm{KCl}$. EV uptake is increased in the treatment with $\mathrm{KCl} 100 \mathrm{mM}$, although less than in control conditions.

This result can probably be explained as a result of depolarization and its link with exocytosis which does not promote endocytosis (EV uptake). High $\mathrm{KCl}$ concentrations could promote membrane destabilization, which could explain an easier entrance of EV, thus the observed increased uptake. Using DAPI counterstaining, cell viability was studied, being for control conditions $77.6 \% \pm 0.4$ $\mathrm{SD}$; for $\mathrm{KCl} 20 \mathrm{mM}$ was $77.3 \% \pm 1.3 \mathrm{SD}$; for $\mathrm{KCl} 40 \mathrm{mM}$ was $81.3 \pm 6.1 \mathrm{SD}$ and for $\mathrm{KCl}$ $100 \mathrm{mM}$ was $64.8 \pm 9.8 \mathrm{SD}$, reflecting the fact that high $\mathrm{KCl}$ concentrations could affect cell integrity.

In a different experiment, SH-SY5Y cells were treated with LPS at different concentrations for 24 hours. LPS has a detrimental effect in cells in vitro, as it promotes inflammatory processes causing toxicity and affects cell viability (Pandur et al., 2019). In order to correlate the in vivo and in vitro results, EV uptake after LPS treatment was checked (Fig. 37). 


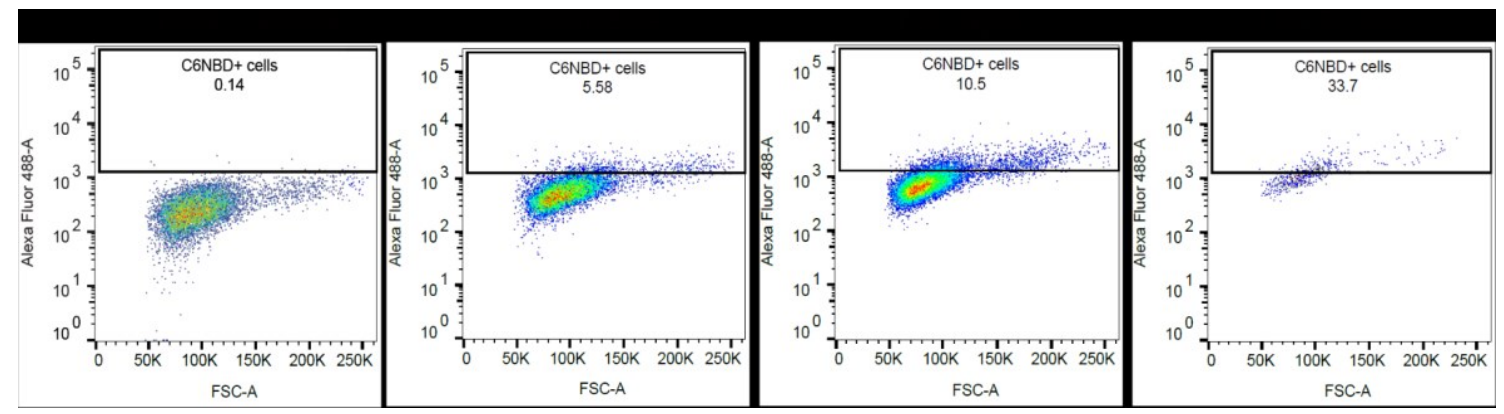

Figure 37. Increasing LPS concentrations promote EV uptake in SH-SY5Y cells. (A) EV uptake in SH-SY5Y cells in control conditions without and with EVs. (B) EV uptake is increased compared to control after treatment with LPS $1 \mathrm{ug} / \mathrm{ml}$. (C) EV uptake is further increased after treatment with LPS $5 \mathrm{ug} / \mathrm{ml}$.

Increasing LPS concentrations of $1 \mathrm{ug} / \mathrm{ml}$ and $5 \mathrm{ug} / \mathrm{ml}$, caused an increase in EV uptake to $10.5 \%$ and $33.7 \%$ respectively compared to control $(5.58 \%)$. This observation might be related to elevated cell stress and the intervention of EVs to protect and avoid cell death (O'Neill, Gilligan, \& Dwyer, 2019). This experiment gives more credence to the fact that $E V$ uptake could be a mechanism to evade conditions of cell stress.

Hydrogen peroxide is a substance widely used to induce oxidative stress and cell damage (Guan et al., 2017), and is a good model to complement the results, obtained with LPS. SH-SY5Y cells were treated with $\mathrm{H}_{2} \mathrm{O}_{2}$ at a concentration of $25 \mathrm{uM}$ and 50uM without and with EVs and the uptake was reduced after 24 hours. The treatment with EVs only showed an uptake of $15.2 \%$ compared to EVs+25uM and $50 \mathrm{uM} \mathrm{H}_{2} \mathrm{O}_{2}$ with $6.13 \%$ and $4.39 \%$ respectively (Fig. 38 ).

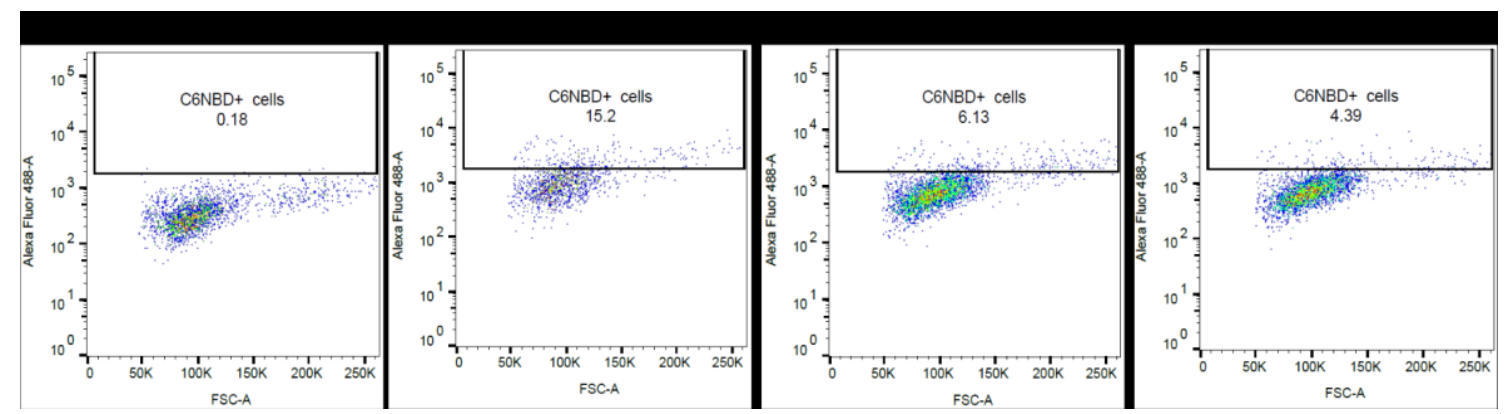

Figure 38. Increasing $\mathrm{H}_{2} \mathrm{O}_{2}$ concentrations decrease $\mathrm{EV}$ uptake in $\mathrm{SH}-\mathrm{SY} 5 \mathrm{Y}$ cells. (A) EV uptake in SH-SY5Y cells in control conditions. (B) EV uptake is decreased compared to control after treatment with $\mathrm{H}_{2} \mathrm{O}_{2} 25 \mathrm{uM}$. (C) EV uptake is further decreased after treatment with $\mathrm{H}_{2} \mathrm{O}_{2} 50 \mathrm{uM}$. 
These results describe a negative effect caused by $\mathrm{H}_{2} \mathrm{O}_{2}$ on the uptake of EVs. Although $\mathrm{H}_{2} \mathrm{O}_{2}$ concentrations were not high enough to have an effect in cell viability, the outcome is different in comparison to LPS treatment. There is evidence that relates $\mathrm{H}_{2} \mathrm{O}_{2}$ with impairments in neuronal excitability (Ohashi et al., 2016), and going back to the hypothesis that EV uptake occurs depending on the status of activation of a cell, the decreased uptake could be explained.

To affect the electrical activity of the cells in culture, SH-SY5Y cells were treated with increasing concentrations of KA. It is known that SH-SY5Y cells express kainate receptors and that the treatment with KA can affect cell viability (Cannarsa, Landuzzi, Cavina, Candeletti, \& Romualdi, 2008; Connor, Yeo, \& Henderson, 1996). $18.5 \%$ of SH-SY $5 Y$ cells took up EVs when incubated for 24 hours. When cells were treated with $25 \mathrm{uM} \mathrm{KA}, 37.9 \%$ of cells took up EVs and a $32.4 \%$ when treated with 50uM KA (Fig. 39).
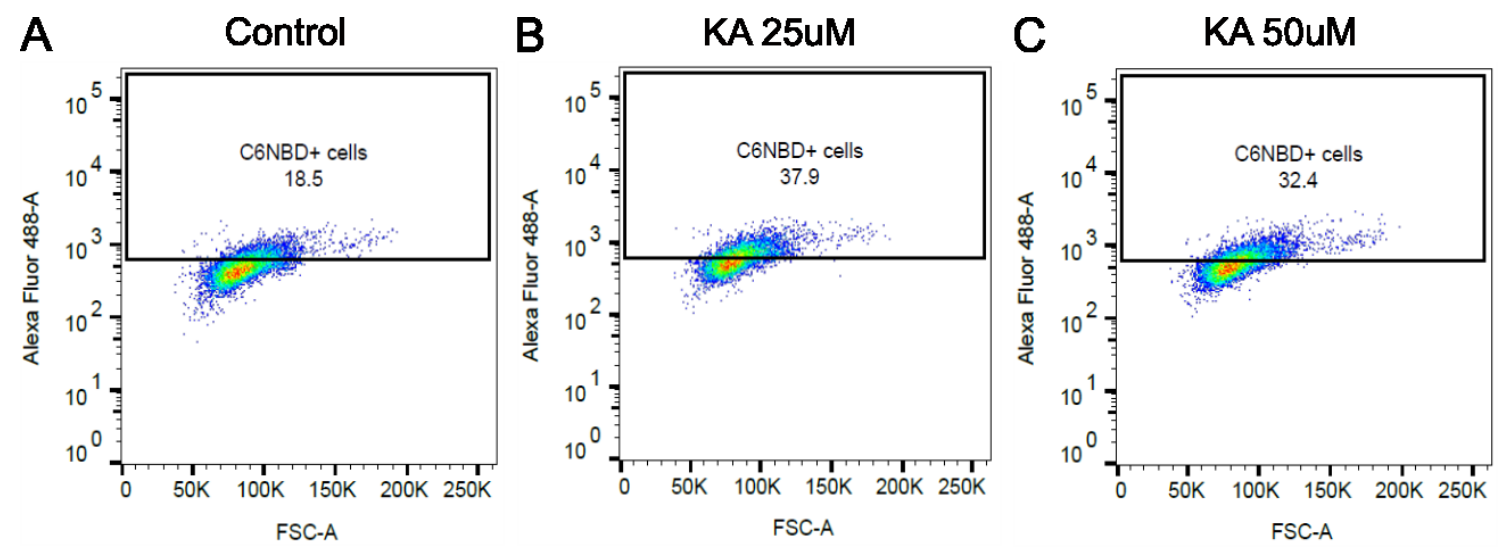

Figure 39. KA increases EV uptake in SH-SY5Y cells. (A) EV uptake in SH-SY5Y cells in control conditions. (B) EV uptake is increased after treatment with KA 25uM. (C) EV uptake is increased compared to control after treatment with KA 50uM and slightly decreased compared to KA 25uM.

This shows a clear response to KA in the uptake of EVs. There is a small decrease in EV uptake when KA concentration increases, although no effect in cell viability was observed. This result is consistent with in vivo experiments.

Finally, SH-SY5Y cells were treated with epoxomicin. Different concentrations of epoxomicin were used and effects checked at different timepoints. After 6 hours treatment, increasing epoxomicin concentrations led to decreased EV uptake. After 24 hours, the same phenomenon was observed apart from 200nM, in which case an increase was detected (Fig. 40). 


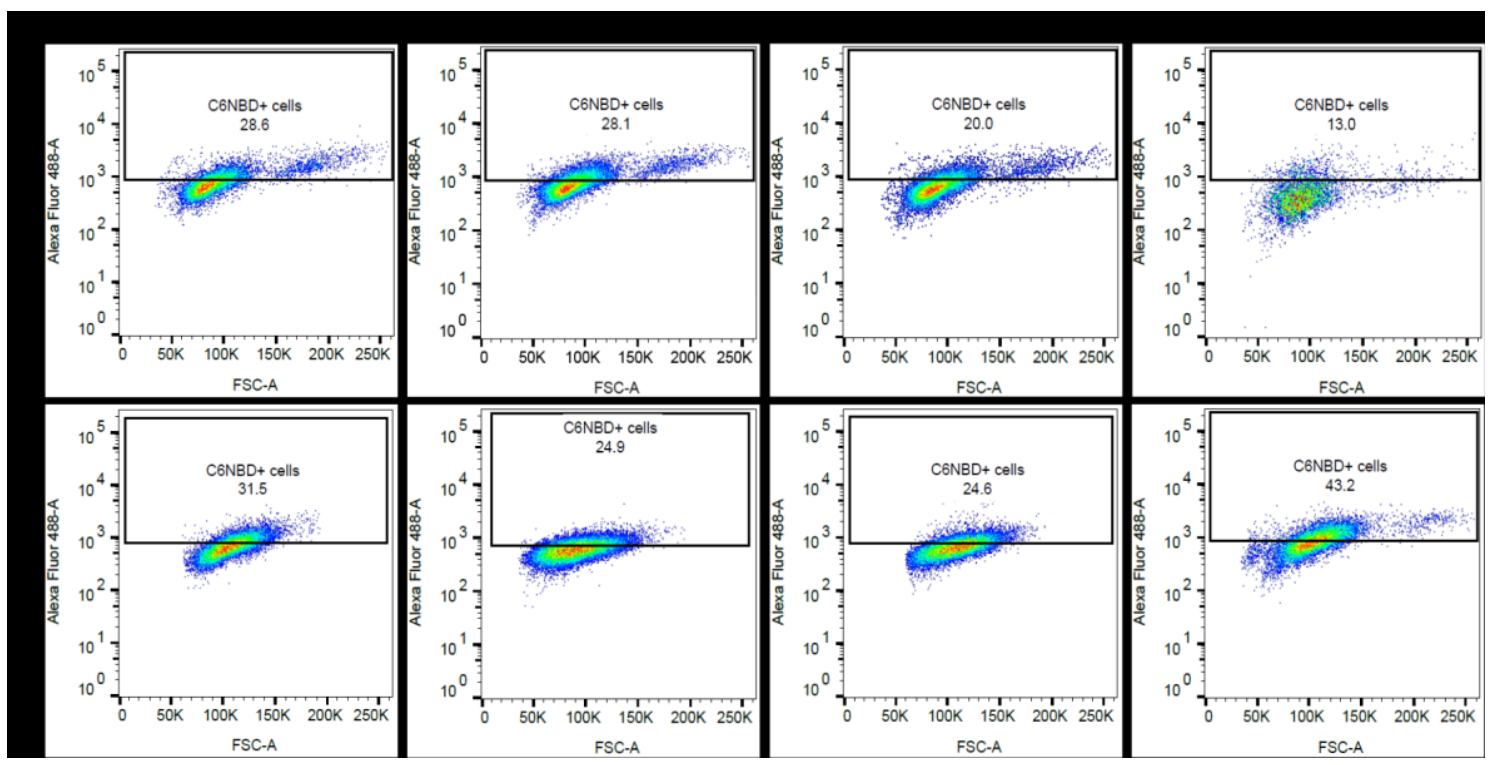

Figure 40. Increasing Epoxomicin concentrations decrease EV uptake in SH-SY5Y cells. (A) EV uptake in SH-SY5Y cells in control conditions after 6 and 24 hours. (B) EV uptake is decreased after treatment with Epoxomicin 50nM. (C) EV uptake is further decreased after treatment with Epoxomicin 100nM. (D) Epoxomicin 200nM treatment decreased EV uptake after 6 hours but increased after 24 hours.

200nM epoxomicin presented an increase in EV uptake and a decrease in cell viability counterstaining with DAPI. EV uptake in control conditions was $16.5 \% \pm 14.7$ SD while in $200 \mathrm{nM}$ epoxomicin treatment was $26.7 \% \pm 14.3 \mathrm{SD}$. Cell viability in control conditions was $96.3 \% \pm 2.2 \mathrm{SD}$ and in $200 \mathrm{nM}$ epoxomicin treatment was $88.2 \% \pm 2.7$ SD.

To further study, which is the effect of the substances used to impair normal physiology of SH-SY5Y cells, cell viability was tracked with the help of an MTT kit measuring the conversion of MTT [3-(4, 5-dimethylthiazol-2-yl)-2,5-Diphenyl tetrazolium bromide] to formazan, which correlates to the number of metabolically active cells in the culture. In this experiment, cells were treated with the same substances, but incubated with unlabelled EVs and general neuronal health was recorded as a readout.

SH-SY5Y cells were treated with $10 \mathrm{ug} / \mathrm{ml}$ LPS and $20 \mathrm{ug} / \mathrm{ml}$ LPS at different timepoints. After $24 \mathrm{~h}$ and $10 \mathrm{ug} / \mathrm{ml}$ LPS mean absorbance values for control conditions were $0.87 \pm 0.04 \mathrm{SD}$; for EV treated cells $1.04 \pm 0.12 \mathrm{SD}$, for LPS treated $0.67 \pm 0.09 \mathrm{SD}$ and for LPS and EV treated $1.03 \pm 0.04 \mathrm{SD}$. The treatment with LPS reduced cell viability significantly, but the combination with EVs negated this effect, showing a clear effect of cell protection by EVs. When cells were treated with 
$20 \mathrm{ug} / \mathrm{ml}$ LPS mean absorbance values for control conditions were $1.26 \pm 0.01 \mathrm{SD}$, for EV treated cells $1.32 \pm 0.18 \mathrm{SD}$, for LPS treated $0.67 \pm 0.03 \mathrm{SD}$ and for LPS and EV treated $0.89 \pm 0.12 \mathrm{SD}$. Again, the protection effect of the addition of EVs is observed. However, although significant, the LPS concentration used is higher and the effect is not as high as before.

SH-SY5Y cells were then treated with $10 \mathrm{ug} / \mathrm{ml}$ for $48 \mathrm{~h}$. Here, mean absorbance values for control conditions were $0.71 \pm 0.07 \mathrm{SD}$, for EV treated cells $0.64 \pm 0.05$ SD, for LPS treated $0.47 \pm 0.04$ SD and for LPS and EV treated $0.66 \pm 0.03$ SD. Cell protection was again observed and was significant although not as prominent as after $24 \mathrm{~h}$. When cells were treated for 72 hours, mean absorbance values for control conditions were $0.80 \pm 0.06 \mathrm{SD}$, for EV treated cells $0.93 \pm 0.03 \mathrm{SD}$, for LPS treated $0.65 \pm 0.05 \mathrm{SD}$ and for LPS and EV treated $0.81 \pm 0.06 \mathrm{SD}$. The addition of EVs protected cells against the toxic effects of LPS, consistent with previous observations, and with a tendency to a beneficial effect on EV uptake (Fig. 41).

A
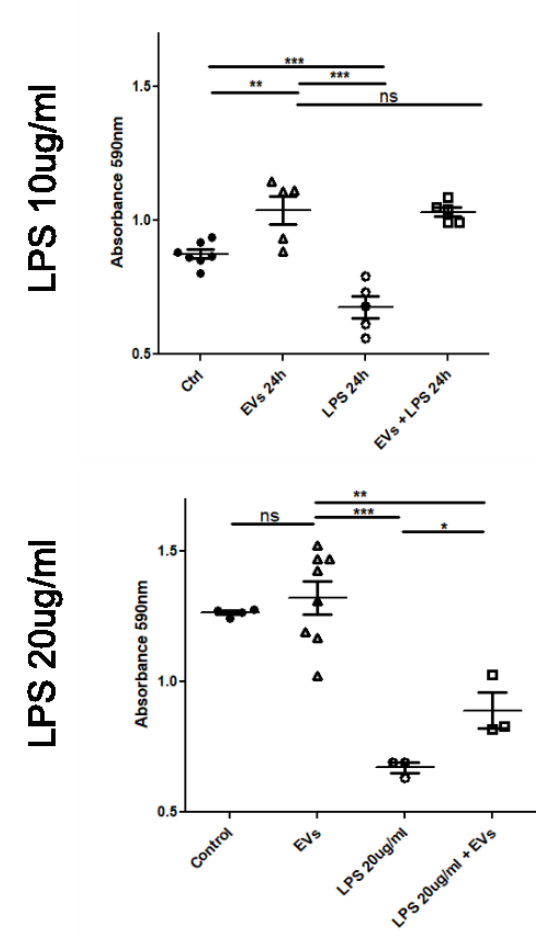

B

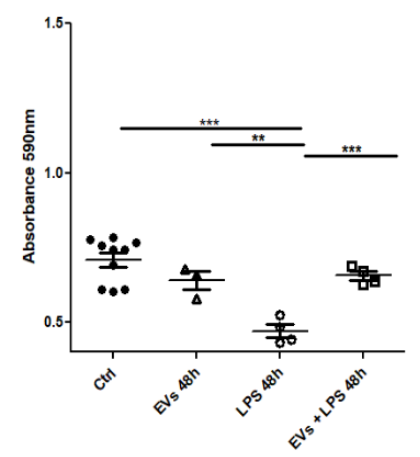

C

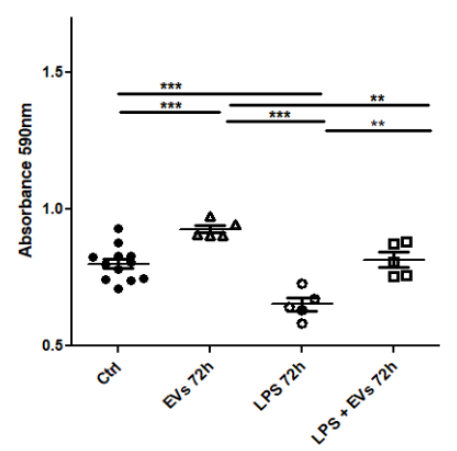

Figure 41. EVs reverse effects of LPS on SH-SY5Y cells. Data groups: 1. Ctrl (cells in normal conditions). 2. EVs (cells treated only with EVs). 3. LPS (cells treated only with LPS). 4. LPS + EVs (cells treated with both LPS and EVs). (A) SH-SY5Y cells treated with LPS 10ug/ml for 24 hours (upper graph) and with LPS $20 \mathrm{ug} / \mathrm{ml}$ (bottom graph). (B) SH-SY5Y cells treated with LPS $10 \mathrm{ug} / \mathrm{ml}$ for 48 hours. (C) SH-SY5Y cells treated with LPS $10 \mathrm{ug} / \mathrm{ml}$ for 72 hours. Significance is indicated with bars and asterisks. 
Afterwards, cells were treated for 24 hours with different concentrations of $\mathrm{H}_{2} \mathrm{O}_{2}$ in order to find the extent of stress. SH-SY5Y cells without EV treatment showed a mean absorbance of $1.34 \pm 0.09 \mathrm{SD}, \mathrm{H}_{2} \mathrm{O}_{2} 50 \mathrm{uM} 1.26 \pm 0.06 \mathrm{SD}, \mathrm{H}_{2} \mathrm{O}_{2}$ 500uM 0.65 $\pm 0.08 \mathrm{SD}$ and $\mathrm{H}_{2} \mathrm{O}_{2} 1 \mathrm{mM} 0.19 \pm 0.02 \mathrm{SD}$. The significant effect on viability was observed using $500 \mathrm{uM}$ and $1 \mathrm{mM} \mathrm{H}_{2} \mathrm{O}_{2}$, although $1 \mathrm{mM}$ killed nearly all cells. Then, the effect of adding EVs was evaluated at different $\mathrm{H}_{2} \mathrm{O}_{2}$ concentrations.

When cells were treated with $200 \mathrm{uM} \mathrm{H}_{2} \mathrm{O}_{2}$ mean absorbance values for control conditions were $1.07 \pm 0.11 \mathrm{SD}$, for $E V$ treated cells $0.88 \pm 0.11 \mathrm{SD}$, for $\mathrm{H}_{2} \mathrm{O}_{2}$ treated $0.70 \pm 0.06 \mathrm{SD}$ and for $\mathrm{H}_{2} \mathrm{O}_{2}$ and $\mathrm{EV}$ treated $0.86 \pm 0.08 \mathrm{SD}$. When cells were treated with $500 \mathrm{uM} \mathrm{H} \mathrm{H}_{2} \mathrm{O}_{2}$ mean absorbance values for control conditions were $0.89 \pm 0.05$ $\mathrm{SD}$, for $\mathrm{EV}$ treated cells $0.85 \pm 0.11 \mathrm{SD}$, for $\mathrm{H}_{2} \mathrm{O}_{2}$ treated $0.64 \pm 0.07 \mathrm{SD}$ and for $\mathrm{H}_{2} \mathrm{O}_{2}$ and EV treated $0.72 \pm 0.08 \mathrm{SD}$. When cells were treated with $1 \mathrm{mM} \mathrm{H}_{2} \mathrm{O}_{2}$ mean absorbance values for control conditions were $1.14 \pm 0.04 \mathrm{SD}$, for EV treated cells $1.16 \pm 0.05 \mathrm{SD}$, for $\mathrm{H}_{2} \mathrm{O}_{2}$ treated $0.26 \pm 0.10 \mathrm{SD}$ and for $\mathrm{H}_{2} \mathrm{O}_{2}$ and $\mathrm{EV}$ treated 0.19 \pm 0.02 SD.

As the $\mathrm{H}_{2} \mathrm{O}_{2}$ concentration increased, cell viability was reduced. Addition of EVs again lowered cell death levels, maintaining the viability nearly as high as the control. This effect is reduced as $\mathrm{H}_{2} \mathrm{O}_{2}$ levels increased, meaning that the protective effect of EVs has a certain limit.

Next, cells were treated with $500 \mathrm{uM} \mathrm{H} \mathrm{H}_{2} \mathrm{O}_{2}$ at different timepoints to see whether its effect was enhancing over time. When cells were treated with $500 u \mathrm{M} \mathrm{H}_{2} \mathrm{O}_{2}$ for 24 hours mean absorbance values for control conditions were $0.82 \pm 0.08 \mathrm{SD}$, for EV treated cells $0.84 \pm 0.07 \mathrm{SD}$, for $\mathrm{H}_{2} \mathrm{O}_{2}$ treated $0.64 \pm 0.09 \mathrm{SD}$ and for $\mathrm{H}_{2} \mathrm{O}_{2}$ and $\mathrm{EV}$ treated $0.88 \pm 0.08 \mathrm{SD}$. After 48 hours mean absorbance values for $\mathrm{EV}$ treated cells were $0.94 \pm 0.12 \mathrm{SD}$, for $\mathrm{H}_{2} \mathrm{O}_{2}$ treated $0.80 \pm 0.09 \mathrm{SD}$ and for $\mathrm{H}_{2} \mathrm{O}_{2}$ and $\mathrm{EV}$ treated $0.88 \pm 0.05 \mathrm{SD}$. After 72 hours mean absorbance values for EV treated cells were $0.86 \pm 0.09 \mathrm{SD}$, for $\mathrm{H}_{2} \mathrm{O}_{2}$ treated $0.75 \pm 0.03 \mathrm{SD}$ and for $\mathrm{H}_{2} \mathrm{O}_{2}$ and $\mathrm{EV}$ treated 0.80 $\pm 0.06 \mathrm{SD}$. These results show a higher effect on viability after 24 hours of incubation with $\mathrm{H}_{2} \mathrm{O}_{2}$. At 48 or 72 hours, toxicity is present as well, but the values are not significant, the same holds true for the protective effect of EVs (Fig. 42). 
A 24 hours

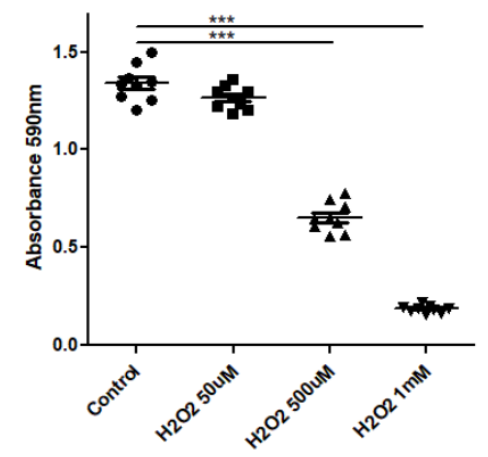

B

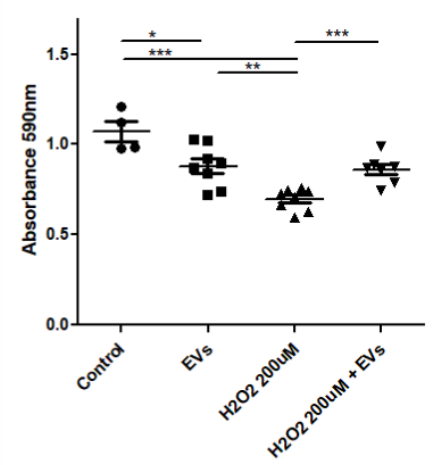

$E$

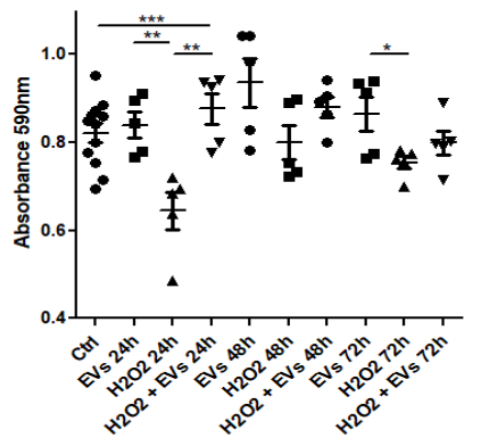

C

$\mathrm{H} 2 \mathrm{O} 2$ 500uM

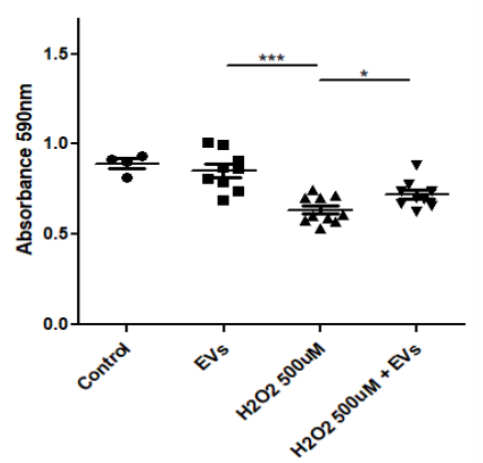

D $\quad \mathrm{H} 2 \mathrm{O} 21 \mathrm{mM}$

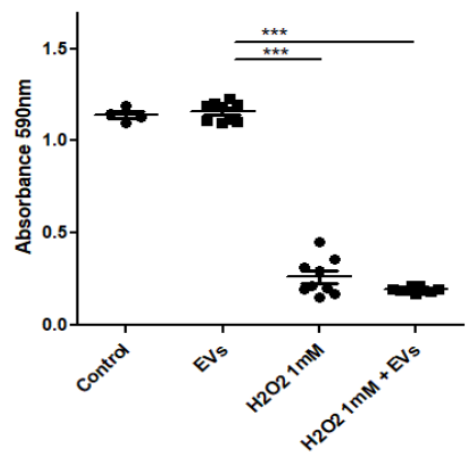

Figure 42. EVs reverse effects of $\mathrm{H}_{2} \mathrm{O}_{2}$ on SH-SY5Y cells. Data groups (in $\mathrm{B}, \mathrm{C}$ and D): 1. Ctrl (cells in normal conditions). 2. EVs (cells treated only with EVs). 3. $\mathrm{H}_{2} \mathrm{O}_{2}$ (cells treated only with $\mathrm{H}_{2} \mathrm{O}_{2}$ ). 4. $\mathrm{H}_{2} \mathrm{O}_{2}+\mathrm{EVs}$ (cells treated with both $\mathrm{H}_{2} \mathrm{O}_{2}$ and EVs). (A) SH-SY5Y cells treated for 24 hours with different $\mathrm{H}_{2} \mathrm{O}_{2}$ concentrations. (B) SH-SY5Y cells treated with $200 \mathrm{uM} \mathrm{H}_{2} \mathrm{O}_{2}$ for 24 hours. (C) $\mathrm{SH}-$ SY5Y cells treated with $500 \mathrm{uM} \mathrm{H} \mathrm{H}_{2} \mathrm{O}_{2}$ for 24 hours. (D) SH-SY5Y cells treated with $1 \mathrm{mM} \mathrm{H}_{2} \mathrm{O}_{2}$ for 24 hours. (E) SH-SY5Y cells treated with $500 \mathrm{uM} \mathrm{H}_{2} \mathrm{O}_{2}$ for 24,48 and 72 hours. Significance is indicated with bars and asterisks.

Going back to the hypothesis that EV uptake is related to neuronal activity, $\mathrm{SH}$ SY5Y cells were treated with different concentrations of KA, namely 50uM, 100uM, $200 \mathrm{uM}, 500 \mathrm{uM}$ and $1 \mathrm{mM}$. After $24 \mathrm{~h}$ treatment with $50 \mathrm{uM}$, mean absorbance values for control conditions were $0.89 \pm 0.06 \mathrm{SD}$, for EV treated cells $0.85 \pm 0.05 \mathrm{SD}$, for $\mathrm{KA}$ treated $0.79 \pm 0.05 \mathrm{SD}$ and for KA and $\mathrm{EV}$ treated $0.88 \pm 0.06 \mathrm{SD}$. After treatment with $100 \mathrm{uM}$, mean absorbance values for KA treated were $0.79 \pm 0.05 \mathrm{SD}$ and for $\mathrm{KA}$ and EV treated $0.86 \pm 0.08 \mathrm{SD}$. After $24 \mathrm{~h}$ treatment with $200 \mathrm{uM}$, mean absorbance values for control conditions were $1.26 \pm 0.01 \mathrm{SD}$, for EV treated cells $1.32 \pm 0.18 \mathrm{SD}$; for KA treated $1.33 \pm 0.25 \mathrm{SD}$ and for KA and EV treated $1.45 \pm 0.11$ $\mathrm{SD}$. After treatment with $500 \mathrm{uM}$, mean absorbance values for $\mathrm{KA}$ treated were 1.12 $\pm 0.24 \mathrm{SD}$ and for $K A$ and $E V$ treated $1.29 \pm 0.18 \mathrm{SD}$. After treatment with $1 \mathrm{mM}$, mean absorbance values for KA treated were $0.71 \pm 0.17 \mathrm{SD}$ and for KA and EV treated $1.31 \pm 0.12$ SD (Fig. 43). 
A

B
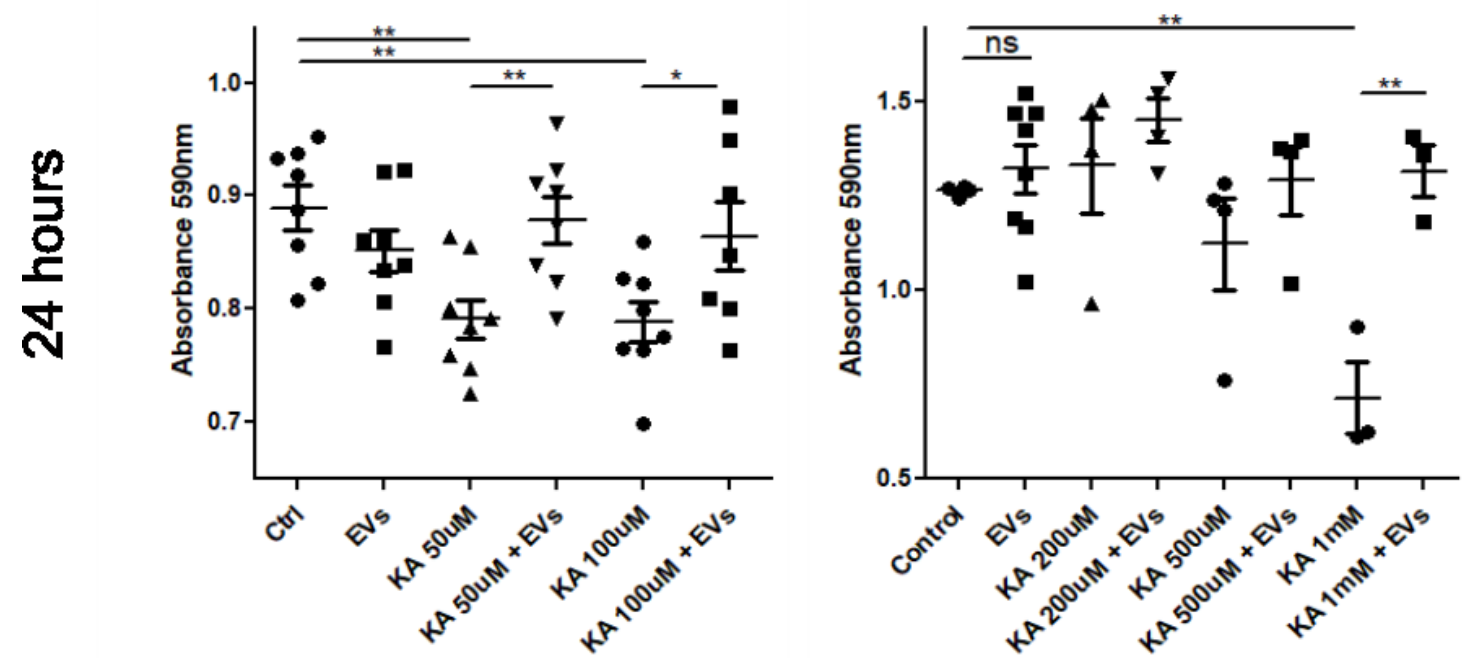

Figure 43. EVs reverse effects of low concentration KA on SH-SY5Y cells. Data groups (in A and B): 1. Ctrl (cells in normal conditions). 2. EVs (cells treated only with EVs). 3. KA (cells treated only with $K A$ ). 4. KA + EVs (cells treated with both KA and EVs) 5 and subsequent columns (increasing KA concentrations). (A) SH-SY5Y cells treated for 24 hours with different KA concentrations. (B) SH-SY5Y cells treated with higher KA concentrations for 24 hours. Significance is indicated with bars and asterisks.

The results obtained showed a high variability within the same conditions, making some comparisons not significant. Nevertheless, there was a tendency towards EV protection against viability reduction, caused by $\mathrm{KA}$, in all concentrations but only significant in 50uM, 100uM and $1 \mathrm{mM}$.

The following tables (Table 22 and 23) summarize the results, obtained from the in vitro experiments described in detail above. After challenging cells with different substances and incubating them with EVs, the analysis was performed by flow cytometry (Table 22) to check for vesicle uptake or by MTT (Table 23) to check for changes in cell viability. Using flow cytometry, the challenge of SH-SY5Y cells with $\mathrm{KCl}$, hydrogen peroxide and epoxomicin showed a decrease in the uptake of EVs compared to control, while KA and LPS showed an increase in EV uptake compared to control. The MTT analysis revealed a decrease in viability when cells were challenged with LPS, hydrogen peroxide and KA and in combination with EVs the viability was rescued to control levels. Epoxomicin and $\mathrm{KCl}$ showed no significant effect on viability. 
Table 22. EV uptake increases or decreases after challenging SH-SY5Y cell line with different substances

\begin{tabular}{|c|c|}
\hline SH-SY5Y + EVs challenged with & $\begin{array}{l}\text { EV uptake increased or decreased (flow } \\
\text { cytometry) }\end{array}$ \\
\hline \multicolumn{2}{|l|}{ Control (for $\mathrm{KCl}$ ) } \\
\hline $\mathrm{KCl}(20 \mathrm{mM})$ & Decreased \\
\hline $\mathrm{KCl}(40 \mathrm{mM})$ & Decreased \\
\hline $\mathrm{KCl}(100 \mathrm{mM})$ & Decreased and increased after $24 \mathrm{~h}$ \\
\hline \multicolumn{2}{|l|}{ Control (for $\mathrm{H}_{2} \mathrm{O}_{2}$ ) } \\
\hline $\mathrm{H}_{2} \mathrm{O}_{2}$ (25uM) & Decreased \\
\hline $\mathrm{H}_{2} \mathrm{O}_{2}$ (50uM) & Decreased \\
\hline \multicolumn{2}{|l|}{ Control (for epoxomicin) } \\
\hline Epoxomicin 50nM & Decreased \\
\hline Epoxomicin 100nM & Decreased \\
\hline Epoxomicin 200nM & Decreased and increased after $24 \mathrm{~h}$ \\
\hline \multicolumn{2}{|l|}{ Control (for KA) } \\
\hline KA (25uM) & Increased \\
\hline KA (50uM) & Increased \\
\hline \multicolumn{2}{|l|}{ Control (for LPS) } \\
\hline LPS (1ug/ml) & Increased \\
\hline LPS (5ug/ml) & Increased \\
\hline
\end{tabular}

Table 23. Effect of EV uptake in cell viability after challenging SH-SY5Y cell line with different substances

\begin{tabular}{|l|c|c|}
\hline SH-SY5Y challenged with & $\begin{array}{c}\text { Viability after EV uptake } \\
\text { measured by MTT }\end{array}$ & $\begin{array}{c}\text { EVs rescued viability after } \\
\text { challenge }\end{array}$ \\
\hline Only EVs $\left(\mathrm{H}_{2} \mathrm{O}_{2} 200 u M\right)$ & $0.88 \pm 0.11 \mathrm{SD}$ & \\
\hline Only $\mathrm{H}_{2} \mathrm{O}_{2}(200 u M)$ & $0.70 \pm 0.06 \mathrm{SD}$ & \\
\hline $\mathrm{H}_{2} \mathrm{O}_{2}(200 u M)+E V s$ & $0.86 \pm 0.08 \mathrm{SD}$ & Yes, only after $24 \mathrm{~h}$ \\
\hline Only EVs $\left(\mathrm{H}_{2} \mathrm{O}_{2} 500 u M\right)$ & $0.85 \pm 0.11 \mathrm{SD}$ & \\
\hline Only $\mathrm{H}_{2} \mathrm{O}_{2}(500 u M)$ & $0.64 \pm 0.07 \mathrm{SD}$ & \\
\hline $\mathrm{H}_{2} \mathrm{O}_{2}(500 u M)+E V s$ & $0.72 \pm 0.08 \mathrm{SD}$ & Yes, only after $24 \mathrm{~h}$ \\
\hline
\end{tabular}




\begin{tabular}{|c|c|c|}
\hline Only EVs $\left(\mathrm{H}_{2} \mathrm{O}_{2} 1 \mathrm{mM}\right)$ & $1.16 \pm 0.05$ SD & \\
\hline Only $\mathrm{H}_{2} \mathrm{O}_{2}(1 \mathrm{mM})$ & $0.26 \pm 0.10$ SD & \\
\hline $\mathrm{H}_{2} \mathrm{O}_{2}(1 \mathrm{mM})+\mathrm{EVs}$ & $0.19 \pm 0.02$ SD & No, limited protective effect \\
\hline Only EVs (LPS 10ug/ml) & $1.04 \pm 0.12 \mathrm{SD}$ & \\
\hline Only LPS (10ug/ml) & $0.67 \pm 0.09$ SD & \\
\hline LPS (10ug/ml) + EVs & $1.03 \pm 0.04$ SD & Yes after 24,48 and $72 \mathrm{~h}$ \\
\hline Only EVs (LPS 20ug/ml) & $1.32 \pm 0.18 \mathrm{SD}$ & \\
\hline Only LPS (20ug/ml) & $0.67 \pm 0.03$ SD & \\
\hline LPS (20ug/ml) + EVs & $0.89 \pm 0.12$ SD & Yes after 24,48 and $72 \mathrm{~h}$ \\
\hline Only EVs (KA) & $0.85 \pm 0.05$ SD & \\
\hline Only KA (50uM) & $0.79 \pm 0.05$ SD & \\
\hline $\mathrm{KA}(50 \mathrm{uM})+\mathrm{EVs}$ & $0.88 \pm 0.06$ SD & Yes \\
\hline Only KA (100uM) & $0.79 \pm 0.05$ SD & \\
\hline KA (100uM) + EVs & $0.86 \pm 0.08$ SD & Yes \\
\hline Only EVs (KA) & $1.32 \pm 0.18 \mathrm{SD}$ & \\
\hline Only KA (200uM) & $1.33 \pm 0.25$ SD & \\
\hline$K A(200 u M)+E V s$ & $1.45 \pm 0.11 S D$ & Not significant \\
\hline Only KA (500uM) & $1.12 \pm 0.24$ SD & \\
\hline$K A(500 u M)+E V s$ & $1.29 \pm 0.18 \mathrm{SD}$ & Not significant \\
\hline Only KA (1mM) & $0.71 \pm 0.17 \mathrm{SD}$ & \\
\hline$K A(1 m M)+E V s$ & $1.31 \pm 0.12 \mathrm{SD}$ & Yes \\
\hline Epoxomicin & Not significant & \\
\hline $\mathrm{KCl}$ & Not significant & \\
\hline
\end{tabular}

\subsection{FACS sorting of NeuN+ recombined and non-recombined cell populations}

To answer the question of how EV uptake changes cellular function and how this influences pathological or physiological states, it was necessary to perform a comparison of gene expression between recombined and non-recombined cells.

Reporter and double transgenic mice were injected with LPS, brains were removed, digested and cells were analysed using FACS. Reporter mice showed no YFP+ 
population but the separation between populations in the Vav-iCre-ROSA26EYFP mouse was not completely clear. For the hippocampus, the gated $\mathrm{NeuN}+\mathrm{YFP}+$ fraction accounted for $2.71 \%(Q 2)$ and the gated NeuN+ YFP- fraction accounted for $15.2 \%$ (Q3). For other brain regions, the gated NeuN+ YFP+ fraction accounted for $1.95 \%(Q 2)$ and the gated NeuN+ YFP- fraction accounted for 20.3\% (Q3) (Fig. 44).

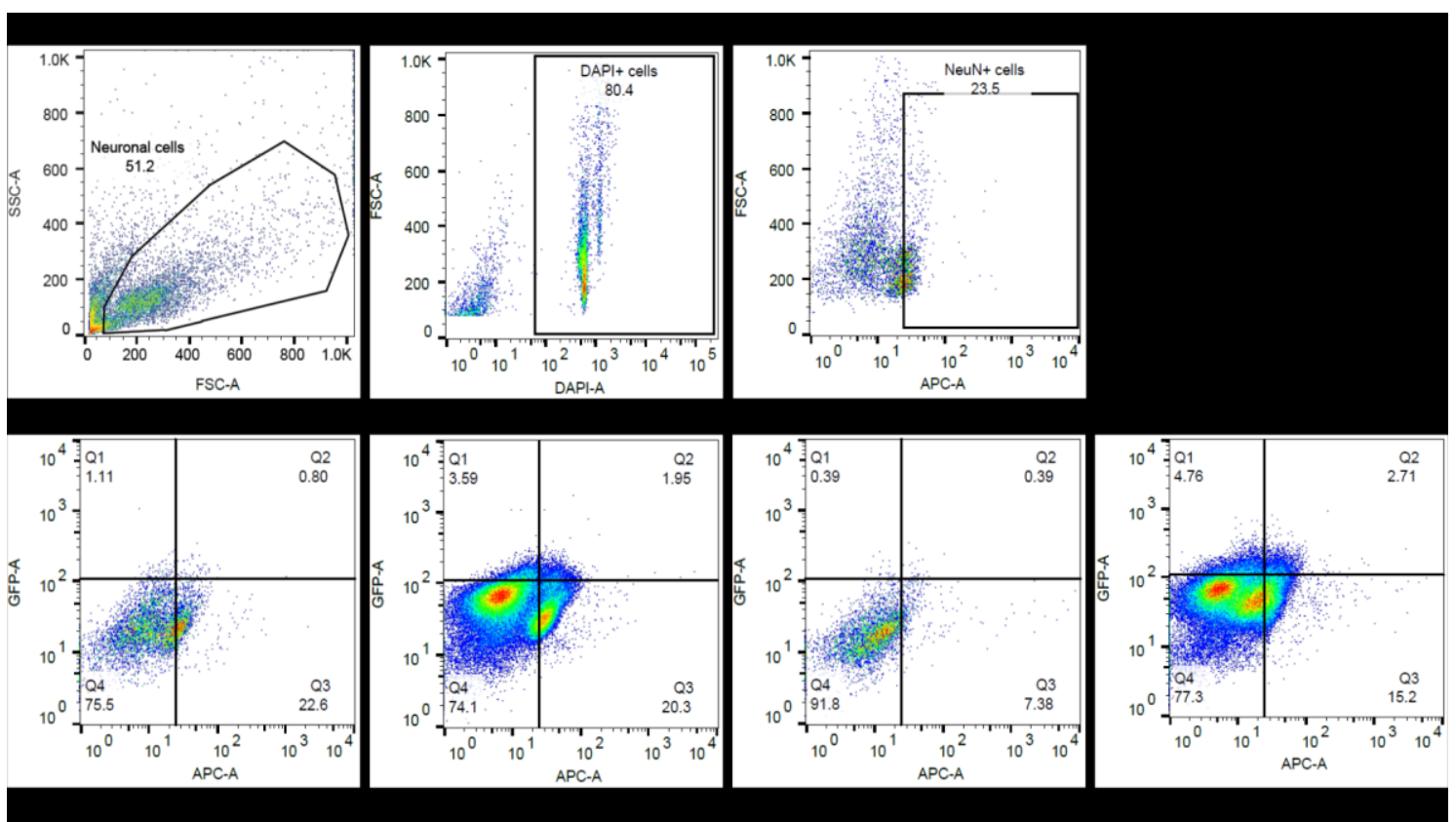

Figure 44. Gating strategy to sort NeuN+ recombined and non-recombined cell populations.

(A) Distribution of neural cells according to size and granularity. The irregular gate delineates the cell population. (B) Percentage of dead cells counterstaining with DAPI. (C) Gate for NeuN positive cells. (D) Quartile distribution for brain samples gated for NeuN and YFP (left: Rosa26-EYFP; right: VaviCre-ROSA26EYFP). (E) Quartile distribution for brain samples gated for NeuN and YFP (left: Rosa26-EYFP; right: Vav-iCre-ROSA26EYFP).

NeuN+ cell populations (YFP- and YFP+) were FACS sorted to extract the total RNA and to assess the quality and specificity for subsequent analysis using RNA sequencing. 600 to $1000 \mathrm{NeuN}+\mathrm{YFP}+$ cells and $1 \times 10^{5}$ to $1,5 \times 10^{5} \mathrm{NeuN}+\mathrm{YFP}$ - cells were sorted. However, the brain digestion protocol and the fixation method used need to be further optimized to improve cell sorting numbers and RNA quality to be analysed by RNA sequencing. Within the scope of this thesis, a complex protocol for FACS sort to compare recombined vs non-recombined neurons was established and will ultimately be used to decipher the effects of EV uptake in future studies. 


\section{Discussion}

The aim of this project was to study the parameters of EV signalling from the haematopoietic system to the brain in the context of brain pathology, such as neurodegenerative diseases, as well as in physiological conditions.

First, the study attempted to characterise EV signalling and to explore its extent and function after peripheral inflammation from blood to brain. Second, the mechanism by which EVs are taken up was studied, using various approaches that involved injury models or ectopic stimuli. Third, the thesis aimed to study EV uptake in normal organism physiology by putting novel objects in a mouse cage (without invasive manipulation). Last, this project aimed to give insight into the question of whether EVs have a beneficial or detrimental effect in uptaking cells.

\subsection{Peripheral injections of LPS and KA caused EV uptake in the brain}

The extent of signalling from the haematopoietic system to the brain was addressed. This mechanism was studied in a devised genetic murine tracing model, based on the intercellular transfer of mRNA coding for Cre recombinase, enclosed in EVs from the blood (haematopoietic system), to neural cells in the brain, expressing a Cre reporter background. This transfer leads to the irreversible expression of the reporter marker gene EYFP. Although rare, under inflammatory conditions, Cremediated recombination in the brain increased substantially.

In order to further investigate these observations in healthy mice, and in mice presenting a peripheral inflammation (LPS injected), blood was collected and EVs were isolated for their characterisation using SEC, WB and TEM, demonstrating an enrichment in exosomes and a higher EV content in samples from LPS injected mice.

The i.p. injection of LPS caused marker gene-expression of the reporter gene in different brain regions, particularly in cells such as neurons and microglia. Because of the important role of microglia, macrophage-resident cells in the brain, in inflammatory responses, one would expect that only this cell type was the one receiving EVs and showing recombination events. However, surprisingly, there was a high percentage of recombined neurons, suggesting a more specific way for EV targeting and uptake and not exclusively related to immune responses (Q. Li \& Barres, 2018; Robbins \& Morelli, 2014). 
Recombination events were mapped to study the extent of marker gene-expression after peripheral inflammation. Cells expressing EYFP were found widespread in the brain, detected in nucleus accumbens in forebrain, lateral ventricles and striatum in midbrain, third ventricle and hypothalamus in hindbrain, and other brain regions such as cortex, cerebellum, hippocampus and Substantia Nigra. Furthermore, various markers were used to determine which cell types were involved in EV uptake. Microglia, neurons and DA neurons were highly recombined in contrast to endothelial cells, astrocytes and oligodendrocytes, which were found very rarely recombined.

In addition to the vav-iCre model, the EpoR-Cre mouse model was used. Here, the injection of LPS revealed the absence of neuronal marker gene-expression (recombined NeuN-positive cells), while recombined Iba-1-positive microglia were again detected. This fact suggests that the cell of origin of the EVs plays a role in the targeting, probably contributing to the decision of which cell will take up EVs.

The mechanisms by which cells take up EV are not yet fully understood. Here, the importance of the cell of origin is demonstrated. Currently, EVs secreted from a particular cell are not targeted to a whole cell-type population, indicating that the receiving cell determines the uptake (Lovinger, 2008; Mulcahy, Pink, \& Carter, 2014).

In order to study another paradigm of injury, KA was injected at a low dose in the mouse model. After the injection of KA, recombination again was observed in $\mathrm{NeuN}+$ and Iba1+ cells. The total number of NeuN+ cells recombined was higher than after an LPS injection and number of Iba1+ cells recombined was lower. This fact suggests that electrical activity of the neurons may play a role and that this might influence EV uptake. We hypothesised that the circulating EVs are taken up when brain cells are electrically stimulated. We further considered that EV uptake is mainly determined by the electrical activity of the uptaking cells and this uptake impacts neuronal function.

The infiltration and activation of immune cells from the periphery to the brain is a highly regulated mechanism. However, inflammatory processes are related to an increase of the number of peripheral immune cells in the brain (Ising \& Heneka, 2018). The presence of immune cells in the brain would indicate an inflammatory process or injury or that some of the treatments used are causing damage to the 
$\mathrm{BBB}$, making the barrier leaky. The fact that the BBB is not working properly as a barrier would imply another route for short-range EV communication, from infiltrating cells to brain cells. To check for immune cell infiltration after the different treatments and to exclude the possibility of EV transfer from infiltrating cells to the brain, brain sections were stained against CD49d to check for peripheral macrophages in the brain parenchyma. Infiltrating peripheral immune cells were never observed at the brain parenchyma, meaning that neither LPS nor KA were causing a damage to the barrier.

Further experiments were performed to exclude the unspecific expression of Cre recombinase and marker gene-expression induction. To this end, chimeric systems (reporter mice with Cre EVs coming from the periphery) were used, excluding the possibility of Cre recombinase miss-expression. The contralateral hemisphere, injected with saline solution, had no recombination events, indicating that marker gene-expression is due to EVs entering the brain via peripheral circulation. Injection of carrier solution alone again showed no recombination, ruling out that the injury could cause marker gene-expression. Injection of KA together with EVs from wildtype animals did not lead to recombination, excluding unspecific labelling caused by KA-driven cell death.

\subsection{Neuronal activity triggers EV uptake in diseased and healthy animals}

\subsubsection{Neuronal activity triggers EV uptake in the brain}

Electrical activity of cells in vivo can be controlled using optogenetics methods. A specific population of neurons expressing CaMKIla, were targeted with an AAV, carrying the expression of the opsin ChR2 together with mCherry. The main advantage of optogenetics is that a particular cell population can be stimulated with a specific wavelength, without affecting other cells or brain areas and with a minimal peripheral damage. Post-stimulation, strong and membrane-bound expression of ChR2-mCherry was found in the primary visual cortex. The functionality of the opsin was tested using local field potential readout (Stroh et al., 2013). Control conditions included injecting opsin only or light stimulating only. Marker gene-expression was never observed. The combination of $\mathrm{AAV}$ and optic fiber stimulation revealed $\mathrm{NeuN}+\mathrm{EYFP}+$ cells, mostly outside the injection area in adjacent cortical areas and in the hippocampus. Only a part of the marker gene-positive neurons co-expressed ChR2-mCherry. 
The expected results of this experiment were that all cells, receiving the virus, would be recombined after optic fiber stimulation, meaning that cell stimulation causes EV uptake. The observation of recombination events outside of the injection area and not in all infected cells, led to the interpretation that cells receiving the opsin, send projections through the neural network that is stimulated. As a result, when neurons increase their firing frequencies, it leads to the uptake of EVs and consequent marker gene-expression. Interestingly, this marker gene-expression can be seen in zones not directly stimulated but that are within a specific neuronal network, connected via cell projections, such as the contralateral hemisphere.

The use of optogenetic tools allowed the targeting of EV uptake by a particular and specific group of neurons, connected to each other and having a synchronised electrical status and firing frequencies. In the CNS, the modulation of electrical activity causes the generation of action potentials and neuronal firing. Some evidence suggest that changes in membrane potential are involved in the regulation of ligand binding by receptors. Of note, in the nervous system many protein receptors are voltage-sensitive, meaning that modulation of membrane potential may influence EV binding on the membrane surface, and/or cause the reorganization of membrane structures facilitating EV interaction. Although the mechanism, involved in the uptake of EVs remains under investigation, these results offer an insight into the importance of the electrical status of a neuron in the regulation of extracellular vesicle uptake (Pivovarov, Calahorro, \& Walker, 2019; Vickery, Machtens, \& Zachariae, 2016).

The variety of experimental models used in this thesis provided insight into the concept of neuronal activation as a stimulus that regulates EV uptake from the circulation. Unfortunately, currently it is not possible to specifically inhibit or modulate EV release or uptake in vivo, although some research has been done using in vitro approaches. However, these results cannot be easily extrapolated in vivo, since extraction and purification of EVs could introduce artifacts into the system, being, therefore, a high impediment in the field.

However, in an in vitro approach using optogenetics or pharmacological channelblockers, it would be possible to combine neuronal stimulation with electrical activity blockage in a particular cell population. This can be achieved using slice cultures, 
in which electrical activity is stimulated or inhibited while treated with EVs isolated from mice.

\subsubsection{Neuronal activity triggers uptake of EVs in a model of Parkinson disease}

In neurodegenerative diseases such as Parkinson Disease, EVs are being studied as vehicles for the intercellular transfer of misfolded proteins from affected to healthy cells, as well as for the removal of unwanted products, or as diagnostic markers (Chistiakov \& Chistiakov, 2017).

It has been shown that extracellular vesicles play a potential role in the spread of $\alpha$ Syn oligomers in the brain, accelerating disease's progression (Zhang, Eitan, Wu, \& Mattson, 2018). Other studies demonstrated that microglia displayed high degree of uptake of EVs, carrying $\alpha-S y n$, thereby facilitating the spread of the disease by releasing these particles (Xia et al., 2019). EVs, carrying a-Syn, can be taken up by recipient cells and form aggregates (Desplats et al., 2009), which can be cleared by astroglia (H. J. Lee et al., 2010). Conversely, it has been shown that EVs can have a neuroprotective role, limiting toxicity by removing toxic products or transferring protective proteins (Krämer-Albers et al., 2007).

One common pathological feature of PD is the progressive loss of dopaminergic neurons. This fact is partly explained by the accumulation of insoluble aggregates, due to an impairment in protein degradation systems (Bentea, Verbruggen, \& Massie, 2017). Evidence, accumulated in the last years, demonstrated the impairment of the ubiquitin proteasome system in patients with $\mathrm{PD}$, which leads to cell death, disturbs protein homeostasis and triggers neurodegeneration (Fornai et al., 2003). These findings led to the generation of animal models in which proteasome inhibitors are used to mimic the pathophysiology of PD. One approach consists of the infusion of epoxomicin, a selective proteasome inhibitor, into the ventral midbrain, causing a selective increase of in vivo firing frequencies in SN (Subramaniam et al., 2014). Double-transgenic mice were infused with epoxomicin and marker gene-positive events were only observable in DA neurons, not in microglia, and only at the ipsilateral hemisphere of the brain. This specific EV uptake in pathologic DA neurons was in line with the hypothesis that the electrical status of a cell controls the uptake of EVs. This result also suggests a possible role of EVs in the onset and progression of disease. 
Whether EV uptake has a beneficial or detrimental effect on neurons remains unclear. Particularly, in light of the recent data showing that neuronal viability is improved after uptake of oligodendrocyte-derived EVs under stress conditions in vitro (Frühbeis et al., 2013) and that macrophage-derived EVs, containing functional NADPH oxidase 2 complexes, promote axonal regeneration (Hervera et al., 2018).

Whether cells, taking up EVs, are pathologic or not, needs to be further investigated. Based on the literature and from the experiments, performed with epoxomicin, it can be speculated that cells under stress seem to be the ones taking up EVs, perhaps as a rescue mechanism. This is consistent with evidence, showing the improvement of neuronal viability, observed after the stressed cultured neurons were supplied with oligodendroglial exosomes (Frühbeis et al., 2013).

\subsection{EV uptake after physiological stimulation of neurons}

The experiments discussed until now, are in line with the hypothesis that the electrical status of a cell triggers EV uptake. However, primarily ectopic stimuli or pathological events were used.

To probe if neuronal firing under physiological conditions is enough for EV uptake, a non-invasive technique, known as novel object placement, was used. As described, novel objects are distributed in a cage with mice for one hour. After that time, they are removed and no longer placed again. This behaviour paradigm has been widely studied and there is evidence relating neural responses to novel objects with early-gene expression, such as c-Fos or Arc (Koizumi, Kiyokawa, Tanaka, Tanikawa, \& Takeuchi, 2019).

The double-transgenic mice, used in these experiments, exhibited recombination mostly in the hippocampus and to a higher extent in midbrain, but to a lesser extent in other regions such as forebrain, hindbrain, or cerebellum, where neuronal activation would not be expected. This mouse model was not suitable for the study of early-genes expression, therefore it was not possible to determine whether neurons, active for a short time, take EVs up, as a minimal period of $48 \mathrm{~h}$ is needed to detect expression of the reporter-gene. In an attempt to see the expression pattern of some early-genes, such as c-Fos or Arc, objects were introduced and mice were euthanized after one hour. Sections stained for these genes showed that Arc distribution was similar to recombined cells in the hippocampus. 
The fact that EV uptake is occurring under physiological conditions, induced by neuronal activity, suggests a role of EV signalling not only after pathology/impairment induction, but also in cognitive processes and behaviour. This leads to the hypothesis, that cognitive tasks, as well as behaviour, could be influenced by EVs coming from the periphery.

\subsection{Use of EVs in therapeutics and as biomarkers}

The fact that EV uptake is observed after neuronal activity, induced by physiological stimuli in a completely non-pathological paradigm, such as novel object placement, is remarkable. If the novel object placement experiment is not taken into account, all experiments performed in this thesis are either an injury-caused model or an invasive technique, to study EV uptake. The result obtained with novel object placement, suggests a continuous communication between blood and brain, which is not driven by pathology-needs; in contrast, this communication is observed in healthy cellular behaviour.

Based on this data, EVs going in both directions, from- and to- the brain, could be used as a therapeutic entity, to regulate or influence cognitive and behavioural processes. Some research groups are already establishing the use of EVs as therapeutic particles, or as modulators in brain diseases. In a murine model of Alzheimer's disease, it has been shown that intracranial administration of mesenchymal stem cell (MSC)-derived exosomes stimulated neurogenesis and reduced cognitive impairment (Reza-Zaldivar et al., 2019). Recent evidence from a murine model of stroke, suggests that MSC-EV-receiving cells display long-term neuroprotection as well as neuroregeneration (Doeppner et al., 2015). In a model of Traumatic Brain Injury, intravenous injection of EVs, isolated from neural stem cells, enhanced neuroprotection and induced reduction in lesion size, suggesting that EV cargo could modulate gene expression (Sun et al., 2020). In a Parkinsonrelated in vitro system of human dopaminergic neurons, obtained by neural stem cell differentiation, cells were treated with 6-hydroxy-dopamine (6-OHDA, a neurotoxin that produces reactive oxygen species and subsequent apoptosis) alone or in combination with exosomes, isolated from stem cells from the dental pulp of human exfoliated deciduous teeth (SHEDs). Exosome treatment was mostly able to supress 6-OHDA-induced apoptosis (Jarmalavičiute, Tunaitis, Pivoraite, Venalis, \& Pivoriunas, 2015). A different setup, based on EV engineering was used to study 
the therapeutic potential of exogenously loaded EVs. Cells were engineered to express an exosomal peptide on the surface that was then present in EVs, and EVs were loaded with siRNA by electroporation, in order to specifically knockdown GAPDH in neurons, microglia and oligodendrocytes only, by intravenous injection in mouse (Alvarez-Erviti et al., 2011).

All therapies, mentioned above, are based on the exogenous administration of EVs, either wild type (without any alteration of the cell of origin) or engineered, to express or to interact with proteins, RNA, etc. Interestingly, and going back to the hypothesis, endogenous EVs, secreted from one cell to the other, can also exert a therapeutic role by modulating synaptic activity (Lachenal et al., 2011), in regeneration of peripheral nerves (Court, Hendriks, MacGillavry, Alvarez, \& Van Minnen, 2008; Court et al., 2011), and possibly others, still under consideration.

Although different approaches are used to manipulate, engineer and deliver therapeutic molecules to the brain by extracellular vesicles, in this thesis, where the signalling from blood to brain is studied, no engineering is implemented, and the model is in vivo. In this system, EVs seem to naturally target cells that are stimulated by pathological or physiological stimuli. Whether the uptake occurs because there is a need of EVs or because EVs are freely available, needs to be further investigated. At least in these experimental settings, the target cell seems to take up EVs based on a requirement, rather than availability.

Growing evidence regards EVs as the most important biomarkers, as their cargo is exclusive and mirrors the situation in which a particular cell is found. In other words, EVs carry a portion of cells that allows to detect cellular changes, occurring in normal physiology and pathology. This cargo could be used for diagnostic as well as prognosis. Up to now, the use of EVs as biomarkers in the field of neurodegenerative diseases, has been widely increasing. Specifically, it has been shown that EVs, carrying proteins related to Parkinson's disease, were detected in different bio-fluids like blood, urine, saliva, etc. (Ho, Yi, Seo, Son, \& Seol, 2014; Taymans, Mutez, Drouyer, Sibran, \& Chartier-Harlin, 2017; Vella, Hill, \& Cheng, 2016; Wu, Zheng, \& Zhang, 2017). Emerging evidence showed that neuron-derived EVs from $A D$ patients contain pathologic proteins, involved in pathogenic spread of the disease. This suggests the possibility of using EVs as toxic product sequestration and cell clearance, meaning that EVs could be useful as early detectors of disease as they 
are involved in AD pathogenesis (S. Lee, Mankhong, \& Kang, 2019; Watson, Hamlett, Stone, \& Sims-Robinson, 2019).

Although solid evidence suggest the use of EVs as biomarkers, there is still a long way and further investigation needed in isolation protocols, purification techniques, labelling and detection, modulation and regulation of release and uptake, their therapeutic application, in order for EVs to become reliable biomarkers (Chen, Tang, Fan, \& Duan, 2018). Further research needs to be done to gain understanding of the molecular mechanisms, regulating EV uptake and the cargo, which is involved in downstream effects. A novel factor to take into consideration regarding blood to brain signalling, is the transfer of different material, such as miRNAs. Some efforts are being made following the discovery that EVs carrying miRNAs can perform immunomodulatory function (Yoshikawa, Teixeira, Sato, \& Oliveira, 2019). It has been shown that specific miRNAs promote neural stem cell differentiation to specific cell types, induce neural cell proliferation, as well as participate in brain development and are implicated in regulation processes after injury (Cho, Xu, Blenkiron, \& Fraser, 2019; Meza-Sosa, Pedraza-Alva, \& Pérez-Martínez, 2014). This opens the question of whether miRNAs contribute to receptor cell functionality and, if yes, to what extent.

In an attempt to answer this question, brains from LPS injected mice were used. A protocol for brain digestion was established and, in the end, cells were stained for $\mathrm{NeuN+}$ and YFP+ / YFP- cells (marker-gene positive and negative neurons). Additionally, a FACS sorting strategy to isolate RNA from these populations and to compare it by RNA sequencing, was established. The results of these future studies may give a great insight into the biology of RNA species in the modulation of different pathways. Afterwards, the selected candidates could be checked as potential EV cargos, or be manipulated, and tested, to see changes in neuronal gene expression.

EVs present another feature that make them useful as therapeutic vehicles delivering material to the brain in that they can cross the BBB. The mechanism, by which EVs arrive to the brain is not yet understood and further research need to be done in this direction. Recent evidence in a tumor model of brain metastasis suggest that tumor-derived EVs gain access to the brain via transcytosis (Morad et al., 2019), and this mechanism could explain, how EVs from the blood arrive in the brain. Further evidence showed that brain activity in mice, such as stimulation of 
neuronal activity or an enriched environment, modulated the entrance of serum IGF1 to the brain (Nishijima et al., 2010), suggesting that the neuronal activity that controls EV uptake could regulate BBB permeability as well.

The experimental approaches, used in this thesis, seemed not to damage the BBB and peripheral cell infiltration was never observed, suggesting that the conditions did not alter the tightness and physiology of the BBB.

\subsection{Possible beneficial role in EV uptake}

In addition to the accumulated evidence, implicating EVs in either disease spread or as toxic product clearing system, the experiments performed in vitro during this project allow the speculation that EVs seem to be involved in a rescue mechanism when a cell is impaired or lacking something.

To study different scenarios, primary neurons or neuronal cell lines, such as $\mathrm{SH}$ SY5Y, were stressed with different concentrations of $\mathrm{H}_{2} \mathrm{O}_{2}$. Viability was reduced when only $\mathrm{H}_{2} \mathrm{O}_{2}$ was used, but the addition of $E V s$ together with $\mathrm{H}_{2} \mathrm{O}_{2}$ rescued cells and viability was restored to control level. In addition, $\mathrm{H}_{2} \mathrm{O}_{2}$ is related to impairments in neuronal excitability and this fact could explain, why there was no increase in EV uptake. SH-SY5Y cells were also treated with LPS or stimulated with KA and an increase in $\mathrm{EV}$ uptake was observed. Whether this increase indicates a protective mechanism against cell stress and death, or a firing response to KA, needs to be further studied. When SH-SY5Y cells were treated with epoxomicin, a decrease in EV uptake together with a decrease in cell viability was observed. It is known that high levels of epoxomicin cause an accumulation of ubiquitinated proteins that leads to cell death (Cheng et al., 2011) and this would be consistent with the results, obtained with $200 \mathrm{nM}$ treatment. The observation that epoxomicin causes a general decrease in EV uptake could be explained by its toxic effect on cells, or could indicate different in vivo-downstream effect, compared to the in vitro.

Cell viability was studied using not only flow cytometry but also a MTT kit (measurement of cell viability, based on the cleavage of MTT salt to formazan by metabolic active cells). When SH-SY5Y cell were treated with increasing concentrations of LPS and for different durations, the addition of EVs maintained high viability, compared to non-EV treatment, suggesting a protective role of EVs. The treatment with $\mathrm{H}_{2} \mathrm{O}_{2}$ had the same outcome. However, the protective effect was 
reduced with increasing $\mathrm{H}_{2} \mathrm{O}_{2}$ concentration. Treatment with $\mathrm{KA}$ did not produce significant results, although there was a tendency towards EV protection against toxicity, caused by high KA concentrations. When cells were treated with epoxomicin and $\mathrm{KCl}$, the analysis of viability by MTT showed no significant effect, suggesting that these substances do not have an impact on cell viability in this particular in vitro approach.

All experiments performed here show a trend in which EVs are beneficial when the uptaking cell needs them or when its physiology is impaired. Although the dynamics of EV uptake are not fully understood, a beneficial effect of EV uptake is observed in a variety of paradigms. Still, more research has to be done in order to clarify the possible beneficial role of EV uptake. 


\subsection{Summary and conclusions}

This project demonstrated that the functional transfer of EVs and their cargo from haematopoietic cells to neurons is widespread and results support the hypothesis that EV uptake is triggered by neuronal activity under pathological and physiological conditions (Fig. 45). Understanding the mechanism, by which EVs transfer their material from cell to cell, may help to create strategies against onset and progression of neurodegenerative diseases, such as Parkinson disease.

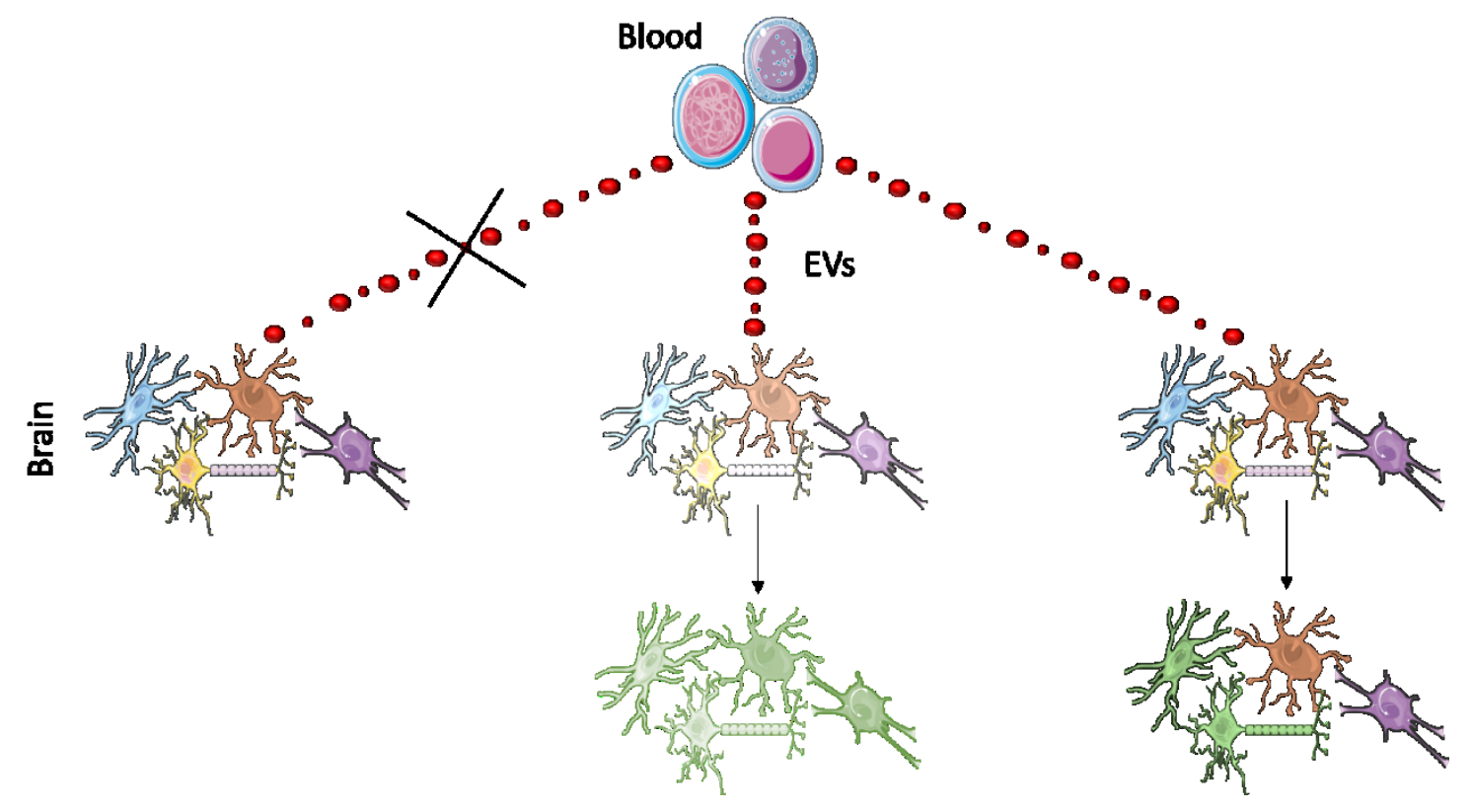

Figure 45. Schematic representation to follow EV mRNA transfer from blood to the brain (actual case). As in the introduction (Section 3.5), the left arm represents no communication from the periphery to the brain. The middle arm shows the first expected situation; all brain cells expressing the reporter gene take EVs up. The right arm shows the state, observed in the different experimental approaches; EVs are transferred to the brain, but only cells that are stimulated either by physiologic or pathologic stimuli take EVs up.

It is worth to highlight, that cell-to-cell communication, studied in this thesis, is from blood to brain, and this research project shows how complex the crosstalk is. However, EVs from any other cell types and organs were not investigated here. Considering global signalling from the periphery to the brain and vice versa, the influence exerted by EVs in the brain may be much more extensive than what is observed in this study (Fig. 46). 


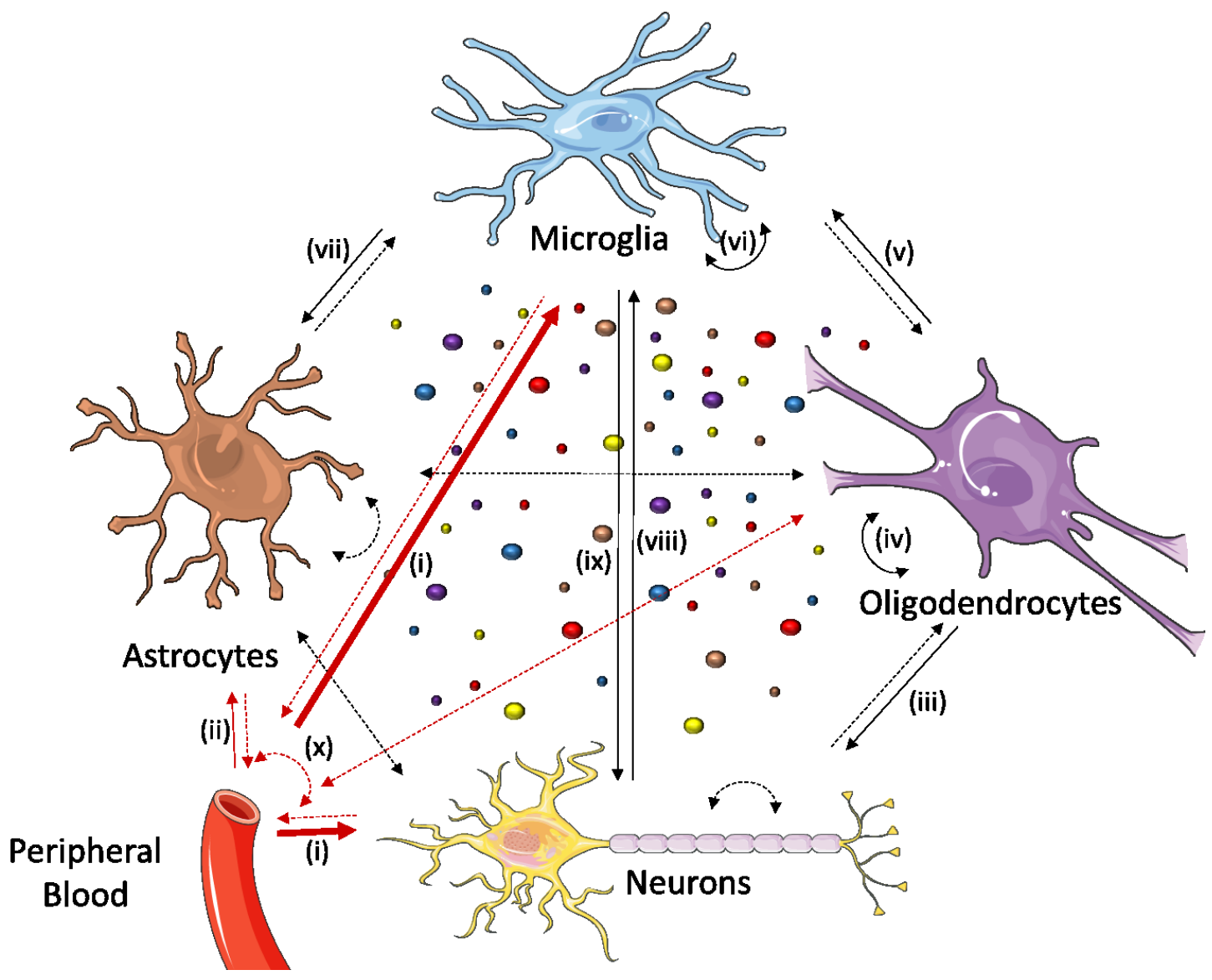

Figure 46. Extracellular vesicles are involved in intercellular and inter-tissue communication.

EVs mediate communication between cells in the same tissue and between tissues in health and disease. EVs are released by most cell types, and can be taken up, releasing their cargo, and modulating own or receptor cell function. Increasing evidence shows crosstalk between cells in the brain, and in this thesis communication from the periphery, has been studied, such as to neurons or microglia, demonstrating complexity of the signalling. Continued arrow: References supporting EV signalling; discontinued arrow: No references known for this signalling; thick arrows: EV signalling studied in this investigation. (i) (Balusu et al., 2016; Kur et al., 2020; Ridder et al., 2014); (ii) (J. J. Li et al., 2018); (iii) (Frühbeis et al., 2013); (iv) (Bakhti, Winter, \& Simons, 2011); (v) (Fitzner et al., 2011); (vi) (Kumar et al., 2017); (vii) (Drago et al., 2017); (viii) (Bahrini, Song, Diez, \& Hanayama, 2015); (ix) (Antonucci et al., 2012; Turola, Furlan, Bianco, Matteoli, \& Verderio, 2012); (x) Supporting evidence shows the detection of EVs from CNS in biological fluids such as the blood (Kanninen, Bister, Koistinaho, \& Malm, 2016).

The next challenge is the identification of markers, present in EVs, in order to catalogue them via cell-type of origin or destination, similar to a recent study, where authors sorted EVs from different neural cells (Ohmichi et al., 2019). This would give an insight and a more substantial prove of the extent of EV signalling in health and pathology. 
The results of this doctoral work allow to explain and to understand the regulatory mechanism, involved in EV uptake from the periphery to the brain in health and disease. Additionally, in vitro experiments provide evidence of a possible beneficial effect in cells taking up EVs. This knowledge will help to inform future research about physiological or pathological implications of EVs, assisting in the design of new therapies against brain damage. The investigation, carried out in this thesis, contributed insights into the signalling mechanism, used by EVs in the communication between tissues, and showed that EV signalling is important not only in a pathological process such as inflammation or neurodegenerative diseases, but also in a physiological process such as normal behaviour. 


\section{References}

Alvarez-Erviti, L., Seow, Y., Yin, H., Betts, C., Lakhal, S., \& Wood, M. J. A. (2011). Delivery of siRNA to the mouse brain by systemic injection of targeted exosomes. Nature Biotechnology, 29(4), 341-345. https://doi.org/10.1038/nbt.1807

Antonucci, F., Turola, E., Riganti, L., Caleo, M., Gabrielli, M., Perrotta, C., ... Verderio, C. (2012). Microvesicles released from microglia stimulate synaptic activity via enhanced sphingolipid metabolism. EMBO Journal, 31(5), 12311240. https://doi.org/10.1038/emboj.2011.489

Bahrini, I., Song, J. H., Diez, D., \& Hanayama, R. (2015). Neuronal exosomes facilitate synaptic pruning by up-regulating complement factors in microglia. Scientific Reports, 5, 1-8. https://doi.org/10.1038/srep07989

Bakhti, M., Winter, C., \& Simons, M. (2011). Inhibition of myelin membrane sheath formation by oligodendrocyte-derived exosome-like vesicles. Journal of Biological Chemistry, 286(1), 787-796. https://doi.org/10.1074/jbc.M110.190009

Balusu, S., Van Wonterghem, E., De Rycke, R., Raemdonck, K., Stremersch, S., Gevaert, K., .. Vandenbroucke, R. E. (2016). Identification of a novel mechanism of blood-brain communication during peripheral inflammation via choroid plexus-derived extracellular vesicles. EMBO Molecular Medicine, 8(10), 1162-1183. https://doi.org/10.15252/emmm.201606271

Bentea, E., Verbruggen, L., \& Massie, A. (2017). The Proteasome Inhibition Model of Parkinson's Disease. Journal of Parkinson's Disease, 7(1), 31-63. https://doi.org/10.3233/JPD-160921

Biedler, J. L., Helson, L., \& Spengler, B. A. (1973). Morphology and Growth, Tumorigenicity, and Cytogenetics of Human Neuroblastoma Cells in Continuous Culture. Cancer Research, 33(11), 2643-2652.

Bielefeld, P., Sierra, A., Encinas, J. M., Maletic-Savatic, M., Anderson, A., \& Fitzsimons, C. P. (2017). A standardized protocol for stereotaxic intrahippocampal administration of kainic acid combined with electroencephalographic seizure monitoring in mice. Frontiers in Neuroscience, 
11(MAR), 1-9. https://doi.org/10.3389/fnins.2017.00160

Bowman, R. L., Klemm, F., Akkari, L., Pyonteck, S. M., Sevenich, L., Quail, D. F., ... Joyce, J. A. (2016). Macrophage Ontogeny Underlies Differences in TumorSpecific Education in Brain Malignancies. Cell Reports, 17(9), 2445-2459. https://doi.org/10.1016/j.celrep.2016.10.052

Cannarsa, R., Landuzzi, D., Cavina, C., Candeletti, S., \& Romualdi, P. (2008). Kainic acid down-regulates NOP receptor density and gene expression in human neuroblastoma SH-SY5Y cells. Journal of Molecular Neuroscience, 35(2), 171-177. https://doi.org/10.1007/s12031-008-9038-x

Cazareth, J., Guyon, A., Heurteaux, C., Chabry, J., \& Petit-Paitel, A. (2014). Molecular and cellular neuroinflammatory status of mouse brain after systemic lipopolysaccharide challenge: Importance of CCR2/CCL2 signaling. Journal of Neuroinflammation, 11(1), 1-15. https://doi.org/10.1186/1742-2094-11-132

Chen, Y., Tang, Y., Fan, G. C., \& Duan, D. D. (2018). Extracellular vesicles as novel biomarkers and pharmaceutic targets of diseases. Acta Pharmacologica Sinica, 39(4), 499-500. https://doi.org/10.1038/aps.2018.15

Cheng, B., Maffi, S. K., Martinez, A. A., Acosta, Y. P. V., Morales, L. D., \& Roberts, J. L. (2011). Insulin-like growth factor-I mediates neuroprotection in proteasome inhibition-induced cytotoxicity in SH-SY5Y cells. Molecular and Cellular Neuroscience, 47(3), 181-190. https://doi.org/10.1016/j.mcn.2011.04.002

Chistiakov, D. A., \& Chistiakov, A. A. (2017). a-Synuclein-carrying extracellular vesicles in Parkinson's disease: deadly transmitters. Acta Neurologica Belgica, 117(1), 43-51. https://doi.org/10.1007/s13760-016-0679-1

Cho, K. H. T., Xu, B., Blenkiron, C., \& Fraser, M. (2019). Emerging roles of miRNAs in brain development and perinatal brain injury. Frontiers in Physiology, 10(MAR). https://doi.org/10.3389/fphys.2019.00227

Cleland, J. P., Willis, E. F., Bartlett, P. F., \& Vukovic, J. (2017). Somatic Arc protein expression in hippocampal granule cells is increased in response to environmental change but independent of task-specific learning. Scientific Reports, 7(1), 1-12. https://doi.org/10.1038/s41598-017-12583-1

Connor, M., Yeo, A., \& Henderson, G. (1996). The effect of nociceptin on Ca2+ 
channel current and intracellular Ca2+ in the SH-SY5Y human neuroblastoma cell line. British Journal of Pharmacology, 118(2), 205-207. https://doi.org/10.1111/j.1476-5381.1996.tb15387.x

Court, F. A., Hendriks, W. T. J., MacGillavry, H. D., Alvarez, J., \& Van Minnen, J. (2008). Schwann cell to axon transfer of ribosomes: Toward a novel understanding of the role of glia in the nervous system. Journal of Neuroscience, 28(43), 11024-11029.

https://doi.org/10.1523/JNEUROSCI.2429-08.2008

Court, F. A., Midha, R., Cisterna, B. A., Grochmal, J., Shakhbazau, A., Hendriks, W. T., \& Van Minnen, J. (2011). Morphological evidence for a transport of ribosomes from Schwann cells to regenerating axons. Glia, 59(10), 1529-1539. https://doi.org/10.1002/glia.21196

Desplats, P., Lee, H. J., Bae, E. J., Patrick, C., Rockenstein, E., Crews, L., ... Lee, S. J. (2009). Inclusion formation and neuronal cell death through neuron-toneuron transmission of a-synuclein. Proceedings of the National Academy of Sciences of the United States of America, 106(31), 13010-13015. https://doi.org/10.1073/pnas.0903691106

Doeppner, T. R., Herz, J., Görgens, A., Schlechter, J., Ludwig, A.-K., Radtke, S., ... Hermann, D. M. (2015). Extracellular Vesicles Improve Post-Stroke Neuroregeneration and Prevent Postischemic Immunosuppression. STEM CELLS Translational Medicine, 4(10), 1131-1143. https://doi.org/10.5966/sctm.2015-0078

Drago, F., Lombardi, M., Prada, I., Gabrielli, M., Joshi, P., Cojoc, D., ... Verderio, C. (2017). ATP modifies the proteome of extracellular vesicles released by microglia and influences their action on astrocytes. Frontiers in Pharmacology, 8(DEC), 1-14. https://doi.org/10.3389/fphar.2017.00910

Encinas, M., Iglesias, M., Liu, Y., Wang, H., Muhaisen, A., Ceña, V., ... Comella, J. X. (2002). Sequential Treatment of SH-SY5Y Cells with Retinoic Acid and Brain-Derived Neurotrophic Factor Gives Rise to Fully Differentiated, Neurotrophic Factor-Dependent, Human Neuron-Like Cells. Journal of Neurochemistry, 75(3), 991-1003. https://doi.org/10.1046/j.14714159.2000.0750991.x 
Fitzner, D., Schnaars, M., Van Rossum, D., Krishnamoorthy, G., Dibaj, P., Bakhti, M., ... Simons, M. (2011). Selective transfer of exosomes from oligodendrocytes to microglia by macropinocytosis. Journal of Cell Science, 124(3), 447-458. https://doi.org/10.1242/jcs.074088

Fois, C., Prouvot, P.-H., \& Stroh, A. (2014). A Roadmap to Applying Optogenetics in Neuroscience. In S. Cambridge (Ed.) (Vol. 1148, pp. 129-147). New York, NY: Springer New York. https://doi.org/10.1007/978-1-4939-0470-9_9

Fornai, F., Lenzi, P., Gesi, M., Ferrucci, M., Lazzeri, G., Busceti, C. L., ... Paparelli, A. (2003). Fine structure and biochemical mechanisms underlying nigrostriatal inclusions and cell death after proteasome inhibition. Journal of Neuroscience, 23(26), 8955-8966. https://doi.org/10.1523/jneurosci.23-26-08955.2003

Frühbeis, C., Fröhlich, D., Kuo, W. P., Amphornrat, J., Thilemann, S., Saab, A. S., ... Krämer-Albers, E. M. (2013). Neurotransmitter-Triggered Transfer of Exosomes Mediates Oligodendrocyte-Neuron Communication. PLoS Biology, 11(7). https://doi.org/10.1371/journal.pbio.1001604

Gallo, F. T., Katche, C., Morici, J. F., Medina, J. H., \& Weisstaub, N. V. (2018). Immediate early genes, memory and psychiatric disorders: Focus on c-Fos, Egr1 and Arc. Frontiers in Behavioral Neuroscience, 12(April), 1-16. https://doi.org/10.3389/fnbeh.2018.00079

Guan, H., Yang, H., Yang, M., Yanagisawa, D., Bellier, J. P., Mori, M., ... Tooyama, I. (2017). Mitochondrial ferritin protects SH-SY5Y cells against $\mathrm{H} 2 \mathrm{O} 2$-induced oxidative stress and modulates $\alpha$-synuclein expression. Experimental Neurology, 291, 51-61. https://doi.org/10.1016/j.expneurol.2017.02.001

Heinrich, A. C., Pelanda, R., \& Klingmüller, U. (2004). A mouse model for visualization and conditional mutations in the erythroid lineage. Blood, 104(3), 659-666. https://doi.org/10.1182/blood-2003-05-1442

Hervera, A., De Virgiliis, F., Palmisano, I., Zhou, L., Tantardini, E., Kong, G., .. Di Giovanni, S. (2018). Reactive oxygen species regulate axonal regeneration through the release of exosomal NADPH oxidase 2 complexes into injured axons. Nature Cell Biology, 20(3), 307-319. https://doi.org/10.1038/s41556018-0039-x 
Ho, D. H., Yi, S., Seo, H., Son, I., \& Seol, W. (2014). Increased DJ-1 in urine exosome of Korean males with Parkinson's disease. BioMed Research International, 2014. https://doi.org/10.1155/2014/704678

Ising, C., \& Heneka, M. T. (2018). Functional and structural damage of neurons by innate immune mechanisms during neurodegeneration review-Article. Cell Death and Disease, 9(2). https://doi.org/10.1038/s41419-017-0153-x

Jarmalavičiute, A., Tunaitis, V., Pivoraite, U., Venalis, A., \& Pivoriunas, A. (2015). Exosomes from dental pulp stem cells rescue human dopaminergic neurons from 6-hydroxy-dopamine-induced apoptosis. Cytotherapy, 17(7), 932-939. https://doi.org/10.1016/j.jcyt.2014.07.013

Kanninen, K. M., Bister, N., Koistinaho, J., \& Malm, T. (2016). Exosomes as new diagnostic tools in CNS diseases. Biochimica et Biophysica Acta - Molecular Basis of Disease, 1862(3), 403-410. https://doi.org/10.1016/j.bbadis.2015.09.020

Koizumi, R., Kiyokawa, Y., Tanaka, K. D., Tanikawa, T., \& Takeuchi, Y. (2019). Novel objects elicit greater activation in the basolateral complex of the amygdala of wild rats compared with laboratory rats. Journal of Veterinary Medical Science, 81(8), 1121-1128. https://doi.org/10.1292/jvms.19-0040

Krämer-Albers, E. M., Bretz, N., Tenzer, S., Winterstein, C., Möbius, W., Berger, H., ... Trotter, J. (2007). Oligodendrocytes secrete exosomes containing major myelin and stress-protective proteins: Trophic support for axons? Proteomics Clinical Applications, 1(11), $1446-1461$. https://doi.org/10.1002/prca.200700522

Kumar, A., Stoica, B. A., Loane, D. J., Yang, M., Abulwerdi, G., Khan, N., ... Faden, A. I. (2017). Microglial-derived microparticles mediate neuroinflammation after traumatic brain injury. Journal of Neuroinflammation, 14(1), 1-17. https://doi.org/10.1186/s12974-017-0819-4

Kur, I. M., Prouvot, P. H., Fu, T., Fan, W., Müller-Braun, F., Das, A., ... Momma, S. (2020). Neuronal activity triggers uptake of hematopoietic extracellular vesicles in vivo. PLoS Biology, 18(3), 1-15. https://doi.org/10.1371/journal.pbio.3000643 
Lachenal, G., Pernet-Gallay, K., Chivet, M., Hemming, F. J., Belly, A., Bodon, G., ... Sadoul, R. (2011). Release of exosomes from differentiated neurons and its regulation by synaptic glutamatergic activity. Molecular and Cellular Neuroscience, 46(2), 409-418. https://doi.org/10.1016/j.mcn.2010.11.004

Lee, H. J., Suk, J. E., Patrick, C., Bae, E. J., Cho, J. H., Rho, S., ... Lee, S. J. (2010). Direct transfer of $\alpha$-synuclein from neuron to astroglia causes inflammatory responses in synucleinopathies. Journal of Biological Chemistry, 285(12), 9262-9272. https://doi.org/10.1074/jbc.M109.081125

Lee, S., Mankhong, S., \& Kang, J. H. (2019). Extracellular vesicle as a source of alzheimer's biomarkers: Opportunities and challenges. International Journal of Molecular Sciences, 20(7). https://doi.org/10.3390/ijms20071728

Li, J. J., Wang, B., Kodali, M. C., Chen, C., Kim, E., Patters, B. J., ... Liao, F. F. (2018). In vivo evidence for the contribution of peripheral circulating inflammatory exosomes to neuroinflammation. Journal of Neuroinflammation, 15(1), 1-16. https://doi.org/10.1186/s12974-017-1038-8

Li, Q., \& Barres, B. A. (2018). Microglia and macrophages in brain homeostasis and disease. Nature Reviews Immunology, 18(4), 225-242. https://doi.org/10.1038/nri.2017.125

Lovinger, D. M. (2008). Communication networks in the brain: neurons, receptors, neurotransmitters, and alcohol. Alcohol Research \& Health: The Journal of the National Institute on Alcohol Abuse and Alcoholism, 31(3), 196-214. https://doi.org/10.3109/01443618909151288

Matsumoto, J., Stewart, T., Sheng, L., Li, N., Bullock, K., Song, N., ... Zhang, J. (2017). Transmission of a-synuclein-containing erythrocyte-derived extracellular vesicles across the blood-brain barrier via adsorptive mediated transcytosis: another mechanism for initiation and progression of Parkinson's disease? Acta Neuropathologica Communications, 5(1), 71. https://doi.org/10.1186/s40478-017-0470-4

Meng, L., Mohan, R., Kwok, B. H. B., Elofsson, M., Sin, N., \& Crews, C. M. (1999). Epoxomicin, a potent and selective proteasome inhibitor, exhibits in vivo antiinflammatory activity. Proceedings of the National Academy of Sciences, 96(18), 10403-10408. https://doi.org/10.1073/pnas.96.18.10403 
Meza-Sosa, K. F., Pedraza-Alva, G., \& Pérez-Martínez, L. (2014). MicroRNAs: Key triggers of neuronal cell fate. Frontiers in Cellular Neuroscience, 8(JUN), 1-13. https://doi.org/10.3389/fncel.2014.00175

Miller, G. (2006). OPTOGENETICS: Shining New Light on Neural Circuits. Science, 314(5806), 1674-1676. https://doi.org/10.1126/science.314.5806.1674

Moeyaert, B., Dedecker, P., Zhang, F., Wang, L. P., Boyden, E. S., \& Deisseroth, K. (2014). Channelrhodopsin-2 and optical control of excitable cells. Nature Methods, 3(10), 261-276. https://doi.org/10.1038/nmeth936

Morad, G., Carman, C. V., Hagedorn, E. J., Perlin, J. R., Zon, L. I., Mustafaoglu, N., ... Moses, M. A. (2019). Tumor-Derived Extracellular Vesicles Breach the Intact Blood-Brain Barrier via Transcytosis. ACS Nano, 13(12), 13853-13865. https://doi.org/10.1021/acsnano.9b04397

Mulcahy, L. A., Pink, R. C., \& Carter, D. R. F. (2014). Routes and mechanisms of extracellular vesicle uptake. Journal of Extracellular Vesicles, 3(1), 1-14. https://doi.org/10.3402/jev.v3.24641

Nishijima, T., Piriz, J., Duflot, S., Fernandez, A. M., Gaitan, G., Gomez-Pinedo, U., ... Torres-Aleman, I. (2010). Neuronal Activity Drives Localized Blood-BrainBarrier Transport of Serum Insulin-like Growth Factor-I into the CNS. Neuron, 67(5), 834-846. https://doi.org/10.1016/j.neuron.2010.08.007

Nithianantharajah, J., \& Hannan, A. J. (2006). Enriched environments, experiencedependent plasticity and disorders of the nervous system. Nature Reviews Neuroscience, 7(9), 697-709. https://doi.org/10.1038/nrn1970

O’Neill, C. P., Gilligan, K. E., \& Dwyer, R. M. (2019). Role of extracellular vesicles (EVs) in cell stress response and resistance to cancer therapy. Cancers, 11(2), 1-14. https://doi.org/10.3390/cancers11020136

Ohashi, M., Hirano, T., Watanabe, K., Shoji, H., Ohashi, N., Baba, H., ... Kohno, T. (2016). Hydrogen peroxide modulates neuronal excitability and membrane properties in ventral horn neurons of the rat spinal cord. Neuroscience, 331(April), 206-220. https://doi.org/10.1016/j.neuroscience.2016.06.033

Ohmichi, T., Mitsuhashi, M., Tatebe, H., Kasai, T., Ali El-Agnaf, O. M., \& Tokuda, T. (2019). Quantification of brain-derived extracellular vesicles in plasma as a 
biomarker to diagnose Parkinson's and related diseases. Parkinsonism and Related Disorders, 61(November 2018), 82-87. https://doi.org/10.1016/j.parkreldis.2018.11.021

Pandur, E., Varga, E., Tamási, K., Pap, R., Nagy, J., \& Sipos, K. (2019). Effect of inflammatory mediators lipopolysaccharide and lipoteichoic acid on iron metabolism of differentiated SH-SY5Y cells alters in the presence of BV-2 microglia. International Journal of Molecular Sciences, 20(1). https://doi.org/10.3390/jms20010017

Pivovarov, A. S., Calahorro, F., \& Walker, R. J. (2019). Na+/K+-pump and neurotransmitter membrane receptors. Invertebrate Neuroscience, 19(1), 1-16. https://doi.org/10.1007/s10158-018-0221-7

Reza-Zaldivar, E. E., Hernández-Sapiéns, M. A., Gutiérrez-Mercado, Y. K., Sandoval-Ávila, S., Gomez-Pinedo, U., Márquez-Aguirre, A. L., ... CanalesAguirre, A. A. (2019). Mesenchymal stem cell-derived exosomes promote neurogenesis and cognitive function recovery in a mouse model of Alzheimer's disease. Neural Regeneration Research, 14(9), 1626-1634. https://doi.org/10.4103/1673-5374.255978

Ridder, K., Keller, S., Dams, M., Rupp, A. K., Schlaudraff, J., Del Turco, D., ... Momma, S. (2014). Extracellular Vesicle-Mediated Transfer of Genetic Information between the Hematopoietic System and the Brain in Response to Inflammation. PLOS Biology, 12(6). https://doi.org/10.1371/journal.pbio.1001874

Robbins, P. D., \& Morelli, A. E. (2014). Regulation of Immune Responses by Extracellular Vesicules. Nature Immunology, 14(3), 195-208. https://doi.org/10.1038/nri3622.Regulation

Rosenwald, A. G., \& Pagano, R. E. (1993). Inhibition of glycoprotein traffic through the secretory pathway by ceramide. Journal of Biological Chemistry, 268(7), 4577-4579.

Seibenhener, M. L., \& Wooten, M. W. (2012). Isolation and culture of hippocampal neurons from prenatal mice. Journal of Visualized Experiments : JoVE, (65), 49. https://doi.org/10.3791/3634 
Stroh, A., Adelsberger, H., Groh, A., Rühlmann, C., Fischer, S., Schierloh, A., ... Konnerth, A. (2013). Making Waves: Initiation and Propagation of Corticothalamic Ca2+ Waves In Vivo. Neuron, 77(6), 1136-1150. https://doi.org/10.1016/j.neuron.2013.01.031

Subramaniam, M., Kern, B., Vogel, S., Klose, V., Schneider, G., \& Roeper, J. (2014). Selective increase of in vivo firing frequencies in DA SN neurons after proteasome inhibition in the ventral midbrain. European Journal of Neuroscience, 40(6), 2898-2909. https://doi.org/10.1111/ejn.12660

Sun, M. K., Passaro, A. P., Latchoumane, C.-F., Spellicy, S. E., Bowler, M., Geoden, M., ... Karumbaiah, L. (2020). Extracellular Vesicles Mediate Neuroprotection and Functional Recovery after Traumatic Brain Injury. Journal of Neurotrauma, (706), 1-40. https://doi.org/10.1089/neu.2019.6443

Tasker, R. A. R., Bernard, P. B., Doucette, T. A., Kerr, D. S., Zabidin, Y., AlvarezFernandez, L., ... Novelli, A. (2002). Comparison of the in vitro and in vivo neurotoxicity of three new sources of kainic acid. Amino Acids, 23(1-3), 45-54. https://doi.org/10.1007/s00726-001-0108-4

Taymans, J. M., Mutez, E., Drouyer, M., Sibran, W., \& Chartier-Harlin, M. C. (2017). LRRK2 detection in human biofluids: Potential use as a Parkinson's disease biomarker? Biochemical Society Transactions, 45(1), 207-212. https://doi.org/10.1042/BST20160334

Teppola, H., Sarkanen, J. R., Jalonen, T. O., \& Linne, M. L. (2016). Morphological Differentiation Towards Neuronal Phenotype of SH-SY5Y Neuroblastoma Cells by Estradiol, Retinoic Acid and Cholesterol. Neurochemical Research, 41(4), 731-747. https://doi.org/10.1007/s11064-015-1743-6

Théry, C. (2011). Exosomes: Secreted vesicles and intercellular communications. F1000 Biology Reports, 3(1), 1-8. https://doi.org/10.3410/B3-15

Turola, E., Furlan, R., Bianco, F., Matteoli, M., \& Verderio, C. (2012). Microglial microvesicle secretion and intercellular signaling. Frontiers in Physiology, 3 MAY(May), 1-11. https://doi.org/10.3389/fphys.2012.00149

VanElzakker, M., Fevurly, R. D., Breindel, T., \& Spencer, R. L. (2008). Environmental novelty is associated with a selective increase in Fos expression 
in the output elements of the hippocampal formation and the perirhinal cortex. Learning and Memory, 15(12), 899-908. https://doi.org/10.1101//m.1196508

Vella, L. J., Hill, A. F., \& Cheng, L. (2016). Focus on extracellular vesicles: Exosomes and their role in protein trafficking and biomarker potential in Alzheimer's and Parkinson's disease. International Journal of Molecular Sciences, 17(2). https://doi.org/10.3390/ijms17020173

Vickery, O. N., Machtens, J. P., \& Zachariae, U. (2016). Membrane potentials regulating GPCRs: insights from experiments and molecular dynamics simulations. Current Opinion in Pharmacology, 30, 44-50. https://doi.org/10.1016/j.coph.2016.06.011

Watson, L. S., Hamlett, E. D., Stone, T. D., \& Sims-Robinson, C. (2019). Neuronally derived extracellular vesicles: An emerging tool for understanding Alzheimer's disease. Molecular Neurodegeneration, 14(1), 1-9. https://doi.org/10.1186/s13024-019-0317-5

Wu, X., Zheng, T., \& Zhang, B. (2017). Exosomes in Parkinson's Disease. Neuroscience Bulletin, 33(3), 331-338. https://doi.org/10.1007/s12264-0160092-z

Xia, Y., Zhang, G., Han, C., Ma, K., Guo, X., Wan, F., ... Wang, T. (2019). Microglia as modulators of exosomal alpha-synuclein transmission. Cell Death and Disease, 10(3). https://doi.org/10.1038/s41419-019-1404-9

Xicoy, H., Wieringa, B., \& Martens, G. J. M. (2017). The SH-SY5Y cell line in Parkinson's disease research: a systematic review. Molecular Neurodegeneration, 12(1), 1-11. https://doi.org/10.1186/s13024-017-0149-0

Yoshikawa, F. S. Y., Teixeira, F. M. E., Sato, M. N., \& Oliveira, L. M. da S. (2019). Delivery of microRNAs by Extracellular Vesicles in Viral Infections: Could the News be Packaged? Cells, 8(6), 611. https://doi.org/10.3390/cells8060611

Zhang, S., Eitan, E., Wu, T. Y., \& Mattson, M. P. (2018). Intercellular transfer of pathogenic a-synuclein by extracellular vesicles is induced by the lipid peroxidation product 4-hydroxynonenal. Neurobiology of Aging, 61, 52-65. https://doi.org/10.1016/j.neurobiolaging.2017.09.016

Zhu, J., Zheng, X. Y., Zhang, H. L., \& Luo, Q. (2011). Kainic acid-induced 
neurodegenerative model: Potentials and limitations. Journal of Biomedicine and Biotechnology, 2011. https://doi.org/10.1155/2011/457079 